Portland State University

PDXScholar

\title{
Short-Term International Service-Learning: Faculty Perceptions of and Pedagogical Strategies for the Design and Implementation of Successful Learning Experiences
}

Thomas Jacob Van Cleave Portland State University

Follow this and additional works at: https://pdxscholar.library.pdx.edu/open_access_etds

Part of the Curriculum and Social Inquiry Commons, Educational Leadership Commons, and the Higher Education Commons Let us know how access to this document benefits you.

\section{Recommended Citation}

Van Cleave, Thomas Jacob, "Short-Term International Service-Learning: Faculty Perceptions of and Pedagogical Strategies for the Design and Implementation of Successful Learning Experiences" (2013). Dissertations and Theses. Paper 1055.

https://doi.org/10.15760/etd.1055

This Dissertation is brought to you for free and open access. It has been accepted for inclusion in Dissertations and Theses by an authorized administrator of PDXScholar. Please contact us if we can make this document more accessible: pdxscholar@pdx.edu. 
Short-Term International Service-Learning: Faculty Perceptions of and

Pedagogical Strategies for the Design and Implementation of Successful Learning

Experiences

by

Thomas Jacob Van Cleave

A dissertation submitted in partial fulfillment of the requirements for the degree of

Doctor of Education

in

Educational Leadership: Postsecondary Education

Dissertation Committee:

Christine Cress, Chair

Heather Burns

Leopoldo Rodriguez

Dilafruz Williams

Portland State University

2013 
(C)2013 Thomas Jacob Van Cleave 


\begin{abstract}
Faculty-led short-term international service-learning (STISL) experiences are thought to have great potential in developing students' global citizenship through combining study abroad and community service pedagogies. However, thorough investigation of the pedagogical strategies employed in STISL courses to achieve such outcomes has yet to be conducted. This qualitative narrative inquiry of STISL faculty at 7 different institutions across multiple academic disciplines and country service sites sought to fill that void. Data reveal a new conceptualization of STISL teaching, learning, and service success that involves culturally contextualized solidarity, global civic engagement, and global competence, which culminate into students' global agency. Emerging from the data, the Van Cleave Pedagogical Design framework for Global Agency illuminates the interactions of five interdependent learning dimensions: academic, professional, interpersonal, intrapersonal, and intercultural. Course, program, and policy implications are explicated across predeparture, host-country, and re-entry experiences.
\end{abstract}




\section{ACKNOWLEDGEMENTS}

I am forever indebted to the amazing support from friends, family and colleagues that enabled me to get to this point in my life. First and foremost, I couldn't have undertaken this monumental endeavor without the unwavering encouragement, salient words of wisdom, and constant support of my mom and dad. In my childhood I was taught to pursue my dreams, no matter the cost, and my parents supported me as those dreams became a reality. It has been a long road, but no matter how lofty my ambitions, they embodied unconditional love and support.

I will always be grateful for the time, energy and support that the PACE faculty provided me throughout the years. I am the scholar, colleague and person I am today because of their guidance and friendship. I am beyond thankful to the extensive investment of time and energy that my committee dedicated to this project. Specifically Dr. Dilafruz Williams, who was not only a committee member and colleague, but also a mentor and friend who equipped me to find my voice through this experience; Dr. Heather Burns who was a constant source of innovative ideas and encouragement; and Dr. Leopoldo Rodriguez for his invaluable perspective and insight. Also infinite thanks to my advisor Dr. Christine Cress, whose guidance and coaching changed the trajectory of my career and life. She not only showed me the depths of what it means to be a scholarly practitioner, but also taught me to believe in my own abilities.

I must also acknowledge the late Elizabeth (Peg) Bond and all of the citizens of my hometown, Batavia, Illinois. From a young age my community showed me 
how rewarding life could be when skills and talents are applied to a cause greater than yourself. Who would have thought that a second grader with a garden trowel volunteering at the Batavia Riverwalk would take that experience and pursue civic engagement as a profession?

Finally, my deepest gratitude and thanks to Jon Garrow, the 2010 PSU Postsecondary Doctoral Cohort, Dr. Sarah Drummond-Hays, Dr. Stephanie Stokamer, Mary Fantozzi, Barbara Cobas, the “Friendship Manor, " Dr. Mary Beth Van Cleave, Dr. Mary Kinnick, (soon to be Dr.) Melissa Byrne, and all of my friends and family who supported me through this process. I am grateful for the grace they extended me when I moved away, called panicking, worked late, missed birthdays, or cancelled date night. It is because of them that I rested when I didn't think I could, kept going when I thought I couldn't, had home cooked meals instead of frozen pizza, and was given the love and support to pursue this life-changing experience. 
TABLE OF CONTENTS

Page

ABSTRACT.

ACKNOWLEDGEMENTS ............................................................................................................. ii

LIST OF TABLES ...................................................................................................................... ix

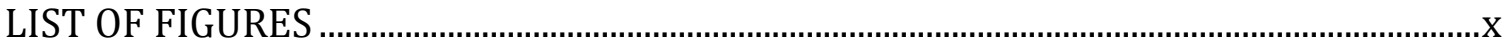

CHAPTER 1: INTRODUCTION TO UNDERSTANDING STISL .............................................. 1

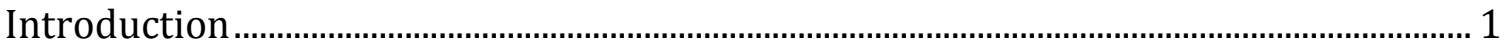

University Values and Beliefs: Local and Global Mission for Civic Competence............ 3

Global Citizenship................................................................................................................... 5

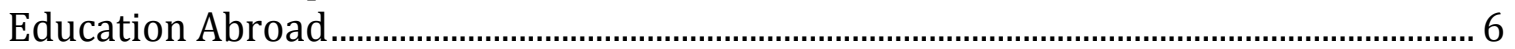

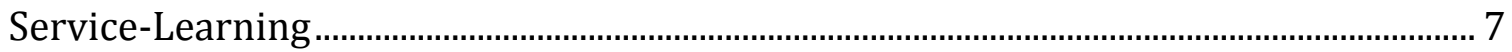

Combining Service-Learning and Education Abroad: International Service-Learning

Short-Term International Service-Learning …………………………………….... 9

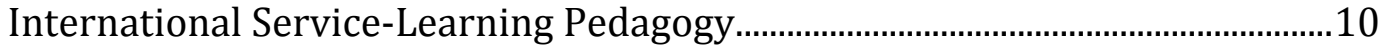

CHAPTER 2: LITERATURE REVIEW ..........................................................................................13

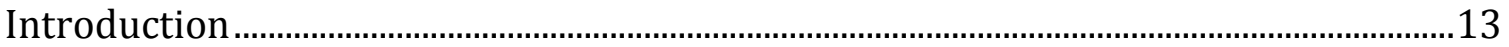

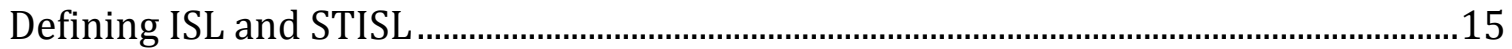

Defining Success on a STISL Experience .............................................................................18

Global Citizenship: A Hallmark of Long-Term Student Success ...........................19

Conceptualizing and defining global citizenship .........................................20

Spirituality and the Global Soul as Student Success................................................24

Defining spirituality .......................................................................................26

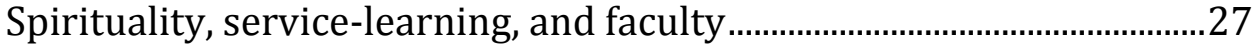

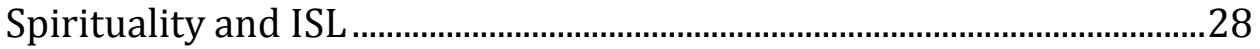

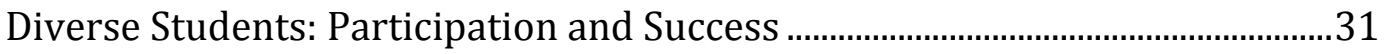

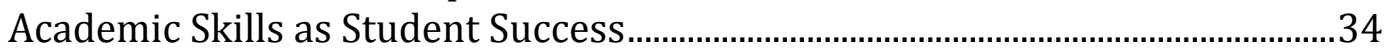

Solidarity and Social Justice as Student Success.......................................................36

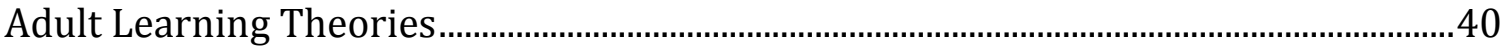

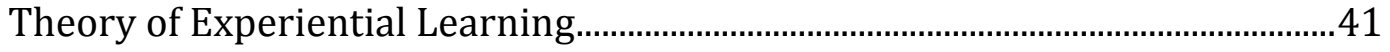

Theory of Multiple Intelligences...............................................................................4 44

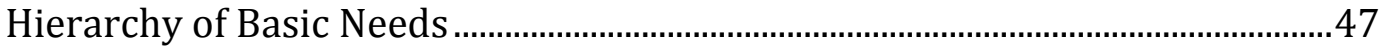

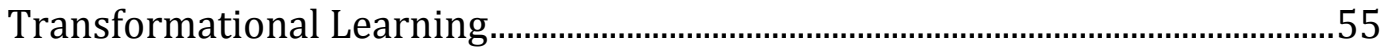

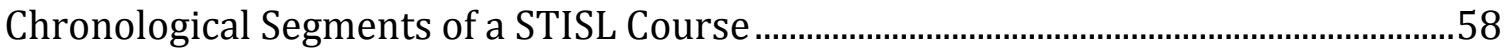


Pre-Departure.............................................................................................59

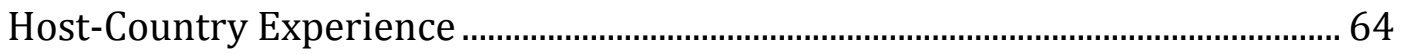

Developing and maintaining overseas partnerships ..................................65

The experience of difference ..........................................................................67

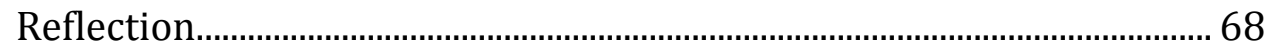

Other host-country design considerations ................................................. 71

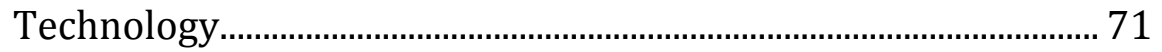

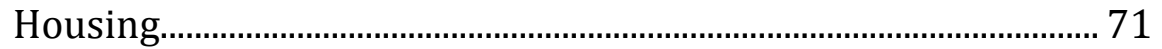

Host-country faculty or home-country faculty .............................. 73

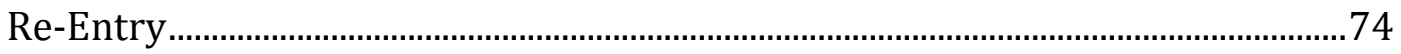

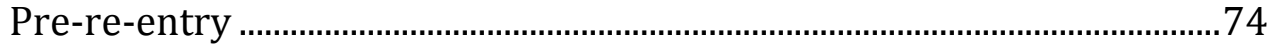

Re-entry: Ongoing process upon return .......................................................75

Iterative Teaching …………………………………………………………………......79

Evaluation During a STISL Experience....................................................................8

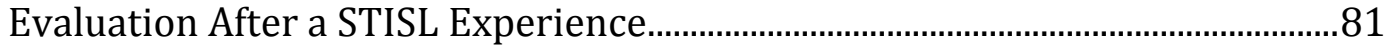

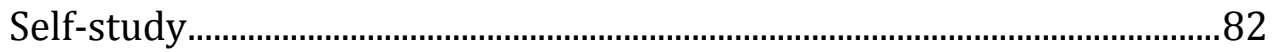

Understanding Institutions Through Four Frames of Organizational Behavior

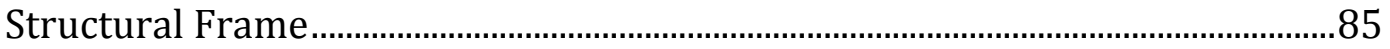

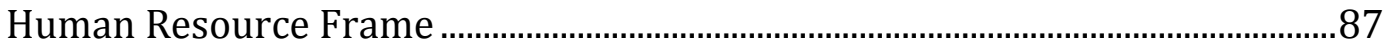

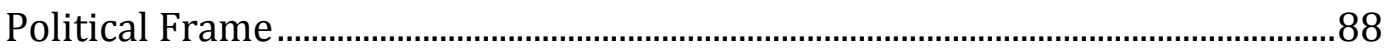

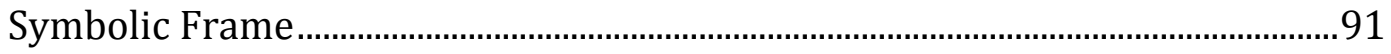

Four Frame Summary .......................................................................................99

Proposed Framework for Exploring Short-Term International Service-Learning

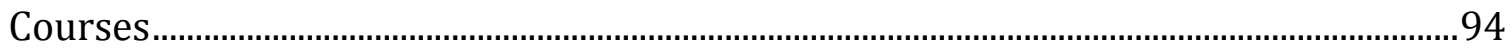

CHAPTER 3: METHODOLOGY …………………………….............................................97

Research Questions and Purpose .......................................................................................97

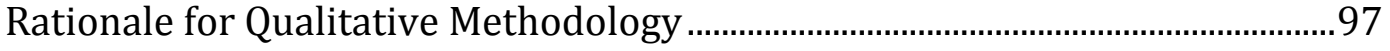

Data Collection ............................................................................................................97

Research Participants and Sites ............................................................................99

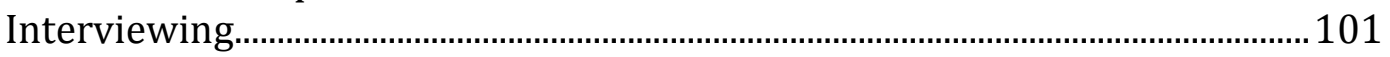

Artifacts................................................................................................................ 103

Research Participants ........................................................................................104

Data Analysis .........................................................................................................109

Study Limitations and Positionality ................................................................................112

Potential Contributions and Conclusion..............................................................................113

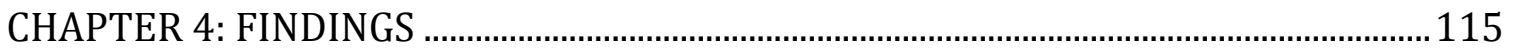

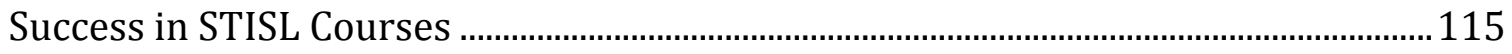

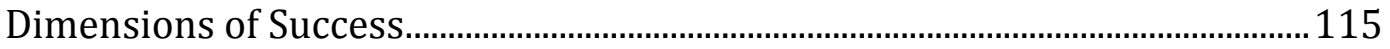

Academic Success .......................................................................................116 
Professional Success......................................................................................117

Interpersonal Success...................................................................................118

Intrapersonal Success................................................................................120

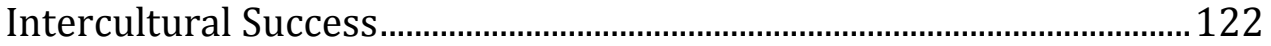

Defining Success: Developing Global Agency ……………….............................. 124

Perspectives on Global Citizenship as a Hallmark of Success ............................129

Three dimensions of global citizenship ...................................................134

Dimension 1: Social responsibility.................................................134

Dimension 2: Global competence .....................................................138

Dimension 3: Global civic engagement ......................................... 140

Ogden's Three Dimensions of Global Citizenship as a

conceptualization of success ........................................................... 142

The Van Cleave Framework of STISL Success.......................................................142

STISL Course Design, Teaching Strategies, and Integration of Service .........................145

Pre-Departure Segment of the STISL Course .....................................................145

Application process ……………………………………………………146

Prerequisites to participating in the STISL Course...................................148

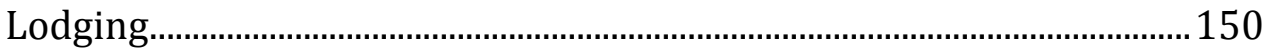

Lodging together as a group .......................................................... 151

Lodging separate in hotels or motels...............................................152

Lodging with community members in homestays .....................153

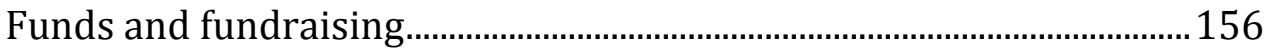

Pre-departure preparation strategies .......................................................158

Practical Pre-departure preparation .............................................159

Academic pre-departure preparation .............................................162

Professional pre-departure preparation........................................164

Interpersonal pre-departure preparation .....................................165

Intrapersonal pre-departure preparation ......................................166

Intercultural pre-departure preparation ........................................ 168

Global civic engagement abroad pre-departure preparation

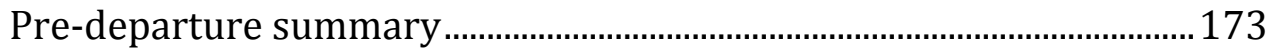

Host Country Segment of the STISL Course …………………………………......175

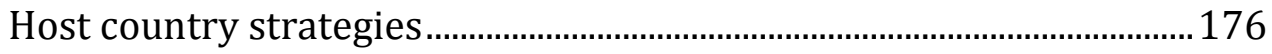

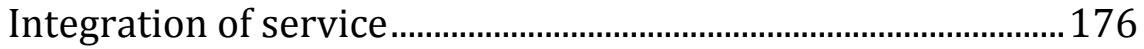

High level of skill required ..................................................177

Medium level of skill required ............................................179

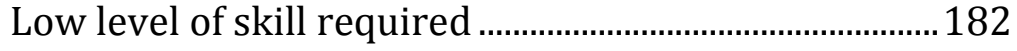

Integration of service summary ..........................................185

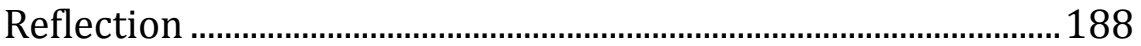

Written reflection.................................................................189

Oral reflection ....................................................................194

Reflection summary ............................................................198

Assignments................................................................................ 198 
Immersive language lessons..............................................199

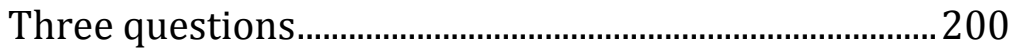

Interviews of host-country community members

Team teaching..

200

Reciprocity .......................................................................206

Host country summary …………………………………………………....2213

Re-Entry Segment of the STISL Course ..............................................................216

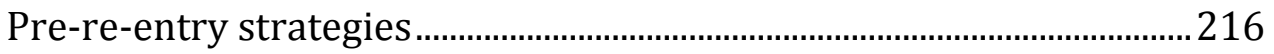

Re-entry assignments ..............................................................................220

Re-entry reflection assignments .................................................222

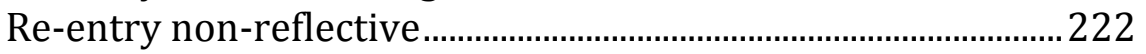

Reunions and post-STISL gatherings ......................................................224

Re-entry summary ………………………………………………….....22

Specialized Issues and Pedagogical Responses .......................................................227

Disequilibrium, dissonance, and difference as a catalyst for

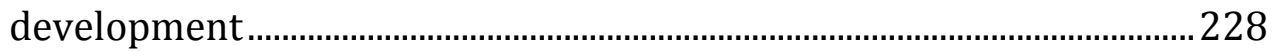

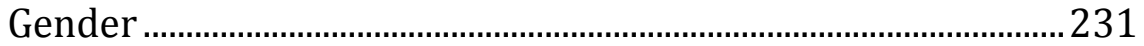

Race and ethnicity ……………………………………………….....235

Intrapersonal spiritual identities ..............................................................223

Summary: Pedagogical Strategies .....................................................................239

The Van Cleave Conceptual Framework for STISL Design ......................244

The Van Cleave Pedagogical Design Framework for Global Agency

Iterative Teaching

246

254

Why Would Faculty Teach, and Keep Teaching Using STISL..............................255

STISL faculty self-study and intuition.........................................................257

Department issued summated rating scales.............................................259

STISL faculty initiated qualitative assessment and scholarly quantitative inventories ................................................................................260

Education abroad assessment ....................................................................2.

Iterative Teaching Summary ………………………………………………....2262

Summary of Key Findings ..............................................................................................26

CHAPTER 5: IMPLICATIONS, SIGNIFICANCE, AND NEXT STEPS ...................................275

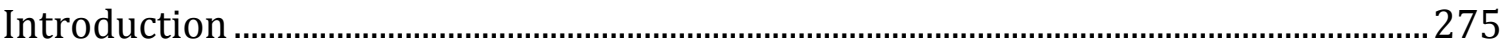

Implications significance, and next steps.......................................................................275

Insights From the Four Frames of Organizational Behavior and Theory for

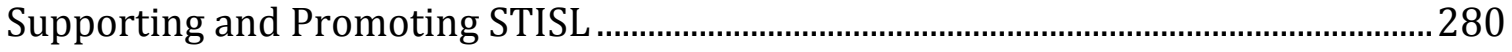

Structural Frame Implications...........................................................................281

A1. Organizations exist to achieve established goals and 
objectives 281

A2. Organizations increase efficiency and enhance performance through specialization and appropriate division of labor 284 A3. Suitable forms of coordination and control ensure that diverse efforts of individuals mesh

A4. Problems arise and performance suffers from structural deficiencies, which can be remedied through analysis and restructuring

Human Resource Frame Implications.

B1. People and organizations need each other

B2. When the fit between individual and system is poor, one or both suffer

Political Frame Implications

C1. Organizations are coalitions of assorted individuals and interest groups

C2. Allocation of scarce resources - who gets what

D1. Facing uncertainty and ambiguity, people create symbols to resolve confusion, find direction, and anchor hope and faith D2. Culture forms the superglue that bonds an organization, unites people, and helps an enterprise accomplish desired ends.

Increasing STISL Faculty Support ……………………………………………. 301

Increasing STISL Access.......................................................................................... 304

Increasing Institutional Support of Pre-Departure and Re-Entry Credit Opportunities..

Increasing Strategies to Understand Power and Privilege in STISL Pedagogy

Conclusion.

A. Invitation to Participate in the Research Study 


\section{LIST OF TABLES}

Table

Page

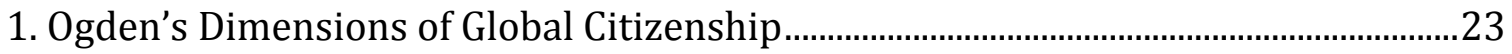

2. Proposed Student Needs on a STISL Experience..............................................................51

3. Campus Compact's Eight-Benchmarks of Genuine Democratic Partnership...........66

4. Research Participant Rank and Degrees ......................................................................... 105

5. Institutional Classification of Research Participants' College or University.......... 105

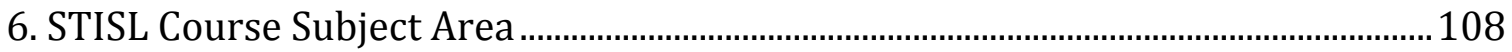

7. STISL Faculty Research Participant, Course Title, and Host Country Location .... 108

8. Dimensions of Data and Associated Thematic Code Identified Through Literature

9. Hallmarks of Success and Overarching Goal of STISL ..............................................125

10. The Van Cleave Conceptual Framework for STISL Design ........................................245

11. The Van Cleave Pedagogical Design Framework for Global Agency....................... 249 


\section{LIST OF FIGURES}

Figure

Page

1. Crabtree's International Service-Learning at the Intersections of Theoretical and

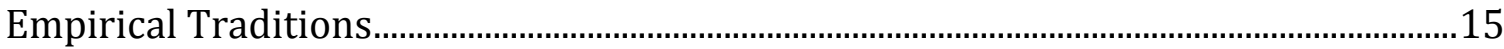

2. Bringle \& Hatcher's Conceptualization of International Service-Learning................16

3. Kolb’s (1984) Four Adaptive Modes of Learning …............................................................41

4. Kolb’s (1984) Experiential Learning Model ...................................................................43

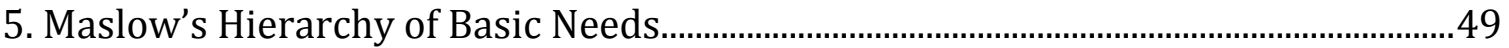

6. Framework for Exploring Short-Term International Service-Learning Courses....95

7. The Van Cleave Conceptualization of STISL Success .................................................129

8. The Van Cleave Framework of STISL Success ……..................................................... 144 


\section{CHAPTER 1:}

\section{INTRODUCTION TO UNDERSTANDING STISL}

\section{Introduction}

In the not so distant past, crossing cultural and national borders required extensive amounts of time, resources, and fortitude. Crossing borders was a foreign concept that was often "accompanied by bloodshed, oppression, or genocide" (Bennett, 1993, p. 21). In the twenty-first century, crossing cultural and national borders has become a way of life. Technological advancements have made it possible to encounter and engage culturally diverse people, ideologies and ways of being on a daily basis in as little as two or three mouse clicks via the internet or in only a few hours by an airplane (Braskamp, 2008; Grusky, 2000; Livermore, 2011; Lutterman-Aguilar \& Gingerich, 2002; Pless, Maak, \& Stahl, 2012). This increased contact with difference, virtual or physical, is as Murphy (2011) asserted, "binding each of us into an interconnected world community" (p. 1); being able to function effectively in this interconnected world community is becoming a necessary skill in the global workforce (Livermore, 2011).

As the world is becoming more interconnected through communication and technology, and we are now more globally conscious about how certain actions by people in one part of the globe have impacted lives of people thousands of miles away and in generations to come. Moreover, in the $21^{\text {st }}$ century as a global community we are also more aware of how local actions can set off a ripple effect throughout the globe (Burns, 2009; Kostigen, 2008). 
From television news programs to the Internet, via imbedded reporters or a simple cell phone video camera, international issues are brought into the homes and lives of people around the globe nearly instantly. From climate change to the publication of controversial political cartoons, actions of individuals in one part of the world have the potential to significantly impact the lives of people in other parts of the world. In his inauguration address, President Barack Obama (2009) made a commitment to the global community and challenged United States citizens to be more mindful of and to accept responsibility for people across the world:

To the people of poor nations, we pledge to work alongside you to make your farms flourish and let clean waters flow; to nourish starved bodies and feed hungry minds. And to those nations like ours that enjoy relative plenty, we say we can no longer afford indifference to the suffering outside our borders, nor can we consume the world's resources without regard to effect. For the world has changed, and we must change with it. (p. 11)

President Obama's words challenge the global community to be aware of human and ecological needs across the world and to be cognizant of the consequences that actions have regardless of national identity. In his commencement address to the Ohio State University graduating class of 2013 President Obama (2013a) reminded students that active citizenship is not a thing of the past, but is needed in the twenty first century in order to address significant local and global needs; "we are a people called to do great things -- like rebuild a middle class, and reverse the rise of inequality, and repair the deteriorating climate that threatens everything we plan to leave for our kids and our grandkids" (para. 34). In order for this to happen, however, a transformation must occur so that people and nations no longer choose 
courses of action that adversely affect the planet and the people on it (Burns, 2009; Pless et al., 2012) and develop the capacity to rectify consequences from decisions made in the past. Burns (2009) warns, "Unless we want more of the same kinds of problems, we must begin to educate future leaders to be able to address these issues and make effective changes" (p. 2). Citizens across the globe must be more aware of world events, be able and willing to change their own actions for the betterment of others, and develop skills to effectively function in an interconnected and intercultural world.

\section{University Values and Beliefs: Local and Global Mission for Civic Competence}

A core mission of education systems in the United States has been to instill in students "a set of values and beliefs" (Chisholm \& Berry, 2002, p. 39). Dewey (1916) noted that education, both formal and informal, serves as the mechanism by which "beliefs and aspirations" (p. 9) are transferred when "a social group brings up its immature members into its own social form" (p. 9). A common value, belief, and aspiration of higher education is to teach the next generation of citizens how to function within a democratic society (Annette, 2002; Bok, 2006; Galston, 2001; Pace \& Bixby, 2008). Colby, Elrich, Beaumont, Rosner and Stephens (2000) articulate many of the values that formal education systems (schools, universities, colleges) aim to instill in the next generation, including the moral principles associated with democracy, including;

Our democratic principles, including tolerance and respect for others, procedural impartiality, and concern for both the rights of the individual and the welfare of the group, are all grounded in moral principles. Likewise, the problems that the civically engaged citizen must confront always include 
strong moral themes - for example, fair access to resources such as housing, the moral obligation to consider future generations in making environmental policy, and the conflicting claims of multiple stakeholders in community decision making. (p. xxi)

While extensive amounts of time and attention have been dedicated to domestic civic education (Stokamer, 2011), the concept of global citizenship education is emerging in scholarly literature (Association of American Colleges and Universities, 2011; Braskamp, 2008; Brustein, 2007; Jacoby \& Brown, 2009; Tarrant, 2010) and on campuses across the country (Stearns, 2009). As Jacoby and Brown (2009) note, “[United States] institutions of higher education universally recognize their fundamental role in preparing students to engage responsibly and productively in a world that is becoming increasingly interconnected and interdependent" (p. 213).

As is being evident through institutional mission statements, universities and colleges have broadened the concept of citizenship education to include international and global citizenship education (Braskamp, 2008). Stearns (2009) asserted "It would be hard to find [a]... community college, college or university [in the United States] that has not devoted serious thought, in recent years, to some aspect - often, to many aspects - of global education" (p. 1). In the Association of American Colleges and Universities' "Shared Futures: Global Learning for Social Responsibility" program description, the organization calls for higher education to include global awareness and competencies because "the challenges our graduates will face with growing urgency are increasingly defined as global problems: environment and technology, health and disease, conflict and insecurity, poverty and development" (Association of American Colleges and Universities, 2011, para. 
2). Therefore, students must prepared to meet these pressing human and ecological concerns

\section{Global Citizenship}

The term that many stakeholders (such as politicians, universities and scholars) use to describe someone who is able to function in an increasingly globalized society is a global citizen. While there is not yet a singular, definitive definition for global citizenship (Falk, 1993), there are some regularly agreed upon overarching themes, which include "the ideas of awareness, responsibility, and participation" (Schattle, 2009, p. 17) on a global scale; these aim to fulfill the learning objectives as articulated by the majority of institutions of higher education as well as the AAC\&U. Schattle noted that innate to the concept of global citizenship is a moral vision for society, or "a one-world community premised on a politics of aspiration and desire" (Falk, 1993, p. 39) where individuals consider not only how decisions impact them personally, but also how these decisions may have consequences felt across the globe. Global citizenship consists of an "array of transnational social forces animated by environmental concerns, human rights, hostility to patriarchy, and a vision to end poverty, based on the unity of diverse cultures seeking an end to poverty, oppression, humiliation, and collective violence" (Falk, 1993, p. 39).

There has been a call across universities to design education programs to develop students as global citizens, and universities are responding by articulating a commitment to graduating global citizens (Jacoby \& Brown, 2009). However, 
what is not yet clear is how are higher education institutions going to address global citizenship education and what the future of global citizenship education is.

\section{Education Abroad}

Education abroad is one form of experiential education that aims to develop students as global citizens (Lewin, 2009; Ogden, 2010). Study abroad is defined as any educational experience that takes place outside a students' home country. The term study abroad is used to describe any "international learning experiences, including internships, work, volunteering, and directed travel, so long as they are driven to a significant degree by learning goals" (Peterson, as cited in Ogden, 2010, p. 10).

In years past, study abroad catered to the highly affluent; Lewin (2009) suggests this was a quest for high culture in order to complete a part of students "classical education" (p. xiv). Also known as high culture classical education, this practice strongly influenced the formation of study abroad paradigms and academic content that focused on art, literature, and language, primarily in European countries. However, as technology has made globalization a part of everyday life, scholars suggest that study abroad can offer much more than "high" culture. Lewin (2009) submits that globalization has made a permanent mark on the practice of study abroad, and therefore the practice of study abroad is undergoing a paradigm shift toward a new model where the focus of study abroad is in "developing knowledge, skills, attitudes, and experiences necessary to 
compete successfully in the global marketplace or to work toward finding and implementing solutions to problems of global significance" (p. xiv).

\section{Service-Learning}

Like study abroad, service-learning is an experiential education pedagogy that can include learning objectives associated with global citizenship. Servicelearning complements, supplements (Stokamer, 2011), and enhances traditional academic classroom teaching with service to the community; this provides students an opportunity for reflection (Cress, 2005; Jacoby, 1996). Students apply newly acquired academic learning to the community in a way "that [addresses] human and community needs together with structured opportunities intentionally designed to promote student learning and development" (Jacoby, 1996, p. 5). Within the field of higher education there are various terms that include some or all of the ideas mentioned above: service-learning, community service, or communitybased learning. While there are important distinctions between the terms (Cress, 2005), service-learning will serve as the overarching term for this dissertation.

Within the service-learning paradigm, students engage in learning activities outside the classroom rather than being facilitated solely within the confines of a classroom. The experiential aspect of service-learning "make[s] learning come alive and [students] experience real-life connections between their education and every day issues in their cities, towns, or states" (Cress, 2005, p. 7). Service-learning emphasizes real-world learning and "rejects the 'banking' model of education where the downward transference of information from knowledgeable teachers to 
passive students is conducted in fifty-minute increments" (Butin, 2010, p. 3). This is not to say that all of the learning in service-learning takes place outside of the classroom. Cress (2005) argues that the academic discipline and course content serve as lenses through which to understand the experience. In a quantitative research study comparing benefits of a service-learning based final project, with a traditional final project in a business statistics course, Phelps and Dostilio (2008) noted that "the [service] experience was perceived more enjoyable and relevant to the real world adding elements of student empowerment while assisting a local agency in need of statistical expertise" (p. 1). Additionally, the service-learning experience provides students an opportunity to practice and implement newly acquired knowledge or skills (Furco, 1996). Therefore, service-learning is not either experiential or academic and instead blends academic content with real world opportunities for application for the betterment of the community and society in general.

\section{Combining Service-Learning and Education Abroad: International Service- Learning}

Study abroad and service-learning as individual and separate pedagogies can and do develop students as global citizens (Ogden, 2010). Practitioners have, however, begun to combine education abroad and service-learning experiences into one international service-learning (ISL) experience. In most basic terms, the combination of service-learning and education abroad makes sense. Both practices have been accepted as impactful pedagogies within higher education, so it is logical 
to assume that there is potential in combining the practices. ISL programs are argued to be profound educational experiences for developing students' intercultural abilities, global awareness, and sense of personal responsibility (Bringle \& Hatcher, 2011; Brown, 2007; Chisholm, 2003). Higher education institutions are increasingly turning to ISL to "fulfill their mission" (Murphy, 2011, p. 3) of global citizenship identity development. While the quantity of research on the impact of ISL on student development is limited (Eyler, 2011; Kiely, 2011; Tonkin, 2011), there is an emerging body of literature that finds ISL can be more "powerful in nature" (Knutson Miller \& Gonzalez, 2010, p. 35) in regard to specific learning outcomes than domestic service learning experiences.

\section{Short-Term International Service-Learning}

As the popularity of ISL programs has increased, so too has the demand for short-term international experiences (Forum on Education Abroad, 2009) as well as faculty-led international experiences. Short-term programs are growing in popularity and demand according to a recent survey of study abroad professionals across the country, and $61 \%$ of institutions "said they had added new short-term faculty led programs" (Institute of International Education, 2011, para. 4). Even though short-term international experiences are sometimes found to have fewer benefits than semester or year-long programs (Dwyer \& Peters, 2004), a shortterm international experience "offers a global understanding to a group of students who currently are not going abroad [due to financial limitations, fears of violence, 
or science/pre-health majors] and who would not otherwise have the opportunity" (Lewis \& Niesenbaum, 2005, p. 252).

Notably, there is no evidence that short-term international experiences are "better than" (Lewis \& Niesenbaum, 2005, p. 253) longer programs or courses; however, short-term programs can meet some of the goals of longer programs. Lewis and Niesenbaum suggest that by combining short-term international experiences (study abroad) with service-learning pedagogy, students will have a deeper cultural experience, which capitalizes on the limited duration of the exposure.

\section{International Service-Learning Pedagogy}

A key component of ISL experiences is exposing students to ways of life, culture, and contexts that are unfamiliar to the students (Grusky, 2000; Merrill, 2005; Williams \& Van Cleave, 2011), such as: religion, climate, language, gender roles, social structures and hierarchies, and social problems. Merrill (2005) suggests that serving in a diverse culture, different from the students own, amplifies cultural and intercultural issues and can serve as a catalyst for learning.

It is here where we are able to see a gaping hole in the ISL literature. While many scholars describe why ISL is important (Crabtree, 2008; Grusky, 2000; Parker \& Dautoff, 2007) or articulate broad learning outcomes from an ISL experience (Kiely, 2004, 2005; Williams \& Van Cleave, 2011), there has been little effort dedicated to understanding what ISL faculty articulate as program success, 
and how they are pedagogically designing the courses to achieve success as they have identified it.

This inquiry is designed to answer these critically important issues. Specifically, the study will investigate the following questions: What do ISL faculty identify as a successful ISL program? What are ISL faculty teaching to achieve this success, and how do faculty measure or assess their effectiveness at meeting desired learning outcomes? Also, do ISL faculty define global citizenship similarly to the literature, or are there different perspectives on what constitutes a successful learning experience, specifically in a globalized $21^{\text {st }}$ century society?

The following two chapters review the literature relevant to the research questions that will be investigated in this dissertation. The literature will be used to better understand perspectives on what could constitute a successful short-term international service-learning (STISL) experience, with special attention being paid to both the pros and cons of global citizenship. Furthermore, the literature will highlight how multiple learning theories pertain to adult education, and more specifically STISL. Also, after reviewing current pedagogical strategies employed in the three main stages of STISL experiences, pre-departure, host-country and reentry, the literature review culminates with a reconceptualized vision of Stokamer's (2011) four elements of service-learning in light of the international component through a model that will be used to structure the exploration of shortterm international service-learning courses. Chapter three will elaborate on the research questions explored in this research study, and an appropriate 
methodology will be explained. Chapter four reports findings to the research questions in light of the literature reviewed and introduces two new frameworks that inform both conceptualizations of success through STISL courses, as well as pedagogical strategies to achieve that success. Chapter five will describe course, program, and policy implications across pre-departure, host-country, and re-entry experiences. 
CHAPTER 2:

\section{LITERATURE REVIEW}

\section{Introduction}

Whether the issue at stake is employability, global ecological or sociocultural sustainability, national security, or international human rights, a global perspective is touted as an essential characteristic in the $21^{\text {st }}$ century. In order to prepare people to both work and live in a globalized world, stakeholders are looking to colleges and universities to rethink curricula and prepare students to graduate as individuals who display characteristics of global citizens.

Already, domestic service-learning, education abroad, and international education are three pedagogies employed at most colleges and universities and to varying degrees incorporate global citizenship education or aspects of global citizenship education. Practitioners and scholars posit that there is unique potential in combining all three pedagogies into one educational experienceinternational service-learning (Bringle \& Hatcher, 2011; Plater, Jones, Bringle, \& Clayton, 2009; Plater, 2011). As it stands, many institutions, practitioners, and third-party study abroad providers (American Institute For Foreign Study, 2012; International Partnership for Service-Learning and Leadership, 2012) are already practicing international service-learning.

However, scholarship on ISL practice and pedagogy has not kept pace with ISL's programmatic implementation. Numerous scholarly publications have touted why ISL matters in the $21^{\text {st }}$ century, yet few articulate practical 
pedagogical frameworks for structuring and implementing an ISL experience. In what has become a seminal piece in the ISL literature, Grusky (2000) supported the development of pedagogical models for ISL and articulated the potential disasters that may occur because of improperly planned ISL experiences, further bolstering the need for such a contribution to the literature.

Without thoughtful preparation, orientation, program development and the encouragement of study, and critical analysis and reflection, the programs can easily become small theaters that recreate historic cultural misunderstandings and simplistic stereotypes and replay, on a more intimate scale, the huge disparities in income and opportunity that characterize North-South relations today. (p. 858)

Not only ISL is becoming a more popular educational experience, but short-term study abroad is as well. Short-term study abroad allows a broader section of student populations to participate in a study abroad experience, when otherwise financial, family, or work obligations would preclude them from the opportunity (Gutierrez, Auerbach, \& Bhandari, 2009; Lewis \& Niesenbaum, 2005; Shaheen, 2004). Considering the emergence and popularity of ISL, as well as increased demand for both service-learning and short-term faculty led study abroad experiences, it is essential that the field of ISL begin to articulate a pedagogy for short-term ISL (STISL) that represents collective perspectives on the best practices for STISL courses that promote student success. First, however, it is important that we define both ISL and STISL. 


\section{Defining ISL and STISL}

In creating both a practical and theoretical definition of international service-learning (ISL), scholars Crabtree (2008) and Bringle and Hatcher (2011) argue that ISL is at the intersection of theoretical, empirical and pedagogical traditions. In a complex eight domain Venn diagram (Figure 1), Crabtree positions ISL as the nexus of international education and study abroad, cross-cultural adjustment and communication, learning theory, specific academic discipline theory, participatory research, development and collaboration, and civic education/service-learning (p. 28).

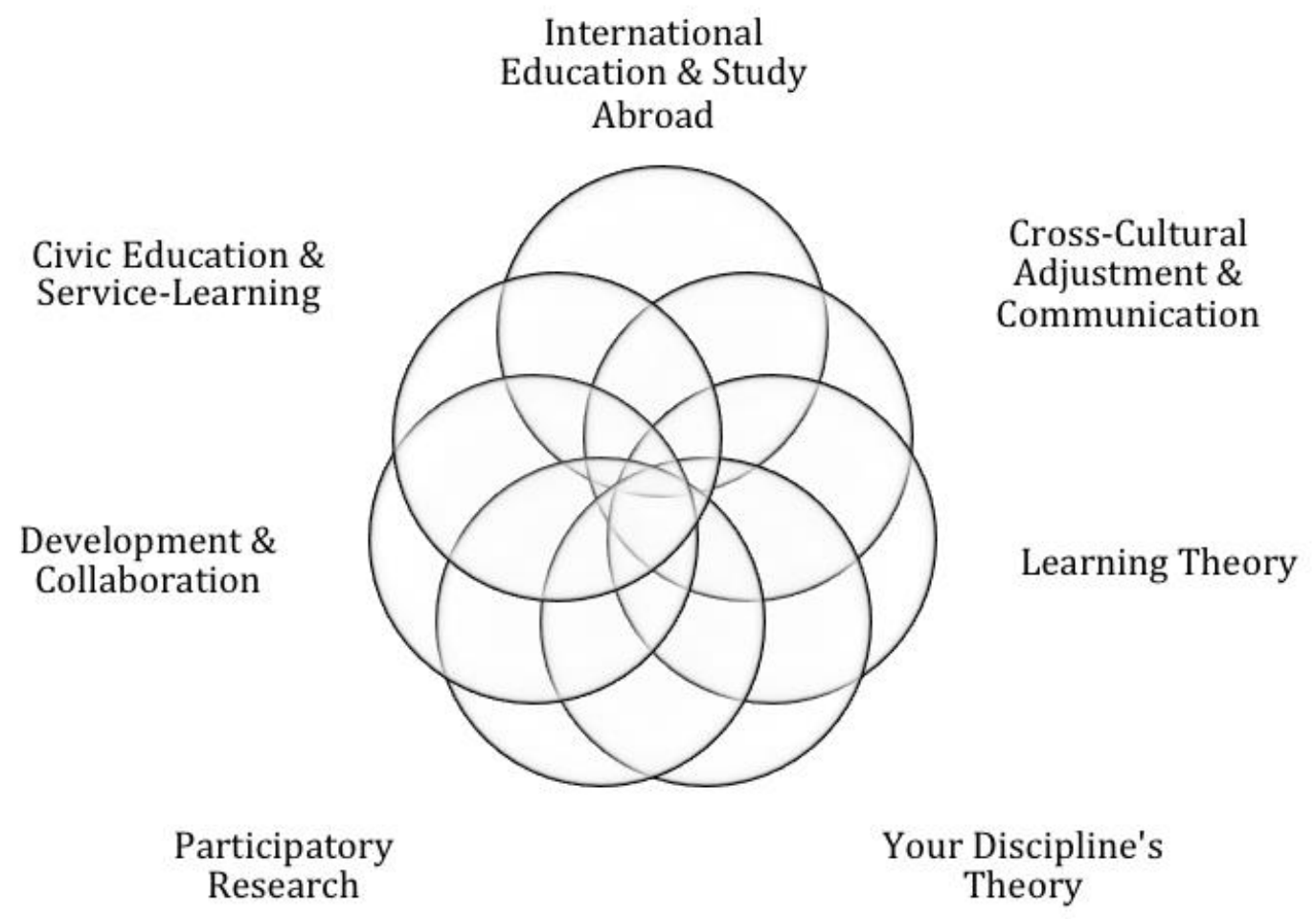

Figure 1. Crabtree's (2008) International Service-Learning at the Intersection of Theoretical and Empirical Traditions (p. 28) 
In a model that is similar, but not an exact duplicate, Bringle and Hatcher (2011) illustrate (Figure 2) ISL as the intersection of three educational domains: service-learning, study abroad and international education. Crabtree's eight domains and Bringle and Hatcher's three domains parallel and differ in important ways.

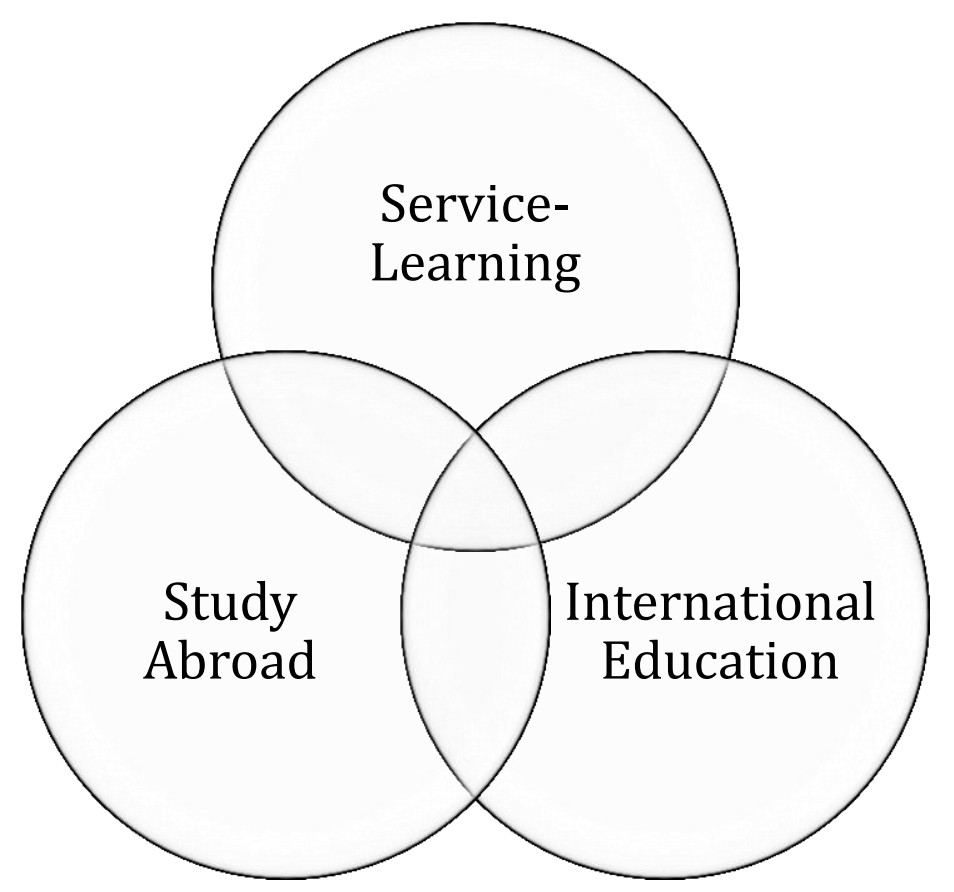

Figure 2. Bringle \& Hatcher's (2011) Conceptualization of International Service-Learning (p. 4)

Crabtree's (2008) eight dimensions of ISL separate learning theory as an independent domain from the other seven, while Bringle and Hatcher's (2011) dimensions of ISL recognize aspects of learning theory, such as critical reflection that comes from learning theory literature (cf. Dewey, 1916), an integral and inseparable part of service-learning (Bringle \& Hatcher, 2011, pp. 5-6). Additionally, Crabtree listed civic education/service-learning in a separate 
domain from development and collaboration, which according to Bringle and Hatcher are nested within the service-learning domain. The final notable difference between the Bringle and Hatcher Venn diagram and the Crabtree Venn diagram is the domain of international education. Bringle and Hatcher have listed international education as its own domain, indicating that it includes the pedagogical practices and theoretical foundations of "global awareness, global education, global learning and development, intercultural competence, world studies, cross-cultural competence, cross-cultural empathy, and cross-cultural understanding [italics in original]" (p. 10). Bringle and Hatcher importantly highlight that simply participating in a study abroad experience does not mean that pedagogical concepts of international education will be introduced.

Defining "short-term" ISL (STISL) requires that we analyze how the field of study abroad has conceptualized what constitutes a short-term experience, as opposed to a long-term experience. Based on the available literature, there is no agreed upon definition of what constitutes a short-term study abroad experience. However, according to the structure of Gutierrez, Auerbach and Bhandari's (2009) survey of study abroad professionals, semester programs and short-term programs are categorically different experiences. Lewis and Richard (2005) cite a course that they consider short-term, which consists of a semester-long course with a two-week international experience. Jackson (2006) defines short-term as a four to ten week international experience. Therefore, for the purpose of this dissertation, a short-term study abroad experience will describe any 
international experience that is less than a full academic semester or term. The actual course may take place over an entire semester or term, however the international experience portion will be less than that a semester or term.

Based on the analysis that the core tenets of both Crabtree's (2008) and Bringle and Hatcher's (2011) eight and three vector articulations of ISL are inclusive of the other's core principles, consensus emerges and makes it possible to articulate a working definition of ISL. Therefore, ISL is best understood using Bringle and Hatcher's (2011) definition :

A structured academic experience in another country in which students (a) participate in an organized service activity that addresses identified community needs; (b) learn from direct interaction and cross-cultural dialogue with others; and; (c) reflect on the experience in such a way as to gain further understanding of course content, a deeper understanding of global and intercultural issues, a broader appreciation of the host country and the discipline, and an enhanced sense of their own responsibilities as citizens, locally and globally. (p. 19)

Bringle and Hatcher's definition of ISL is broad and complex; nevertheless, it aptly summarizes essential components of ISL pedagogy. Furthermore, their definition provides the groundwork for understanding and articulating what constitutes "success" in a STISL experience.

\section{Defining Student Success on a STISL Experience}

Defining student success on a short-term international service-learning experience is a difficult matter, considering the variety of desired learning outcomes articulated in the ISL literature. However, by reviewing servicelearning, study abroad, and ISL literature, we are able to find commonality in 
what constitutes a successful student learning experience in this particular educational experience. For example, Parker-Gwin and Mabry (1998) suggest that the two "primary goals of service learning for students are positive civic and academic outcomes" (p. 277). Similarly, commonly agreed-upon goals of study abroad are largely academic as well as intercultural (Brewer \& Cunningham, 2009; Vande Berg, 2007).

These assertions allude to the evidence in the literature that there are both short-term learning goals and long-term learning goals. The most pervasive term in the literature when discussing successful learning experiences through ISL is the concept of global citizenship, which encapsulates the learning goals of both service-learning and study abroad. Lutterman-Aguilar and Gingerich (2002) highlight that study abroad and service-learning are "natural partners because they share the common goal of empowering students and preparing them to become responsible global citizens" (p. 46).

\section{Global Citizenship: A Hallmark of Long-Term Student Success?}

Numerous scholars have asserted that student success on an ISL experience is an enhanced global citizenship identity (Bringle \& Hatcher, 2011; Lutterman-Aguilar \& Gingerich, 2002; Plater et al., 2009), yet there are few places where the concept of global citizenship is operationally defined. Therefore, it is difficult to assess if this educational goal is being met; this leaves few pedagogical resources for faculty trying to create a new ISL experience. Thus, it is important to understand the semantics behind the phrase global citizenship and 
acknowledge shortcomings and ethical issues with this concept. Understanding global citizenship is essential, considering "nearly every institutional mission statement includes something to the effect of educating students to be global citizens" (Jacoby, 2009, p. 99).

Conceptualizing and defining global citizenship. The themes of "ideas of awareness, responsibility, and participation" (Schattle, 2009, p. 17) on a global scale have been called many things. Historically, cosmopolitanism dates back to the $4^{\text {th }}$ century BCE. The original Greek, kosmou polite, means “'citizens of the cosmos'” (Appiah, 2006, p. xiii). Cosmopolitanism was meant to serve as a paradox between actual citizenship to a particular city or state as well as the world, in a cosmic, universal sense. (Appiah, 2006; Dower \& Williams, 2002). Later in the $18^{\text {th }}$ century, Immanuel Kant, a self-proclaimed cosmopolitanist (Dower \& Williams, 2002) articulated the concept of humanity's universal relationship to each other when he said, "[t]he peoples of the earth have thus entered into varying degrees into a universal community, and it has developed to the point where a violation of rights in one part of the world is felt everywhere" (Kant, 1991, p. 108). Kantian scholar Kleingeld (2012) reflected that in "Kant's view, cosmopolitanism is an attitude taken up in acting: an attitude of recognition, respect, openness, interest, beneficence and concern toward other human individuals, cultures, and peoples as members of one global community" (p. 1). 
Kant's (Kleingeld, 2012)conception of a global community correlates with the modern concept of global citizenship, which is the most common term used when referring to awareness, responsibility, and participation on a global scale. McIntosh (2005) would agree with Kant's definition of world or global citizenship. In speaking about global citizenship, she acknowledges that the word citizen can be confusing, considering there is no global government. Regardless, if global citizenship is the chosen phrase to encompass global awareness, responsibility, and participation, she argues that the way citizenship is conceived must change. According to McIntosh:

Political definitions of citizenship would need to be augmented by more affective definitions. The ideas of loyalty, protection, duties, rights, responsibilities and privileges would need to be expanded and multiplied to the point where one's loyalty and expectation of protection come not only from such units as the living place, province, or nation, but also from a sense of belonging to the whole world. Within this vast world, the marks of citizenship would need to include affection, respect, care, curiosity, and concern for the well-being of all individuals. (p. 23)

McIntosh's perspective on citizenship broadens the definition of a citizen and asserts that there is an affective component to the concept, in that a sense of belonging, respect, care, curiosity, and concern for others are a "subjective aspect of an emotion considered apart from bodily changes" (Merriam-Webster, 2012, l. 2-3). McIntosh aligns this broadened concept of citizenship with many of the values higher education institutions articulate in their mission and vision statements. However, a more affective and subjective definition of citizenship and 
conceptualization of global citizenship proves problematic in that it is difficult to articulate and operationalize (Morais \& Ogden, 2010).

In a dissertation (also reported in a scholarly article by Morais and Ogden (2010)) exploring the concept of global citizenship, Ogden, (2010) utilizing thematic grouping, developed the "Dimensions of Global Citizenship", which proposes a tri-fold multidimensional perspective on what it means to be a global citizen; this includes affective components including self-awareness, respect, empathy, altruism, and personal responsibility. The dimensions include descriptions, core assumptions, and sample perspectives of each dimension. They also articulate affective learning outcomes, which are "overarching themes or dimensions of global citizenship [that are] pervasively noted across many disparate perspectives" (Ogden, 2010, p. 32). The three recognized domains are social responsibility, global competence and global civic engagement, as highlighted in Table 1 (pp 32-35). 
Table 1

Ogden's (2010, pp. 34-35) Dimensions of Global Citizenship

\begin{tabular}{|c|c|c|}
\hline Social Responsibility & Global Competence & $\begin{array}{l}\text { Global Civic } \\
\text { Engagement }\end{array}$ \\
\hline $\begin{array}{l}\text { Description } \\
\text { Interdependence and } \\
\text { social concern to others, } \\
\text { to society and to the } \\
\text { environment }\end{array}$ & $\begin{array}{l}\text { Understanding one's own } \\
\text { and others' cultural norms } \\
\text { and expectations and } \\
\text { leveraging this knowledge } \\
\text { to interact, communicate, } \\
\text { and work effectively } \\
\text { outside one's environment }\end{array}$ & $\begin{array}{l}\text { Recognize local, state, } \\
\text { national, and global } \\
\text { community issues and } \\
\text { responding through } \\
\text { actions such as } \\
\text { volunteerism, political } \\
\text { activism and } \\
\text { community } \\
\text { participation }\end{array}$ \\
\hline $\begin{array}{l}\text { Core Assumptions } \\
\text { Global justice and } \\
\text { disparities; Altruism and } \\
\text { empathy; Global } \\
\text { interconnectedness and } \\
\text { personal responsibility }\end{array}$ & $\begin{array}{l}\text { Self-awareness; } \\
\text { Intercultural } \\
\text { communication; Global } \\
\text { knowledge }\end{array}$ & $\begin{array}{l}\text { Involvement in civic } \\
\text { organizations; Political } \\
\text { voice; Glocal [hybrid } \\
\text { term for global and } \\
\text { local (A. Ogden, } \\
\text { personal } \\
\text { communication, } \\
\text { November 30, 2011)] } \\
\text { civic activism }\end{array}$ \\
\hline $\begin{array}{l}\text { Sample Perspectives } \\
\text { "I respect and am } \\
\text { concerned with the right } \\
\text { of all people. Globally." } \\
\text { "No one country or group } \\
\text { should dominate and } \\
\text { exploit others in the } \\
\text { world." }\end{array}$ & $\begin{array}{l}\text { "I am informed of current } \\
\text { issues that impact } \\
\text { international relations." } \\
\text { "I am able to mediate } \\
\text { interactions between } \\
\text { people of different } \\
\text { cultures by helping them } \\
\text { understand each others' } \\
\text { values and practices." }\end{array}$ & $\begin{array}{l}\text { "I volunteer my time by } \\
\text { working to help } \\
\text { individuals or } \\
\text { communities." } \\
\text { "I boycott brands or } \\
\text { products that are } \\
\text { known to harm } \\
\text { marginalized people } \\
\text { and places." }\end{array}$ \\
\hline
\end{tabular}

Because of its extensive grounding in the literature, this "multi-dimensional

construct [of] interrelated dimensions of social responsibility, global competence

and global civic engagement" (p. 34) is the most appropriate and fitting

framework to operationalize and analyze global citizenship education.

It is important to note that within academic circles the phrase global

citizenship has proven controversial (Dower, 2008; Roman, 2003). Many 
individuals advocating for global citizenship have close ties with higher education and a capitalist economy, both signs of cultural and social privilege. Dower (2008) noted: "[t]hose who are active global citizens either by self-description or because of what others recognize in their style of life are simply privileged people - mainly in the rich North, who have sufficient wealth, leisure, opportunity, access to organizations" (p. 47). Even though he acknowledges the elitist tones sometimes present in the term global citizenship, Dower refuses to "accept especially the implication that somehow all of global citizenship is a bad thing or that is [a] bad thing that those of us who call ourselves global citizens do so" (p. 47).

\section{Spirituality and the Global Soul as Student Success}

Developing the sense of being a global citizen includes affective components such as sensing the oneness of humanity, caring for others, and interconnectedness (Bennett, 2008; Woolley, 2008). Bennett (2008) sees global citizenship as more than a cognitive concept of rights and responsibilities and suggests that global citizenship is more than a mindset. Global citizenship is also a heartset, or emotive and affective experience, expanding the concept of a global citizen to that of a global soul. "Being 'global souls' - seeing ourselves as members of a world community, knowing that we share the future with others - [which] requires not only intercultural experience but also the capacity to engage that experience transformatively” (p. 13). For Woolley, “[b]ecoming aware of one’s global citizenship opens up opportunities to begin to sense the often intangible 
and yet very real connection with others" (pp. 145-146). He asserted that global citizenship is a spiritual concept, "which relates to all human beings, whether religious or not, and is not located exclusively in cognition" (p. 150). Williams and Van Cleave (2011) cite an example of this; when on a STISL experience in India a student reflected:

How does one impart this wisdom: that denying oneself in order to serve another, to look out for another, to prefer another above oneself is the very key to understanding the self, to discovering the heights and depths of which one is capable? Jesus said that if you seek to save your life, you will lose it, but whoever loses his life will find it. This is the paradox of service-learning; in giving we gain, in losing self we find self. (p. 16)

Williams and Van Cleave's example is not an isolated finding. In an empirical study of undergraduate students, Astin and associates $(2005,2011)$ discovered that service-learning was a spiritual experience for a majority of students.

The term spirituality means "different things to different, people, which makes it a challenging topic to discuss within the academic framework" (Chickering, 2009; Shahjahan, 2004, p. 295). Regardless, spirituality deserves consideration in higher education in that it plays a very important role in many people's lives (Astin, Astin, \& Lindholm, 2011; Astin, 2004; Chickering, 2009; O’Sullivan, 1999; Palmer, 1999). According to Astin, Astin, Lindholm, and Bryant (2005), 81\% of students believe in the sacredness of life, $80 \%$ have an interest in spirituality, and 79\% are searching for meaning/purpose in life. But what is spirituality, and what does it have to do with global citizenship and international service-learning? 
While some consider spirituality synonymous with transcendent awareness (Bento, 2000; Dossey, 1989; O'Brien, 1983) and others with wholeness (Hover-Kramer, 1989; Narayanasamy, 1991; Palmer, 1999), Greenstreet (1999) asserted:"[t]here are numerous definitions of the concept of spirituality; these vary in their degree of commonality but do not reflect a consensus of thought" ( $p$. 649). Speck (2005) argues that the confusion around the term, especially in a secular American university or college context, can be explained by three points of tension: the separation of church and state, reigning epistemology of higher education, and a lack of faculty education in addressing spirituality. For many, the term spirituality "carries baggage from worlds of established religions and churches which [students and educators] do not want to identify" (Chickering, 2006, p. 2). Palmer (2003) asserted that teaching students "as a matter of survival, to keep their hearts hidden when in the groves of academe" (p. 379) is a tremendous disservice to students, society, and the learning process.

Defining spirituality. Therefore, when defining spirituality it is important to understand the term as an inclusive concept that honors the lived experiences of all students, including not only those who identify as a member of a religious community, but also atheists, agnostics and persons with strong humanistic orientations (Chickering, 2009). For the purpose of this dissertation, and with the intention of being inclusive to various perspectives, the definition of spirituality is borrowed from Teasdale (1999) and "opens with what ...is an important 
distinction and goes on to language with which we... identify" (Chickering, 2009, p. 7):

Not every religious person is spiritual... and not every spiritual person is religious. Spirituality is a way of life that affects and includes every moment of existence. It is at once a contemplative attitude, a disposition of a life of depth, and the search for ultimate meaning, direction, and belonging. The spiritual person is committed to growth as an essential ongoing life goal. (Teasdale, 1999, pp. 17-18)

Astin, Astin and Lindholm (2011) contend that spirituality is "fundamental to students' lives" and suggest that the "big questions" students ask are essentially spiritual: "Who am I? What are my most deeply felt values? Do I have a mission or purpose in my life? Why am I in college? What kind of person do I want to become What sort of world do I want to help create?" (p. 1). The answers to these profound questions are deeply relevant to the development of personality qualities that in many ways mirror Ogden's (2010) three dimensions of global citizenship, including "self understanding, empathy, caring, and social responsibility" (Astin et al., 2011, p. 1).

Spirituality, service-learning, and faculty. Sikula and Sikula (2005) argue that service learning can facilitate student reflection on personal perspectives of spirituality, including "help[ing] them to understand God and their own spirituality and connectedness to society and to the world in which they live" (p. 77). Service, they argue, transcends religious distinctions, considering that service is innate to many spiritual traditions. Perspective uniformity is not the intention in viewing service-learning as a spiritual act and 
can create a unique platform for students to understand and value the "complexities involved in a diverse society" (p. 79).

In an extensive empirical research project, Astin et al. $(2005,2011)$ investigated how students search for spiritual meaning and how students find spiritual meaning within higher education. The researchers found that there are a number of college experiences and educational practices that facilitate students' spiritual development. For example, according to their study, students who engage in course-based service-learning reportedly experience "larger-thanaverage gains in inclination toward spiritual questing," actively searching for meaning and purpose (Astin et al., 2011, p. 40). Additionally, college faculty can have a significant impact on students' sense of caring and connectedness. Interaction with faculty outside of class is positively associated with growth in measures of student caring and connectedness. Highly student-centered pedagogies inspire similar results; in these, teaching methods "take a more individualized and interactive approach to instruction, in contrast to the traditional teaching methods, in which the teacher is the 'knower' and the student is the vessel where the teacher's knowledge is deposited" (Astin et al., 2011, p. 74). Astin and associates posit that by using a student-centered pedagogy, a faculty member models caring and connectedness, providing the students real life examples of the principles in action.

Spirituality and ISL. Research focusing on understanding the spirituality in ISL courses is very limited and the vast majority of the literature highlights 
specific programs, locations, courses and institutions. Regardless, scholars have identified that a spiritual way of knowing influences the way students understand their ISL experience. For example, in studying a ISL experience for healthcare students from the U.S. in Guatemala, Berg (2006) discovered students identifying as spiritual for the first time and wrestling with integrating spirituality as component of holistic healthcare with balancing cultural-spiritual expressions with which students were unfamiliar.

Mather, Karbley and Yamamoto (2012) described a Japanese study abroad student who, through participating in an ISL experience through a U.S. institution, struggled to balance her own cultural experience with spirituality as a private experience with the Honduran culture, where Catholicism seemed to permeate nearly every aspect of the society, but articulated that she "saw similarities that they all shared, such as lovely smiles, beautiful hearts and infinite potential" (p. 8). Additionally, another participant, “Megan," struggled to reconcile her experience as child from a strong Evangelical Christian background, as a lesbian, and as a woman with the conservative Catholic doctrine in Honduras. Megan's journey in Honduras served as a catalyst to explore "more deeply her inner terrain," and become more comfortable with complexity and ambiguity.

In an analysis of meaning making and border pedagogy for two cohorts of students participating in a STISL program in India, Williams and Van Cleave (2011) note that students re-examined their preconceived notions of service. In reflection journals, group discussions, and final reflection papers, students 
reflected how they had a tendency to want to "do" things and see "concrete" results from their service. Although the authors did not articulate this as spiritual, the students were "awakened to the language of love which transcends all cultures and nations" (p. 10). One student states that she

learned to celebrate every person. I learned that love really does transcend all language barriers. When I looked into the eyes of the women at Mother Teresa's Home, I saw wonder and love...I felt like India and the amazing women here have shown me what it means to live and love with an open heart. No barriers. Just acceptance. (pp. 10-11)

Similarly, a student who worked at an infant orphanage reflected: "[I] learned not to be afraid to try something. When you operate on fear you cannot fully experience what the world may have to offer you. I have also learned more about love and compassion than I thought I could" (p. 10).

In the same research project, Williams and Van Cleave (2011) report students asking "big questions," which according to Astin, Astin and Lindholm (2011) is an indication of students engaging in a spiritual quest. Students asked, "how has this experience informed my decision for the collective community at home? Do I ignore the cries of my own backyard? Is there a way for us to be globally connected without negatively affecting things globally?" (pp. 17-18). Spirituality is rarely mentioned in the ISL literature. For example, spirituality is only mentioned twice in passing (see Kiely, 2011; Longo \& Saltmarsh, 2011) in Bringle, Hatcher and Jones' 2011 book International Service Learning: Conceptual Frameworks and Research, which is arguably the most thorough resource for ISL conceptual frameworks, pedagogy, and research to 
date. Regardless, spirituality as defined by Teasdale (1999) is a concept that is evident in many ISL research articles describing student meaning making processes. It would prove beneficial to better understand if STISL faculty recognize the spiritual elements of students' experiences and to inquire if the faculty specifically design pedagogical elements to support students though this process.

\section{Diverse Students: Participation and Success}

As stakeholders assert the sweepingly positive outcomes of study abroad experiences (Association of International Educators, 2011; Lincoln Commission, 2005 ) and its potential to address the needs of a $21^{\text {st }}$ century citizenry, it is important to note that diverse students, specifically students of minority race and ethnicity, are not proportionally represented within international education, specifically study abroad. According to Institute of International Education (Institute of International Education, 2012), 78.7\% of study abroad participants in 2010 were White, $7.9 \%$ were Asian-American, $6.4 \%$ were Hispanic or Latino(a) Americans, 4.7\% were Black or African-American, $1.9 \%$ were multiracial, and $.05 \%$ were American Indian or Alaska Native. These percentages have not improved greatly for diverse students since the 1996/1997 academic year (Murray Brux \& Fry, 2010).

Study abroad experiences are less accessible educational options for diverse students for a variety of reasons. "The most significant constraints, in rank order were finances, family disapproval, safety concerns, work 
responsibilities, family responsibilities, the program being too lengthy, no desired program, and academic scheduling difficulties" (Murray Brux \& Fry, 2010, p. 512). The short-term nature of STISL experiences may eliminate some barriers to participation, considering students would not have to leave family or job responsibilities for months at a time, and short-term programs are significantly less expensive than long-term programs.

Murry Brux and Fry (2010) suggest that one set of benefits from diversifying study abroad "accrues to 'majority' student participants in diverse study abroad programs..." (p. 509). This is articulated by Cressy (2005) and the Institute for International Education, when she argues that "through interactions between and among diverse groups of U.S. American students, students can help one another progress in their various stages of identity development" (p. 1). Talbert and Stewart (1999), for example, noted that the participation of an African-American female student on a study abroad experience in Spain benefitted the white students in the program who were able to learn from their classmate's experiences with racism, coupled with their own feelings of being different and outsiders.

Murray Brux and Fry's (2010) second set of benefits from diversifying study abroad accrues to the diverse student participants themselves, specifically when they are studying with students from similar ethnic and racial backgrounds. Day-Vines, Barker and Exum (1998) investigated the learning outcomes from a study abroad program in Ghana on 18 African-American students. The 
researchers did not identify the learning outcomes as a global citizenship, although some of the findings align with the Three Dimensions of Global Citizenship. The research discovered five major learning themes from students' essays: a) Dispelling myths about Africa and African people; b) liberating and inspirational experiences; c) noticing contrasting values between Africa and Western value orientations; d) psychosocial development and a solidified ethnic identity; and e) academic achievement and enhanced motivation.

It is important to see that a considerable amount of the research that reports positive learning outcomes for diverse students on study abroad was through programs where students participated with other diverse students was "for the purpose of learning about [their] own ethnicity," which is known as heritage tourism (Comp, 2008; Day-Vines, Barker, \& Exum, 1998; Neff, 2001, p. 38). In non-heritage study abroad, however, where students travel to and study in primarily Caucasian countries, diverse students experienced discrimination, harassment and racism (Talburt \& Stewart, 1999).

Fear of discrimination is a major factor for why many diverse students do not study abroad (Comp, 2008; Day-Vines et al., 1998; Goodwin \& Nacht, 1988; Murray Brux \& Fry, 2010). Talburt and Stewart (1999) conducted an ethnographic study based on students' experiences during 5-week study abroad program in Spain and learned that the program's only woman of color "described feeling vulnerable, verbally harassed and singled out for intimidation by men on the basis of her race, gender and foreign status" (p. 83). According to Holmes's 
(2008) narrative inquiry into ten African-American students' study abroad programs, these students experienced significant benefits, including identity development, independence, self-reliance, sense of belonging, and global perspectives. Holmes's findings are largely positive; however, her research participants are from very different contexts, including European, African, Asian, and Central and South American countries. It is not clear how the experiences compare with one another.

While it is outside the scope of this research project, it is important to highlight that if universities intend on promoting study abroad, ISL, or STISL as pedagogies for preparing students to be ready to work and live in the $21^{\text {st }}$ century, institutions must acknowledge the diverse student participation disparity and that diverse students sometimes fear participating in international experiences due to discrimination and harassment. Also, considering students' own admissions that they were experiencing the international exposure differently than their classmates of a different race, culture, or ethnic background, it would be beneficial to know how faculty navigate and develop pedagogical structures that facilitate the development of global citizenship for all students, including diverse students.

\section{Academic Skills as Student Success}

In addition to the somewhat lofty goal of developing students' global citizenship identity, ISL programs claim that the acquisition of discipline-specific skills contributes to what constitutes student success on ISL experiences. 
Although individual discipline-based skill acquisition is outside the scope of this project, it is important to acknowledge that individual disciplines articulate specific desired learning outcomes, as is appropriate to the academic content area. Academic disciplines citing specific learning objectives include dental hygiene students (Tabor, Carter, Kovar, \& Ramsing, 2008), education students (Williams \& Van Cleave, 2011), physical therapy students (Dockter, 2004), environment and resource management students (Lewis \& Niesenbaum, 2005), and nursing students (Lewis \& Niesenbaum, 2007), to name just a few. While all of the ISL experiences listed above describe affective student development goals-such as intercultural competency, leadership skills, and civic engagement-actual discipline-related learning outcomes are not articulated in the literature. Acknowledging the applicability of ISL to a variety of disciplines is significant. Moreover, it is important to recognize the similarities these varying ISL experiences share, further bolstering the need and demand for a cross-discipline STISL pedagogical model.

Within the ISL literature (including study abroad and service-learning literature) there are both long-term learning outcomes, such as identity development, global citizenship development, and intercultural development, and other short-term academic-based learning outcomes specific to individual programs' focus areas. Next, it is important to understand how students learn in general, as well as how students learn in both long-term and short-term ways. 


\section{Solidarity and Social Justice as Student Success}

In addition to the necessity of developing students' academic skills through higher education, institutions are increasingly recognizing the role that higher education plays in terms of developing students as caring, informed, and capable citizens willing and able to address pressing social and ecological needs (Burns, 2009; Jacoby, 2009; Stokamer, 2011, Zlotkowski, 1996). Many scholars link this thought with the work of Paulo Freire (see Freire, 1970), a pioneer in critical, emancipatory, and liberation pedagogies. Freire's work and the pedagogies that stem from Freirean thought seek to emancipate individuals from oppressive forces (Deans, 1999; Freire, 1970; Jacoby, 2009; McLaren \& Farahmandpur, 2005; Rosenberger, 2000).

According to McLaren and Farahmandpur (2005), critical pedagogy based on Freirean pedagogy "supports the practice of students and workers reflecting critically not only on their location in the world and against the world, but also on their relationship with the world" (p. 53). In applying these thoughts to STISL pedagogy, performing acts of service is only one component of the service experience. In addition, a significant portion of the practice is understanding context, which includes power and privilege, relationship with community members, and the social and political forces that exist and perpetuate the needs facing the host community. According to Jacoby (2009) and other scholars, service-learning pedagogy is deeply political and can be "a counter normative 
pedagogy in which 'the political becomes the very center of learning' (Vogelgesang \& Rhoads, 2003, p. 4)”.

Freire's (1970) pedagogy seeks to equip individuals to "regain their humanity" (p. 33), thereby ending the cycle of oppression that dehumanizes certain individuals at the hands of people benefitting from being oppressors. Freire was adamant that liberation is not something that is done to a group of oppressed people, but with and by the group of oppressed individuals. Cushman (1999) contended that liberation pedagogy, or emancipatory pedagogy, can be achieved by equipping students to develop solidarity with a community. While Cushman does not define solidarity, according to Webster's Dictionary (2013) the term is understood as "unity (as a group or class) that produces or is based on community of interests, objectives and standards" (para. 1). Embedded within the definition of solidarity is a sense of action, that something is produced or acted upon by developing a relationship with a group or community.

Arguably, foundational to the definition of solidarity is a sense of social justice. Social justice, according to Monard-Weissman (2003), is "striving for the fair treatment and conditions of all members in our society" (para. 3), and the concept permeates the field of service-learning (Einfeld \& Collins, 2008) and international service-learning literature (Mondard-Weissman, 2003). Specific to the context of ISL, Baker-Boosamra, Guevara and Balfour (2006) asserted that ISL "must be more than the donation of time or charity. Programs must be designed to be intentionally mutual and inclusive in structure and relationship..." (p. 480). 
The authors also asserted that "educators must address the pitfalls of privilege that often go unexamined in relationships between groups of affluent university students and the underprivileged populations that service learning programs traditionally seek to 'serve'”' (p. 479). Through qualitative data collection of ISL community partner perspectives and subsequent analysis, Baker-Boosamra et al. discovered dozens of instances where community partners reflected their desire to be heard and that the community partners believe that "solidarity, organizing and the power in numbers" (p. 490) are essential to identifying and subsequently addressing community issues in an international and cross-cultural context in pursuit of social justice. Through Baker-Boosamra et al.'s research, international community partners asserted that, "in our struggle for justice [we want to know] that we are not alone" (p. 490).

Baker-Boosamra et al. (2006) asserted that solidarity itself is a complicated principle and that students' understanding of concepts related to real or imagined power and privilege is essential in order to develop this concept with a community. Heldman (2011) defines privilege as "a set of advantages enjoyed by one group that are not commonly experienced by another group" (p. 35), and noted privilege can be problematic within a service-learning setting. Heldman (2011), Rosenberger (2000), and Baker-Boosamra et al. put forth the idea that students must reframe their thinking from that of a savior mentality to a collaborator seeking to partner in ways that the community finds most appropriate and helpful. Service-learning courses must first do no harm, and that 
includes recalibrating ideas of who has power and who does not, or else risk perpetuating dependency, "with the use of a community as a lab and even the denigration of human beings who are objectified and looked at as the 'other' and as poor people (Baker-Boosamra et al., 2006, p. 480). By avoiding the perception that community members are others or simply 'needy,' and intentionally pursuing meaningful relationships that work toward a common good, participants can develop and institute real and long lasting change.

Heldman (2011) asserted that "insensitive actions of privilege go hand in hand with the paradigm of performing charity work instead of solidarity work" (p. 36). Also, according to the findings of Baker-Boosamra and colleagues (2006), the Salvadorian community partners and other stakeholders with whom their institution partnered (and participated in the study) did not articulate that they wanted foreign aid, charity, or ISL students to enter their country and solve the issues that faced the community. Instead, the community desired relationships and partnerships with potential advocates that could assist in meeting community identified needs, not the needs that the outsiders thought were most pressing. The authors conclude that there is a difference between service based on charity and service based on solidarity. Service based on charity "perpetuates or accepts Salvadorans' dependence on others" (p. 498), while service based on solidarity "is an act of partnership that seeks to transform the structural causes of injustice and to empower those perceived to be in need of service (p. 498). 
As is consistent with the service-learning literature, relationships with the host community through which community identified needs are addressed is a goal of this pedagogy and can be extrapolated to apply to STISL pedagogy. This

principle can be understood as solidarity. Scholars believe (Baker-Boosamra et al., 2006; Cushman, 1999; Rosenberger, 2000) that in order to truly impact students for long-term civic engagement, either locally or globally, students must both care enough to act and be willing to so. Ultimately, this can be summarized as developing solidarity with a community in order to meet community-identified needs.

\section{Adult Learning Theories}

First, it is necessary to understand what we mean by the term pedagogy. This dissertation borrows Cress's (2011) definition of pedagogy and understand s the concept as "instructional strategies and methods - the external processes of what (content) and how (lecture, tests, service) we teach" (p. 51). Epistemology, on the other hand, is used to "represent how we learn - the internal processes of coming to know and understand" (p. 51). How faculty teach and how students learn are intimately intertwined and it is not possible to talk about pedagogy without discussing epistemology, and vice versa. Therefore understanding the epistemological theories of Kolb (1984), Maslow (Harper \& Guibault, 2008; Maslow, 1970), and Gardner (1993) will serve as a way to frame the pedagogical implications of STISL. 


\section{Theory of Experiential Learning.}

Based on his study of Kurt Lewin, John Dewey, and Jean Piaget, Kolb's (1984) theory of experiential learning offers a "fundamentally different view of the learning process from that of the behavorial theories" (p. 20). The Kolb theory of experiential learning is described as a process "of performing work in realworld settings to strengthen learning” (Wong, Green, \& Wan, 2012, p. 275). Experiential learning contends that learning is a continuous loop (Montrose, 2002) constructed by four adaptive modes of learning, namely concrete experience (CE), reflective observation (RO), abstract conceptualization $(A C)$, and active experimentation (AE) (Figure 3).

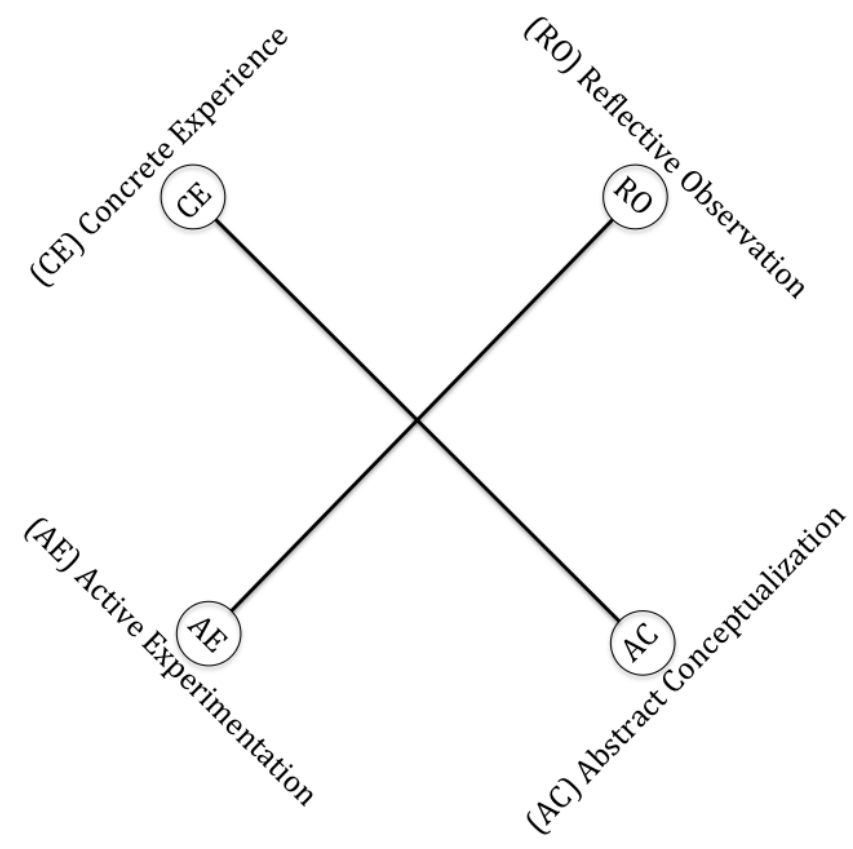

Figure 3. Kolb’s (1984) Four Adaptive Modes of Learning 
Kolb is careful not to suggest that experiential learning is an alternative to behavioral and cognitive learning, but holistically combines experience, perception, cognition and behavior.

Within the four modes of learning, certain modes conflict or oppose others. For example, concrete experience is differentiated from abstract conceptualization, and active experimentation is differentiated from reflective observation. While it is possible for modes to occur at the same time, they are fundamentally different conceptualizations of the learning experience. The CE/AC learning mode is referred to as "prehension," comprised of two "dialectally opposed" ways of understanding an experience or the world (p. 41). The AE/RO learning mode is referred to as "transformation... representing two opposed ways of transforming that grasp or 'figurative representation' of experience" (p. 41). While $\mathrm{CE}$ is on one end of the prehension spectrum from $\mathrm{AC}$, and $\mathrm{AE}$ is on one end of the transformation spectrum from R0, learners tend to gravitate toward quadrants that best resonate with how they learn through experience. Although it is possible, it is not typical that people learn equally from two diametrically opposed learning modes.

Considering learners prefer one way of absorbing concepts and information over the other for both prehension and transformation, learners are then have an identifiable learning style. A learning style is essentially the way a student prefers to absorb or take in information. Each learning style has unique 
characteristics that provide insight into how a person learns most effectively (Figure 4).

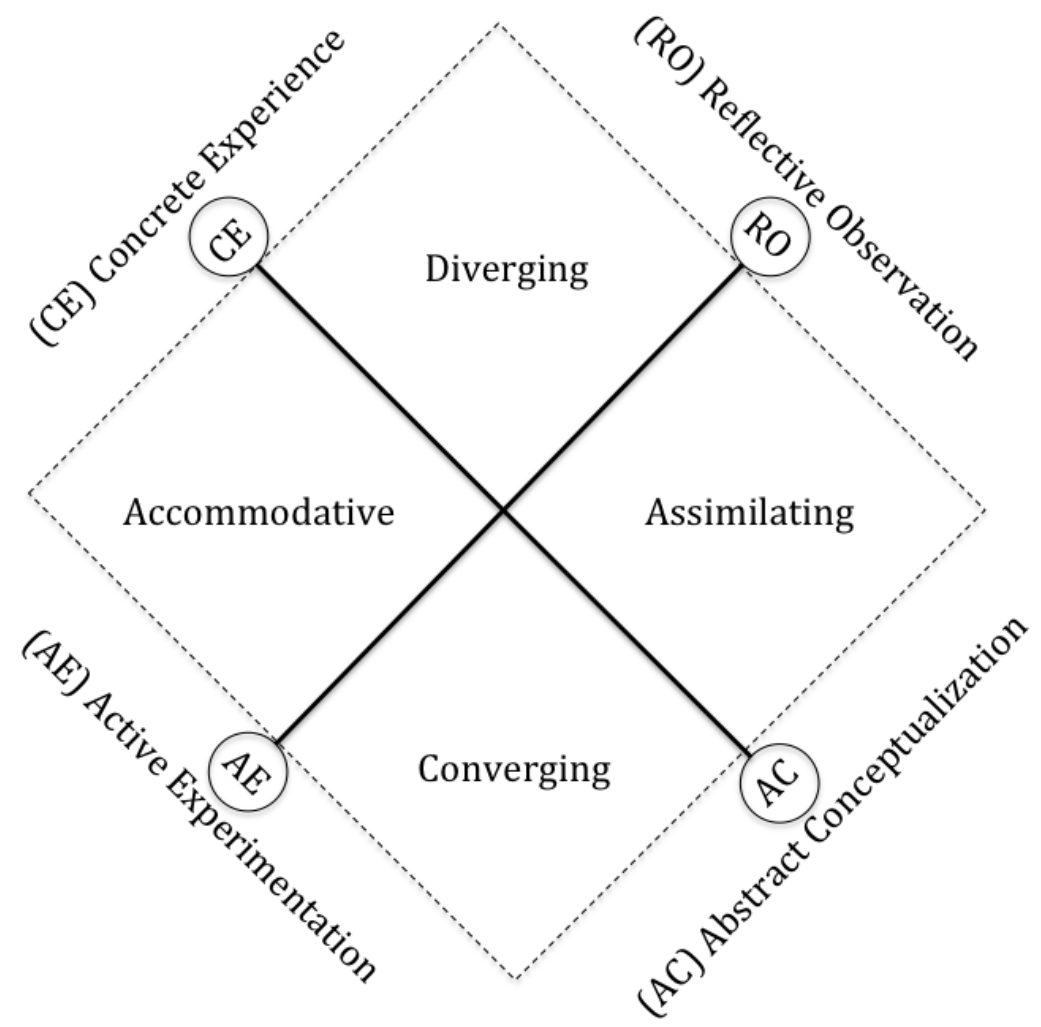

Figure 4. Kolb’s (1984) Experiential Learning Model

The accommodative learning style addresses learners who best learn through active experimentation and concrete experiences. The diverging learning style describes learners who best learn through reflective observation and concrete experiences. The assimilating learning style outlines learners who best learn through reflective observation and abstract conceptualization. The converging learning style describes learners who best learn through abstract conceptualization and active experimentation. While individuals usually prefer a 
particular style to others, learners must experience all modes (AE/CE/RO/AC) in order to have fully integrative learning (Cress, 2011).

When designing curricula based around the four modes of learning, Petkus (2000) reminds practitioners there is no designated starting point for the cycle and notes, "learning is most effective when the student goes through all points, regardless where he or she starts" (p. 64).

Kolb's theory of experiential learning is a suggested epistemological frame in which to structure the pedagogy of service-learning courses (Collier \& Williams, 2005; Cress, 2011; Montrose, 2002). Cress (2011) suggests that service-learning practitioners frame course descriptions, learning objectives, service-site expectations, reflective journal activities, and other course activities using Kolb's four epistemological categories as a frame. But in terms of STISL, how are faculty structuring or not structuring the experience based on Kolb? Are STISL faculty using available inventories in order to discover which learning styles a particular group of students gravitate toward, or are faculty using informal learning style assessment techniques? These questions will be explored more in-depth in chapter three.

\section{Theory of Multiple Intelligences}

The theory of Multiple Intelligences asserts that every learner has different ways in which he or she learns best. These ways of learning are known as intelligences, of which there are nine different categories. According to Gardner (1993), individuals' have varying strengths in one or more of the 
intelligences, which include visual/spatial, verbal/linguistic, mathematical/logical, bodily/kinesthetic, musical/rhythmic, intrapersonal, interpersonal, naturalist, and other intelligences such as spiritual or existential. The visual/spatial intelligence represents people who best learn through visual stimuli and usually have strong visual memory, senses of direction, and hand-eye coordination. The verbal/linguistic intelligence represents people who learn well through writing, reading, and memorizing words and dates. The mathematical/logical intelligences represent people who are best solving problems and generally have good logic, reasoning, and scientific investigative skills. The bodily/kinesthetic intelligence represents people who learn best through activity, games, movement , and building. Musical/rhythmic intelligence represents people who lean well through songs, patterns, rhythms, and musical expression. Intrapersonal intelligence represents people who are often labeled introverts and are in touch with their own feelings. Typically individuals with intrapersonal intelligence work best alone as opposed to in a group setting. Interpersonal intelligence represents people who are noticeably people oriented and outgoing. They learn best when working cooperatively and in group settings. Naturalist intelligence represents people who learn best from natural environments and nature and are more aware of subtle differences in meanings. Finally the other intelligence represents people who have strengths such as spiritual or existential intelligence. They often learn best in the context of "the big 
picture" and are ask philosophical questions like, "why are we here" and "what is our role in the world?" (Cortland University, n.d.; Gardner, 1993).

Gardner (1993) asserted that each person can learn from any of the nine intelligences; however, the profile of how individuals learn best is unique to each person. Gardner points out that even identical twins have different learning intelligence styles. Also, conveying this epistemological learning model into pedagogical practice, Gardner claimed that "the educator should know as much as possible about the intelligences profiles of each student for whom he[she] has responsibility" (Gardner, 1993, p. xvi).

Curricula can be designed in ways that take students' intelligences into account. The theory of Multiple Intelligences can serve as a "'metamodel' for organizing and synthesizing all the educational innovations" (Armstrong, 2000, p. 38). Additionally, the theory of Multiple Intelligences can provide a framework for assessing student learning outcomes that goes beyond narrow verbal or logical domains. Armstrong asserted that when teaching through Multiple Intelligence pedagogy, faculty must be flexible and creative in terms of assessment. He contended that the most "important component in implementing authentic assessment is the documentation of student products and problemsolving processes" (p. 89). Documentation of students' performance can take a variety of approaches, including a faculty journal, work samples, audio or video recordings, photography, student journals, sociograms, informal tests and standardized tests, and interviews. 
While scholars assert the importance of knowing each student's individual learning preferences, there is little evidence in the study abroad, service-learning or ISL literature that describes the best practices for ascertaining this information. Do faculty rely on their own intuition, or do they utilize formal inventories such as the Teele Inventory for Multiple Intelligences (McMahon, Rose, \& Parks, 2004), or publically available inventories available online, i.e. from Western Michigan University (n.d.)? At this point, there is not enough information in the literature to know the extent to which faculty either formally or informally inventory students' individual learning preferences or intelligences.

\section{Hierarchy of Basic Needs.}

Kolb's and Gardner's epistemological theories of learning styles and intelligences have provided a framework from which STISL faculty can pedagogically design and implement the experience. Regardless of how students learn, Maslow's (1970) theory of human motivation provides a framework to understand what students need to know, and in what order, regardless of delivery. Maslow's theory asserts that in order to optimize learning one must meet basic human needs, which allows individuals to progress into higher levels of thinking and analysis. It is important to note that scholars have discussed flaws with Maslow's theory (Neher, 1991); these will be discussed.

Maslow's theory of human motivation suggests that all people have needs that "can be arranged on a hierarchy according to prepotency [influence, importance] or pressing drive for gratification" (Harper \& Guibault, 2008, p. 1). 
Describing his theory, Maslow (1970) states, "Freedom, love, community feeling, respect philosophy, may all be waived aside as fripperies that are useless, since they fail to fill the stomach. Such a man may fairly be said to live by bread alone" (p. 37). Significantly, Maslow goes on to acknowledge "it cannot possibly be denied that such things are true, but their generality can be denied" (p. 37), meaning that his model is not entirely rigid and that the model's generalizability can at times be problematic.

According to Maslow, (1970) there are different types of need, including physiological, safety, esteem, and aesthetic needs. In sum, there are seven levels of basic needs, and is often depicted as a pyramid, or triangle, with the most tangible needs serving as the foundation, leading upward toward the least (Harper \& Guibault, 2008)(Figure 5). 


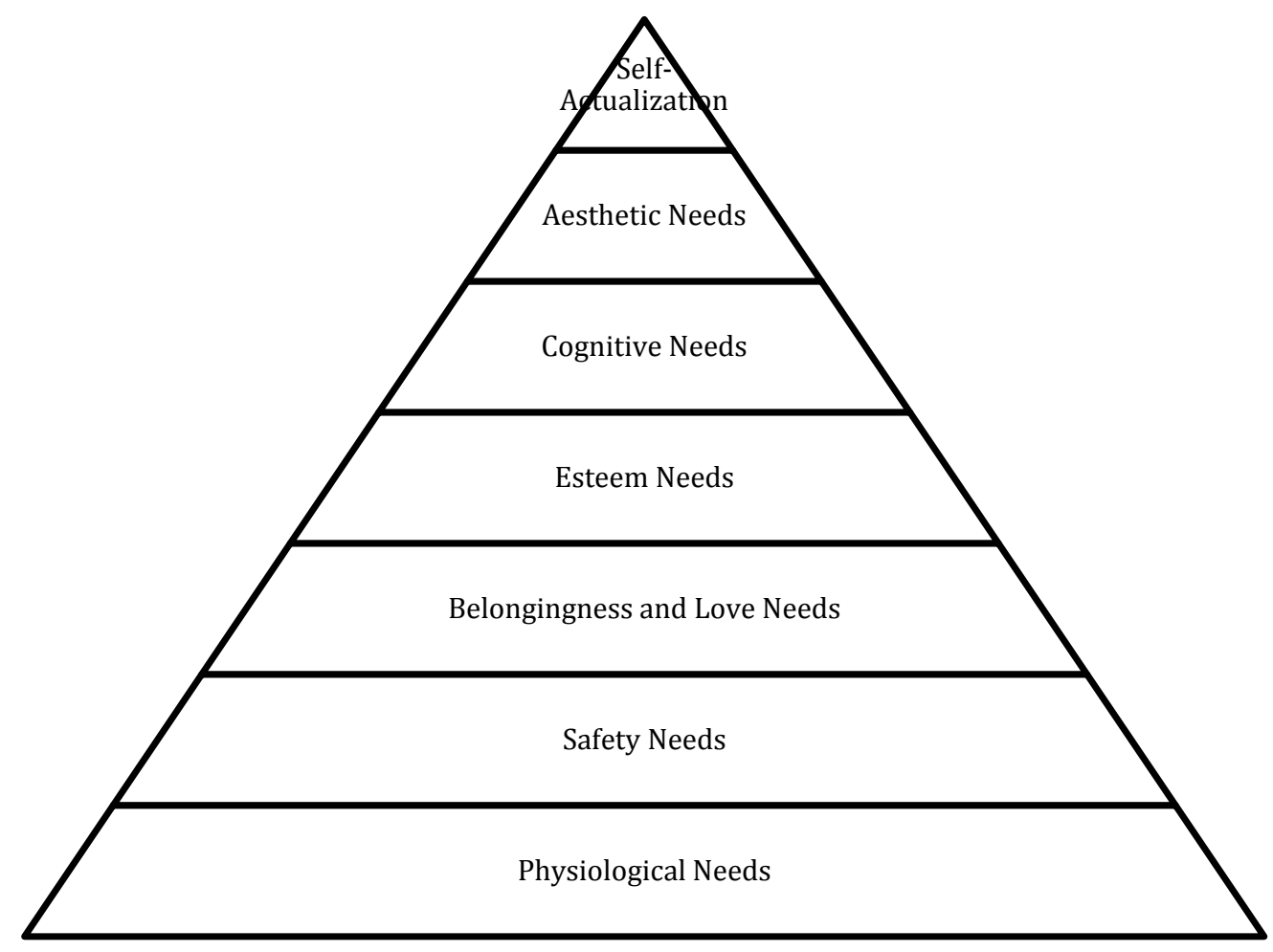

Figure 5. Maslow's Hierarchy of Basic Needs

Harper and Guibault (2008) describe self-actualization, located at the top of the hierarchy, as the "need for growth to develop one's common and unique potential or talent; to find one's mission, purpose, or vocation in life; need for fulfillment" (p. 2). Merriam, Caffarella and Baumgartner (2007) assert that for Maslow selfactualization is the goal of learning and that educators should "strive to bring it about" (p. 282). It is important to note that self-actualization is best met when the needs below are previously addressed. For instance, it is unrealistic to expect a learner to be in Maslow's cognitive needs level, where a learner feel the "need to know, understand, and explore their world" (Harper \& Guibault, 2008, p. 2), if their need for safety not been met. 
Cress, Stokamer, Van Cleave, and Edwin (2013) noted that principles of Maslow's Hierarchy of Needs can be useful when approaching the implementation of ISL pedagogy:

Assuming... foundational needs are met, and community is formed, one can then engage in reflection, which leads to insight and learning (or selfactualization). Indeed, if hungry, cold or scared of others, one is not likely to have the resources to engage in higher-order learning. Instead the person will be focused on surviving. As a case in point, many schools provide breakfast for low-income kids so they can focus on reading and writing. (p. 178)

Therefore, theory suggests that attention should first be paid to the most tangible need (located at the bottom of the pyramid)-human physiological needs (Maslow, 1970) such as "hunger and thirst, which must be attended to before one can deal with safety needs"- before progressing up the hierarchy toward self-actualization or meaningful learning (Cress et al., 2013; Merriam et al., 2007, p. 282).

The third need in Maslow's hierarchy, a need for belongingness and love, is described as the "need for acceptance and approval of others; need to belong to a group and acquire warmth from another or others; need to love and be loved" (Harper \& Guibault, 2008, p. 2). Therefore, the way that a student experiences belonging with other students in the group and the faculty member matters as a part of students meaning-making process. Students' sense of belonging to a group, however, has not yet been represented in the study abroad or service-learning literature. If an individual does not feel belongingness or love, it is less likely that they will seek to fulfill higher-level thinking. 
Table 2 articulates potential student needs a faculty member coordinating a STISL should to meet in order to progress through Maslow's Hierarchy of Needs.

Table 2

Proposed Student Needs on a STISL Experience

\begin{tabular}{|c|c|}
\hline Needs & STISL Needs \\
\hline Physiological & $\begin{array}{l}\text { - Will there be potable water? } \\
\text { - I am allergic to peanuts, will I be safe eating the local } \\
\text { food? } \\
\text { - Will the air be clean enough because I have asthma? }\end{array}$ \\
\hline Safety & $\begin{array}{l}\text { - Are there travel warnings to this country? } \\
\text { - What precautions can I take to ensure I do not get sick, } \\
\text { (i.e. immunizations, not eating from street vendors)? } \\
\text { - Have there been instances of political unrest that I } \\
\text { should be concerned about? } \\
\text { - How can my family get in contact with me should there } \\
\text { be an emergency at home? }\end{array}$ \\
\hline $\begin{array}{l}\text { Belongingness } \\
\text { and Love }\end{array}$ & $\begin{array}{l}\text { - Do my classmates like me? } \\
\text { - Does my professor value my opinion? }\end{array}$ \\
\hline Esteem & $\begin{array}{l}\text { - Do I feel like my opinions are important and that the } \\
\text { class wants to hear my thoughts? } \\
\text { - Do I feel like I am adding a valuable perspective to this } \\
\text { experience for my classmates? }\end{array}$ \\
\hline Cognitive & $\begin{array}{l}\text { - Why is there so much trash in this country and how is } \\
\text { it impacting people's health and livelihood? } \\
\text { - How is my African-American classmate experiencing } \\
\text { this course differently than I am? } \\
\text { - What can we do to change this social injustice? }\end{array}$ \\
\hline Aesthetic & $\begin{array}{l}\text { - Things are so strange here, but does that mean what I } \\
\text { know as normal is better, or is it just is different? } \\
\text { - In what ways is this culture similar to my own? }\end{array}$ \\
\hline Self-Actualization & $\begin{array}{l}\text { - How has this experience changed me? } \\
\text { - What does this course mean for me and what I want to } \\
\text { do for my career? } \\
\text { - Should I change my major and follow what I think I } \\
\text { would be personally and spiritually fulfilling? }\end{array}$ \\
\hline
\end{tabular}


The proposed student needs listed above is not meant to be exhaustive, but does illuminate potential needs that faculty members should consider when structuring STISL pedagogical strategies so that students can progress into higher levels of learning and understanding through a STISL course experience.

It is important to recognize that much of Maslow's work is philosophical and theoretical. Maslow himself conducted very little research on the theory's concepts (Harper \& Guibault, 2008). As Neher (1991) noted, "humanistic psychologists have yet to probe the flaws in Maslow's theory in any concerted or thorough fashion" (p. 89). Specifically, Neher contends that a significant flaw with Maslow's theory is that various flaws in his theory stem from a general overstatement of the rigidity of Maslow's stages of human needs. Additionally, Maslow's theory "does not include the need to learn language or any of the other cultural traits that create our humanness and bind us socially" (p. 94). The omission of cultural components of Maslow's work is thought to promote Western values of individualism, and fails to transcend cultural priorities and boundaries. Maslow (1970) himself admitted that initially he described the needs in a

fixed order, but actually it is not nearly so rigid as we may have implied... There are some people in whom, for instance, self-esteem seems to be more important than love...There are other apparently innately creative people in whom the drive to creativeness seems to be more important than any other counter-determinant... So far, our theoretical discussion may have given the impression that these [needs] are somehow in such terms as the following: if one need is satisfied, then another emerges. This statement might give the false impression that a need must be satisfied 100 percent before the next emerges. In fact, most members of our society 
who are normal are partially satisfied in all their needs and partially unsatisfied in all their basic needs at the same time. A more realistic description of the hierarchy would be in terms of decreasing percentages of satisfaction as we go up the hierarchy of prepotency. (pp. 51-54)

Despite these criticisms, from Maslow (1970) himself as well as other strong critics (see Neher, 1991), the field of psychology still contends that "Maslow certainly deserves credit for his general thesis: undoubtedly, we do have a difficulty time reaching the heights of experience if we are preoccupied with attaining the base essentials of life" (p. 109). Within the field of adult learning and motivation Maslow's work has been influential and has served as a framework for understanding motivation. The theory's influences can be seen in many other adult learning theories (Merriam et al., 2007).

Another theoretical model for student learning articulates how adult learners go about experiencing a perspective transformation, a theme that is prominent in the ISL and STISL literature.

\section{Transformational Learning}

An often touted claim about "experiential education, SL [service-learning], and international immersions alike regards their ability to transform participants [italics in original]" (Crabtree, 2008, p. 26; Kiely, 2004, 2005, 2011; Porter \& Monard, 2001; Tonkin \& Quiroga, 2004). The word transform and its application to ISL programs is associated with Mezirow and his theory of transformational learning. Transformational (or transformative) learning is the process by which we transform our taken-for-granted frames of reference (meaning perspectives, habits of mind, mind-sets) to make them more 
inclusive, discriminating, open, emotionally capable of change, and reflective so that they may generate beliefs and opinions that will prove more true or justified to guide action. (Mezirow, 2000, pp. 7-8)

According to Mezirow (2000) transformative learning must be understood in the context of cultural orientations embodied in one's frames of reference that "shape one's preferences, willingness, and readiness to engage new ways of living, knowing, and acting in the world" (Ogden, 2010, p. 51). A perspective shift must occur in order that attitudes become more inclusive and those attitudes manifest in changed action as guided by the knowledge acquired, and occurs by progressing through a ten stage non-sequential learning process (Cranton, 1994; Mezirow, 1978, 1991, 2000, 2009). The first stage of the transformational learning process begins when a person experiences a disorienting dilemma and culminates as the person reintegrates into their life context before the disorienting dilemma on the basis of conditions as dictated by their new perspective.

Also known as transformative learning, this learning process has been important in the development of adult education since Mezirow (1978) originally proposed it more than 35 years ago. From trying to understand how business students experience curricula (Brock, 2010) to analyzing how high school students prepared for college (Peacock, 2008), transformative learning has been used as a means of explaining and evaluating adult learning as seen in "a plethora of articles, books, and dissertations" (Merriam et al., 2007, p. 131). By and large, the vast majority of empirical research studies on transformative learning theory 
have been qualitative (Brock, 2010; Merriam et al., 2007), with a few exceptions like mixed methods (see Brock, 2010; Fullerton, 2010), based on both practicality and the "amorphous nature of transformative learning. In many ways positivism seems to contradict the constructivist orientation that is so indicative of transformative learning theory" (p. 321).

Transformative learning theory has been used as a way to understand the student experience in a variety of service-learning (Eyler \& Giles, 1999; Kiely, 2004, 2005) and study abroad (Donahue, 2009; Tacey, 2011) research projects. In their empirical research project and subsequent book, Where's the Learning in Service-Learning?, Eyler and Giles (1999) note that not every instance of learning is transformative learning. Learning can simply be the acquisition of new information or the expansion of past information. However, in addition to new information being introduced, the new information causes students to question the sensibility of previous conceptions or values. With transformative learning, students:

struggle to solve a problem where our usual ways of doing or seeing do not work, and we are called to question the validity of what we think we know or critically examine the very premises of our perception to the problem" (p. 133).

In a hypothetical application to a service-learning experience, Eyler and Giles propose that:

... students who acquire more complex information on the many factors that contribute to homelessness are merely deepening their understanding of the issue, the student who begins to question government budgetary priorities or zoning regulations or the way in 
which access to medical care is linked to employment is starting to question some assumptions about the way society operates. This process of questioning may lead to a transformation of perspective. (p. 133).

Eyler and Giles summarize that students who were involved in service-learning projects, specifically those that with "highly reflective" pedagogy, were more likely to experience perspective transformation than those in control groups with no service-learning component or a service-learning course with little reflection. Further, they note that transformation of perspectives is rare, however, "About a third of participants in service-learning claimed that it gave them a new perspective on social issue" (p. 149).

Hunter (2008) argues that international educators, which we can infer includes STISL faculty members, should actively engage students in the transformative learning process by designing courses that equip students to live, know, and act in the world in a different way. She elaborates that if the goal of international education is to create global citizens capable of interacting effectively and responsibly in the world, then international educators should encourage students to take action on their new learning and bring insights full circle, either in their personal choices or in the civic activities in which they engage. This assertion correlates with the Dimensions of Global Citizenship, in that students are able to apply newly acquired knowledge in a local and global context for the betterment of society (Ogden, 2010). Hunter goes so far as to suggest that a service-learning or volunteer experience embedded in a study abroad experience could be an ideal pedagogy for transformational learning. In 
this type of pedagogy Ogden (2010) reflected that students "who have such experiences that potentially challenge their frames of reference, should be encouraged to critically reflect on and discuss their experiences in ways that lead them to constructive and purposeful action" (p. 52) and that failure to do so may thwart the transformational potential embedded in ISL.

In summary, all four learning theories described above explain both how students learn (epistemology) and provide frameworks in which to structure what material is delivered and in what way (pedagogy). Kolb's Experiential Learning theory provides STISL practitioners with insight into how students learn and conveys that students may have different learning style preferences from each other. No way of learning is "better" than another, simply different. Additionally, Kolb's theory provides a framework that can be useful in deciding how to design pedagogical components such as "course descriptions, learning objectives, service-site expectations, reflective journal responses, and other class assignments and activities “ (Cress, 2011, p. 52).

Similar to Kolb's Experiential Learning theory, Gardner's theory of Multiple Intelligence serves as both an explanation of how individualized student learning can be and a potential framework that be used to design STISL course pedagogical components taking into account student individuality. Furthermore, Maslow's Hierarchy of Needs, while not taking into account individual learning styles of preferences or intelligences, serves as a way to understand how students best learn, and a theory of needs can inform practitioners about the chronology of 
pedagogical implementation and the scaffolding that must occur to achieve higher order thinking processes.

Finally, Mezirow's theory of Transformational Learning illuminates how students go about the process of experiencing perspective transformation, which could be at the heart of what constitutes long-term success for STISL practices. Beginning with a disorienting dilemma and culminating in a perspective transformation, Kolb and Gardner's theories of learning and Maslow's theory of needs provide insight into how a STISL practitioner can structure an ISL experience with the potential to be transformative.

Learning theory should be considered when structuring STISL pedagogy, since if instructors acknowledge that individual students learn differently and scaffold knowledge students will be better prepared to develop a global citizenship identity. However, considering that STISL courses have multiple segments, including pre-departure, host-country, and re-entry, it is most appropriate and logical to discuss design strategies chronologically.

\section{Chronological Segments of a STISL Course}

Chronologically, there are three distinct segments of an ISL experience: pre-departure, host-country, and re-entry. The pre-departure segment is any portion of the STISL course or program that takes place in the country where the credit granting university or college is located. While "country where the credit granting university or college is located" is cumbersome, it recognizes that students who participate in a STISL program may not consider that country their 
"home country." The host-country portion of a STISL program takes place in the destination country where the service portion of the trip will be held. The reentry segment of a STISL course or program takes place after students return to the country where the credit granting university or college is located, although pre-re-entry discussion can begin in the host-country.

\section{Pre-Departure}

Chisholm (2003) contended that ISL experiences "should be a time of uncertainty, as the student faces a wholly new set of values and assumptions about human life" (p. 280). Althen and Bennett (2011) categorize what Chisholm refers to as "uncertant[ies]" into three reactionary levels, including culture surprise, stress, and shock. Culture surprise is considered a small cultural difference, such as how the toilets work or using foreign currency. Culture stress is "handling the small events in the new culture such as how to wait in lines or cultural rules in social settings" (Shaheen, 2004, p. 38). And finally, culture shock is a response to larger events and paradigm differences in the new place. Facilitating students' understanding of these cultural differences can begin before the student ever leaves his or her home institution.

Orientation programs are often utilized by institutions of higher education in order to prepare students for a successful transition into college life (Pascarella \& Terenzini, 2005). Additionally, orientation programs are noted as an integral step in preparing for overseas experiences. As Kohls (2001) noted, "the success-rate of overseas adjustment is not nearly as high as it might be... But it doesn't have to be 
left to luck. There are things you can do" (p. 1) to plan and prepare for the experience.

While there are few resources in the literature on pedagogical pre-departure programs for ISL courses specifically (with the exception of Kiely, 2005), the fields of service-learning and study abroad provide insight into how to prepare students for a STISL experience. In describing people's response to change in general, Robertson (1988) asserted that the effect a transition has on individuals can be estimated based on five continua, three of which (numbers 2, 3, and 4) can begin to be addressed before students leave for a STISL experience:

1. Major-Minor

2. Anticipated-Unanticipated

3. Planned-Unplanned

4. Gradual-Eruptive

5. Positive-Negative (p. 64)

In pre-departure stages the ISL faculty can proactively support students by encouraging them to anticipate and plan for and gradually introducing students to potentially dissonant experiences, preparing them for cultural surprise. A similar concept to cultural surprise is the idea of low intensity dissonance, which Kiely (2005) suggests can be mitigated by providing students with logistical background that can help them cope when they are abroad. STISL faculty have the option of structuring pre-departure orientations that build students' knowledge base, so that during the host-country experience students have background knowledge to draw on and successfully navigate the situation. Examples include sanitation, essential items to pack (sunscreen, insect repellant, 
etc.), medications and vaccinations, basic language lessons, etc. (Kiely, 2005).

Preparing students for low intensity dissonance-or culture surprise-aligns with fulfilling students' physiological (food, water) and safety (sense of security, protection from threat, adequate shelter) needs and could enable students to move to fulfill higher order needs.

Pre-departure can also be the setting for beginning to fulfill students' need for belongingness and love, described as the "need for acceptance and approval of others; need to belong to a group and acquire warmth from another or others; need to love and be loved" (Harper \& Guibault, 2008, p. 2). Intellectual safety describes an environment where students can fulfill their need for belonging and love. An intellectually safe environment, as defined by Schrader (2004), is an atmosphere that:

Is a caring environment in which the professor is open and caring, demonstrates respect, and embraces the uniqueness of the students and their perspectives and does so in a classroom format where all are invited to participate actively, engage in personal self-disclosure while trusting the confidentiality of such openness, and where the professor maintains a sense of control and direction to facilitate learning. (pp. 95-96)

Faculty members play an important role in creating an atmosphere that is perceived by students as intellectually safe. In an intellectually safe environment, the faculty are seen as "in charge of the classroom...yet [give] freedom to the student to explore ideas within a limited range... maintain[ing] confidentiality about student issues concerns, respect privacy and express confidentiality" (Schrader, 2004, p. 95). A faculty member must set the tone for the course 
through words and actions and must be willing to disclose stories and information about their own developmental journey.

Creating an intellectually safe environment is especially important, if the goal of the experience is "transformation of epistemological world views.

Students are most vulnerable and most likely to feel defeated when they are in the process of deconstructing different ways of thinking about knowledge, information, themselves, and the world around them" (Schrader, 2004, p. 99). If we recognize that intellectual safety enables students to reflect more deeply, a critical part of Kolb's learning cycle, and we understand that reflection is an integral part of meaning making (Ash \& Clayton, 2004; Bringle \& Hatcher, 1999; Collier \& Williams, 2005; Cranton, 1994), we should be able to look to the literature to see what faculty are doing in order to create and sustain intellectually safe learning atmospheres, including in the initial stages of program pre-departure orientation. However, again we are faced with a gap in the ISL literature. As of now, we do not know how faculty are using the pre-departure orientation as a way of establishing the dynamics necessary for an intellectually safe environment, both in the home country as well as abroad.

Pre-departure preparations can "give students the skills to handle... new challenges" (Shaheen, 2004, p. 38) which may lessen culture stress and shock. Referring to a study abroad experience, not ISL, La Brack (1993) uses predeparture orientations as a platform to discuss culture shock as an academic lesson. Students are taught the signs, causes, possible reactions, and ways to 
minimize stress while studying abroad. Students are shown a video about culture shock and are then assigned articles on the subject, which are to be analyzed and responded to in a 4-page paper, either "'Problems I anticipate abroad and what I can do to prepare myself to meet them' or 'What I will miss most about America and what I am most looking forward to about being overseas.' " (p. 252). During the class session when the papers are due the students and the faculty member engage in a discussion about the paper topics. La Brack noted that this exercise both lowers apprehension for the students who may felt alone in his or her worries and helps to build rapport between the students. Williams and Van Cleave (2011) incorporated pre-departure writing assignments where students could express both their worries about the upcoming ISL experience and things that excited them about it (personal communications, D. Williams, 2012).

Pre-departure orientations can help students develop basic coping skills for low intensity dissonance and can also begin to teach students how to reflect on their own emotions about the experience, as well as serve as an opportunity to build rapport with other sojourners. According to the Georgetown Consortium Project (Vande Berg, Connor-Linton, \& Paige, 2009), students who participated in a study abroad pre-departure orientation with a cultural education component showed a significant, but not large, association "between gains in oral proficiency and pre-departure orientations" (p. 15) and reported significantly higher satisfaction with their study abroad experience. However, pre-departure orientation sessions have not been explored in the ISL literature and a summary 
of pedagogical strategies that faculty have found beneficial would prove to be a significant contribution to the field.

Pre-departure orientations are significant in STISL pedagogy and must be considered when structuring a STISL experience. As opposed to treating predeparture orientation as a peripheral component, faculty should consider it the launching pad for a successful learning experience culminating in developing a global citizenship identity.

\section{Host-Country Experience}

According to Chisholm (2003) there are three overarching models for structuring a faculty-led ISL experience. First, the faculty member may choose to partner with an international institution that has an already established servicelearning program for its own students, although typically faculty do not accompany students when fully relying on an already established servicelearning program in a different country. The second option is to "design, develop, and manage a program" (Chisholm, 2003, p. 263) that is entirely new. The third option is to use a mix of options the first options, "developing one or two programs yourself, and using other programs to provide a wider array of locations, types of service, and program designs" (p. 263). With few exceptions (see Williams \& Van Cleave, 2011; King, 2004), the literature does not clearly articulate which of the three options STISL faculty choose in order to structure their programs (Kiely, 2005; Mellom \& Jakubiak, 2011; Murphy, 2011). 
Furthermore, there has not yet been a critical analysis comparing the benefits or drawbacks of the three types of structures.

Developing and maintaining overseas partnerships. Chisholm (2003) urged that when choosing which structure works best for individual universities or departments within universities, stakeholders honestly examine the resources that can be dedicated to the program. This is especially true if institutions choose options two or three listed above. Stakeholders must ask themselves, "[a]re you prepared to make the long-term commitment that is necessary for the program to be effective, in terms of both the learning and the service, and one that is fair to your overseas partners?" (Chisholm, 2003, p. 267). Here we are faced with gaps in the ISL literature that deserve further investigation. In this era of economic hardship at both the institutional and student level, are faculty making long-term commitments to overseas partners or are faculty only planning year to year agreements, depending on funding and students ability to participate? Also, if faculty are making long-term commitments to overseas partners, how long of commitments are they making?

Chisholm (2003) asserted that a lasting partnership must be mutually beneficial. The term for this in the service-learning literature is a reciprocal relationship. A reciprocal relationship, more commonly referred to as reciprocity, is described by Dostilio, Brackmann, Edwards, Harrison, Kliewer and Clayton (2012) as "foundational concept in service-learning and community engagement" (p. 17), and is understood a relationship where there is an equal exchange of 
benefit between both community and student, where "both the server and those served teach, and both learn" (Kendall, as cited in Jacoby, 1999, p. 8).

Resoundingly, scholars and practitioners argue that having a reciprocal relationship between students and the community partner is essential to the service-learning paradigm (Butin, 2010; Jacoby, 1996, 2009; Sigmon \& Pelletier, 1996). In 1998, Campus Compact staff joined with service-learning practitioners in order to "examine the anatomy of campus/community collaborations" (Campus Compact, 2000, p. 1). The resulting eight benchmarks (Campus Compact, 2000, pp. 5-7) (see Table 3) represent "essential features of genuine democratic partnerships" (Jacoby, 2003, p. 9).

Table 3

Eight Benchmarks of Genuine Democratic Partnerships

\begin{tabular}{|l|l|}
\hline $\begin{array}{l}\text { Stage 1: } \\
\text { Designing the } \\
\text { Partnership }\end{array}$ & $\begin{array}{l}\text { - Founded on a shared vision and clearly articulated values. } \\
\text { - Beneficial to partnering institutions }\end{array}$ \\
\hline $\begin{array}{l}\text { Stage 2: } \\
\text { Building } \\
\text { Collaborative } \\
\text { Relationships }\end{array}$ & $\begin{array}{l}\text { - Composed of interpersonal relationships based on trust } \\
\text { and mutual respect. } \\
\text { - Multidimensional: they involve the participation of } \\
\text { multiple sectors that act in the service of a complex } \\
\text { problem. }\end{array}$ \\
\hline $\begin{array}{l}\text { Stage 3: } \\
\text { Sustaining the } \\
\text { Partnerships } \\
\text { Over Time }\end{array}$ & $\begin{array}{l}\text { - Integrated into the mission and support systems of the } \\
\text { partnering institutions. }\end{array}$ \\
& $\begin{array}{l}\text { - Evaluaned by a "partnering process" for communication, } \\
\text { decision making, and the initiation of change. }\end{array}$ \\
\hline
\end{tabular}


The extent to which partnerships are developed and sustained in ISL are unknown. In the SL field, Dostilio and colleagues (2012) contend that the concept of reciprocity related to institutional partnerships with community organizations is not precisely conceptualized leading to "widely, and unexamined or unintentionally differing conceptualizations of reciprocity [which] can lead to confusion in practice" (p. 17). Therefore, the question remains: do STISL faculty develop partnerships in a vein similar to the eight benchmarks as articulated by Campus Compact, or is there general confusion about the concept, as per Dostilio et. al, or is there a different model specific to ISL and/or STISL that has not yet been articulated within the literature? Overall, partnership development and sustainment yet need to be understood in order to ensure truly beneficial experiences for all stakeholders in the experience and to provide guidelines for faculty new to ISL and STISL.

The experience of difference. Exposure to difference is a key component in service-learning, study abroad, and ISL/STISL pedagogy and is necessary for developing intercultural competence (Bennett, 1993; Paige, 1993), which is necessary for global citizenship identity (Bennett, 2008), an indicator a successful STISL pedagogy. Difference is a broad term and can refer to any point of reference that is dissimilar or unlike a student's routine way of life. Difference on an ISL program can be experienced in a number of ways. For instance students may taste different foods, feel different climates, smell different odors, or hear unfamiliar languages (Kiely, 2005; Tonkin \& Quiroga, 2004; Williams \& Van 
Cleave, 2011). Also, students may experience difference in less tangible ways, such as different religious values, different gender roles, different social priorities, different marriage systems, and differences in political persuasions (Kiely, 2005; Sawyer \& Lopopolo, 2004; Williams \& Van Cleave, 2011). Often in the ISL literature, difference is called "dissonance [which] occurs frequently because much of what students see, feel touch, hear and participate in is new and incongruent with their frame of reference or world view" (Kiely, 2005, p. 10). In a longitudinal case study of students who participated in an ISL course over a 10 year span in Nicaragua, Kiely (2005) identified two intensities of dissonance: high and low. Low intensity dissonance is usually short-term and easily overcome by providing learners with applicable background knowledge, like how to dress for the different climate or boil non-potable water. High intensity dissonance, on the other hand, is caused by "witnessing extreme forms of poverty, hunger, scarcity, and disease" (p. 11). High intensity dissonance has the potential to stay with students for an indefinite period of time. Significantly, Kiely noted that reflection does not make high intensity dissonance go away, but other scholars assert that reflection is a key component in helping students begin to make life decisions that take the dissonant experience into account (Kiely, 2005; Mather et al., 2012; Williams \& Van Cleave, 2011).

Reflection. Reflection appears in the ISL literature as the primary meaning-making tool utilized in ISL pedagogy (Crabtree, 2008; Mather et al., 2012; Monard-Weissman, 2003; Tabor et al., 2008; Williams \& Van Cleave, 2011). 
This pedagogical practice is supported by Morton and Campbell (2007) who suggest that "[r]eflection to a large degree, is the process of balancing cognitive dissonance so that it becomes a motivating perplexity, rather than an emotional or psychological threat that results in withdrawal or a retreat to over-simple dualisms" (p. 13). Similarly, Hutchings and Wutzdorff (1988) support this argument in noting, "[r]elated to dissonance, and a key to turning dissonance into learning is reflection, the ability to step back and ponder one's own experience, to abstract from it some meaning or knowledge relevant to other experiences" (p. 15).

Instead of using the term reflection, Whitney and Clayton (2011) suggest that ISL experiences should include critical reflection, which, as opposed to simply recalling an experience, actually generates learning. "Critical reflection generates learning (articulating questions, confronting bias, examining causality, contrasting theory with practice and pointing to systemic issues), deepens learning (challenging simplistic conclusions, inviting alternative perspectives, and asking "why" iteratively), and documents learning" (pp. 151-152). As opposed to simply regurgitating what a student observed, critical reflection asks students to enter into the realm of asking what the observation could mean, and what could be done about it.

Whitney and Clayton (2011) highlight the many forms of reflection, which can be oral or written, individual or collaborative. They suggest that, perhaps, the most useful form combines all four. But about what and how are students 
encouraged to undertake this sort of reflection? The DEAL model for critical reflection "more clearly demonstrates rather than reports learning; pushes students beyond superficial interpretations of complex issues; and facilitates academic mastery, personal growth, civic engagement and critical thinking" (Ash \& Clayton, 2004, p. 140). DEAL is an acronym for:

Description of experiences in an objective and detailed manner, Examination of those experiences in light of specific learning objectives (in the case of service learning at least in the categories of academic enhancement, civic learning, and personal growth, and Articulation of Learning. (Whitney \& Clayton, 2011, p. 156).

The DEAL model provides a framework that encourages rigorous reflection, which improves student learning outcomes (Eyler \& Giles, 1999). Furthermore the DEAL model enables students to move from "haphazard, accidental, and superficial" (Stanton, 1990, p. 185) learning outcomes that are contradictory to the Dimensions of Global Citizenship, and could be the result of unresolved dissonance (McGregor, Newby-Clark, \& Zanna, 1999).

Collier and Williams (2005) suggest that there are four primary modes of reflection, including writing (journals, directed writing), activities (role playing, interviewing classmates), multimedia (photo/video essay, collage), and telling (oral class presentation, class discussion) (p. 92). Each mode has its own strengths, and which mode is utilized depends on the context of the experience. This being said, there is an obvious gap in the ISL literature concerning which modes of reflection are most appropriate and lead to student learning and supporting students as they experience dissonance in particular contexts. 
While identifying which modes of reflection are most appropriate and in what context, the intentionality of reflection is regularly cited as the key element in incorporating reflection into course pedagogy, because on their own students are unlikely to identify the conflicts between new experiences and old suppositions on their own (Eyler, 2002; Van Cleave, 2011).

\section{Other host-country design considerations.}

Technology. As has already been explained and highlighted, technology has left an indelible mark on relationships and communication in the $21^{\text {st }}$ century. These technological advances can impact STISL pedagogy. Early research noted that communication with friends and family members can ease a sojourner's transition as they reenter their home context (Brabant, Palmer, \& Gramling, 1990). However, communication technology has significantly advanced since 1990, when the article was published, and there has not been an inquiry into learning how email, social media or video conferencing has adversely or positively impacted student learning and experience.

Housing. In research studying students' study abroad experience, the place the student stays matters. This assertion aligns with the first tier of Maslow's Hierarchy of Needs, in that people need to feel that they will have safe food, water, air and housing (Harper \& Guibault, 2008). According to SchmidtRinehart (2004), a homestay, where the students live in a family's home in the host-country, "makes or breaks" (p. 254) a student's experience. Some students reported that living with a host family significantly impacted their study abroad 
experience for the better, while others reported that it impacted their experience negatively. Schmidt-Rinehart reports that host families report less problems with student that stayed an entire semester or longer, as opposed to a summer or six weeks.

According to Vande Berg, Connor-Linton, and Paige (2008), students studying “More Commonly Taught Languages (MCTLs: French German and Spanish)" as opposed to "Less Commonly Taught Languages (LCTLs: Arabic, Chinese, Japanese, and Russian)" (p. 12) experienced significant oral proficiency gains when the amount of time a student spent with their host family was accounted for. Also even though it may seem counterintuitive, Vande Berg et al. found that students who lived with other U.S. students, rather than with international students or with a host family, showed statistically significant gains in intercultural learning. This finding must take into account the fact that students who opted to live with other U.S. students had statistically significantly lower intercultural development levels than students who lived with host families. So, this is not to say that all students who lived with host families did not grow in intercultural learning. In fact, the researchers found that students who spent $25-60 \%$ of their time with their host family showed significant gains in intercultural learning. The more time students spent with their host families, the more intercultural learning took place.

Overall, Vande Berg et al. asserted that there is a significant correlation between spending free time with host-nationals and intercultural learning, 
regardless if the student lives with other U.S. students or in a homestay situation. The authors reiterate that staying with a host family can be a positive experience, provided that students are given the mechanisms to cope with the homestay situation. "This finding reinforces the argument that students do not learn because of simple exposure, but because of the ways they responded to that exposure" (p. 24).

Host-country faculty or home country faculty. Within the literature on STISL, faculty members from the students' home institution are very often the primary course instructors for the course (see Kiely, 2004, 2005; Mather et al., 2012; Murphy, 2011; Sawyer \& Lopopolo, 2004; Tabor et al., 2008; Williams \& Van Cleave, 2011). Chisholm (2003), however, highlights that there are benefits and drawbacks to using U.S. faculty as primary instructors on an ISL experience.

By utilizing U.S. faculty members, institutions avoid the complicated task of agreeing upon curriculum, teaching methods, and compensation, and "no one will seek return favors" (Chisholm, 2003, p. 279). However, students' learning may not be as deep as it could be by having host-country faculty. By not utilizing host-country faculty, the U.S. institution may inadvertently convey the message to students that no one in the host country is capable of "delivering a quality academic program" (p. 279). Additionally, students will not have the experience of learning by the host country's methods of education "that both reflect and shape cultural patterns" (p. 279). Finally, it limits the amount of contact and quality of contact that U.S. students will have with students from the host country. 
Utilizing the expertise of host-country faculty, U.S. students will receive more sophisticated and current insights into the cultural intricacies of the host country. And while a U.S. faculty member may be the primary instructor on the ISL experience, host-country faculty members may be able to occasionally lecture, so that students receive the benefits of learning from a cultural insider (Chisholm, 2003). It is evident in the literature that U.S. institutions are using this model, while serving as the primary program instructor (Kiely, 2005; Tabor et al., 2008; Williams \& Van Cleave, 2011).

\section{Re-entry}

Pre-re-entry. Re-entry is the stage at an international experience where the sojourner returns to his or her home country (Martin \& Harrell, 2004). Preparing students to reenter their country of origin is said to begin before students ever leave the country that they are visiting. Most of the available literature about pre-re-entry pedagogy focuses on sojourners that have been abroad for an extensive amount of time. Regardless, students are advised to begin to conceptualize how the experience abroad will impact their life once they return home (Martin \& Harrell, 2004). Even more specifically, students should start thinking about logistical implications of being home, including taking care of financial aid issues for the upcoming term, finding housing, and employment. Some of these suggestions are irrelevant due to the limited duration of STISL experiences, however Martin and Harrell suggest that faculty prepare students to think about how they will reconnect with family and friends and help "them 
create realistic expectations about social and cultural adjustments during repatriation" (p. 326).

Finally, students must begin the "task of leaving," which includes saying their goodbyes to the host community. Goodbyes can be a time where significant emotions are felt and expressed (Robertson, 1988); Thomas and Harrell (1994) noted that the ease or difficulty students experience will depend on previous experience with transitions and the extent to which they integrated with the culture.

Re-entry: Ongoing process upon return. Within the intercultural literature, re-entry is noted as being an "ongoing process that can last for several months or a lifetime" (p. 326). Both Kiely (2005) and Williams and Van Cleave (2011) assert that this is a significant learning experience for STISL participants. Specifically, both articles highlight that the dissonance caused by the experience follows students home. Kiely highlights one student who was still experiencing dissonance six years after the STISL experience. Neither Williams and Van Cleave nor Kiely articulate if prolonged dissonance is a positive or negative phenomenon. The authors instead assert that dissonance is not resolved quickly or easily and that the international experience stays with students for many years.

Williams and Van Cleave (2011) discovered that students relied on their classmates in order to process the experience. "Dissonance also began to surface when students returned home and for several months they needed one another to process their experience on their home front and home turf" (p. 21). 
Reentering their home culture can be a time of significant hardship for some students. Despite participants' age, Carsello and Creaser (1976) discovered negative changes after a study abroad experience in $20 \%$ of those who participated. The respondents noted negative changes in study habits, ability to concentrate, reading, physical health, peace of mind, and memory. In a more recent study, Wielkiewicz and Turkowski (2010) discovered that even when age and gender are controlled, students who studied abroad consumed more alcohol than those who did not, and their study habits were negatively affected. However, unlike previous studies (Sahin, 1990), Wielkiewicz and Turkowski did not find any significantly different levels of depression or use of anti-depressants when students returned from an abroad experience, compared with students who did not participate in an abroad experience. Finally, the authors discovered that students who participated in a study abroad experience returned more skeptical of their own culture than students who did not study abroad. It is significant to articulate that in terms of re-entry research, there has not been a significant empirical research study that deeply investigates the re-entry process for students who participate in ISL experiences. As many authors have noted (Crabtree, 2008; Kiely, 2004, 2005; Monard-Weissman, 2003; Plater, 2011; Williams \& Van Cleave, 2011), ISL exposes students to poverty, disease, sanitation (or lack there of) and ecological degradation which may not be present for traditional study abroad participants. Even though the duration of experiences 
are significantly different, re-entry from Peace Corps volunteer experiences may prove insightful.

Peace Corps volunteers work abroad for two years, focusing on positively contributing to a community with a pressing social need. Bosustow (2006) discovered that returning Peace Corps volunteers (RPCV's) experience both depression and loneliness; however, being female was a significant contributing factor for depression. Interestingly, Bosustow asserted that it takes RPCV'S significantly longer to readjust after returning home than it does other expatriate populations who have been abroad for similar amounts of time.

In terms of pedagogy for structuring re-entry programs, the vast majority of the literature focuses on programs for individuals who have been abroad for a significant amount of time (Bosustow, 2006; La Brack, 1993; Martin \& Harrell, 2004; Martin, 1993). Nevertheless, the same principles are applicable to pedagogical strategies for short-term programs. Martin (1993) contends that reentry training "should be viewed as part of a long-term process of cultural adaptation and learning" (p. 314). Students need to be guided through three stages of re-entry: intrapersonal psychological, interpersonal skills leading to functional fitness, and cognitive learning.

The first stage of re-entry, intrapersonal psychological, should mimic predeparture orientation, in that students are encouraged to "develop positive realistic expectations" about re-entry. Students should examine their own personal changes, as well as any that they may have observed about their home 
communities. La Brack (1993) contends that students over-idealize home, and are disappointed upon re-entry. Also, Martin (1993) noted that one of the most disappointing experiences for students when they returned was when family or friends did not ask about their experience abroad.

The second stage of re-entry, interpersonal skills, should assist students in "developing the functional fitness aspect of re-entry" (Martin, 1993, p. 316). Students often isolate themselves during a re-entry experience, assuming that no one will understand what they had just experienced, especially those who did not study abroad. While isolation is not ideal in re-entry, families are warned against large 'welcome home' parties immediately after a student returns, because the student may become overwhelmed by the attention or frustrated by his or her inability to thoroughly answer the inevitable question, "so how was it?" (La Brack, 2010).

The final stage of re-entry is intercultural growth. Unlike the first two stages of re-entry, practical suggestions for intercultural growth is not well articulated in the re-entry literature. However, Martin (1993) suggests that acknowledging the existence of re-entry shock serves as a way for students to better understand their own reactions to cultural transition. Additionally, "Sojourners need to explore how this [abroad experience has changed them] may differ from their original identity and how awareness of cultural identity can enhance ... their effectiveness and comfort when repatriating" (Martin \& Harrell, 2004 , p. 330). Students often claim that they have been changed after a STISL 
experience (Kiely, 2004, 2005; Knutson Miller \& Gonzalez, 2010; Tabor et al., 2008), but do not know what said change means long term and re-entry programs should serve as a place where students are encouraged to explore these implications.

As with pre-departure orientation sessions, re-entry deserves significant consideration when planning and implementing a STISL experience.

\section{Iterative Teaching}

As has been noted, there are numerous pedagogical strategies that STISL faculty employ during the three segments of the TISL experience. However, a question remains: as STISL faculty facilitate more experiences, what do they learn about themselves as practitioners, the STISL as a pedagogy and education for global citizenship? In order to answer this question, it is important to look at how course evaluation and assessment techniques are used.

According to Brookfield (1990), a significant component of good teaching, is being attentive to and understanding learners' needs and being able and willing to respond accordingly. Stokamer (2011) defines iterative teaching as, "the process of assessing student learning and elements of pedagogy during and after a course and making changes with the intention of improvement" (p. 101). As a way of gauging whether or not changes should be made during a course and in preparation for a future iteration of the course, faculty should be willing to accept responsibility for student learning, as opposed to blaming students for not achieving desired course learning outcomes. "If a critical mass of students is not 
demonstrating sufficient learning, this may suggest that either learning strategies are not effective in meeting learning objectives or learning assessment methods are not effective in measuring student learning" (Howard, 2001, p. 21). Stokamer noted that iterative teaching has not received much attention within the servicelearning literature, and the same applies to both study abroad and ISL.

\section{Evaluation During the STISL Experience}

Stokamer (2011) argues that "ongoing assessment of teaching during a term is necessary in all courses, but perhaps particularly so in community-based learning" (p. 102). This assertion can be applied to a STISL experience. First, faculty can conduct informal assessments by observing students in a variety of ways. Students make their reactions to the course and course material "known through body language, comments, attendance, attitudes, and grades" (Dean, 1994, p. 114). In evaluating student learning and needs during a STISL experience, Williams and Van Cleave (2011) used group oral discussions, daily student open-ended written reflections, and intermittent handwritten written assignments.

Faculty should be responsive to the results of evaluation and assessment during a STISL experience and determine if the planned teaching strategies are still appropriate. Perhaps the students are not learning as the faculty member had intended, and the faculty member may need to decide how to adjust teaching strategies as a consequence. An example by Stokamer (2011) illustrates this 
concept; "an experience of conflict at the service site might warrant adding a reading to the syllabus or forgoing a planned film for discussion" (p. 102).

\section{Evaluation After the STISL Experience}

Student feedback on course and instructor remains most popular formal evaluation technique used to better understand the student experience in a course and is aimed to serve as a catalyst for faculty to improve teaching strategies (Dean, 1994; Stokamer, 2011; Wolfer \& McNown Johnson, 2003). Course evaluations, however, have proven controversial. Studies identify that various factors can influence course and teacher evaluation other than the instructor or the course, including class size (Hanna, Hoyt, \& Aubrecht, 1983) and an instructor's gender (Anderson \& Miller, 1997) and sexual orientation (Russ, Simonds, \& Hunt, 2002). Regardless of the problematic correlations not related to teaching, student feedback remains the most popular institutionalized course evaluation technique.

In terms of evaluating service-learning specific courses, the University of South Carolina developed six hallmarks for high quality service-learning. In their analysis, the sixth hallmark is evaluation and disclosure. The purpose of evaluation and disclosure is to "provide corrective feedback and continuous quality improvement" (Smith et al., 2011, p. 320). Smith et al. suggest that the 10step "Getting to Outcomes" method as developed by Wandersman, Imm, Chinman and Kaftarian (2000) provides a rigorous approach to program and institutional 
accountability. Outcomes should then be disseminated to "relevant community stakeholders, and future direction is considered" (Smith et al., 2011, p. 320).

Self-study. A type of assessment technique that has only been articulated in the ISL literature once (see Murphy, 2011), but has been practiced by many (Kiely, 2004, 2005; King, 2004; Mather et al., 2012; Tabor et al., 2008; Williams \& Van Cleave, 2011) is self-study. Self-study "is used in relation to teaching and researching practice in order to better understand: oneself; teaching; learning; and, the development of knowledge about these" (Loughran, 2004, p. 9). Loughran (2005) noted that "Self-study has thus been an important vehicle for many teacher educators to find meaningful ways of researching and better understanding the complex nature of teaching and learning about teaching" (p. 5), and Murphy contends that self-study of her ISL experiences "contributed to [her] pedagogical development and improved effectiveness of future service learning experiences" (p. 3).

LaBoskey (2004) outlines what she considers to be the four integral aspects of self-study. First, self-study is aimed at improving, in that it "looks for and requires evidence of the reframed thinking and transformed practice of the research, which are derived from an evaluation of the impact of those development efforts" (p. 859). Second, self-study is naturally interactive, in that it demonstrates "interactions with our colleagues near and far, with our students, with the educational literature, and with our own previous work... to confirm or challenge our developing understandings" (p. 859). Third, self-study "employs 
multiple, primarily qualitative methods, some that are commonly used in general education research, and some that are innovative...[and] provide us with opportunities to gain different, and thus more comprehensive, perspectives" (pp. 859-860; emphasis in original). Finally, the fourth requires that educators incorporate the findings of self-study in "and make it available to our professional community for deliberation, further testing, and judgment" (p. 860). These four integral aspects of self study "demonstrate an expectation that the learning from self-study will not only be informative to the individual... but also meaningful, useful and trustworthy for those drawing on such findings for their own practice" (Loughran, 2005, p. 6).

While self-study has benefited the field of ISL and STISL (see Kiely, 2004, 2005: King, 2004; Williams \& Van Cleave 2011), the extent to which faculty engage in self-study is unknown unless the faculty member publishes their findings. A question for exploration is: do faculty engage in self-study and not publish their findings, or do STISL faculty use less formal self-assessment techniques? Or do faculty rely on other forms of assessment?

Evaluation and assessment are essential to the STISL pedagogy. Both as the program is being executed and for future iterations of the program, faculty need to be able to respond to student needs so as to create a learning experience that leads to student success, including the development of a global citizenship identity. 


\section{Understanding Institutions Through Four Frames of Organizational Behavior}

Before articulating a proposed framework for exploring the design and implementation of STISL courses, it is essential to first recognize that organizations themselves impact the implementation of pedagogy, including STISL. In order to glean a holistic understanding of how organizations may impact pedagogical design, which will be discussed in detail in chapter 5 as it specifically pertains to the findings of this study, it is important to understand that organizations can be analyzed from a myriad of perspectives. Bolman and Deal's (2008) four-frameworks of organizational behavior and theory enable such analysis by approaching organizations from a variety of perspectives, namely the (a) structural, (b) human resources, (c) political, and (d) symbolic influences, known as the four frames of organizational behavior and theory. As the scholars noted when describing the creation of and purpose for the four frames,

we consolidate[d] major schools of organizational thought into a comprehensive framework encompassing four perspectives. Our goal is usable knowledge. We have sought ideas powerful enough to capture the subtlety and complexity of life in organizations yet simple enough to be useful. (p. 14)

The four frames guide people within organizations away from a common misconception that individual people are usually to blame for issues within organizations and toward examining more closely the organization's structural, 
human resources, political, and symbolic components (p. 25). While there is limited information regarding organizations and ISL or STISL pedagogy

When he described usefulness of the four frames, Coghlan called (2000) Bolman and Deal's (2008) work "immensely useful" (p. 429) and said that the four frames "help readers make sense of both the multiple perspectives from which people view what goes on in organizations and the wide array of literature on management and organizations" (p. 429). In relation to institutional research, Parmley (2009) similarly contended that the four frames help in "developing a more robust multiframe approach to understanding the decision-making process [which can] provide important insight into improving [institutional] strategies" (p. 78).

Considering that the attention dedicated to ISL and STISL pedagogies is relatively new (Bringle \& Hatcher, 2011), there are not may resources to draw upon that adequately discuss organizational theory as it relates to ISL and STISL. However, there is an abundant amount of literature that directly discusses the relationship between SL pedagogy and organizations (see Langseth \& Plater, 2004) that will help to better understand how dimensions of organizations impact more specialized pedagogical implementations, such as STISL.

\section{Structural Frame}

The first of the four frames is structural (Bolman \& Deal, 2008) and can be imagined as a traditional organizational chart hierarchy that "reflect[s] a belief in rationality and a faith that a suitable array of formal roles an responsibilities will 
minimize distraction personal static and maximize people's performance on the job" (p. 47). Summarizing the structural frame, Bolman and Deal described it as the "[frame, which] focuses on the architecture of organization - the design of units and subunits, rules and roles, goals and policies" (p. 21). Nested within frames are various assumptions that Bolman and Deal use to further describe each frame. Not all assumptions articulated by the authors are directly applicable to the context of this literature review, and only salient assumptions will be discussed as they relate to STISL pedagogy. The assumptions for the structural frame relevant to the discussion of STISL include:

1. Organizations exist to achieve established goals and objectives.

2. Organizations increase efficiency and enhance performance through specialization and appropriate divisions of labor.

3. Problems arise and performance suffers from structural deficiencies, which can be remedied through analysis and restructuring. (p. 47)

Aligned with assumption 1, colleges and universities have increasingly incorporated an explicit intention to equip students to function in and meet the needs of a globalized society into their institutional missions (Jacoby \& Brown, 2009; Stearns, 2009; Thompson-Jones, 2013). Based on the definitions and conceptualizations of ISL, STISL pedagogy is well poised to fulfill the goals described in institutional mission and vision statements (Brown, 2007).

In relation to assumption 2, many institutions have decided to designate a central organizational office or center on a college or university's campus to serve as a resident expert in SL pedagogy (Langseth \& Plater, 2004). By having a university-wide service-learning center or a service-learning coordinator, the 
college creates greater specialization through a division of labor. This is thought to increase the quality and depth of an institutions' relationship with the community, be a resource for faculty engaged in service-learning, and effectively collect data regarding records of student service hours (Jones, 2004). Gray and colleagues (1998) noted that institutions who had service-learning specialists (coordinators and/or centers) were more likely to succeed at institutionalizing SL initiatives.

According to Driscoll (1998), a strong central SL coordinating body is extremely useful to faculty in equipping them to utilize SL pedagogy into their teaching. Additionally, Abes, Jackson, and Jones (2002), scholars who investigated motivators and deterrents to using SL pedagogy, "logistical support is essential, as anticipated logistical and time difficulties were not only the most frequently cited actual deterrents to service-learning use, but also the most frequently cited potential deterrents to service-learning faculty's continued use (p. 14). Therefore, related to structural assumption 3, without an institutional structure that is intentionally designed to support faculty as they incorporate SL pedagogy, like a service-learning coordinator or office, they are less likely to engage in this complex pedagogy.

\section{Human Resource Frame}

The second frame according to Bolman and Deal (2008) is human resources, which "emphasizes understanding people, their strengths and foibles, reason and emotion, desires and fears" (p. 21) and "centers on what 
organizations and people do and for one another" (p. 117). Based on their work, the authors described several assumptions that further elaborate how organizations and people interact.

1. Organizations exist to serve human needs rather than the converse.

2. People and organizations need each other. Organizations need ideas, energy, and talent; people need careers, salaries, and opportunities.

3. When the fit between individual and system is poor, one or both suffer. Individuals are exploited or exploit the organization - or both become victims. (p. 122)

Based on assumptions 1 and 2, institutions of higher education should aim to create environments in which employees' needs are met so that the employees can meet organizational goals and fulfill their role in meeting the institution's mission. According to the logic of Bolman and Deal (2008), employees' needs are the foundational component of accomplishing institutional goals. When human needs are met and there is a balance between what employees want and institutions can provide, institutional goals are more likely to be met as well.

Also, assumption 2 asserts that employees should be rewarded for the time and energy that they expend pursuing organizational goals. While this often takes the form of fair compensation, Furco and Holland (2004) and Bringle and Hatcher (2004) noted that within the academy other rewards are pursuant to the context of colleges and universities. For example, the literature suggests that in order to further SL pedagogy (which can be extrapolated to include STISL), faculty must be encouraged and equipped to incorporate SL in their scholarly agendas (Furco \& Holland, 2004, p. 31) and given institutional support during the 
promotion and tenure process for considering such scholarship and other SL related initiatives (Bringle \& Hatcher, 2004, pp. 136-137).

Bolman and Deal's (2008) assertion that organizations must meet the needs of employees resonates with SL literature, which suggests that faculty need to be supported through an infrastructure that manages the logistics of SL, ideally through a "coordinating agency that facilitates the advancement of servicelearning and community partnerships" (Furco \& Holland, 2004, p. 31). This thought corresponds with assertion 3 and is supported by various scholars, who contend that a significant deterrent for incorporating SL pedagogy is a real or perceived lack of logistical support by the institution (Abes, Jackson, \& Golden, 2002; Gray, Ondaatje, \& Zacaras, 1999). Overall, Bolman and Deal contend that when employees' needs are met, organizational needs will also be met.

\section{Political Frame}

The third frame Bolman and Deal (2008) outline is the political frame, which sees organizations as "competitive arenas of scarce resources, competing interests, and struggles for power and advantage" (p. 21). Regarding this frame, the authors noted that "political processes are universal" (p. 194) and must be handled skillfully. According to the scholars, there are five assumptions that best encapsulate the political frame.

1. Organizations are coalitions of assorted individuals and interest groups.

2. Coalition members have enduring differences in values, beliefs, information, interests, and perceptions of reality.

3. Most important decisions involve allocating scarce resources - who gets what. 
4. Goals and decisions emerge from bargaining and negotiating among competing stakeholders jockeying for their own interests.

Aligned with assumption 1, universities and colleges are made up of diverse stakeholders, which includes faculty, staff, administration, students, andin some instances-state governments joining together in pursuit of fulfilling an agreed upon mission. In order to meet these goals, institutions are constantly under pressure to deliver high quality education within the context of fiscal constraints, which has become exacerbated in light of the recession of 2008-2009 (Barr \& McClellan, 2011). Due to the changing economic status of institutions, some colleges and universities are eliminating programs or positions that may be seen as peripheral to the institutional mission. For example, in 2008 Clemson University reacted to a $\$ 25$ million budget cut from the state by instituting furloughs, "halting construction on six buildings, freezing non-essential hiring and cutting some temporary positions as well as non-essential travel" (Ellis, 2008, para. 11). This is not to say that institutions of higher education are in all instances diminishing opportunities for students; they are often being asked to maintain current offerings or even do more with less (Milken Institute, 2012), which increases stress for faculty members and can reduce the attention students are receiving (Jaschik, 2012).

Being asked to "do" more, doing so with fewer resources is a point of stress for faculty members (Jaschik, 2012), and while it has not yet been thoroughly studied, this stress may be impacting faculty availability or 
willingness to incorporate SL or STISL pedagogy into their workloads. Furthermore, the financial constraints facing administrators, as seen with the Clemson University example, may be negatively impacting what would be deemed as non-essential programs.

Plater (2004) asserts that it is in this tension between what institutions have and what they need to do in order to fulfill their mission that Chief Academic Officers are essential allies. Additionally, Plater asserts that by advocating for and including service initiatives, which presumably can include STISL, in the institution's strategic plan, CAO's are more likely to be able to advocate for resources that can be allocated to such programs.

\section{Symbolic Frame}

The final of the four frames according to Bolman and Deal (2008) is the symbolic frame, which "focuses on issues of meaning and faith. It puts ritual, ceremony, story, play, and culture at the heart of organizational life" (p. 21). Specifically related to the story component of the symbolic frame, the authors noted the work of Denning (as cited in Bolman \& Deal), who articulates the role that story plays in organization life in eight categories: sparking action, communicating who you are, communicating who the company is - branding, transmitting values, fostering collaboration, taming the grapevine, sharing knowledge, [and] leading people in to the future (p. 260). In addition to these, Bolman and Deal highlight several assumptions, which further describe this particular frame: 
1. Facing uncertainty and ambiguity, people create symbols to resolve confusion, find direction, and anchor hope.

2. Culture forms the superglue that bonds an organization, unites people, and helps an enterprise accomplish desired ends. (p. 253)

Given the myriad issues facing the ecological and human world in the $21^{\text {st }}$ century (see Burns, 2009), scholars argue that complacency is not an option (Colby, Ehrlich, Beaumont \& Stephens, 2003; Ehrlich, 2011); higher education is well positioned to "shape character and [instill] a sense of social responsibility" (Colby et al., 2003, p. xii). At the root of their argument is the belief or hope that higher education will in some ways develop students who are able to address significant problems facing local and global communities. As Colby and colleagues assert, in many instances college and university education settings are one of the last places where individuals can be impacted with information that formatively and substantially impacts the ways in which they interact with their society and world, providing direction toward becoming responsible and caring citizens ( $\mathrm{p}$. 5).

In his seminal writing, Tierny (1988) acknowledged that in addition to "external factors, such as demographic, economic, and political conditions [institutions are] also shaped by strong forces that emanate within" (p. 3), which includes the culture and context of an institution. In line with Bolman and Deal's (2008) second assertion related to the symbolic frame, Tierny noted that "a central goal of understanding organizational culture is to minimize the occurrence and consequences of cultural conflict and help foster the development 
of shared goals" (p. 5). As per Plater (2004), institutional culture is often a result of the organization's mission statement; however, the intentions of the mission must be consistently reinforced and rearticulated by senior administrators for it to actually become a part of the school's culture. In addition to articulating commitments to fulfilling the institutional mission, senior administrators must also be proactive in supporting initiatives that put the mission into practice. For instance, Plater asserted that in addition to verbal rhetoric, senior level administrators must take "action [steps] that affirms the value of service-learning as an institutional strategy as a hallmark of campus-community relationships. Plater also stated that without senior level administrator support, pedagogies like SL are unlikely to grow.

\section{Four Frames Summary}

Bolman and Deal's (2008) four frames of organizational behavior and theory, along with the assertions that describe the frames, provide a multidimensional way of understanding the factors that could impact the integration of STISL pedagogies at institutions, including both possible deterrents to and strategies to promote the pedagogy. While most of the literature reviewed above is from the SL field, the findings can be extrapolated to STISL, considering the central role (according to the literature) that SL plays in STISL and SL's more established literature base from which other fields can learn and benefit. More specific connections between Bolman and Deal's four frames and STISL pedagogy 
will be described after data have been collected and analyzed and implications are identified.

\section{Proposed Framework for Exploring Short-Term International Service-}

\section{Learning Courses}

Planning and facilitating short-term international service-learning

programs is a complex, unique, and challenging practice, requiring deliberate and innovative approaches to teaching. The adult learning literature provides insight into how students learn and how faculty can design pedagogical strategies that respond to preferred learning styles and multiple intelligences. Furthermore, by understanding student learning needs, faculty are able to structure teaching strategies that have the potential to maximize student learning. Based on the literature reviewed that focused on pedagogical strategies for implementing predeparture, host-country and re-entry, we are able to see the multi-dimensional considerations needed to achieve student and program success. Additionally, based on the work of work of Stokamer (2011) who identified the four pedagogical elements of service-learning pedagogy (course design, teaching strategies, integration of service and iterative teaching), it is possible use these elements in order to investigate pedagogical strategies used in short-term international service-learning courses. (Figure 6). This can serve as a framework in which to better understand how faculty design, implement and improve STISL pedagogical practices. 
The four pedagogical elements of service-learning, as described by Stokamer (2011), surround and describe each of four elements of servicelearning in detail. The three chronological segments of STISL experiences, predeparture, host-country, and re-entry are then placed in the center of the framework, conveying that each of the four pedagogical elements should be considered when planning each of the three segments of the STISL experience. Program success is then located at the center of the framework and serves as the overall guiding factor in pedagogical implementation of a STISL course.

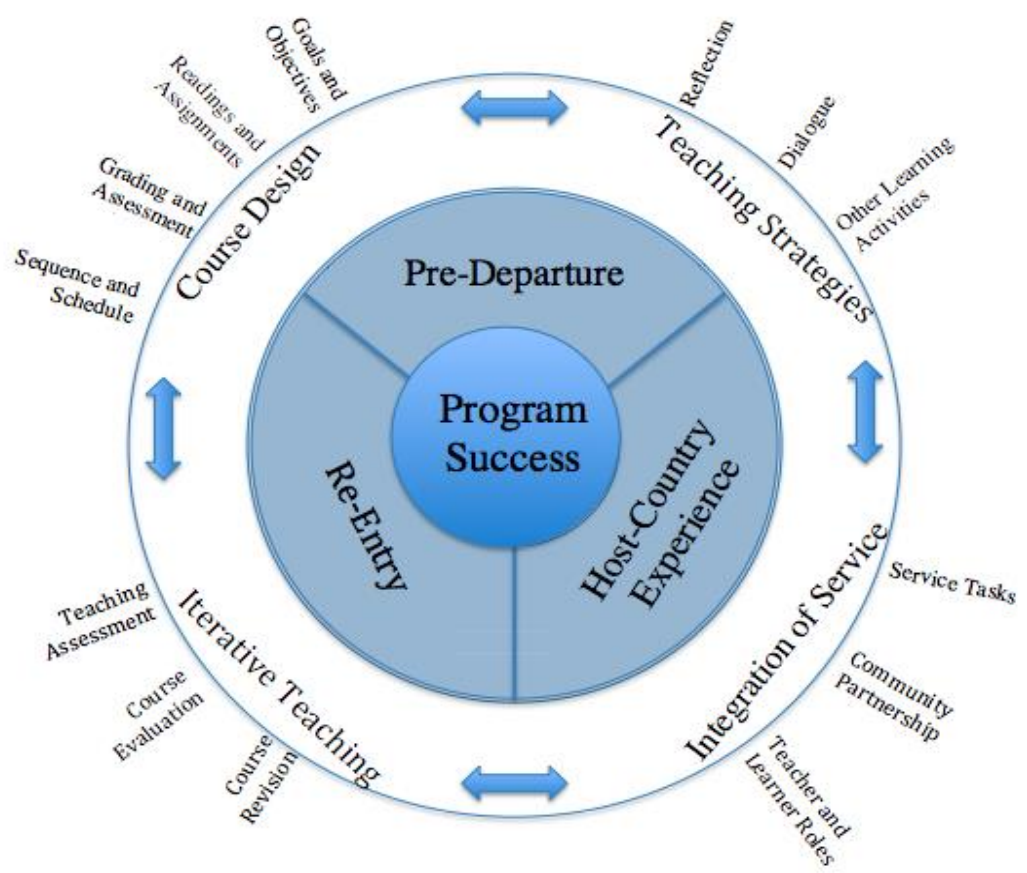

Figure 6. Framework for Exploring Short-Term International Service-Learning Courses

STISL as an educational pedagogy is becoming more popular across campuses as institutions respond to the need to graduate students who are able to live and work in a globalized society. Despite STISL's popularity, there has yet 
to be an articulated pedagogical framework for program success. Therefore, building on Stokamer's (2011) Pedagogical Elements of Community-Based Learning and others, this study seeks to synthesize and articulate pedagogical strategies faculty are employing in order to plan and facilitate what faculty consider to be necessary for a successful STISL courses and developing students' global citizenship identity.

STISL is a complex educational experience that relies on extensive knowledge of study abroad, service-learning, adult learning, and global citizenship. It is essential that a pedagogical framework for student success through short-term international service-learning is identified so as to provide STISL faculty with a framework in which to structure these complicated educational experiences. Global citizenship as a learning objective for postsecondary institutions is not likely to disappear and will continue to grow. 


\section{CHAPTER 3}

\section{METHODOLOGY}

This chapter explains the rationale for the methodological techniques chosen in order to conduct this study. Additionally, rational for using narrative research design will be described, including strategies for collecting, analyzing, and interpreting data, and the validity and limitations of the study are addressed. Finally, the potential implications of the research study are highlighted.

\section{Research Questions and Purpose}

The purpose of this research study is to investigate and better understand short-term international service-learning faculty members' perceptions of successful programs and the pedagogical strategies they select toward these ends. Specifically, how do ISL faculty define a successful experience in terms of students, community partners, the university or college, and themselves? Secondarily, how do STISL faculty intentionally design teaching, learning, and service experiences to achieve desired outcomes?

\section{Rationale for Qualitative Methodology}

This study used qualitative research methods in order to answer the two primary research questions. Qualitative research methods are most appropriate for this research project due to the exploratory nature of the project, as well as the importance of personal experiences (Johnson \& Christensen, 2012). Specifically, this study utilized a narrative inquiry approach which "assumes that 
people construct their realities through narrating their stories" (Marshall \& Rossman, 2011, p. 153). This study investigated faculty stories, experiences, observations, opinions, and pedagogical techniques. As described by the journal, Narrative Inquiry, this research method "give[s] contour to experience and life, conceptualize[s] and preserve[s] memories, or hand down experience, tradition, and values to future generations" (Narrative Inquiry, n.d.). Thus, narrative inquiry is more likely to capture the "often messy, unpredictable complexities of teaching practice" as opposed to traditional assessment techniques, "namely objective tests" (Lyons \& Kubler LaBoskey, 2002, p. 1).

Scholars differ in regard to the definition of narrative inquiry, and according to Squire, Andrews and Tamboukou (2008) this is because of varying disciplinary frameworks, theoretical orientations, topics of study, and methodological approaches. Gergen (2009) provides a concise and useful definition of the narrative approach: narrative inquiry includes stories that have a valued end-point, in that there is a specific point that stories help to illuminate. The stories include events that are relevant and incorporate events in "a coherent order, typically in relation to a linear conception of time; and that provide a sense of explanation" (Wells, 2011, p. 5).

It was essential that the researcher asked open-ended questions and continued to shape and formulate questions after exploring the topic with the research participants. As Creswell (2007) noted, the researcher's “questions change during the process of research to reflect an increased understanding of 
the problem" (p. 43). Therefore, the interview protocol, based on the Framework for Exploring Short-Term International Courses-a reconceptualization of Stokamer's (2011) Pedagogical Elements of Community Based-Learning-sought to answer the research questions through narrative inquiry that was allowed to evolve within the context of the interviews.

\section{Data Collection}

\section{Research Participants and Sites}

Participants in this qualitative study were selected because of the researcher's assumption that the participants would substantively contribute to the topic being explored (Creswell, 2003; Polkinghorne, 2005). Furthermore, due to the specificity of the topic, purposeful sampling was employed, choosing particular participants to include "because they [were] believed to facilitate the expansion of the developing theory" (Bogdan \& Knopp Bilken, 2007, p. 73). Sample size for narrative studies ranges greatly in size (Creswell, 2007), and for this study, the target sample size was no more than 8 participants, with two pilot interviews, totaling 10 participants.

Specifically, participants identified and subsequently selected to participate have facilitated an ISL experience to the same location, using same or similar community partners, at least two times. Rather than collect data from only one institution or one type of institution, the inquiry investigated the perspectives of five different types of institutions in hopes that the findings may have some applicability across institutional classification. 
Education (or study) abroad and service-learning offices at all five institutions were contacted and asked to identify potential research subjects to participate in this study. While some institutions obliged with this request, other schools denied the request for faculty names and contact information. Instead, these institutions offered to forward an email from the researcher to faculty who the institution thought might qualify for the study, based on the expressed criteria and their professional judgment. This indirect research participant identification and recruitment technique did not produce any viable candidates. For the institutions that did provide names and email addresses for faculty who met the criteria, the researcher contacted the potential research participants through emails describing the research study, explained why they had been selected as potential key informants, and invited the potential research participant to be a subject in this study. The informational email was made more specific over time in response to clarifying questions initial potential research participants posed to the researcher. The final invitation can be viewed in Appendix A. After potential research participants agreed to participate and before the interview occurred, they were emailed Ogden's (2010) Three Dimensions of Global Citizenship, as well an electronic copy of the study's informed consent. Research participants were asked to review both documents, and were prompted to ask clarifying questions about the informed consent during the interview.

Once the research participants confirmed their interest in being interviewed, the researcher schedule a one-on-one 90 minute interview in a 
location chosen by each research participant. Two research participants chose to have the interview conducted over the phone, one chose through an online video conferencing software program, while the other seven were interviewed inperson. The researcher followed the interview protocol, but also remained flexible considering the context of the interview in some instances did evolve; however, the interviewer did remain within the scope of the research agenda.

\section{Interviewing}

Interviewing is the most common qualitative data gathering technique within the field of education (Glesne \& Peshkin, 1992; Merriam, 1998) and is the most appropriate data collection methodology in accordance with the exploratory nature of this study, which aims to better "understand the world from the subjects' [in this study, ISL faculty's] point of view, to unfold the meaning of their experiences, and to uncover their world prior to scientific explanations" (Kvale \& Brinkmann, 2009, p. 1). The purpose of this data collection technique was not to learn facts or absolute truths, but instead gather the research participants' interpretations of experience (Warren, 2002). In particular, this study used in-depth interviewing, which "encourages interviewees to produce 'thick descriptions' - where interviewees are specifically encouraged, by questions and other verbal and non-verbal methods, to elaborate and detailed [italics in original] answers" (Rapley, 2005, p. 15).

Each interview was conducted according to an interview protocol particularly designed for this research project (see Appendix B). The questions 
were derived from two sources: (a) relevant topics identified during the literature review, including Stokamer's (2011) four elements of service-learning and research literature about international service-learning experiences, modes of reflection (cf. Ash \& Clayton, 2004, 2009) service-learning, study abroad, and learning theory as represented in the Framework for Exploring Short-Term International Service-Learning, and (b) the researcher's experience as an international service-learning facilitator and instructor. As a result, the researcher created interview questions constructed in order to answer the research question.

Of the ten interviews, nine lasted about 90 minutes each, while one interview lasted about three hours. After each interview was conducted, an audio recording of it was professionally transcribed into a typed document. Seeing as transcription is the first stage in processing raw data, such as audio recording (Marshall \& Rossman, 2011), the researcher reviewed the professional transcription in relation to the audio recording so as to ensure data were interpreted in a manner consistent with the context of the interview. "The judgments involved in placing something as simple as a period or a semicolon are complex and shape the meaning of the written word and, hence, of the interview itself" (Marshall \& Rossman, 2011 p. 164). Converting audio data to text data is a well known limitation within qualitative research that is inherent to the practice, considering so many aspects of "interpersonal interaction and nonverbal 
communication are not captured in audiotape records, so the audiotape itself is not strictly a verbatim record of the interview" (Poland, 2002, p. 635).

The researcher was not a part of a larger research team, therefore member checks with co-researchers were not possible. However, the researcher did provide the typed transcriptions via email to each RP to member check the data to ensure that it was accurate and that the research participant expressed themselves in a way that they feel appropriately answers the researcher's questions. Many-but not all-research participants replied to the researcher with changes to or elaborations on the typed transcripts. No research participant offered substantial changes to the original typed transcript document or asked that specific responses be omitted from the project's final data analysis.

\section{Artifacts}

In addition to interviews, data sources for narrative inquiry research can be obtained from written materials, electronic communication, or visual forms such as photo diaries or films (Wells, 2011). Collecting documents supplements interviewing and is an unobtrusive way to better understand the context surrounding how and why faculty employ certain pedagogical methods. In this case research participants were asked to provide the researcher with artifacts such as course syllabi, assignments, and schedules; other written or published materials provided by the STISL faculty member (syllabi, published articles about STISL, student blogs, or student applications, grant applications) could also be data sources. The researcher also combed institutional websites for data 
regarding these research participant's specific STISL courses, which in some instances unearthed program descriptions, course applications, syllabi, and other publically accessible qualitative data.

The researcher utilized the artifacts to clarify, expand upon, and better understand the context for the data that was collected in the interview process. Due to the limited number of artifacts submitted for the researcher's review, a full content analysis of the artifacts was not possible. The artifacts did, however, provide valuable details in terms of pedagogical strategies and community partner details that were only briefly discussed during the interview process.

\section{Research Participants}

Through the process of identifying potential research subjects for this research project, faculty of nearly every rank-including adjunct, fixed term, and tenure-track (with the exception of assistant professor)-qualified to participate in this study. This is not to say that untenured assistant professors do not teach STISL courses; the researcher can only report that none were identified through this study's recruitment process. Additionally, while no full professors participated in this study, at least two were identified, but they either declined to participate or did not have time to participate in an interview. In this research project, the following faculty chose to contribute to the study (Table 4), and represented a wide variety of institutional types (Table 5). 
Table 4

Research Participant Rank and Degrees

\begin{tabular}{|l|c|l|}
\hline Faculty Rank & Participants & \multicolumn{1}{|c|}{ Degrees Held } \\
\hline Fixed-Term & 4 & $4-$ Masters' \\
\hline $\begin{array}{l}\text { Tenure Track Assistant } \\
\text { Professor }\end{array}$ & 0 & n/a \\
\hline $\begin{array}{l}\text { Tenured Associate } \\
\text { Professor }\end{array}$ & 5 & $\begin{array}{l}1-\text { MBA } \\
1-\text { Ed.D. } \\
2-\text { Ph.D. } \\
1-\text { D.S.N. }\end{array}$ \\
\hline Full Professor & & n/a \\
\hline $\begin{array}{l}\text { Administrative Dean, with } \\
\text { teaching appointment }\end{array}$ & 0 & 1 - Master's \\
\hline
\end{tabular}

Table 5

Institutional Classifications of Research Participants' College of University

\begin{tabular}{|l|c|}
\hline Institutional Classification & Number of Participants \\
\hline Large Public Urban & 4 \\
\hline Large Public Research & 1 \\
\hline Small Private Christian (Catholic) & 1 \\
\hline Small Private Christian (non-Catholic) & 1 \\
\hline Small Private Non-Religious & 1 \\
\hline Large Community College & 1 \\
\hline Large Private Non-Religious & 1 \\
\hline
\end{tabular}

In terms of educational backgrounds, fixed-term faculty members had all earned Masters' degrees, yet none held a terminal degree (i.e. Ph.D., Ed.D., J.D., M.D., D.S.N., D.P.H., etc.). Only one tenure-track faculty member's highest degree was non-terminal, a Masters' of Business Administration (MBA), while all other tenure-track faculty members had earned terminal degrees; one an Educational Doctorate (Ed.D.), one a Doctorate of Nursing Science (DSN) and three had earned 
Doctor of Philosophy (Ph.D.) degrees. As previously noted, all tenure-track faculty had already earned tenure and were classified as Associate Professors.

Originally this study sought to identify ten faculty members from four different types of higher education institutions in the Pacific Northwest. Data would be collected from two STISL faculty at each institution, in addition to two pilot interviews at any institution, totaling ten interviews. The researcher for this project contacted institutional service-learning (SL) offices and education abroad (EA) offices via phone and email, and very few representatives from these offices reported knowledge of any faculty who were teaching STISL courses. Representatives often reported that no one at their institution was teaching a STISL course-which was not always correct-or referred the researcher to faculty who did not qualify for the study. Reasons for the participants not qualifying varied, but included: the course did not incorporate service-learning, the course had been taught at least twice, or it was not an academic course and was a cocurricular spring break trip.

On numerous occasions, the researcher identified possible research participants on an institution's website, yet when representatives from those institutions' SL/EA offices were asked about STISL courses, the representatives said that there were no such programs supported by their institution. Through this project, there were only two SL/EA offices that provided leads to speak with potential research participants, every other SL/EA representative said that they 
did not know of any faculty member doing this type of work or did not respond at all to the researcher's inquiry.

After unsuccessful months of attempting to identify potential research participants who were both qualified to participate in this study and willing to participate in this study, the interview pool was broadened and sought data from more than four different types of institutions nationwide. Table 5 illustrates the number of faculty from which types of institutions chose to participate in this study. Note that because some research participants asked that their identities remain confidential, course names were slightly altered and the research participant will only be referred to as "research participant," or by a random pseudonym.

The research participants in this study represent a wide variety of institutional and academic departments, including nursing, education, public administration, social work, general studies, health sciences, history, and physical therapy. While identifying potential research participants, two faculty members were identified in the STEM disciplines; however neither qualified for this study because they each had only coordinated one STISL course. Table 6 illustrates the eight different academic disciplines that participated in this study and Table 7 illustrates the name of the course and the host country. 
Table 6

STISL Course Subject Area

\begin{tabular}{|l|}
\hline STISL Course Subject Area \\
\hline 1 course - undergraduate nursing \\
\hline 1 course - undergraduate teacher preparation \\
\hline 3 courses - undergraduate interdisciplinary senior capstone courses \\
\hline 1 course - undergraduate interdisciplinary, social work focus \\
\hline 1 course - graduate level public administration \\
\hline 1 course - community college level humanities \\
\hline 1 course - undergraduate healthcare interdisciplinary course \\
\hline 1 course - undergraduate physical therapy \\
\hline 1 course - undergraduate social work \\
\hline
\end{tabular}

Table 7

STISL Faculty Research Participant, Course Title, and Host Country Location

\begin{tabular}{|c|c|c|c|}
\hline $\begin{array}{c}\text { Research } \\
\text { Participant } \\
\text { Pseudonym }\end{array}$ & STISL Course Topic & $\begin{array}{c}\text { Approximate } \\
\text { Time in Host } \\
\text { Country, time } \\
\text { of year }\end{array}$ & Host Country \\
\hline Angela & $\begin{array}{c}\text { Inter-professional } \\
\text { Promotion of Health in } \\
\text { Elders }\end{array}$ & $\begin{array}{c}1.5 \text { weeks, } \\
\text { Winter Break }\end{array}$ & Nicaragua \\
\hline Barbara & $\begin{array}{c}\text { Intercultural } \\
\text { Development and } \\
\text { Physical Therapy }\end{array}$ & $\begin{array}{c}1.5 \text { week, } \\
\text { Spring Break }\end{array}$ & Quito, Ecuador \\
\hline Christina & $\begin{array}{c}\text { Healthcare for Rural } \\
\text { Families and Women }\end{array}$ & $\begin{array}{c}2 \text { weeks, } \\
\text { Week before } \\
\text { Spring Break, } \\
\text { and Spring } \\
\text { Break }\end{array}$ & Andre Pradesh, \\
India
\end{tabular}




\begin{tabular}{|c|c|c|c|}
\hline Henry & $\begin{array}{c}\text { Environmental Activism } \\
\text { and Community } \\
\text { Engagement }\end{array}$ & $\begin{array}{c}2 \text { weeks, } \\
\text { Summer Term }\end{array}$ & Oaxaca, Mexico \\
\hline Isabelle & $\begin{array}{c}\text { History, Culture, and } \\
\text { International } \\
\text { Development }\end{array}$ & $\begin{array}{c}2.5 \text { weeks, } \\
\text { Summer Term }\end{array}$ & Costa Rica \\
\hline Jacqueline & $\begin{array}{c}\text { International Community } \\
\text { Service in Action }\end{array}$ & $\begin{array}{c}1.5 \text { weeks, } \\
\text { Winter Break }\end{array}$ & Nicaragua \\
\hline
\end{tabular}

Nine faculty members reported that they were still teaching STISL courses, and one faculty member said that she recently stopped teaching her STISL course as of Summer 2010 because of her age, comfort level, and time constraints; she had, however, equipped another faculty member to take over the course.

\section{Data Analysis}

As was previously mentioned, the data analysis began with transcribing the data, and all research participants had the opportunity to member check the transcripts before data analysis took place. Next, the transcribed and member checked interview data, as well as data obtained form artifacts, were analyzed in a variety of ways. First, data were uploaded to a computer program called NVIVO, a qualitative data analysis software. Next, data were coded according to previously assigned thematic codes developed through a thorough review of the literature in accordance with the interview protocol, as seen in Table 8. 
Table 8

Dimension of Data and Associated Thematic Code Identified Through Literature

\begin{tabular}{|c|c|}
\hline Dimension of Data & Thematic Code Identified Through Literature \\
\hline $\begin{array}{l}\text { Research Participant } \\
\text { Background } \\
\text { Information }\end{array}$ & $\begin{array}{l}\text { Areas of expertise; academic rank; years of experience } \\
\text { in higher education; STISL specific courses taught } \\
\text { including in which countries, and number of times. }\end{array}$ \\
\hline $\begin{array}{l}\text { Successful STISL } \\
\text { Experiences }\end{array}$ & $\begin{array}{l}\text { What constitutes STISL success both long term and } \\
\text { short term; Perceptions of the term global citizenship; } \\
\text { Perceptions of Ogden's Three Dimensions of Global } \\
\text { Citizenship and if they correlate with what the RP } \\
\text { considers STISL success; pedagogical strategies used } \\
\text { in order to achieve success as it relates to the Three } \\
\text { Dimensions of Global Citizenship; the role of adult } \\
\text { learning theories in developing pedagogical strategies }\end{array}$ \\
\hline Pre-Departure & $\begin{array}{l}\text { Application process; have the faculty ever turned } \\
\text { students away from the course; pre-departure content } \\
\text { including assigned readings, papers, bonding } \\
\text { activities; }\end{array}$ \\
\hline Host-Country & $\begin{array}{l}\text { Types of community partners, type of service work, } \\
\text { and why that particular community partner; } \\
\text { perceptions of international reciprocity and whether } \\
\text { or not the RP has a reciprocal relationship with the } \\
\text { community partner; assignments due while in host- } \\
\text { country, the role of reflection; strategies for facilitating } \\
\text { reflection; models used to structure reflection; rules or } \\
\text { guidelines about students and technology; student } \\
\text { lodging; host-country faculty }\end{array}$ \\
\hline Re-Entry & $\begin{array}{l}\text { When RP begins preparing students for re-entry; } \\
\text { reunions; re-entry culminating assignments; struggles } \\
\text { with re-entry }\end{array}$ \\
\hline $\begin{array}{l}\text { Student Learning and } \\
\text { Meaning Making }\end{array}$ & $\begin{array}{l}\text { The role of difference in learning and meaning making; } \\
\text { high-intensity dissonance; low-intensity dissonance; } \\
\text { strategies for making meaning out of dissonance; } \\
\text { recognizing students struggling with dissonance; the } \\
\text { role of spirituality in the students' experience }\end{array}$ \\
\hline Iterative Teaching & $\begin{array}{l}\text { How STISL faculty evaluate their own teaching; how } \\
\text { the faculty assess student learning and development }\end{array}$ \\
\hline Faculty Experience & $\begin{array}{l}\text { Motivations for teaching STISL; hindrances to teaching } \\
\text { using STISL; support for teaching using STISL; }\end{array}$ \\
\hline
\end{tabular}


Through the process of thematic coding, research participants identified that one of Ogden's Three Dimensions of Global Citizenship did not fully match their conceptions of success, and instead of a dimension of social responsibility as a hallmark of success, a more appropriate conceptualization was culturally contextualized solidarity, from which social responsibility emerges.

After data were analyzed according to previously assigned thematic codes and new thematic codes that emerged from the data, codes were then individually analyzed using open coding, "the process of breaking down the data into distinct units of meaning... [and] may comprise key words, phrases or sentences" (Goulding, 2002, p. 170). As per Bogdan and Bilken (2007), developing a coding system takes many steps. First, the researcher looked within the thematic coded data for regularities, patterns, and topics. The researcher then listed key words and phrases that represented these topics and patterns. Also known as meaning units, these key words, phrases, and sentences were organized into "different processes or phases, referred to as domains" (Elliott \& Timulak, 2005, p. 154). The data were then categorized "with a taxonomy that describe[d] and interprets the whole phenomenon as it was contained in the gathered data" (p. 155).

Through analyzing the thematic codes using open coding, data showed dimensions, strategies, and perspectives that otherwise would not have been noticed. For example, in terms of research participants' perceptions of success in STISL courses, five dimensions of success emerged, namely academic, 
professional, interpersonal, intrapersonal and intercultural hallmarks. Also, pedagogical strategies surrounding specific assignments and the roles that they play as a part of achieving success became apparent. Examples of this include the integral role that both culture-general and culture-specific preparation play in terms of pre-departure preparation so as to provide students with background knowledge with which they can make more informed conclusions regarding course content. Also, through analyzing the iterative teaching thematic code, five different assessment techniques became apparent, as did the function each of these techniques serves in terms of understanding and evaluating student learning.

Overall, through initially grouping the data using thematic coding, then analyzing the thematic codes utilizing open coding, the data support findings that have not yet been articulated in the literature. Examples of these include the role of lodging related to pedagogical strategies, faculty perceptions of international community-partner reciprocity, the concept of solidarity, the impact of technology on students' and community partners' experience, and the most influential assessment techniques for STISL iterative teaching, all of which will be described in detail in chapters four and five of this study.

\section{Study Limitations and Positionality}

While many issues have been considered and subsequently accounted for (e.g., qualitative validity, ISL faculty experience and the number of times a program has been facilitated) through the design of this study, limitations still 
remain that may have affected this research project. First, the pool of interviewees is small. While the small number of participants positively contributes to the depth of time and focus that each key informant's experience received, this did affect the breath of faculty voices that were included. Second, the ISL courses as described by faculty and articulated in course syllabi are very different experiences from one another (including varying countries, students, service-projects, academic fields), therefore consensus may be hard to identify. Third, the researcher is an STISL instructor and facilitator. This required the researcher to set aside his pedagogical techniques and fully rely on the data collected, not past personal experiences. Fourth, the researcher was the sole research team member. Therefore the transcripts and the open coding data analysis were not corroborated by other research team members, although transcripts were member checked with the research participants.

\section{Potential Contributions and Conclusions}

The purpose of this qualitative, narrative study is to describe the process by which experienced STISL faculty members define success through an STISL course and to uncover the pedagogies used that aim to achieve these goals. Additionally, this study aims to better understand the process faculty use in order to evaluate and improve practice for future iterations of the course.

Academic institutions in the United States are beginning to recognize their role in preparing students to engage both responsibly and productively in an society that is becoming exponentially more interdependent and interconnected. 
In response, nearly every university and college now includes in its mission statement a commitment to educate students as global citizens. For this reason, the results from this research project are potentially far reaching. First, this research project will identify how faculty who teach STISL courses define program and student success and, if they identify global citizenship as a desired learning outcome, compare with scholars' assertions throughout the ISL literature. Also, based on faculty definitions of program and student success, the data analysis will highlight insights into the pedagogical strategies STISL faculty employ in order to achieve the learning outcomes they have defined. Faculty definitions of student and program success and the pedagogical strategies faculty use to achieve success will inform the development of both a conceptual framework of STISL success and a pedagogical framework for STISL success. is thus a pedagogy that can significantly contribute to institutions as they pursue this lofty goal of educating students to live in, work in, and positively contribute to an increasingly globalized world. 


\section{CHAPTER 4}

\section{FINDINGS}

This chapter is organized pursuant to the results from data collected and themes that emerged through analyzing data in relationship to the two overarching research questions that guided this study: (a) how do STISL faculty define successful STISL experiences, and (b) how do STISL faculty intentionally design teaching, learning, and service experiences to achieve their desired outcomes?

\section{Success in STISL Courses}

In order to understand how faculty understand success in a STISL course, two different questions were asked of the research participants in regard to their particular STISL courses. Faculty were first asked to describe their initial conceptualizations and perceptions regarding what they thought constituted success or what the hallmarks of a successful STISL program would be, without guiding prompts that would influence their responses. Research participants were encouraged to describe their thoughts in terms of success both on a micro and macro level for both the short and long-term.

\section{Dimensions of Success}

Utilizing open coding, the following five dimensions of success emerged from the data: (a) academic, (b) professional, (c) interpersonal, (d) intrapersonal, and (e) intercultural. 
Academic Success. First, faculty want students to take what they have learned in their coursework and then be able to apply the knowledge in the field specifically to a community need. According to these STISL faculty, student participants in a STISL course should learn how to transfer "theoretical principles that they have been exposed to in the course and then [turn] around and [see], okay, this is how it really works" in light of community need. The concept of academic success as a hallmark of student learning is well aligned with the service-learning literature (see Cress, 2005; Jacoby 1996). This is noted by Enos and Troppe (1996), that "not only does service-learning have the potential to help students learn the [academic] content in a particular discipline, it also asks students to consider the context of a discipline and how its knowledge base is used in practice “ (p. 156).

In order to truly be able to address a community's needs through appropriate theoretical lenses, students need to be exposed to and understand the complex forces that impact the design of a culture specific intervention. As David, a STISL faculty member who teaches a two week course in Oaxaca, Mexico focusing on health and migration noted,

A hallmark for students is being able to connect a number of large scale phenomenon and see how they are related to each other...[I]ssues like nutrition and health, the local agricultural picture and market, and how those things are connected with the local economy, the economy at the micro level, the local household, and how that connects with the forces, the push forces that lead to out migration from [this city] to other places. Also, I think that an especially important factor is... [for] students to understand how micro-level interventions in organizations can have 
multiple kinds of direct impacts on larger-scale problems that seem unmanageable.

David also stated that he hoped by seeing the direct impact of interventions that are seeking to address large-scale, seemingly unmanageable problems, students will feel empowered to be change agents.

The application of academic skills to building an understanding of largescale community needs not solely pertain to concerns that take place across national borders. In addition to understanding how to navigate the complexities of international community needs, successful students must also be able to apply academic principles to complex community needs in a local context.

Professional Success. The concept of empowerment and advocacy through an academic discipline was a recurring theme for many of the research participants, and faculty often mentioned that the academic components of the course should impact the way that students act within their specific professional disciplines (faculty specifically identified educators and health care providers). STISL faculty Ethan (who is tenured at a large state research university and teaches a class on emigration and education in Tijuana, Mexico) noted that a hallmark of professional success includes when students incorporate principles of social change in their chosen professions. He hopes that students will, in light of the STISL course, "want to change things structurally for the better, if they are trying to change the families, they are trying to change the kids, that they have a broader sense of what's happening and [are able to] advocate for the community." 
Jacqueline (a full-time administrator and part-time academic instructor at a community college who teaches a course in Nicaragua focusing on international community service initiatives) echoed David and Ethan's sentiments, in that she strives for students to "see in action what it means to work with people who are underserved, so really seeing how they can make a difference" through the application of their own professional skills and knowledge.

Interpersonal Success. Success in a STISL course as it relates to social change is not limited to practical applications of academic concepts or culturally sensitive service. Research participants reported that in addition to being able to apply skills to community needs, students also need to feel emotionally compelled to provide resources to a community on a humanistic level based in solidarity. Bennett (2008) described this as the "global soul... - seeing ourselves as members of a world community, knowing that we share the future with others" (p. 13). Concepts of emotional connection, intercultural competence, relationship, and solidarity appear to be essential when understanding what success may entail in a STISL course. Isabelle (a fixed-term instructor at a large, public, urban institution and teaches a STISL course in Costa Rica focusing on history, culture and international development) elaborated regarding ideal outcomes she hopes her students achieve and explained that

We are interconnected and I think people don't care about issues unless they feel a sense of connection and through international programs, service learning programs, you meet face-to-face with people in other countries and hopefully you develop that sense of interconnectedness and as a result care about what happens in Costa Rica, or Ireland, or Egypt 
because you have had some exposure to those places and the people living there.

Similarly supporting the theme of developing interpersonal solidarity, Ethan asserted that he views success as being grounded in more than statistics and readings; instead, it is embedded in experiencing the humanity of STISL and the stories, names, and people behind the numbers: "that is the short-term goal, [to] tug at their subjectivity..." In terms of a long-term goal, Ethan connects challenging students subjectivity to developing "prepared teachers who are a little more sympathetic to the plight of some students and the families and want to change things structurally for the better...advocate for the community."

Many research participants noted that another hallmark of interpersonal success is seen when students unite as a team in order to accomplish the tasks that have been laid out for them through the service experience. Angela is a tenured faculty member at a small private, secular school who teaches a STISL course to Nicaragua focusing on geriatric healthcare; she described that interpersonal is central to what she hopes students take away from the STISL course

one of the major, major goals of this Nicaragua program is to enlighten students on how to work better together in an inter-professional manner, interdisciplinary manner, so they are just not always thinking about their own profession but how do I work with the others? When would I refer to other professions? How can they help me? What can they teach me? Once again, what comes back on student surveys always is, 'oh, my gosh, I learned so much about the other professions and how to work together.' I am hoping in the long term that carries over to their careers so that they are always collaborating with all their colleagues. 
In another health professions-based course focusing on physical therapy in Ecuador, Barbara from a large secular private school says that a goal of her course is for her students to develop "a real sense of commitment to a team and a mission, becoming part of a community of practice."

The concept of interpersonal collaboration is consistent with both empirical and theoretical literature. For example, Cress, Burack, Giles, Elkins, and Stevens (2010) note that service-learning experiences, whether co-curricular or academic, have the potential to enhance students' abilities to interact effectively with diverse people. Also, in terms of theoretical literature, the Social Change Model of Leadership (Higher Education Research Institute - UCLA, 1996) postulates that collaboration is an essential skill for transcending individual goals and working toward a common purpose and "multiplies group effectiveness because it capitalizes on multiple talents and perspectives of each group member and the power of that diversity to generate creative solutions and actions" (p. 48).

While interpersonal success is an integral component of STISL success, intimately interwoven with that is students' "inner-self" or intrapersonal success.

Intrapersonal Success. For nearly every RP, hallmarks of a successful STISL course included deepening the extent to which the students know themselves, as well as an expanding and enriching appreciation for what could be considered different. Co-teaching a course in India focusing on women's development and micro finance, research participant Gail (a fixed-term instructor from a large, urban, state university) noted that being in a different country and 
experiencing the feeling of being the 'other' is per se a success. She goes on to say that immersion and difference push boundaries and serve as catalysts for "personal growth and revelations about [who the students are]." Gail's assertion is consistent with the literature on transformative learning, which contends that difference-or a disorienting dilemma-is a catalyst for development, perspective transformation, and action based on a newly acquired perspective (Cranton, 1994; Mezirow, 1991). Also, the experience of difference as a catalyst for development aligns with principles of the development of intrapersonal components of intercultural sensitivity (Bennett, 1993).

The personal growth and introspection that Gail alluded to was in part reiterated and elaborated upon by fellow STISL faculty research participant. For example, Christina, a tenured associate professor from a small, private, faith based school who takes students to India explains that in the field of nursing, nursing students must first "understand themselves and they have to understand where they are," both as professionals and as cultural beings. Christina believes that students, once they begin to understand their own cultural perspectives, can start to discover the foundations of cultural competence, which is a cornerstone of the nursing profession. "Our whole approach is to provide holistic care and that includes the spiritual, ...the cultural component, that includes the physical as well as emotional.“

This idea mirrors Paige's (as cited in Paige, Cohen, Kappler, Chi, \& Lassegard, 2009, p. 40) assertion that a significant component of intercultural 
development includes recognizing oneself as a cultural being; this understanding enables individuals to recognize and honor the cultural influences and identities of others. Student self-understanding is identified by the Higher Education Research Institute at UCLA (1996) as a "fundamental value [in relation to social change] because it constitutes a necessary condition for realizing all other values [of social change]" (p. 31). The authors assert that self awareness, a component of intrapersonal development, equips people to better collaborate with others, participate in and share a common goal, and handle conflict with civility.

Overall, cultural competence, according to Christina, does not simply fall under the realm of good things to do, but instead relates the concept to professionalism that is required to provide the best care possible.

[Students must] be aware of the person and recognize that you may not agree with everything that they do, it might not be anything that you even know about, but you want to be aware that it is different from what you have seen before and ask and get understanding of where they are and how that impacts their health and what we are trying to do to support their health.

It is important to note that the example that Christina provides clearly indicates how four dimensions (in this case intrapersonal, intercultural, interpersonal and professional) may overlap; this will be discussed in subsequent sections.

Intercultural Success. Other research participants connected understanding and appreciating cultural difference to some sort of ethical standard, whether in terms of a specific profession or service work in general. Barbara expressed hope that her students learn that there is a distinction 
between what outsiders may think an underserved community may need and what the community actually needs. This resonates with Keene and Colligan's (2004) assertion that when performing service-learning projects with a community, participants must conduct the service in a way that has been shaped by the perspectives and cultural identities of the host-country.

For Barbara, success occurs in part when students take away not only a desire to make a difference, but also an understanding of "what it means to give people what they need, versus what you think they need...." Faculty research participant Felicia, a tenured associate professor from a small, faith-based school and teaches a STISL course in Tobago, echoed this sentiment: "I hope [students] gain an understanding of some of the challenges facing developing countries and some of the... culturally specific approaches to social, health, and educational issues." Additionally, Felicia thinks that in order to do this, students must have their "Western mindset" or paradigm challenged, so that they will leave thinking “'hey, we don't have all the answers and one way doesn't work for everyone and may not even work that well for us."' Time and again, Research participants asserted the importance of not imposing American conceptualizations on nonAmerican situations or contexts. As Angela strongly stated:

You can't, you don't, create your own ideas and impose them on other cultures. You may have some ideas before going... but you might just need to let them blow off with the wind, because we have to empower the [host country's citizens] and they have to be in control. In other words, [students] go away learning 'thou shalt not impose my services upon others. 
While other Research participants may categorize not imposing Western-centric conceptions of service on a host community as a shift in mindset, Isabelle also connected the concept with deeply embedded values, perceptions, and possibly even a heartset, as opposed to or possibly in addition to a mindset:

Oftentimes in international service-learning programs, either the host community views the incoming US students as people who are coming to fix or do something for them, and/or the US students perceive themselves as saviors or people who are coming to fix... the host community. What I strive for is that students' understanding of that relationship really deepens to one of seeing their relationship with the [host country] ... as one of solidarity rather than charity.

\section{Defining Success: Developing Global Agency}

Overall, faculty engaged in STISL pedagogy identified that STISL hallmarks of success manifest through these five dimensions including academic, professional, interpersonal, intrapersonal and intercultural, as shown in Table 9. 
Table 9

Hallmarks of Success

\section{Hallmarks of Success: Dimensions and Overarching Desired Outcomes}

Academic - Students are able to apply academic principles to communityidentified needs in ways that honor host-country cultural perspectives and ways of knowing.

Professional - Students are able to recognize how their own professional skills can contribute to addressing community-identified needs in ways that honor host-country cultural perspectives and ways of knowing, both during the STISL experience and long after returning to the students' home country.

Interpersonal - Students develop solidarity with and are able to work with diverse groups of people in order to meet community-identified needs in ways that honor host-country cultural perspectives and ways of knowing. Intrapersonal - Students are able to identify how their own cultural perspectives impact the ways in which they approach meeting local or global communityidentified needs. Intercultural - Students are able to identify how cultural perspectives impact the ways in which groups approach meeting local or global community-identified needs and view cultural differences as value-neutral.

Overall Success: Through the five dimensions of success, students are able to develop agency, or the ability and proclivity to act in ways that meet a community-identified need, either locally or globally, through sustainable and responsible means.

Throughout the data, there was no shared vocabulary or terminology used by research participants that summarized an overarching hallmark of success, or even the five dimensions of success. The STISL faculty's descriptions were lengthy, complex, and rich with detail and description. However, through the process of data analysis, including open and thematic coding, various themes emerged from which the researcher was able to extrapolate meaning to understand order and coherence across the data. The process of extrapolation in raw quantitative data involves the researcher "choos[ing] a best-fitting line (or 
curve)... for data (Chapin, 2004, p. 363) that best describes trends and displays order. Because raw data with qualitative research are words, in lieu of a graphical line to describe trends or coherence, as is the case with quantitative research, words and phrases can function similarly in order to bring "meaning and insight into the words and acts of the participants in the study" (Marshall \& Rossman, 2011, p. 210) Therefore, even though there was not a shared vocabulary, there were themes and perspectives that were shared and describe a complex and detailed conceptualization of STISL success, as described in Table 9.

Through extrapolating and interpreting the data, the research participants articulated five dimensions of success (academic, professional, interpersonal, intrapersonal, and intercultural), and the amalgamation of these culminates in a common, overarching hallmark of success, which is best described by the term global agency. Even though the term global agency was not articulated by research participants verbatim and is an extrapolation from the data, this term is thought to best summarize and the overall conceptions of success.

Research participants consistently reiterated that success from their perspective ultimately means that students develop the capacity to actively engage either local or global groups through interventions or actions that address social, cultural, or ecological issues through long-lasting (or sustainable) solutions by culturally responsive (or responsible) means; in doing so, they then change the condition of people and the environment. 
Global agency is a broad term; it encompasses in significant ways learning outcomes that have been deemed useful or even necessary in addressing what is needed to meet pressing environmental, ecological, and human needs on a global or local level. Global agency as a concept shares many components with sustainability education (or leadership), "which reflects an emerging consciousness among people who are choosing to live their lives and lead their organizations in ways that account for their impact on the earth, society, and the health of local and global economies" (Ferdig, 2007, p. 26). One reason why sustainability leadership did not fully encompass the overarching hallmark of success for STISL courses was its tenuous connection to the concept of cultural context, which is "the collection of meanings, beliefs, symbols, values, and feelings that individuals or groups associate with a particular locality" (Williams \& Steward, 1998, p. 19). This is not to say that cultural context is always excluded from theories of sustainability leadership; in Burns' (2009) model of Sustainability Pedagogy, she argues: "Sustainability must be addressed multidimensionally in order to take into account relationships between the biological and cultural dimensions" (p. 35). Therefore, similar to the notion that cultural context can be inferred in regard to the concept of global citizenship (see Ogden, 2010), with the many definitions of sustainability leadership, cultural context is not always as explicit as Burns (2009) has described. This lack of explicitness proves problematic when attempting to discern the overarching hallmark of success, especially considering research participants' multiple 
assertions of the centrality of the cultural context as a means of avoiding a "recolonization" of less developed countries through the act of service.

While Table 8 accurately articulates research participants' perceptions of STISL success, a visual framework of this conceptualization and its interrelated dimensions illustrate that the dimensions are not isolated and often overlap with another dimension, as is represented by the dashed line between the dimensions (rather than a solid line (Figure 7)). 


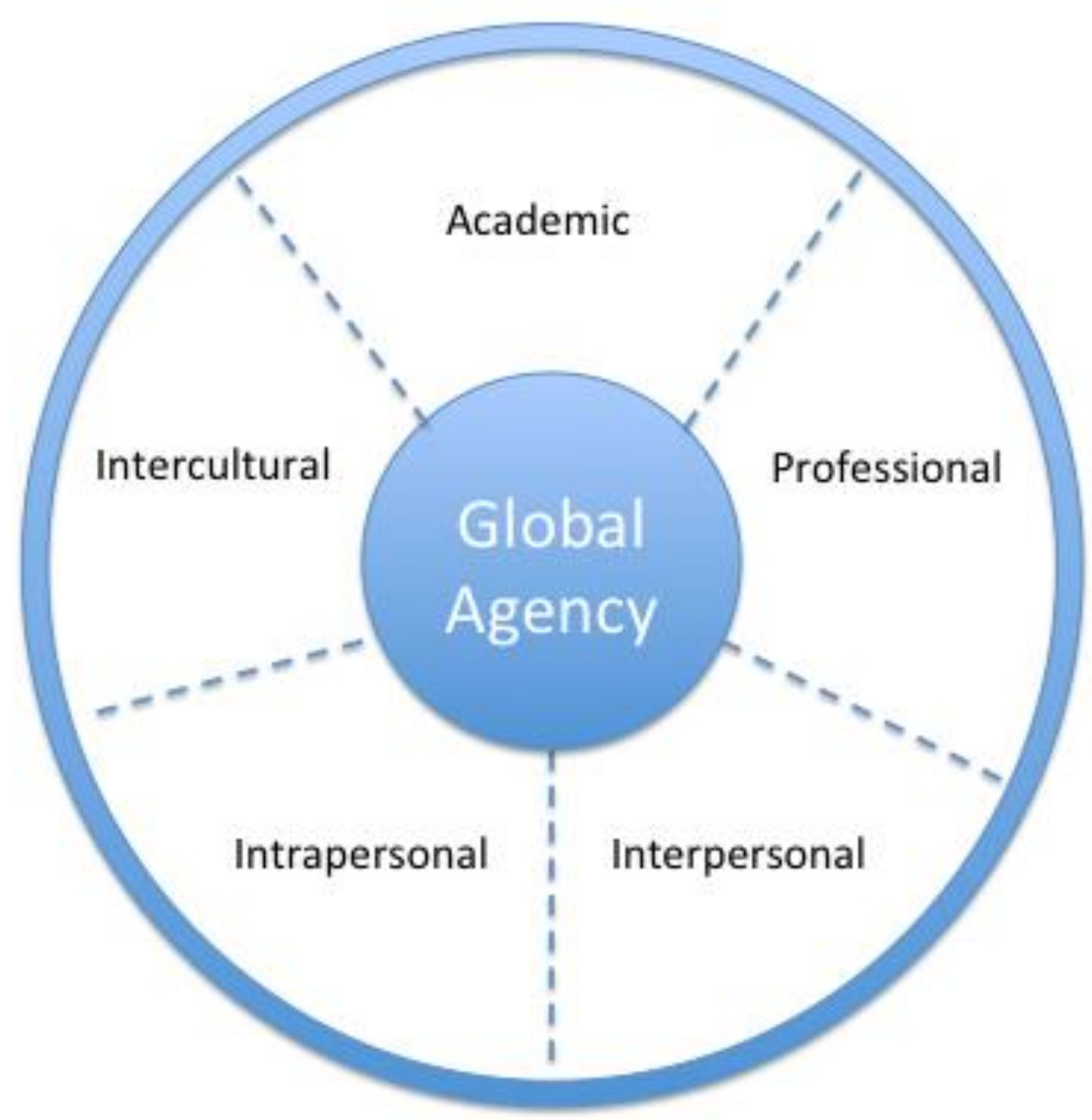

Figure 7. Van Cleave Conceptualization of STISL Success

\section{Perspectives on Global Citizenship as a Hallmark of Success}

The literature on international service-learning suggests that the development of a global citizenship identity is a comprehensive standard for determining success(Bringle \& Hatcher, 2011). Therefore, the next section investigates whether faculty definitions of success match those in the literature related to the concept of global citizenship. 
First, though, it must be remembered that the term global citizenship-or global citizen-has has been criticized in the literature (Davies, 2006, Dower \& Williams, 2002; Dower, 2008). Examples of such criticism include Dower (2008) who suggested that the concept of global citizenship is in itself elitist and primarily only usable by the privileged North. In a critical assessment of the term global citizenship, Dower (2008) warns, "those who accept a global ethic and work toward realizing it are in effect attempting to impose their values on others" (p. 47). Furthermore, Dower stated:

If, for instance, one believes in global community, one may act as if there is a far greater degree of harmony in the world than there really is, and this may mask real power conflicts in which those with the dominant discourse (as reflected in the universal values of self-styled global citizens) usually have the upper hand. (p. 47)

Additionally, the term global citizenship has been criticized as inaccurate in light of the fact that organizationally there is no united global government. Davies (2006) questions that if as a term global citizenship is appropriate, or more of a "paradox or oxymoron" (p. 5), because there is no such thing as a global government. As she noted, “' we cannot be citizens of the world in the way that we are of a country (or, for an increasing minority of stateless people, would like to be)" (p. 5). Finally, Davies noted that honoring individual cultures when conceptualizing global citizenship proves difficult:

One of the important tensions in global citizenship then is how to treat 'culture'. In discussion of cultural integration, there is often the language of 'one's own culture' and 'others' culture' - yet as our research has stated to imply (Yamashita, in this issue), this notion of 'us' and 'them' 
may become more complex in a world of migration and of dual or hybrid identities. (p. 8)

Therefore, it was important to know the general thoughts the research participants had regarding the term before delving into a discussion of how or if faculty were teaching using a specific conceptualization of the concept. In essence, the question tried to discern the research participants' gut reaction to the conceptualization of the term as they have experienced it in the past.

There were a wide range of reactions to the term global citizenship, including positive, negative and neutral, but the research participants resoundingly acknowledged that the concept of global citizenship is complicated, illusive, and contextual. Positive reactions from research participants went so far as one faculty member (Isabelle) stating, “[y]ou know, I love the concept of global citizenship!" And a negative reaction from Ethan, who believes “...it is somewhat of a classist idea.... [p] ossible for those who have the resources to cross borders..." This assertion resonates with the criticism of global citizenship by Dower (2008), who noted the concept of elitism and its relationship to the term, global citizen:

But there is another strand of criticism that also homes in on another aspect of elitism - namely the privileged status of the global citizen. Those who are active global citizens either by self-description or because of what others recognize in their style of life are simply privileged people - mainly in the rich North, who have sufficient wealth, leisure, opportunity, access to organizations, and so on. (p. 47)

More than anything, research participants felt that the term global citizenship was difficult to understand and needed to be approached as a contextual concept. "I think it is one of those terms that is way more involved than people think" 
(David). "It is a kind of academic conceptualization and makes a great writing point to engage other academics... It strikes me as difficult to operationalize in reality because in part... citizenship historically has been seen as national-state based. A global vision is a very different kind of vision" (Henry, an associate professor at a large, public, urban institution who teaches STISL courses in Oaxaca, Mexico focusing on environmental activism)". "Sometime we fall into the trap of thinking, 'if I just assign an article about another country, then perhaps my students will become global citizens'"' (Isabelle).

For Angela, defining global citizenship was difficult, so she relied upon her own definition, to which she has a positive response. "I'm not sure what definitions are being used, so I can tell you my reaction based on my definition. I have a positive reaction based on my definition and maybe that is different from somebody else's' definition." Angela's response resonates with other research participants' experiences as they have struggled to understand the concept, even though their respective institutions have committed themselves to educate for global citizenship. Gail, from a large, public, urban state institution, noted that she knows her institution has made a commitment to develop global citizens but does not know how her practice aligns with institutional goals or conceptualizations.

In response to this question, some research participants reported that they have felt pressure from their institution to be more "global" in light of recent institutional proclamations, including explicit commitments to developing global citizens and being a global partner. One faculty member felt pressed to use his 
course as marketing tool to bring local students he had met through the STISL course back to the U.S. institution as exchange students. This account was heard second hand through David, who believed his institution may have been putting its enrollment desires ahead of what would be best for the student from the host country. Recalling a conversation with the faculty member, David noted how he agreed with his colleague that the exchange that their institution was hoping to institute could actually be detrimental for the student from the host country psychologically, socially, or academically. Paraphrasing his colleague's words, he said “I'm not going to bring [an international] student here if they don't have a good chance of being successful. They expect me to be bringing bunches and bunches of students [back to our home institution]." In response to his colleague's experience, David asserted, "I think there is a disconnect between the university's ambition about being global universities and what it actually takes to do that."

In summary, there was a mixed reaction to the term global citizenship. While some faculty members "loved" the term global citizenship, other research participants thought that the term was classist and unrealistic. While it is outside the scope of this study's findings, faculty attitudes to the term global citizenship may be related to institutional support-or a lack thereof-for internationalization and globalization initiatives. Overall, however, faculty in general agreed that the term global citizenship was a difficult concept to understand, operationalize, and articulate. 
Three Dimensions of Global Citizenship. In order to understand if STISL faculty agree with the idea that global citizenship is a hallmark of success for STISL courses (in light of the literature's assertion that global citizenship is a difficult concept to operationalize and the concerns expressed in the previous section), the researcher presented the research participants with a theoretical conceptualization of global citizenship, which was divided into three dimensions: social responsibility, global civic engagement, and global competence (Ogden, 2010). research participants were e-mailed an electronic version of the Three Dimensions of Global Citizenship and were read the descriptions during the interview process. After the descriptions were read, research participants were asked (a) whether or not they believed their courses sought to teach for each of the individual dimensions. Later, if research participants thought they were trying teach for learning outcomes in any of the three dimensions, they were (b) asked to describe pedagogical strategies that they employed and that they thought served as a catalyst for development and learning. Finally, faculty were (c) asked if there were anything they would add, subtract, or modify in regard to Ogden's conceptualization. The following section reports results from data analysis in regard to these three questions.

Dimension 1: Social responsibility. Social responsibility, according to Ogden (2010), is a multi-faceted dimension and is understood as:

the perceived level of interdependence and social concern to others, to society, and to the environment (Andrzejewski \& Alessio, 1999; Braskamp, Braskamp, \& Merrill, 2008; Parekh, 2003; Westheimer \& Kahne, 2004). 
Socially responsible students evaluate social issues and identify instances and examples of global injustice and disparity (Falk, 1994; Lagos, 2001). They examine and respect diverse perspectives and construct an ethic of social service to address global and local issues (Noddings, 2005). They understand the interconnectedness between local behaviors and their global consequences. (p. 32)

By and large, faculty believe that they strive to teach students to be socially responsible individuals through their specific STISL courses. The following excerpts highlight the variation in initial responses to the question but also display overall support for the dimension in regard to what they hope students take away from the course:

- (Henry) "It is a desired outcome"

- (Isabelle) "Yes, I think all of that resonates with me, certainly."

- (Barbara) "Yes, because for one, social responsibility is one of the core values of [our field]. We have 7 core values and that is one of them."

- (Felicia) "I would say yes, the short answer. [Our institution] has its own mission statement and it is developing an ethnic of care for others and for the environment. There is an overlap between [the Ogden conceptualization of social responsibility and our institution's] mission statement."

Only Angela reported that she did not believe she taught for social responsibility necessarily; instead, she preferred to say that she designed her STISL courses around the concept of social capital. "I probably don't teach that word specifically. Actually what I teach more is building social capital, not as a total replacement but this is where my focus is."

As the data evinces, faculty overwhelmingly agree that social responsibility is a facet of global citizenship; however, the standard definition of social responsibility does not fully encapsulate research participants full conception of what social responsibility truly is. Some followed up their initial 
positive response to the question regarding social responsibility with caveats that they felt were necessary to contribute; most commonly, they expressed a belief that social responsibility must be understood through cultural contexts and ways of knowing. Following up on his initial response, Henry argued that the term social responsibility was value laden and that cultural perspective has a strong impact on what we deem to be socially responsible, which might not be appropriate in all contexts. In a similar vein, Isabelle strongly contended that service must be seen as culturally influenced:

The only thing that I would disagree with, again, and I am just testy about this term, this concept of -- somewhere in there you said global service as being one dimension of that and I'm careful around that. I think service is appropriate if the host community requests that, is asking for us as US citizens to be in solidarity with them and this is one way we can do that. But I don't agree with folks who embark on service without being really thoughtful about how that affects the dignity of the host community or individuals within that community.

Aligned with critical pedagogy, Isabelle's perspective on dignity mirrors Freire's (1970) work that sought to equip individuals to "regain their humanity (p. 33), through ending the cycle of oppression and dehumanization. Isabelle's contention also resonates with McLaren and Farahmandpur's (2005) assessment of critical pedagogy that not only emphasizes individuals' relationship in and against the world, but "also on their relationship with the world" (p. 53). As both Isabelle and Cushman (1999) asserted, service initiatives (the manifestation of a sense of social responsibility) must not be instituted in isolation. Instead, service must be approached through multiple lenses including, the ability to honor and respect 
cultural context, as well as solidarity, "unity... that produces or is based on community of interests, objectives, and standards" (Websters, 2013, para. 1). Therefore, while many of the principles of social responsibility are essential and desired learning outcomes for students who participate in STISL courses, significant components are missing or not sufficiently explicit in the way it has been described in the literature. Therefore through data interpretation, a more appropriate term should be articulated as it pertains to STISL success.

Through interpreting the data, as well as extrapolation in order to articulate coherent and usable findings, the new term of "culturally contextualized solidarity" will be used in lieu of social responsibility in order to better encapsulate what STISL faculty have noted are factors of STISL success. It is important to note that social responsibility as it has been articulated in the literature (Ogden, 2010) is a component of culturally contextualized solidarity, however there are other significant concepts embedded within this term.

Within the concept of solidarity is a relationship based on unity in pursuit of a goal based on communal interests. This is not to infer that unity means the same, related to identity. However unity describes concerted efforts based on similar goals and intentions. Relationship with host-country community members is essential in developing solidarity, which provides context for the issue that the community is facing. This relational component was echoed by community partners from other research projects who asserted "in our struggle for justice [we want to know] that we are not alone" (Baker-Boosamra et al., 2006, 
p. 490). Furthermore, while in Ogden's (2010) conceptualization of social responsibility he noted that students "examine and respect diverse perspectives" (p. 32), faculty research participants in this study did not think that it did not clearly assert what was for them a strong conviction and commitment to honoring and a culture's identity and context. Consistently, research participants noted that what may be socially responsible for one culture, may be socially destructive in another. Therefore, according to these STISL faculty social responsibility is contextual and not universal. However, if service initiatives are performed though the lens of both cultural context and solidarity, socially responsibility (as manifested through service) can be realized in a more ethical and productive manner that meets the community's needs while preserving its unique identity.

Using culturally contextualized solidarity as a standard for success encapsulates other voices in the SL literature that have strongly differentiated between solidarity and charity, in that charity can detrimentally impact a community while solidarity can bring about long lasting social change (BakerBoosamra et al., 2006, Cushman, 1999; Heldman, 2011).

Dimension 2: Global competence. Global competence is the second dimension of global citizenship and according to Ogden (2010) is understood:

as having an open mind while actively seeking to understand others' cultural norms and expectations, and leveraging this knowledge to interact, communicate, and work effectively outside one's environment (American Council on Education, 1998; Deardorff, 2006b; Hunter, White, \& Godbey, 2006; Peterson et al., 2007; Westheimer \& Kahne, 2004). Globally 
competent students recognize their own limitations and abilities to engage in intercultural encounters. They demonstrate an array of intercultural communication skills and have the abilities to engage successfully in intercultural encounters. Globally competent students display interest and knowledge about world issues and events. (p. 33)

Similar to the social responsibility dimension, faculty generally supported the notion that global competence is a standard for success for a STISL course:

- (Henry) "It is actually a major element,"

- (Jacqueline) "Yes, 100 percent, 100 percent"

- (Barbara) "Yes, and what comes into play - Campinha Bacote's model measures that, because having interest about world issues and events is part of cultural desire"

Multiple faculty mentioned that global competence is an innate part of a STISL course in much the same way as making cultural mistakes, living with host families, or interacting with local residents at service sites are. A recurring comment from faculty members in their responses to this question was the idea that the development of global competence is a long-term goal, and STISL courses are a catalyst for a desire to be more globally competent. Henry mentioned the long-term nature of the goal: "[m]y concern is less student competence when they go. It is more: do they appreciate the significance of competence by the time they return?"

According to these STISL faculty, success is not simply coming into a country or culture informed but is instead garnering information in order to make sense out of the experience through the lens of the host community. Gaining background information from which to make meaning is an essential hallmark of success according to these research participants. 
Dimension 3: Global civic engagement. Finally, the last dimension of

global citizenship is global civic engagement, which according to Ogden (2010) is:

understood as the demonstration of action and/or predisposition toward recognizing local, state, national, and global community issues and responding through actions such as volunteerism, political activism, and community participation (Andrzejewski \&Alessio, 1999; Lagos, 2001; Paige, Stallman, \& Josić, 2008). Students who are civically engaged contribute to volunteer work or assist in global civic organizations (Howard \& Gilbert, 2008; Parekh, 2003; Westheimer \& Kahne, 2004). They construct their political voice by synthesizing their global knowledge and experiences in the public domain, and they engage. (pp. 33-34)

By and large, research participants believe that global civic engagement is integral to STISL courses and a key component of a successful STISL course in creating global agency (per Figure 7, p. 110). For many of these faculty, global civic engagement is inextricably intertwined with the purpose of the course and is often mirrored in an institutional mission. As Gail noted, "I think that we do [educate for] global civic engagement just by the very nature of the trip." Also, both Angela (from the large, secular, private university) and Felicia (from a small, religious, private university) contend that both their institutions "want civically engaged people with global awareness" and that this STISL course was just a manifestation of what the institution was already committed to doing in terms of preparing students to be civically engaged on a global scale. According to findings, core aspects of Ogden's (2010) global civic engagement dimension manifested as an important learning outcome through the eyes of STISL faculty.

- David asserted that he hopes students are able to see connections between mezzo and "micro, mezzo and macro level phenomen[a].... that equip 
students to better understand the context behind social needs and what would be needed in order design an appropriate intervention.

- (Ethan) "Yes, in the long run I do want [the students] to be engaged and to understand the broader context of what is happening with this phenomenon."

- (Isabelle) "I do believe that our program encourages students as citizens of the U.S. to consider the rest of the world and folks from other countries consider the rest of the world as they are voting... or making decisions related to politics."

- (Barbara) "Yes [global civic engagement is a desired learning outcome], because social responsibility is one of our core values."

Felicia spoke of witnessing students begin to make commitments in line with the principles of global civic engagement and of noticing connections that the students are able to make between their actions and global consequences as a result of a STISL course.

It is interesting because [the students] grapple with stuff around our own sort of consumerism and materialism and seeing other values from another culture that are higher than those values. So some of them talk about actions they will take, 'I will not be so...' 'I will donate my time...' 'I will donate my money to causes in my own community.' Some of [the students] plan to do something globally afterward. I think they get sense of the interconnectedness and the actions that they can take here, and after they get back home, really can in some ways ripple throughout.

Overall, while there was a range of what global civic engagement might mean (such as future action or advocacy both local and global, understanding phenomena, and context to inform future action), it appears that faculty do hope that students become more civically engaged on a global level as a result of a STISL course. As is evident from the data, preparation for informed future action is central to why faculty choose STISL as a pedagogical tool. 


\section{Ogden's Three Dimensions of Global Citizenship as a conceptualization.}

There were various perceptions of success within Ogden's (2010) three dimensions, namely social responsibility, global competence, and global civic engagement, as per Ogden's conceptualization of global citizenship. While the dimensions of global competence and global civic engagement correspond well with STISL faculty members' perceptions of success, the first dimension of social responsibility is in their opinions not complete because the literature on global citizenship, from which Ogden formed these dimensions, omitted significant components of relationship, cultural context, and solidarity (as opposed to charity).

Though research participants agreed that social responsibility is a hallmark of success for STISL courses, it is better understood by them as culturally contextual solidarity, out of which social responsibility emerges in ways that honor local ways of knowing and do not impose culturally loaded perspectives of what communities need.

Therefore, a slightly revised three dimensions of culturally contextual solidarity, global civic engagement, and global competence can be understood as three overarching hallmarks of successful STISL experiences, which culminate in global agency (per Figure 7)

\section{The Van Cleave Framework of STISL Success}

There are three overarching standards of success in terms of STISL courses, including (a) culturally contextualized solidarity, (b) global competence 
and (c) global civic engagement, which represent a more accurate conceptualization of the concept of global citizenship. In addition to the revised three dimensions of STISL success, there are five distinct yet interrelated dimensions of a successful STISL course: (a) academic, (b) professional, (c) interpersonal, (d) intrapersonal, and (e) intercultural. Overall, the overarching hallmark of success through a STISL course in relation the lenses of each of these interrelated dimensions is the development of agency for sustainable and responsible action. 


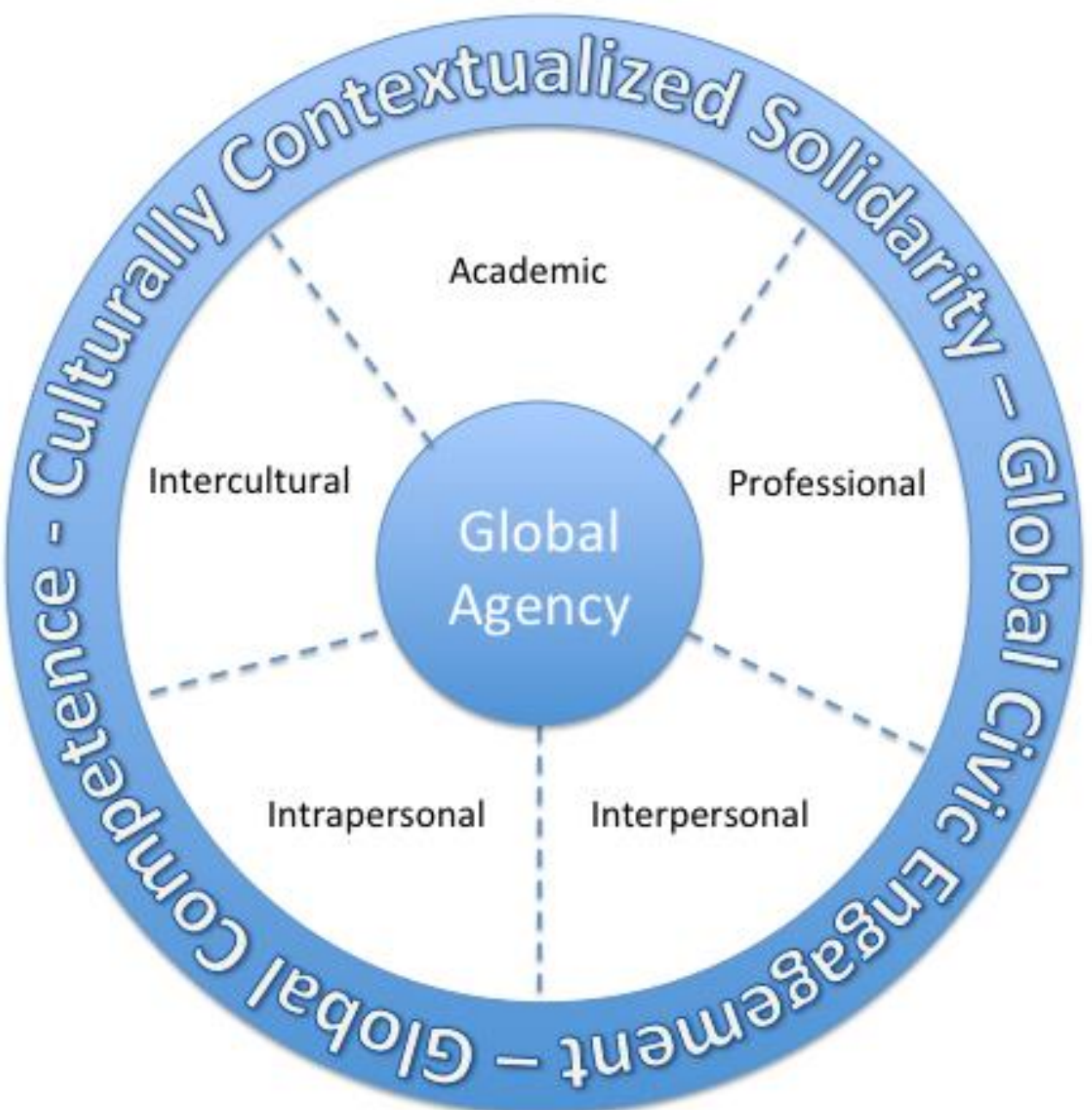

Figure 8. Van Cleave Framework of STISL Success

The Van Cleave Framework of STISL Success (Figure 8) shows how faculty define a successful STISL experience, which answers the first question that this research project sought to understand. Based on this framework, it is now possible explore the second research question for this project, namely: how do faculty design STISL courses in order to achieve success, as they have defined it? Therefore, the next section of this describes findings and will articulate strategies 
based on pedagogical strategies employed by experienced STISL faculty members according to the Van Cleave Framework of STISL Success.

\section{STISL Course Design, Teaching Strategies, and Integration of Service}

The following section of this research project answers question two by articulating, in chronological order, pedagogical strategies employed during the pre-departure segment, host-country segment, and re-entry segment of the STISL experience as they relate to various dimensions of STISL success.

\section{Pre-Departure Segment of the STISL Course}

From the data, there are two significant components to the pre-departure segment of the STISL course experience, the A1.) application process, A2.)prerequisite requirements and the B.) pre-departure preparation sessions. First, results from an exploration of the application process will be presented both in terms of practical strategies and the purpose that they serve, from the research participants' perspectives and in terms of the dimensions of success. Second, results will be presented that explain perspectives regarding pre-requisite academic experience in order to participate in the STISL course. Third, because of the great number of pre-departure strategies that were articulated by the faculty, findings will be reported according to Van Cleave's Framework of STISL Success as they relate to the five dimensions(academic, professional, interpersonal, intrapersonal, and intercultural) and three factors of success (culturally contextual solidarity, global civic engagement, and global competence), thus highlighting specific pedagogical strategies. 
Application process. Overall, the application process for STISL experiences serves multiple purposes. First, as a pedagogical tool, the application process helps to prepare students in terms of professional development to reflect on the reasons that the student wishes to participate in the STISL experience overall. Second, in terms of interpersonal development, it serves as a tool for faculty to better understand who the student is and the perspectives that he or she will bring to the course. Related to academic development, the application process serves as a way for STISL faulty to gauge the academic knowledge that the students will bring to the course and helps faculty to identify academic areas that may need to be developed before the group departs.

All the faculty included certain basic requirements for participation in STISL courses given by academic departments or institutional Study Abroad/Education Abroad centers, including: students' GPA, letters of reference, and answering supplemental questions. In the written component, according to Ethan, "they tell me why they want to take a class such as this." Specific application questions reported by the research participants allude to all five dimensions that appear in the Van Cleave Pedagogical Framework for STISL Success, such as:

- (intercultural/intrapersonal) Why do [you] want to go to the particular country or region of the country?

- (intrapersonal/academic) Why is [the topic] important for [you]?

- (professional) What could the course mean for [you] in [your] future careers?

- (intercultural/intrapersonal/interpersonal) If you are a person going to another country, how would you introduce and describe yourself? 
- (intrapersonal) Reflect on what international travel you have done so far and how those types of experience contribute to who you are.

Ethan, who teaches at a large state research university, was the only participant who reported requiring student conduct records as part of the application process.

Nearly every faculty member reported conducting an interview with potential STISL students. Research participants would use the information submitted by students through the application to better inform what questions each would ask or to identify what additional information the RP felt he or she needed to know in order to accept the student into the STISL course. Henry asserted that "I depend heavily in the end on my capacity to, through discussion with the student, come to some judgment whether or not I think that person will not only survive the experience, but will not do damage to the host culture." Through all of the application materials, there was resounding concurrence that student initiative, adaptability, and flexibility are the key traits that STISL faculty are looking for in students when deciding who should participate in these experiences. Henry provides insight into why he believes these characteristics are essential for STISL students.

I've found that programs are more difficult to manage in terms of the quality of student experience in a setting such as [our host-country] where it is sometimes uncertain today what we are going to be doing tomorrow if you have student who really want an hour-by-hour structure, because the structure makes them feel more comfortable, more secure, more confident, all of which are great things. But if you are going into a setting where the interaction means that you are dependent on what other actors are 
available to do or prepared to do or juggling their own priorities -structure works a lot better when the experiences are passive.

Most research participants noted that within the application materials, they or their institutions require that students, in order to be considered for the course, disclose aspects of their health histories, and, as was previously stated, only one required documentation from the institution's conduct database. Faculty do not generally use the health or conduct histories to exclude students from participating, with the exception of severe mobility issues in certain circumstances. Instead, research participants use the histories as a way of understanding what particular students have struggled with in the past (alcohol abuse, depression, drugs, etc.) in order to better understand how to support the student while on the STISL course. As Christina noted, "I need to know upfront... if there are any anxiety or depression [concerns...so that] we can be proactive and address those issues. If I do know, and I get over there... [I can proactively develop] plans on how to address the issue." It may be significant to note that Christina is a registered nurse and therefore has a deeper insight into emotional and health related issues than faculty without a medical background.

Ethan echoed many of Christina's thoughts and asserted that as opposed to using the medical and/or conduct histories to preclude students form participating, these histories help him in preparing for the STISL experience that lies ahead. For instance, if students applying for one of Ethan's STISL courses 
indicate health or conduct related issues "we research that [issue]... to make sure that the students are okay to travel in these conditions."

David noted that on the STISL course he facilitates, it would be very difficult for someone with mobility issues to participate. "It is not a friendly place for people who are not highly mobile. Elevators do not exist. You hardly ever see a wheelchair ramp. Everything is stairs and it is a walking city... The sidewalks and the streets are even not that conducive to walking." There is no evidence to show that institutions are explaining accessibility issues in the program descriptions, and institutions may use the health inquiry as the initial and primary mechanism for identifying potential instances where an experience may be incompatible with a student's level of mobility.

The health related issues that research participants discussed highlight important concerns that the faculty have when faced with understanding students that have expressed interest in joining the STISL course. As Ethan noted, it is important to know what faculty need to be aware of in terms of supporting students while they are on the STISL course itself. According to Christina, who works at a faith-based institution, her course is not designed only for Christian students; however, she does "like to know what their spirituality is in the event that we get over there and they are stressing or having issues. I need to know where they find their strength, where they find their hope so that I can help them."

Prerequisites to participating in the STISL course. In terms of who would be eligible to apply for a particular STISL course (discipline specific or 
open to all students), only three of the ten courses investigated were restricted to students in a particular area of study: the three health based courses that focused on nursing, physical therapy and healthcare interdisciplinary. The three health based courses were restricted due to the discipline specific skills required to participate in the pre-established service projects.

The only other course that encouraged but did not required prerequisite coursework was the graduate course in public administration, with content specializing in women's development and microfinance. As Gail noted, she encouraged students to take a particular women's development and microfinance course at Large Public Urban University's home campus, so that when the students then participate in the STISL course they would be able to "[take] the theoretical principles that they have been exposed to in the [women's development and microfinance course] and then [turn] around and [see], okay, this is how it really works".

Every capstone course at Large Urban Public was restricted to students who had already earned a specific number of undergraduate credits and junior status. The only faculty member that mentioned having students audit the course was the community college administrator who taught the STISL course in international development.

Lodging. In terms of lodging, there are two main structures for students lodging while they are on a STISL experience: together as a class or separate/in pairs. Although logistical ease did play a role in deciding which lodging options to 
utilize in the host-country, STISL faculty also use lodging as a way to better implement specific teaching strategies while in the host-country.

Overall, the faculty reported that housing plays a significant role in the students learning experience, and specific housing strategies are aligned with various pedagogical strategies in order to achieve what the research participants consider success. In the together as a class category, the entire group (including the faculty member) stays in the same hotel or at the NGO site. In the separate or in pairs category, students stay in homestays or hotels spread throughout the community. Faculty members chose the housing structure based on the priorities of the program and the learning outcomes that the faculty member hoped to achieve, as well as overall logistical ease and safety.

Lodging together as a group. There are two overarching reasons that faculty chose to have students stay together in a hotel or at the NGO site. First, in terms of logistics and safety, staying in a hotel gives faculty members peace of mind in regard to students' physical wellbeing. In addition, staying together enables faculty to be more engaged in the service work, rather than focus on the logistics of homestays. As Angela noted, "I don't want to spend time teaching them how to get from their homestay and where they need to be and running around the town and tracking them and making sure they are okay and that they are safe." She goes on to say that if the course were longer, she would have more time to help students adjust to the homestay and that the short duration of the trip makes is so that 
if there is a problem [with the homestay], then I might be in danger of spending my time dealing with that instead of putting my focus on...the health of the elders. If I put them in a hotel all together, [it is] easy to meet with them, easy to organize, so the pragmatics work.

While it was not directly expressed, there appears to be a relationship between what housing strategy a faculty member decided to utilize and the regularity that the participants gather in order to reflect as a group. With the exception of one participant (Angela), all research participants that chose to have students stay together in hotels, hostels, or at the NGO site held regular group reflection sessions, which Barbara asserted is essential to her pedagogical strategy for interpersonal development and intrapersonal introspection. This is not to say that group reflection cannot or does not take place when students do not stay in the same place, as will be discussed in the subsequent sections.

Lodging separate in hotels or motels. The second type of lodging has students stay away from the service site in separate hotels or motels. In fact, Ethan does not tell students where to stay, but rather gives them options from which the students can choose those that best suit their preferences. Typically, students arrange to share rooms with other students in order to keep the cost of lodging reasonable. As discussed earlier, staying together as a group, in some faculty's options, makes it easier to gather as a group for large group oral reflections. However, as Ethan described, he still manages to structure daily reflection sessions with his students despite the fact that they are staying at different locations. 
Ethan insists that the students gather every day to process. "I tell them that regardless of how tired they get while we are in San Diego that we are going to debrief every day. We are not just going to do the experience and then go home or do what we want to do." So while it is possible to have group reflection sessions every day, staying together could make it logistically easier to gather as a group as opposed to staying in separate locations.

Lodging with community members in homestays. For David, Henry, and Isabelle, who decided to utilize the homestay structure for student housing, the act of being housed with a local family is an important strategy used to achieve myriad learning outcomes-including interpersonal, intercultural, culturally contextualized solidarity, global competence, and interpersonal development-by providing students with deeper context for the issues investigated through the course. Simply being in contact with community members more regularly is a strategy thought by these research participants to more deeply engage students with the intercultural dimensions of the course. Homestays also provide students with the opportunity to practice a foreign language and experience a richer and more prolonged cultural experience. Interestingly, based on the Georgetown Consortiums Project (Vande Berg et al., 2009; Vande Berg \& Paige, 2012) , there is not evidence within the study abroad literature to support the belief that students who live in host-family situations gain any more in terms of intercultural development when compared to students in other housing situations. 
Henry reflected that "We expect students to live with local families, not in dorms, not in hotels, but live in local households... [I believe that there are significant benefits through] the interaction with people." He believes that the interaction that a student has with a host-family helps the student gain more context when trying to understand the issues that are raised throughout the course. For example, he asserted that the context a home-stay provides "helps ... students to have a better understanding of what environment activism means in a broader sense. Otherwise, all you are doing is a [service] project." Additionally, David noted that homestays develop students interpersonally and interculturally as they struggle with the challenge and the opportunity to see and overcome barriers that become apparent through a homestay. "They stay with a [local] family and learn to navigate the language barriers and hopefully begin to realize some cultural barriers as well."

Faculty who utilize homestays for housing generally agree that homestays increase a student's understanding of the issues investigated through the course and deepen a student's cultural learning, despite the fact that homestays can be difficult for the faculty, the host-families, and the students. As Henry noted, "Sometimes the experiences will be unpleasant or difficult or awkward."

For example, David recalls a time when a student may have had a significant cultural learning experience, but nearly caused an "international incident". 
No matter how old they are, no matter what their status is, they may still be thought of as children who the parents feels responsible to take care of. We had a student who was there the last night of the experience and told his host mother, I am going to be going out with some of the other Capstone students tonight. We are going to go out on the town a little bit. I might be out late. If it is too late, rather than wake people up in the household, I will just find another place to crash and sleep for the night so don't worry. The student was in his mid-30's. He did not realize that that was an unreasonable request for a [local] woman, to not worry about this American in her household going out and not coming home. So, of course, he ended up not coming back night and she ended up calling frantically around to the instructor and insisted on calling hospitals and every place to find out where he might be and if he was okay. Of course, he showed up with our last meeting together in the morning completely unaware that he had practically precipitated an international incident by not coming home. Of course, that parent still regarded him as a child because he was single, because he was living in the household, and she felt responsible for him.

Similarly Henry discusses how detrimental it can be when cultural norms

and standards between a student and host-family clash, irreparably damaging

relationships and livelihoods.

I had a program a few years ago where a student was in a middle class household. In Mexico many middle class households will have someone who helps in the house. The someone was a young woman, maybe 16 or 17 from a distant indigenous community and the family treated that young lady very badly. That is also not uncommon and we talked about this because I knew students, in some cases, would be encountering that. But the young woman from [my institution] was filled with righteous ire about what she perceived as mistreatment, and by our standards it was. Unfortunately, the host mother heard the student talking to the young woman and called me and said, I want this student out of the house by sundown tonight and fired the young woman on the spot... For the young woman, to be tossed out on the street in a city she didn't know, far from home, no money, who knows what happened to her. For our student it was embarrassing. For the young lady, it was literally a threat to her life.

While faculty who chose to have students stay together feel that the proximity of having students close gives the faculty a better perspective on how 
students are doing emotionally and physically, other faculty, like David and Henry, note that the community itself serves as a monitor for helping them understand how students are doing and what they are doing.

A host family will call and say, you know, this student is great, he is personable, she is charming, but what I notice is [after they] come back from Spanish class in the evening and immediately go to their room, not to appear again until the next morning. Are they just tired or has something happened in the household that we are not aware of? I get feedback from all over the city. Again, this is the advantage of having worked in a setting for a long time, but it is not so much that you cultivate a network of informants, but people appreciate that it can be helpful...It can help to keep them out of trouble...That is a very, very important mechanism for that kind of monitoring.

Funds and fundraising. While not included in the interview protocol, the issues of cost and strategies for funding these courses was often discussed.

Overall, research participants recognize the significant financial investments that are required for STISL courses. While STISL courses are generally less expensive than longer international courses, the tuition, fees, travel expenses, and time away from work may be prohibitive for certain students, especially nontraditional students, like those at the West Coast Community College.

They are dealing with that life or the hardships of their families -- they don't have health insurance, for example. I would like to have more students who are disadvantaged -- not disadvantaged, that is not the right word because they have a lot of advantages but don't have the financial means to have access to it. That is a big failing point in the program I think, and study abroad in general. It is very expensive.

Throughout the data, fundraising became a recurring theme, both as a way to make the course more accessible to students and also to raise support for purchasing supplies to assist in the service projects associated with the STISL 
course. Only one course, "Mexico Emigration and U.S. Education" did not make students liable for the expenses of the course; students had to pay only the tuition associated with the academic credits, similar to an on-campus academic course. The faculty member for this course sought funding opportunities from his institution's internationalization grant program, internal university charitable foundations, and directly from the institution's honor's college, resulting in over $\$ 30,000$ that was applied directly to the students' program expenses (including lodging, food, and honoraria).

The RP from West Coast Community College stated: "I hate fundraising... But I'll do it. I'll ask for money." When scheduling the interview for this study, this RP invited the primary investigator of this research project to observe a presentation that the RP and her students were making to a local service organization asking that they partner with the community college financially and make a contribution that will help subsidize students' program expenses. The RP spoke to the organization for just a few minutes, and then two students delivered impassioned speeches detailing the impact that this course had made on their personal and professional lives.

Other than subsidizing student expenses, STISL students and faculty members also organized fundraisers that aimed to increase the amount of supplies that the group could purchase in order to perform their service activities. From participating in a fundraising $5 \mathrm{k}$ race to bake sales, many STISL students designed and executed various programs as a means of supplementing and even 
expanding the financial resources that could be allocated to service related expenses while in the host-country. In addition to a grant that she applies for on her own, Barbara uses the fundraising experience as a pre-departure bonding exercise:

Usually what we do I submit a grant, through my church I get money, and they submit a grant on campus for some money from the Provost Office. Then they do these fundraisers to help defray some of the cost of the travel, because the university doesn't cover it. They only cover a small portion of it. The trip itself is around $\$ 2,000$ so they have to figure out how to fundraise for that. They are doing a whole bunch of really creative things to fundraise... We meet weekly and talk about stuff. I do a lot of encouragement.

It may be important to note that Barbara's course spans an entire academic year, with the international component taking place over spring break vacation. Therefore, students have ample time to design and implement fundraising initiatives.

Pre-departure preparation strategies. For every STISL course investigated through this project, the pre-departure class sessions and preparation for the housing situation were an integral component in the STISL experience. This is consistent with the study abroad (Paige, Cohen, Kappler, Chi, \& Lassegard, 2009; Vande Berg et al., 2009), service-learning (Keene \& Colligan, 2004), international service-learning (Kiely, 2005), and intercultural literature (Juffer, 1993), all of which assert that pre-departure preparation sessions are essential to equipping individuals to engage in more meaningful learning 
experiences. There are numerous components to STISL pre-departure sessions, but they can be broken down into seven conceptual categories. These are:

- Practical (logistics, behavior, packing, health)

- Academic (academic topic general, academic topic through the lens of host-country's culture)

- Professional (explore way that professional skills can be applied to hostcountry identified need)

- Interpersonal (group team building, exploring concept of solidarity versus charity)

- Intrapersonal (affective preflection, coping mechanisms during stress, flexibility, consciousness of self)

- Intercultural (basic history of country, anthropological foundations, current events)

- Global civic engagement (critiques of international service, sustainable international service efforts)

Findings will be reported as they relate to seven categories of pre-departure orientation sessions are more fully explained, that the three factors of culturally contextualized solidarity, global civic engagement, and global competence are interwoven with the six components listed above. Also, while these categories of pre-departure orientation are explained separately, it is important to recognize (as displayed by the dashed line between the dimensions of success in the Van Cleave Framework of STISL Success) that the components often overlap and rely on each other for a holistic pre-departure preparation pedagogy.

Practical pre-departure preparation. For practical preparation, research participants consistently noted the importance of preparing students for the STISL experience in terms of logistics, health, and safety. While the practical preparation component does not directly align with the five dimensions or three factors of STISL success, practical preparation serves as a foundation for students 
to more fully engage in the learning STISL experience and is therefore integral to STISL success. Logistics were reported by research participants as one of the most important steps in pre-departure preparation in the eyes of students. For this, these faculty usually have a detailed outline of what to pack, how to purchase travel insurance, or even procedures for going through customs and immigration. Research participants consistently reiterated the importance of telling students what is considered culturally appropriate dress in the host-country, though this can also be categorized as intercultural preparation. They feel that if students wear culturally appropriate clothing female students will be less likely to be sexually harassed and males will better assimilate to the cultural surroundings.

As Henry noted, "In these communities, exposure of that much leg by females is seen as an invitation to a sexual encounter. Guys wearing shorts are seen as pre-adolescents and so expect comments about your manhood." An experienced STISL instructor, Henry, uses case studies from his previous STISL courses as a pedagogical strategy for students to understand how simple cultural norms, such as gender appropriate behavior, can have long lasting impacts on community relationships. He focuses on conveying to his students the fact that while certain cultural practices might be outside the students' normal routines, it is important to abide by local perceptions of culturally appropriate behavior. This is consistent with Kiely's (2005) findings that pre-departure knowledge can equip students to more easily overcome low-intensity dissonance but still engage cognitively and emotionally with the experience. 
Another common point to address during pre-departure preparation is how to prepare students to make good decisions about their health. As will be discussed later in this section, Barbara and Christina provide students with a list of optional medications the students can bring in the event they have certain health issues such as stomach ailments or problems adjusting to the altitude. She also prepares students to, "hydrate, hydrate, hydrate" so as to not become seriously ill due to the altitude. In her nursing STISL course, Christina reminds her students that their health is a primary concern in terms of the service activities, because "you need to be healthy so that you can provide health care to others, not trying to take care of yourself."

Safety is the final component of practical pre-departure STISL preparation. As many research participants noted, issues surrounding student safety are a great concern for the faculty members and for the institution as well. According to Christina, discussions about safety precautions are essential because of some students' naiveté in terms of international travel experience. "That is probably one of the biggest deficits of some of the students who... are in that American mindset of I'm trying to help you, so surely you will be kind to me."

Christina's concerns are not unfounded, as both RP4 and RP8 describe instances when students' were injured or violated during a STISL experience. As RP4 recalls:

Having had the misfortune on the program I ran for [a number of years at a different institution] in Ecuador, of having two rapes and having had some years ago a student robbed when he went to a place that I said, 
'Don't go to this place because it is dangerous. There is a high probability that you will get robbed if you go.' [The student thought] 'Oh, wow, it will be really interesting, that must be a cool place to go.' Of course, he went and he got robbed.

In response to these examples, in the pre-departure sessions RP4

encourages his students to develop a code that will alert classmates that someone is in need of help:

[We] develop a code, essentially [of] words that if students are out... and you see local guys approaching women from the group, [they can ask one another]- 'did you hear from your grandmother?' That enables her to say, 'no, not yet,' meaning, no, everything is fine, or 'yes, she said to say hello'. That means this person needs help [and is looking for a way out of the situation].

Even more in depth, Christina ensures that students know proper protocol for how and when to reach the American embassy, an evacuation plan in the event of a natural disaster or political upheaval, and how to contact the their travel insurance company in the event of a hospitalization or medical evacuation.

In summary, the health and safety portions of pre-departure preparation sessions aim to ensure student health and physical safety; students also thus protect the institution against potential liability.

Academic pre-departure preparation. The second category of predeparture sessions is academic preparation. As with all of the pre-departure categories, academic preparation is multi-faceted construct with strong intercultural education influences. Overall, the academic dimension can be understood as either broad background or host-country specific anthropologic backgrounds regarding academic concepts that will be explored through the 
course. Regarding broad academic concepts, the instructor for Environmental Activism and Community Engagement STISL course noted that it was important for students to have a basic understanding of the issue being explored through the course, broader than country-specific backgrounds:

So let's say as a part of environmental activism, we are going to be working with a community organization on some reforestation projects. Well, it helps for students to have a better understanding of what environment activism means in a broader sense. Otherwise, all you are doing is a reforestation project.

Likewise, another RP requires that all students have taken a course that explores women's development and microfinance or have read assigned books about the concept so that they have background knowledge on the specific academic concept. Henry asserted that background knowledge on the academic concept that will be explored through the STISL course provides students with more context to interpret what they are both seeing and doing, which leads to deeper levels of meaning for the students. With a broader background on the issue being explored through the course, students should be better equipped to translate these experiences to other cultures or contexts, not just the culture and context of the host-country.

Research participants did not mention that additional host-country specific academic concepts that would be explored should be addressed in the pre-departure portions of the course; however, numerous syllabi reflect hostcountry specific readings from academic journals, conference presentations, and periodicals. 
Whether broad or host-country specific, it does not appear that the students need said knowledge in order to perform the service, but the knowledge does help students interpret the service experience in light of larger academic concepts.

Professional pre-departure preparation. The third category of predeparture preparation does not apply to every STISL experience and is generally reserved for STISL courses where students are applying specific professional skills (such as health care) to a community identified need. While it may seem that the professional category of preparation parallels the academic category of preparation, it is in fact different because professional preparation encourages students to consider how to apply professional skills that a student already has and plans to use throughout their career in ways that meet community identified needs. In other words, there is no new academic training necessary in order to perform the service activities, however students must consider how their professional skills (such as dental care, occupational therapy, physical therapy, or optometry) can best be applied to the host-country's cultural context, utilizing only the resources that are available during the experience. Often, as Angela noted, students must re-think how to deliver services to patients because what may be common medical supplies in the United States may in fact be difficult to obtain in the host-country. In terms of professional preparation, Barbara reports that she and her students review patients' medical histories before they leave 
their home country in order to acquire any materials that the students can easily bring to the host-country.

Interpersonal pre-departure preparation. The next component of interpersonal pre-departure preparation is for the class as a community. Nearly every RP reported that it was essential that students form a strong and supportive learning community. While only one RP reported utilizing formal team building activities, many research participants relied on less formal group bonding experiences. Many noted that informal dinners, where socializing was the priority, proved to be effective for students in becoming acquainted in a less academic environment. As Jacqueline noted, “[the students] typically know each other but they are not friends... what I do is before we go... they come over to my house for dinner." Another informal strategy that faculty have utilized are social media tools, such as Facebook groups. Whether formal or informal, due to the short nature of the STISL structure, faculty feel that students need to begin community building before they leave for the host-country.

The concept of preparation for interpersonal connections is not limited to between the students themselves, and also includes between the students and the host-country community members. While many research participants alluded to the concept of solidarity, only Isabelle outwardly mentioned the concept. "What I strive for is that students' understanding of that relationship really deepens to one of seeing their relationship with the... hosts as one of solidarity rather than charity." Isabelle prepares her students to feel solidarity with the host-country 
before students ever leave their home campus. One of her "pre-flection" assignments is for students to write a reflection paper based on their reaction to the following quote by Lilla Watson (as cited in Eckerman et al., 2010) , an aboriginal woman: "If you have come to help me you are wasting my time. But if you have come because your liberation is bound up with mine, then let us work together (p. 193)." Isabelle noted that solidarity is not taught, but instead must be experienced. Therefore, Isabelle finds it necessary to have students already thinking about the concept of solidarity, so that when they are performing their service activities, students can use the idea to interpret the experience.

Intrapersonal pre-departure preparation. There are several components to the fifth pre-departure category that aim to prepare students to be intrapersonally prepared for the STISL course. Typically, this type of preparation includes components of emotional preflection, articulating coping mechanisms for stressful times, and preparing to be flexible during times of confusion or when plans change. Additionally, there was a strong intrapersonal/intercultural development component mentioned by research participants where students participated in exercises that explored their own cultural identities and how that shapes the way they understand and interact with the world.

Reflection papers were noted as important intrapersonal pedagogical strategy by nearly every RP that participated in this study. Often, the reflective papers as a pedagogical strategy overlap with other pedagogical dimensions, 
including interpersonal and intercultural. There is no evidence that STISL faculty assign reflection papers (outside of reflection journals) during the STISL course. In the pre-departure portion of the course, however, reflective papers are used to "prepare for the cross-cultural experience but also for a cross-cultural experience that involves service" (Isabelle). Isabelle outlines three separate intrapersonal and interpersonal reflection papers required for students before they arrive in the host-country:

- Reflective Writing \#1: Describe a time when you have crossed a border in your life - literally or figuratively. What happened? What challenges and successes did you face? Who did you meet along the way? What help did you receive in making this transition? What did you learn from this experience?

- Reflective Writing \#2, part 1: Imagine your first day at your service placement in [the host community]. What hopes or expectations will you bring to your service experience? How would you like to be received by your [host-country] site hosts? What hopes or expectations might your hosts have as they prepare to receive you? What preconceived notions might they have of you as a visitor from the US? What can you do to foster a meaningful connection with [the host-country] at your site?

- Reflective Writing \#2, part 2: As you prepare for your service experience [in the host-country] what are your reactions to the following quote? "If you have come to help me you are wasting my time. But if you have come because your liberation is tied up with mine, let us work together" Lilla Watson (an aboriginal woman)

Another RP, Jacqueline, assigns a written reflection paper "about the power of one" where students are asked to articulate their own intrapersonal principles and perspectives on the concept of self efficacy:

Yeah, you know that phrase, everybody says it, 'Be the change you wish to see.' The first class that we do is a whole segment called the power of one. It is talking about sometimes you see giant -- you go to something and you see a giant organization like Mercy Corps, Medical Teams and think I couldn't really do anything. Then I have the guy who runs [inaudible]... and then they read some other readings about it. It is like, you can 
contribute in your way, a small way, and you make a difference. Students leave saying -- I think Amber referenced it and it made me happy because that was the first assignment they did was writing a paper about the power of one. To see themselves there, self efficacy, I can make a difference. I can help in this. I don't have to be the president of Mercy Corps to make a difference. I can help right in this small way.

Often called "pre-flection", pre-departure written reflection papers encourage students to "[prepare] their minds and hearts a little bit for what they are about to do."

While there are many factors to intrapersonal pre-departure preparedness, a very common topic addressed by research participants are flexibility and putting others' needs above your own. Christina asserted, "You are not going to have an easy life." Or as Angela noted, "I do not want students to expect [I] created this whole wonderful education experience for [the students]. It is messy and not all about you...It is about them [as a community]." Repeatedly research participants reported the importance of making students understand that certain components of the course will change at a moment's notice, that vehicles will break down and people will get upset, so it is essential that students remain flexible. While flexibility itself is not an emotion or feeling, a lack of flexibility can lead toward negative emotions that could negatively impact instructor/student, community partner/student, or student/student relationships.

Intercultural pre-departure preparation. Intercultural preparation is the sixth category that research participants reported as being important in the 
pre-departure preparation of a STISL course, which is consistent with the study abroad (Paige et al., 2009) and service-learning literature (Keene \& Colligan, 2004). Intercultural preparation, according to these faculty members, includes both specific and universal cultural knowledge. In terms of culture specific knowledge, research participants consistently reported that it was essential for students to be familiar with components of the host-country's culture, including its history, current political systems, economy, social norms, and language. This pedagogical strategy directly aligns with Keene and Colligan's (2004) assertion that in terms of preparation, service-learning practitioners must provide learners with an anthropological context before engaging in service, from which students will be able to make informed and contextualized meaning out of the experience. Having working knowledge of these cultural components is seen by many research participants as important for students to have internalized so that students have reservoirs of knowledge with which to interpret their experiences in the host country. Isabelle asserted that, "I think if you don't have that basic knowledge going on, you don't even know what questions to ask. It is hard to be curious if you don't have a foundation to draw upon. I think you miss out on a lot." In order to ensure students have a basic understanding of these cultural components, research participants most commonly assign readings, screen videos, or facilitate interactive activities. An example of an activity comes from Isabelle, who designed a game that tests students' knowledge of significant cultural norms and historical events. Similarly, Angela assigns particular cultural 
readings and videos and subsequently has students take an ungraded online inventory, testing their knowledge. Angela also makes it a point to bring the hostcountry's flag to the pre-departure sessions in order to explain the cultural significance behind all of the symbols that the flag displays. Describing these activities, Angela noted,

People have a psyche and a mindset and a lot of it comes from their history. So you have to get into their psyche and mindset of where they are coming from. I teach [my students] some of the history... I am always espousing the importance of that and why is it important to understand what the things on the flag mean. It tells you so much about where the people are now, where they are coming from.

A common pedagogical strategy reported by research participants in terms of specific cultural understanding was for students to generate a list of questions they have about the host-country's culture that they hope to explore through the course. This list is created in the pre-departure portion of the course in response to unanswered questions students have after reviewing the preparatory cultural readings or videos. Students are encouraged to keep the same questions throughout the experience and report what they have learned near the end of the host-country experience.

Universal intercultural preparation appears to be less common than specific cultural preparation, but some research participants reported including cultural understanding, principles of cross-cultural encounters, and interculturalism as pre-departure preparation topics. The purpose of universal cultural preparation is to encourage and equip students to begin to identify with 
the host culture and to practice non-judgmental forms of interpretation. Isabelle provided two examples of pedagogical strategies she utilizes to teach these concepts:

- Questions: Ask students to generate a list of questions they have about the culture. Encourage them to pursue answers to these questions through dialogue with site hosts, host families, international students, guest speakers, etc.

- Observation vs. Interpretation: Present students with an image of a person. Ask them "What do you see?" and record their observations into two categories (observations and interpretations) that are NOT labeled. Next, ask the students how what would label each category. Use this activity as a reminder to students that we view the world through our own cultural lens and that humans are quick to form interpretations of others. Encourage students to absorb the cross-cultural experience slowly and resist forming interpretations early in the experience.

As was described earlier, many dimensions of success overlap, and therefore so

do pedagogical strategies. The above examples illustrate overlapping dimensions because intercultural development requires exploration of the self as a cultural being, which is an example of intrapersonal development.

For her STISL course, Felicia said that a simple metaphor activity during the pre-departure sessions proved to be impactful for students while they were on the STISL course itself:

There is one [lesson] about culture is an iceberg. The part above the surface, and there is so much more below the surface. We kept revisiting that. Students brought that up themselves about, 'I'm seeing more of the iceberg now, our little metaphor.' 
For her students, having the iceberg metaphor in their working memory equipped them to make better sense of the cultural differences that they were experiencing.

Global civic engagement abroad pre-departure preparation. The seventh and final dimension of pre-departure sessions is global civic engagement, or preparation for the service experience itself. This multi-faceted dimension includes different components that serve many purposes, including preparing students to broadly and critically analyze service efforts in general and to effectively and efficiently perform service activities in the host-country itself.

A significant component of the pre-departure service preparation involves the incorporation of literature that critiques both international service and global citizenship itself and students' reflections on those critiques. Sources research participants reported utilizing in order to accomplish this goal includes:

- "To Hell with Good Intentions" (Illich, 1990)

- Lilla Watson's (as cited in Eckerman et al., 2010) speech to the United nations, with the quote, "If you have come to help me you are wasting my time. But if you have come because your liberation is bound up with mine, then let us work together."

- Undergraduate student Talya Zemach-Bersin's (2008) rebuttal in the Chronicle of Higher Education to the assertion that U.S. students have the capacity to become global citizens. Angela instigates discussion and reflection sessions with her STISL

students regarding the difference between academic tourism and international service learning. "Academic tourism, you go down, you dump some service, you had a good time, you come back. Who wins?" As opposed to a 'service dump and go,' model, Angela introduces the concept of sustainable community development, 
which promotes the long-term health of the citizens in the host-country that will persist after the students leave for their home country. Repeatedly, research participants noted that pre-departure preparation was the place to begin the conversation about long-term commitments to sustainable service. The concept of pre-flection as it relates to service-learning experiences is consistent with Toole and Toole's (as cited in Collier \& Williams, 2005, pp. 84-85) assertion that reflection on the service experience should begin before students ever engage in a service activity.

The pre-departure sessions' emphasis on cultural knowledge and students' intercultural development served as a foundation for the notion that was evident throughout the data: that according to research participants, service must be conducted in ways that honor local ways of knowing. So the cultural preparation component is integrally intertwined with understanding sustainable service, either in the host-country itself or back in a student's home country. Many research participants reported that in terms of pre-departure preparation, emphasizing the fact that the community organization had the right to change service activities at a moment's notice based on community priorities was par for the course. In the past some research participants have seen this ambiguity or spontaneity as a catalyst for frustration in the students but made sure to forewarn students so they could be emotionally prepared should this occur.

Pre-departure summary. Overall, the pre-departure preparation portion of the STISL experience is a significant pedagogical component that aims to 
provide students with the background knowledge that equips them to have a significant and meaningful STISL learning experience that leads to the development of global agency. In order to ensure that students have acquired the necessary background knowledge, STISL faculty choose to use a variety of pedagogical techniques (didactic, collaborative, self-directed, reflective) that often correlate with the stages of Maslow's (Harper \& Guibault, 2008) hierarchy of basic needs, specifically physiological, safety, belongingness and love, cognitive, aesthetic, and self-actualization needs.

First, the practical category of preparation is often delivered pedagogically through didactic means that impart basic information regarding how to be physically prepared for (physiological need) and safe (safety need) during the STISL experience. Second, through both didactic and self-directed means, students are exposed to the academic content (cognitive need) of the STISL course and begin to explore how the content may or may not be culturally contextual. Third, students collaboratively consider how to deliver professional skills (cognitive need), such as health care, to the host-community while honoring cultural context. Fourth, students begin to coalesce as a team (belongingness and love need) and explore the concept of intercultural solidarity (belongingness and love need). Fifth, through both reflection and self-directed learning, students intrapersonally examine themselves to understand what makes them uncomfortable (esteem need) and develop strategies to overcome the dissonance. Also, students explore their own culture and reflect on how that will impact their 
perceptions of the experience (cognitive need). Sixth, students explore culture general and cultural specific (cognitive need) concepts through didactic and selfdirected means and then reflect on those concepts; this strives to prepare students to progress from what could be considered ethnocentric view points to more ethnorelative understandings. Seventh and finally, the students explore the concept of international service in general, including critiques of international service, as a capstone of the pre-departure preparation process, preparing students to begin to understand global engagement through the five dimensions of success.

Overall, the pre-departure segment of the STISL course design serves as a foundation from which students can begin to conceptualize how to effectively and efficiently address issues of global concern. Pre-departure preparation ensures that students have the perspective necessary to be able to implement interventions that address human and ecological needs through the application of academic and professional skills in ways that honor local ways of knowledge.

\section{Host-country segment of the STISL course.}

The host-country segment of the STISL course was the most data laden component of this research project. The teaching strategies that the research participants provided were complex, multi-faceted and addressed many of the five dimensions of success at the same time. Additionally, the course design often directly impacted how teaching strategies were implemented and will be discussed in relation to the teaching strategies when possible. In the final portion 
of the host-country findings section, overarching course design strategies will be highlighted and addressed.

Host-Country Strategies. There were many different types of service or global engagement that students performed while on a STISL course. Overall, the service experiences can be classified according two different characteristics: A.) the service preformed (either direct, indirect, or a combination of the both) and B.) the skills necessary to perform that service (requiring a high, medium, or low amount of previously mastered knowledge). This second characteristic will be addressed at the outset, considering skill level required strongly affects course design, pre-departure, and host-country experiences.

Integration of service. According to the data, the host-country service experiences utilized many pedagogical strategies in order to achieve the various dimensions of success, per the Van Cleave Framework of STISL Success. Throughout the data, there is evidence that the service experience was integral in every pedagogical dimension of success. The service experience itself aligns well with dimensions of Kolb's (1984) Model of Experiential Learning, specifically his notion of concrete experience, because the students are actually performing service as opposed to just discussing it, and active experimentation, in that students are able to apply academic or professional skills in ways that honor cultural context. Specific examples of pedagogical strategies that address various dimensions of success will be highlighted as host-country experiences are discussed. 
Also, as noted above, the pedagogical strategies change in relation to the amount of previously acquired knowledge and skills that were necessary in order to perform the service. Therefore, the service experiences are categorized into one of three groups: those that require either high, medium, or low amounts of previously acquired knowledge and skills in order to fully participate in the service experiences themselves.

High level of skill required. Students who participate in STISL courses classified as requiring high amounts of previously acquired skills (referred to as "high" throughout this section) need to be very proficient in a specific academic discipline or a certain skill set well before the STISL course began. Pedagogically, these courses focus less (and sometimes not at all) on students developing skills in order to perform the service activity, because students were already expected to have previously mastered these skills through their academic coursework. So instead of pedagogical strategies for skill acquisition, high STISL courses pedagogically focus more on the application of professional skills through service activities in culturally appropriate ways. There is a clear connection with the intercultural pre-departure preparation and students' ability to make culturally sensitive decisions when it comes to service implementation.

Both "Intercultural Development and Physical Therapy" in Ecuador (Barbara) and "Inter-Professional Promotion of Health in Elders" in Nicaragua (Angela) provide healthcare services for residents of the host-community. In the months leading up to the host-country portion, both courses abstractly 
conceptualize what it would mean to deliver culturally sensitive healthcare services for residents of the host-country, with very limited access to what may be commonplace supplies in the United States; students also devise a plan of action for the host-country component. As a pedagogical strategy, both high STISL courses equip students (under the guidance of the faculty member) to design what the actions (abstract conceptualization) will be during the service experience and to acquire any materials that may be needed.

Both courses provide students a concrete experience in the host-country of actively implementing (active experimentation) healthcare services that they had abstractly conceptualized in the pre-departure segment of the course. Professionally and academically, the pedagogical strategy of implementing healthcare services with limited resources aims to help students identify how to deliver the best healthcare possible, even if access to medical supplies is limited. Interculturally, both high STISL courses' service experiences expose students to ways of life that are in many ways different from the students' home culture; students are able to practice delivering health care (often in light of language barriers) that is both high quality and culturally sensitive. Additionally, in relation to experiential education, both STISL faculty members pedagogically determined that the groups live with the host-communities, which facilitates making meaningful interpersonal relationships with individuals from different cultures. 
Medium level of skill required. The next group of service experiences can best be categorized as requiring medium amounts of previously mastered knowledge (referred to as "medium" throughout this section). With medium STISL courses, students had to learn specific material before they arrived in the host country; however, unlike the high courses that took years to acquire, the necessary knowledge could be gained in the months or weeks leading up to the STISL courses.

This research project identified three medium STISL courses, one that participated in direct service (Healthcare for Rural Families and Women," in Andhra Pradesh, India taught by Gail) and two that performed indirect service (Women's Development and Microfinance" in Northern and Central India taught by Christina and "Health and Migration" in Mexico taught by David). The program with direct service experiences resulted in immediate benefits to the community that were readily seen, felt, or in some other way experienced. The two indirect service experiences gathered data from which the class later produced a written report, which community organizations could use to inform their practice.

All three medium STISL courses required that students have specific knowledge in order to preform pre-arranged service activities, which were identified by the community partners, not the students or the faculty. This is different from both high STISL courses, where students and faculty are presented with a community need and are charged with designing appropriate (healthcare) interventions based on professional skills and intercultural knowledge. 
Healthcare for Rural Families and Women is an example of a medium STISL course where the service to be preformed is clearly articulated; however, students are charged with preparing for and implementing the service when in the host-country. For example, the community partner associated with this course asks that the students teach basic tenets of health education for disease prevention and health maintenance but does not dictate how to accomplish the task. The STISL faculty member for this course then charges students to design activities, lessons, or other community education programs that will meet the community's needs but also honor their culture and context. With this course, some preparation is necessary, but this preparation is not as extensive as high courses delivering highly skilled healthcare services.

The second medium STISL course, Women's Development and Microfinance, is designed in a manner that heavily relies upon generic academic skills, such as writing, as well as general knowledge about microfinance. The faculty member for this course and the community partner have designed numerous one-time, low skilled service activities so as to provide students with the context necessary to perform a larger indirect service project, like a strategic plan or an analysis of microfinance practices around the world and how those practices can improve this particular community partner's work.

Students will be visiting, interviewing, and participating in administrative and community programs at the NGOs as well as having the opportunity to interview and assist with organizational activities in field settings. Students will learn about microcredit, microfinance, agency administration, client needs and the like. Finally they will be able to share 
their own experience and expertise in nonprofit and non-governmental programs that can assist the NGOs develop tools in communication, planning, fundraising, governance, staff development, grant writing, etc. All students will make presentations, and in some cases, develop written materials for the NGOs we will be visiting.

As opposed to performing direct service for a community (that immediately benefits the community), this particular course's service activities were more focused on building the capacity of international NGO's through research and long-term planning.

Similar to the course previously described, "Health and Migration in Mexico" also requires medium skill in order to apply academic research skills at their service project, which includes producing a final report from which the partner NGO can make decisions about future action. In terms of service experiences, this STISL course also requires research-based service activities that aim to equip NGO's to improve their practice. While this course has been taught numerous times over many years, the most current iteration relies on a two year service model, where students from subsequent years will build on previous courses' research. In the first year of this two-year model, students will:

Develop a needs assessment and action plan for the second year students to follow up on. The assessment will contain all relevant findings about prevalence and distribution of diabetes in Oaxaca, especially among indigenous populations. The assessment will be based on first hand observations and visits to a number of key stake-holders including a rural clinic, a traditional village healer, the food bank of Oaxaca, the Center for Attention to the Migrant, the Center for Population, State of Oaxaca, the public health authorities. This report will be produced in Spanish and English and distributed to interested parties in Oaxaca. The report will conclude with suggestions for next steps, to be taken up by subsequent 
...classes. A preliminary report to invited guests in Oaxaca, and a public presentation at [our home institution].

As with Women's Development and Microfinance in India, this course required that participating students have generic academic skills, such as data collection, data analysis, academic writing, and effective presenting, but students need to acquire additional knowledge in the months preceding the course in order to produce the preliminary report. Therefore, in order to fully participate in the service experience and accomplish the goal of writing the assigned report, students needed to learn more about the history, culture, and context of the social issues being investigated in Oaxaca.

Low level of skill required. The final category was the most predominant categorization identified through this study; five STISL courses required only low amounts of previously acquired knowledge and skills in order to perform the service required for the course. Every low STISL course was available to students from any academic discipline, and none performed any service that required prerequisite knowledge in order to effectively accomplish service activities. Overall, in addition to exploring academic areas of interest, the research participants noted the significant role that interpersonal relationships between the students and the community partners played in the learning experience.

Low STISL service experiences varied in terms of the duration of each project and the number of community partners. Because there are very few skills required to perform the service, some courses such as "Mexico Emigration and 
U.S. Education" (taught by Ethan) partner with numerous NGO's that address a multitude of community needs including prison conditions, humanitarian aid for people attempting to cross the Mexico/U.S. border, and a Chicano memorial park. Each of these NGO's were visited by the STISL students for only one day, and student work primarily consisted of building relationships and hearing the stories of individuals impacted by emigration/immigration. Each community partner in this course provided a guest lecture that outlined the organization's goals and mission and invited students to participate in a day of service alongside a community leader. As opposed to other courses, this course emphasized the relationship between the students and the community issue being investigated. Concepts of identity, perception, and cultural norms were significant learning strategies for the RP who facilitates this course. One example of a service activity that the students performed was going into a Mexican jail and speaking with inmates about their lives and how they ended up incarcerated. There is little evidence of tangible impacts that this STISL course had on the community it worked with, considering the affective and relational service activities in which the students participated. There is no evidence that there were any prerequisite skills or knowledge that students needed to have acquired before participating in this STISL course.

Both "International Community Service in Action" in Nicaragua (taught by Jacqueline) and "Social, Educational and Health Services" in Tobago (taught by Felicia) also partnered with numerous community-partners, including a public 
health group, a hospital and other health clinics, schools, schools particularly for children with disabilities, centers for adults with disabilities, and a private orphanage, but instead of students switching community-partners throughout the course, some of the students served with each partner for the duration of the course. In terms of service design and integration, these research participants work with students to identify where they would like to serve based on their skills and areas of interest. The design of the service experience was not focused on implementing any specific skills, but rather served to expose students to and provide context for the various social and environmental needs of the hostcommunity.

Unlike all other STISL courses investigated in this study, the faculty member for "History, Culture and International Development" in Costa Rica (taught by Isabelle) does not have direct relationships with the community partners involved in this STISL course and instead partners with a co-instructor who owns an independent "educational company that... bring[s] US citizens to Costa Rica for educational immersions, typically service learning immersions." The RP has primary teaching responsibilities for the course, while the owner of the educational company is responsible for logistics and service placements. It is unclear how community partners are identified; however, similar to the Tobago and Nicaragua courses, the service experience provides a concrete experience for long-term abstract conceptualization for global agency. The service experience in Costa Rica is strategically designed to put students directly in contact with a 
community need and community members, through which students develop meaningful relationships. Relationships with community members are in a very strong sense a significant pedagogical strategy for developing culturally contextualized solidarity. Isabelle went so far as to say that she really didn't care what service activity students experienced, as long as they developed meaningful relationships with the community members.

Integration of service summary. In summary, there are three different categorizations of the amount of previously acquired knowledge and skills related to the integration of service activities associated with these STISL courses: high, medium, and low. In terms of service as a pedagogical strategy for academic success, the service experience itself served as a laboratory for implementing abstract conceptualizations formed during the pre-departure preparation segment of the course, and conceptions were further refined through concrete experiences. All levels of service were designed to expose students to service experiences that were implemented with cultural context (through direct contact with host-community members), from which students could learn more about how culture impacts how service is best implemented.

For professional success, service experience design varied between high, medium and low. For high STISL courses, and to some extent for medium courses, service experiences were designed so that students could apply professional skills (primarily healthcare related) to a specific cultural context. High STISL experiences required that students be highly skilled practitioners in order to 
efficiently and effectively participate in the service experience. Medium and low STISL experiences were designed in ways that exposed students to a communityidentified need and encouraged them to explore ways that professional skills, or potential professions, could be used in ways that met global needs. Therefore, exposure to and participation in meeting a community-identified need was a significant pedagogical strategy.

Faculty also utilized pedagogical strategies through service implementation as a means of equipping students to achieve interpersonal success. Across skill levels, many research participants reported that students, by serving with other classmates, developed integral interpersonal teamwork skills (such as collaboration and compromise) in order to meet a community need. Often, students were presented with a community need and subsequently assigned to collaboratively design a service activity that met the community need in a culturally sensitive manner. Additionally, service experiences were always designed in a way that put students in direct contact with host-country citizens, thereby increasing the likelihood that students would develop meaningful interpersonal relationships with individuals from a different culture. This strategy was directly related to the concept of developing culturally contextualized solidarity and global competence.

For intrapersonal success, the service experience functioned as a laboratory of sorts, in which students' experience meeting a communityidentified need helped form meaningful intercultural relationships from which 
they were encouraged to reflect upon how the experience would impact their future global engagement. This is directly related to the concept of culturally contextual solidarity as well as future global engagement in light of professional skills. Considering reflection is such an integral strategy for intrapersonal development, it will be discussed in great detail in a subsequent section.

Finally, in terms of intercultural success, the service experience design serves as a significant mechanism for applying abstract conceptualizations of culturally appropriate service to the concrete experience of actually implementing it. Serving alongside host-community citizens, students performing STISL experience a "real world" example of how both academic and professional skills can best be applied to a community need. Additionally, similar to interpersonal designs for success, the STISL service experience puts students in direct contact with host-community citizens, where students are encouraged not only to demonstrate behaviors and attitudes that honor local knowledge, but also to form meaningful relationships with the citizens themselves.

Overall, the service experience serves pedagogically as a laboratory for applying academic, professional, interpersonal, and intercultural knowledge to a "real world" problem. Students are faced with analyzing what worked, what didn't, and what should change in order to successfully meet a community's needs while honoring the community's identity. Related to Kolb's (1984) Model for Experiential Learning, the service experiences serve multiple functions, including providing a place to actively experiment with the implementation of 
abstract conceptualizations that were formed during the pre-departure segment of the course through a concrete service experience. Students are then able to tangibly observe and later reflect on those observations, something that equips them to become agents of global action.

Reflection. Reflection is a significant pedagogical strategy that research participants rely upon in order to equip students to make meaning from their service experience in relation to the academic content and is thought to be "probably the most important learning of the whole experience" (Barbara). This is consistent with Collier and Williams' (2005) assertion that "reflection serves as a bridge for the back-and forth connecting between what [students]... learn in class and what [they] are experiencing in the community" (p. 83). Reflection also encourages students to explore their own identity and intrapersonal conceptualizations of self; this is significant in order to make meaning, mirroring principles of transformative learning (Mezirow, 1991).

Reflection is embedded in nearly ever aspect of the STISL experience, including pre-departure, host-country, and during re-entry, which is consistent with Toole and Toole's (as cited in Collier \& Williams, 2005) service-learning cycle and serves two purposes according to the data: A.) being the primary mechanism where students are encouraged to make connections between what they have seen and experienced through the service experience and the academic content that is being explored and B.) serving as an important assessment technique regarding learning, thus providing the faculty members an opportunity 
to see what is working, what needs to be changed, and how to implement those changes in light of the host-country context.

According to the data, reflection is facilitated utilizing multiple modalities, including: A.) written reflection (reflection journals, reflective papers) and B.) oral reflection (one-on-one reflections with faculty members and both small group and large group reflections with classmates).

Written reflection. There are two main types of assigned written reflections that are associated with STISL courses: reflection journals and reflection papers. Reflection journals are a key pedagogical tool for facilitating reflection and serve as a central place to collect students' intrapersonal reactions to what they are experiencing and their interpretations of their service experience through the lens of the academic and intercultural components they are exploring. This aligns with Paige and associates (2009), who contend that reflection journals serve as a record of experiences, as a reference for culture and language learning, or as an emotional coping mechanism during the stresses of cultural adjustment (p. 179).

The reflection journals often contain very personal information about what the students are thinking, feeling, and doing. Some research participants mentioned this tension, and either made submission of the reflection journal optional, encouraged students to keep two journals (one that the students would not have to turn in and one that the faculty would review), or told students that they could have PDF copies of their journals, should they want one. Consistent 
with Williams and Van Cleave's (2012) assertions in a research project that investigated meaning making in a STISL course, reflection journals provide insight into transformative and significant learning experiences that students may be undergoing, but not verbally expressing.

The reflection journals' entries vary in structure, but they often contain three main components: observations, reactions to the observations, and connections between students' consciousness of self, observations, and learning in light of the course content and experiences. These three components are well aligned with principles of the Social Change Model (Higher Education Research Institute - UCLA, 1996) and Whitney and Ash's (2011) DEAL model of reflection, which include

Description of experiences in an objective and detailed manner, Examination of those experiences in light of specific learning objectives (in the case of service learning at least in the categories of academic enhancement, civic learning, and personal growth, and Articulation of Learning. (p. 156).

Gail states that her structure for reflection focuses on "anthropology sort of observations. [With questions like] What happened today? What did you notice about this and this and this and how did you respond to it?" Within these three seemingly simple questions, students begin to explore concepts of intercultural, interpersonal, intrapersonal, and even academic learning. Other research participants alluded to an anthropological foundation of observation and reporting, in addition to emotional reactions to the observations. Taking reflection beyond observing STISL faculty use reflection to connect observations 
with feelings and course content through instructor-guided prompts, such as "how do you think this experience impact your actions when you are home", which is consistent with the literature (Ash \& Clayton, 2004; Collier \& Williams, 2005). These prompts encourage students to relate their experiences while in the host-country to the academic course content. For example, Jacqueline asks her students to "explain your opinions about the [service] project based on your knowledge of themes and concepts of international development."

The extent to which faculty read and used the journals varied. Ethan required that students submit their journals (the students were able to obtain a copy if they requested one), which he keeps for multiple reasons:

I keep them, actually. I tell them the first day of class, I am going to keep every one of your journals... I tell them that I will take parts of their journals and will use it for sharing out the stories, to share out your story. I won't use your name but I will pull from these journals and I will use it to help get funded for future classes and to help share out why we need a class like this.

Ethan also uses the students' journals as secondary data for his research agenda, including conference presentations and scholarly papers. Ethan was the outlier in that he did not give students their journals back and thoroughly combed the journals for data.

Due to the intrapersonal content, many research participants who required reflection journals either did not read them at all or gave students the option of submitting them, for fear that students would not fully express themselves if they were aware someone else may read the journal. As Jacqueline 
noted, "I actually don't read [the reflection journal] often... Sometimes they ask me not to read them, too. [The journal] is really for them." This is not to say that students do not get graded on their reflections for Jacqueline's course, because at the end of the course students use their reflection journal to create a five-minute graded summary presentation, in which the students are asked to recap, synthesize, and analyze their reflections for the whole class. Having students use their reflection journals to inform their final assignment was a common practice for many of the research participants.

As will be described in the re-entry section of this paper, revisiting reflection journals helps to remind students of significant experiences and helps them use those experiences in future global civic engagement efforts. Gail has students use their reflection journals as an account of their "first impression" about a subject, but then also assigns a separate reflective paper that revisits the students' first impressions and asks them to articulate a "second impression" after the student has had time to find deeper meaning and make more significant connections between the experience and the academic content of the course.

Written reflection papers were a significant pedagogical tool that STISL faculty utilized in order to equip students to make meaning out of the STISL experience. Often, faculty who chose not to read students' reflection journals chose written reflection papers as a way of better understanding how students are individually experiencing the STISL course. While this knowledge could also be gleaned through oral reflection (which will be discussed in the next section), 
some research participants noted that some students do not feel comfortable sharing during the group oral reflection sessions, so writing fits better with their particular learning style. It is important to note that written reflection papers during the host-country segment of the STISL course were not as common as in the pre-departure (as discussed in the pre-departure section of this reports findings) and the re-entry segments (which will be discussed in the subsequent re-entry findings section), but were still utilized as a pedagogical strategy in order to facilitate student meaning-making.

Specifically, written reflections were typically short, handwritten documents in response to an instructor guided prompt, very similar to the anthropological observations that were discussed in the oral reflection findings section. In addition to their observations, students were encouraged to use the reflection papers to make connections between these observations, the academic content of the course, and cultural context. For example, one prompt from an RP asked students to briefly talk about how their service experience and hostcountry cultural experiences had changed the way they thought about providing service in a contextual way that honored the host-country's identity and cultural values.

Written reflections were also more heavily utilized during the pre-re-entry component of the STISL course, while students were still in the host-country. Through writing, one RP asks students to articulate commitments that the 
students are willing to make in terms of future actions that have the potential to positively impact either local or global communities.

Oral reflection. In addition to written reflection being a significant pedagogical strategy employed during the STISL host-country segment, oral reflection also served as an influential and important strategy. Overall, there were two primary modes for oral reflection including oral group reflective discussions and oral one-on-one reflection with the faculty member.

The first mode of oral reflection is group reflective discussions, which are faculty-led interpersonal discussions between either the whole class or a small group that primarily focus on anthropological observations and personal perceptions of the service activities. Gail described questions that she poses to her STISL students during reflection discussions:

[I ask the students, ] 'What happened today? What did you notice about this and this and this and how did you respond to it?' Hopefully they are encouraged to look, again, both personally and educationally at the world in a slightly different way than maybe they are getting in the classroom.

Cultural differences were a common topic of discussion during oral reflections.

One strategy employed by research participants involves tying written reflections in journals with oral group reflections, where students are provided a prompt (similar to the prompts mentioned by Gail above) and are subsequently asked to share significant learning experiences that they articulated through the reflection journal with the group. Another specific example of the journal/group reflection technique is having students list as many of the cultural differences they saw in 
one day as they can and then having them share the list with the group. Together the students discuss which of those differences were exciting and which were confusing. By sharing their thoughts and observations with the group as opposed to the thoughts only being recorded in reflection journals, students discover that their classmates may be struggling with making meaning out of similar experiences. By sharing and possibly identifying with other students' experiences, students are more likely to grow as a cohesive team unit and to empathize with their classmates' perspectives and values; they can then provide support during stressful or strenuous experiences.

Ethan elaborated that students are often tired but still need to participate in the reflection discussions and described how he uses the sessions as a place to better understand how students are processing the experience on individual levels:

I think it is important. It is a big piece of it. I tell them that regardless of how tired they get while we are [there] that we are going to debrief every day. We are not just going to do the experience and then go home or do what we want to do. We need to talk about what we saw. We need to discuss what we saw and how we felt, what questions we have, because some folks may have -- you have different lenses. People are looking at it through different lenses. Some people may look at it through a lens that I think may not be a good learning experience.

Barbara noted that it is during the oral reflection sessions that she is able to identify if a student is struggling and provide what the student needs in order to better make meaning out of their STISL experience. Research participants feel that by gathering in a group setting everyday (or almost every day) they can 
examine student's body language and (lack of) communication; the faculty member may then instigate a one on one discussion with the student to better understand how they can support the student.

Though oral reflection sessions were not graded, research participants felt that they were integral to the STISL experience. In order to ensure that all students participate in the session, Isabelle noted that it is important that students feel comfortable with one another, that they feel their input is valued, and that everyone has a chance to share:

Team building in the very beginning is so important if you want people have a voice. The more comfortable people are with each other, the more likely they are to speak. Over the course of two weeks together, I would say it would be very rare for a student to not speak up in any way as part of our group gatherings...One of the phrases I say over and over again is, 'Is there anyone who has not yet had a chance to speak who would like to make a contribution'. That is kind of my code phrase for those of you who are talking a lot, shut up and leave some space for folks who might have something to say. Again, we know the students well enough that I might say...'you haven't said anything today. It looks like you are really thinking about your time or it looks like you had a hard day at the site. Are you willing to share with us what is going on?' If things are really bad, I would use a talking stick, for sure, but usually it doesn't come to that.

In addition to oral group reflections, STISL faculty also utilize one-on-one discussions (between the student and the faculty member) as a pedagogical strategy for reflection. These one-on-one reflections usually take place as the group is traveling to a service site or during free time when there are no structured activities. As one RP noted, the faculty on STISL courses are constantly around the students, so finding one-on-one time is not an inconvenience. 
As opposed to the oral group reflections, one-on-one reflections are often unstructured, free-flowing, and student-focused. Rather than have pre-designated discussion questions, faculty rely upon their own intuition regarding what to ask the students individually. Questions are generally simple, such as 'how are you doing, what questions has this experience stirred up in you, or is there anything you need from me in order to better support you?' Also, based on group oral reflections or submitted reflection papers or journals, a faculty member may ask more specific questions that help a student to make meaning out of the experience. For example, if a student is reserved during the oral group reflections, the faculty member may ask if the student feels comfortable talking in the group or if there is anything that is bothering the student. Also, as with Felicia, who noted that many female students felt sexually harassed by the host-country's men, this faculty member may pull an individual female student aside for a discussion to ensure that she feels adequately supported as she is experiencing a very dissonant experience from her normal way of life.

Generally, one-on-one reflection times are not necessarily focused on academic content; instead, they address intercultural, intrapersonal, or interpersonal dimensions of the experience that may be puzzling or confusing to the student. No research participants mentioned that they intentionally schedule one-on-one discussions with each student, so they instead rely upon their own observations to determine when a one-on-one discussion would be helpful. 
Reflection summary. Reflection, both written and oral, is a significant pedagogical strategy for STISL experiences. In general, reflection strategies encourage students to articulate observations and report the significance of these observations through academic, intrapersonal, and interpersonal dimensions; STISL faculty can use reflection to best evaluate how students are experiencing the STISL course and thereby develop individual strategies to support the student. Also, logistics may play a role in facilitating reflection. For instance, both David and Henry have limited group reflections during the experience because of the home-stay lodging that these faculty members have chosen for their courses. This is not to say that home-stays preclude group reflection, but they do make it more difficult to find opportunities for group reflection time.

Assignments. Outside of service activities and reflective exercises, there were relatively few assignments that STISL faculty assigned when students are in the host-country. However, there are a few examples of non-service-related, nonreflective assignments that students were required to accomplish while in the host-country. While the assignments themselves were considered non-reflective, they may be used as experiences that can later inform reflective journaling or discussions. Additionally, while they did not directly apply to the service experience, the intercultural lessons that faculty aimed to teach do inform students about intercultural application of service, overall global competence, and interpersonal relationships with host-country citizens. 
Immersive language lessons. One example of host-country assignments includes language courses, a form of educating for global competence; both David and Henry's STISL courses required them:

They do participate in a language school while they are there. That is part of the program. We have wanted to increasingly integrate the language school into what they are doing in the project. So the first year that I was there, the language school was just general language development. Because it is a small language group and they are wonderful about adapting to the needs of our students and the purposes of this trip, this time we asked the language school to focus the language develop on the skills that the students would need to do their surveys in the mercados, so the students were better prepared language-wise of what they were going to do.

Research participants report varied levels of language lessons, ranging from instruction by host-country faculty members to less formal community-based language instructions from a private language instructor. In both instances, language lessons were taught to the class as a whole and did not include students from the host-country in the classes.

Three questions. Another example of a host-country assignment actually spans the pre-departure and host-country segments of the course. For his STISL course, Henry assigns students to develop three questions that they are to pose about the host-country and the issues it is facing before ever leaving the home campus. Students are encouraged to develop questions in relation to the intercultural context, the academic discipline, and long-term global civic engagement and culturally contextualized solidarity. Upon arrival in the hostcountry, the students submit proposed answers to these three questions, and 
Henry provides quick feedback on each essay. Then, as the course progresses, students are asked to reevaluate their initial conceptions regarding the questions; this reevaluation is submitted to Henry for feedback.

[The] essay is given to me on arrival in Oaxaca. I give them a quick turnaround in terms of comments and observations. Then their responsibility, in addition to the day-to-day participation and activity, is to pursue deeper understanding of those. Now, they might talk with their host families. They may talk with their teachers. When we are visiting organizations they be asking questions that engage the topics they have identified. At the end of their time in [the host-country, before they arrive home] their responsibility in terms of this assignment is to...and rewrite the essay through the lens of what have we learned.

Interviews of host-country community members. The final example of an assignment during the host-country component comes from Felicia, who assigns an interview exercise for all of her students to submit while they are in the hostcountry. This interview assignment aims to address many components of their experience, including intercultural, interpersonal, and academic issues explored in order to increase students' global competence and sense of culturally contextualized solidarity.

We also have them interview somebody and they have to present the questions to use ahead of time. Then they write up a summary of the interview. But they generally interview somebody, so if they are in a health care setting, they interview somebody in that setting like a nurse or a physician. If they are in an educational setting they interview somebody from that setting, social service. They usually interview somebody from the kind of setting where they have been doing their service learning. I think they gain an understanding, sort of a deeper understanding of the challenges facing people and sometimes frustrations. (Felicia)

Host-country assignments summary. These three examples do not fully encompass all of the assignments required during the host-country component of 
the course, but instead detail some of the non-reflective assignments that students are required to submit while they are in the host-country. These pedagogical strategies, combined with the three constructs of culturally contextualized solidarity, global civic engagement, and global competence, facilitate the development of global agency, as will be described later by the introduction of a new pedagogical design framework.

In terms of the three factors of success, all three of the above mentioned assignments aim to develop students' global competence by increasing language proficiency, pursuing answers questions related to culturally specific social or environmental issues, and learning more about the culture-specific perspectives of host-country community members.

For culturally contextualized solidarity, the language lessons appear to improve communication between the students and the host-country citizens, deepening the level to which students can form meaningful relationships with people who speak a non-English language. Both the three questions assignment and the interview assignment expose students to culturally contextualized community issues and equip students to develop empathy for and solidarity with the host-community members.

Team teaching. This research project discovered a logistical and teaching strategy that has not yet been noted in the literature. Only one faculty member (Felicia) who participated in this study traveled with only students and no other supportive instructional or logistical partners. Overall, there were five different 
ways that the STISL faculty collaborated with other professionals in order to facilitate the STISL course. Most commonly, two faculty members from the same institution co-taught the course. Gail, David, Henry, Ethan and Angela were all coinstructors with other institutional faculty members (adjunct, fixed-term, and tenured faculty members). For these five STISL courses one instructor served as an STISL mentor for an instructor who was new to the STISL pedagogy.

Instead of having co-facilitators that were faculty members, Christina taught her STISL course with the support of alumni who had already been on the course or were experienced nurses that were willing to supervise student service projects.

I always take other people with me. I don't go just by myself... As it has gotten bigger and bigger, I don't go with myself, because I have to have other nurses... I always had nurses and students together... It is really, really good if I can take people back who have already been. They went as students and now they are going back as nurses. They have a much better understanding of the culture and can help the students work through things.

Jacqueline consistently has administrators or community members from her home country accompany and help facilitate the STISL course. Part of her rationale for including administrators as co-facilitators is to ensure institutional support for her program. Barbara utilizes a teaching assistant with a background in physical therapy as a co-instructor and co-facilitator on her physical therapy based course. Finally, Isabelle, as previously mentioned, contracts with an external experiential education company to handle most of the course logistics, arrange service projects, and serve as a cultural insider for the STISL course. 
Research participants consistently asserted that teaching an STISL course without support during the experience would be difficult. Since students struggle with making meaning interpersonally or interculturally with what they are witnessing, the research participants believe that they have to be both physically and emotionally present in order to assist students through this process. However, considering how taxing these courses are for faculty, through coteaching faculty have the opportunity to rest while a co-instructor provides the necessary support for students. Isabelle contended that "I think what hinders a lot of people is it is hard to instruct these courses alone. It is just too much to take on, on your own. It is really important to have a co-instructor, [but] the funding structure hinders me." Similarly, Jacqueline noted that securing funding to cover the costs of two facilitators versus one is sometimes difficult but is worth the expense. "It is probably better to have two people, just in the event that there could be a difficulty, but financially that is tough, paying for two leaders is expensive."

Cultural insiders. In terms of the overall STISL experience, STISL faculty members consistently rely on host-country citizens to serve as 'cultural insiders' to provide students with supplemental instruction, expertise, and perspectives that STISL faculty members cannot provide; this practice is consistent with the international service-learning literature (Chisholm, 2003). Through this investigation, only one RP identified as a member of the host-country cultural 
community. This RP is Latino, speaks Spanish, and has a scholarly agenda that correlates with the topics being explored through the course.

While only one RP was considered a cultural insider, other research participants had spent extensive amounts of time in the host-country. One RP had facilitated over twenty trips to Mexico, although her course was not in that country, and was able to speak Spanish fluently. While she may perceive herself as being somewhat of a cultural insider in Mexico, she did not express that this partial insider status necessarily translated to the other countries where she taught STISL courses. Another RP had facilitated over fifty international courses to Mexico, where he also spent time through out the year pursuing his own scholarly agenda. He consistently partners with faculty members in the hostcountry on academic projects and publishes in scholarly journals in the hostcountry's language. While he feels that he is able to offer students deeper insights into the host-country's culture, he was not born and raised in the host-culture and still might not be considered a cultural insider.

Many research participants ameliorate their lack of insider status by partnering with local universities and community organizations that provide the option for a cultural insider's perspectives that can be incorporated into the course experience. Many research participants noted that a local community partner provides an invaluable cultural resource for the STISL course. Cultural insiders from community organizations are able to assist STISL faculty in implementing culturally appropriate service experiences and provide in depth 
insight into how the local culture impacts the issue that is being addressed. For some STISL courses, community-organizations provide 'hosts' that conduct lectures or class sessions that give students salient historical and cultural information related to the course content. Additionally, hosts sometimes arrange visits to historical sites that allow students to experience culturally significant components of the host-communities' cultures. Other STISL courses, such as the one facilitated by Ethan, work with numerous community organizations; representatives from these organizations discuss with students how service is conducted through cultural lenses specific to the host-country's context.

Local academics have also provided students with an insider's perspective on the issues being studied through the course. Henry consistently partners with local universities in order to supplement students' learning about the course topic through a cultural insider lens:

If we are doing something in migration, somebody in [the host-country] from the university has worked on that, then I'll arrange for students to meet with that person. We will get a lecture from that person, just in the same way that we would engage any professional. ...[The students] get observations, comments, they get challenged on something. That way it gives [the students] a better understanding.

For her course in Costa Rica, one RP partners with an international education provider that co-instructs the course, although he is not the faculty of record. This co-instructor is Costa Rican and arranges all of the service experiences for students. This RP feels that her co-instructor, as he is from Costa Rica, is able to handle logistics that she would not be able to arrange and is able to 
provide students with a meaningful local perspective that they might not otherwise hear.

Reciprocity. In terms of reciprocity, research participants were asked to articulate what they thought constituted a reciprocal relationship with an international community partner and were subsequently asked if they thought that they had a reciprocal relationship with their international community partners. For the purpose of this report, the concept of reciprocity is nested under the theme of the cultural insider, because the vast majority of research participants related the concept of reciprocity to the individuals or groups that served as the cultural insider for the group.

While some research participants noted components of reciprocity that extend beyond the time when students are in the host-country, data show that the vast majority of the acts of reciprocity take place during the host-country segment.

While many research participants had considered reciprocity as an important component of a relationship with a community partner few had given it much consideration. Regardless, research participants' responses mirrored Cress and Patton's (2005) conceptualization of a "symbiotic relationship" (p. 118). Christina noted "I've never really had to worry about it." She elaborated that she has never had a problem because she has met with them before the experience in order to discuss both groups' expectations. 
I always let [the community partner] know what our expectations are, what the goals are, and then I always want to make sure that we are meeting their goals and what they are doing and that what we are doing is promoting their work.

David asserted that reciprocity is "extremely important" and reiterates Christina's thought that the teaching strategies employed through a service activity must actually fit with the community organization's articulated needs. Furthermore, he says that "legitimate service and legitimate learning... [serve] both the community organization's needs and also the students' needs to as learners." Understanding the host-community organizations' needs is sometimes, according to David, more difficult than in domestic settings. "Internal organizational dynamics and those things are always more opaque in international and cross-cultural settings."

For Henry, who spends extended time in the host country beyond the STISL courses, "reciprocity is a fundamental value [in the host-country]," but he also believes that reciprocity is always defined or expressed in the same way: "I think that the ways that [reciprocity] may be expressed will be contextual in culture, to the extent that our culture tends to value what I'm calling reciprocity, that there is a clear cause and effect relationship." Calling on his 45 years of experience in the host-country, Henry noted that reciprocity in the host-country's perspective is not "tit for tat", but rather a much more complex and intimate concept. Henry asserted that reciprocity in the host-country's perspective is, "'I do things for you because I value you. I think you are important. You do things for 
me because you think that I am important.' Furthermore, reciprocity is a longterm commitment in that I will do something for somebody and they may not be able to reciprocate for ten years, but [they] remember."

Overall, reciprocity can take many forms and includes both immediate benefits to both parties, where both groups can "cash the check right then" (Angela), and other forms of reciprocity that "will be cashed some day in the future" (Angela). Research participants seem to conceptualize reciprocity as a multi-faceted process that may fall on a continuum spanning immediate and longterm benefits to both students and the community partner.

As was already articulated, many research participants believe reciprocity entails understanding a community organization's needs as the community sees them and responding through service to fill those needs. In turn, community organizations reciprocate by allowing students into the host-country to participate in and learn from "meaningful" (David) service experiences:

Students need [service experiences] to be a legitimate service project. I think students' investment in [the service experience] and satisfaction goes down if it feels to them like made-up work, if it feels like they are doing something for their own learning or enjoyment but there are not sure what difference it actually makes in the community.

Reciprocal relationships must include listening to what a community partner identifies as its own needs and providing forms of service to meet the needs. As Angela asserted,

"[w]hen the [host-country] says they want something we try to provide it...[when a community partner] says 'oh, could you come and do a training 
on this and this?' Yes we can! They get the training that they asked for and my students get the benefit of [providing the training]."

Some research participants (Gail \& Felicia) note that sometimes, responding to community partners' needs is spur of the moment and can vary from year to year. For some students, the spontaneity of service or the last-minute changes to service activities can be frustrating.

Also, some STISL faculty members believe that reciprocity with an international community partner includes a financial contribution from the institution to the community partner. Gail admits that some people may not think that financial contributions are legitimate, but "I actually think is legitimate." David also agrees that financial contributions to the community partners are a legitimate form of reciprocity and considers the money to be "honoraria for all the time of the organizations that our students visit and get involved with." He admits he has experienced blowback from his institution regarding honoraria because "student loan situations and their scholarships and finances are coming under increasing scrutiny..." Ethan also includes honoraria as a part of a reciprocal relationship with his community partners; he notes that one of the many reasons that he started this course was to help fund the community organizations themselves:

When I started this class, I did it for several reasons. One was a learning experience for our students. The other was to get money to these organizations. At [my institution] we can't just give money, donations. We give them honoraria. It was basically a way for us to hire them to do what they do, and for us to tag along... For some of these organizations, they get very little money and it is very helpful for them. 
Regarding financial compensation for community partners, Angela suggests: "[t]hat is a nice business agreement. That is how businesses are run. You stay at my house, you pay me money." However, she noted that for her context, financial contributions are not necessarily sustainable for the community organization unless "one forms a relationship and returns ever year so [the group] knows they can count on that income."

The final manifestation of reciprocity does not involve the students and the community partner, but instead emphasizes a direct reciprocal relationship between the community partner and the faculty member outside the STISL course. There are many different ways that STISL faculty members have engaged in reciprocity with community partners. The first way faculty reciprocate is by incorporating the needs identified by the community partner in faculty members' scholarly agenda. For example, Christina described a research project that she has undertaken exploring the impact of photo memory books on host-country children who have experienced significant loss and grief. Henry has published numerous articles in scholarly journals with community partners and hostcountry academics that explore environmental and health issues plaguing the community; these issues are also explored through the STISL course. Additionally, Henry and Ethan mentioned hosting community partners and host-country academics (who participate as guest lecturers for the STISL course) at their home 
institutions, either as guest presenters aiming to raise awareness regarding the issues facing the host-country or visiting scholars in academic departments.

Regarding whether research participants thought that they had reciprocal relationships with their community partner, these faculty members reiterated prior assertions that reciprocity with community partners through STISL courses is a complex concept. Most noted that in the short-term they feel that they have reciprocal relationships with their community partners. Whether they provide honoraria or services, the research participants feel that their STISL course and students contribute as much to the community partner as the community partner contributes to the students' experiences. The faculty are quick to note, however, that while it may be easy to quantify reciprocity through investments of time, energy, and resources for both parties involved, it is much harder to know if the partnership is qualitatively reciprocal.

Some research participants noted that in some ways it is hard or even impossible to reciprocate the transformational experience that the community partner helped to facilitate for the STISL students.

The students get so much out of it...[The community partners] say, 'oh, you are so helpful, you fund the project, you bring people, you get everybody motivated!' But I think we get more than they do truthfully. Students come back transformed... so how can you put a dollar amount on that. (Barbara)

Barbara contends that while she thinks that on the surface her STISL course and the community partner have a reciprocal relationship, in terms of emotional 
impact and transformational learning, "I think there is more benefit, at least from my perspective, for the American students."

One RP even asserted that reciprocity might be the wrong word to describe equitable exchange between parties on a STISL course:

I don't know, [reciprocity] is the wrong word. I think students gain much from their site hosts as they give. Sometimes they gain a lot more than they contribute. [In fact] I could really care less about what the final product is that they contribute. I am most interested in the relationships that are built and how that affects your behavior in the world. (Isabelle)

Similarly, Henry contends, "[r]eciprocity does not mean exchange in a direct sense. It is more an encompassing set of relationships...it is a fundamental value"; according to David, "it is going to take a lot of time and development to really figure that out." Through the data, it appears that only one RP did not have a direct relationship with her community partner, but instead hired an experiential education company that did have a long-term reciprocal relationship with the community to help facilitate the course. In a sense, this RP was borrowing the reciprocal capital that the company and course co-facilitator had developed over the course of many years.

Research participants reported that reciprocity is an important factor in a relationship with an international community partner, although it may be more complex than in domestic service learning. In addition to an equitable exchange of service and learning, STISL faculty members believe that meaningful relationships between the students and the community need to be considered a part of the reciprocity dynamic. 
Host Country Summary. Overall, the host-country segment of the STISL experience is a crucial experiential educational component that allows students to put into practice the skills and knowledge necessary to meet communityidentified needs in culturally contextualized ways that honor local ways of knowing. This is essential for the development of long-term global agency in the students, which allows them to address significant issues facing the planet, both human and ecological. It is important to note that the STISL experience itself is not designed to be a panacea for all of the world's most pressing issues. However, it does serve as an experience that students can draw upon long-term in order to integrate global agency into their everyday lives. Research participant Henry articulated this point by saying

I would consider a program to be successful from the student standpoint... [if] it result[ed] in some kind of change in behavior. By that I mean perhaps greater engagement with other courses, which volunteer activities, with a reframing of the way that the student approaches his or her education and his or her relationship with the community. [Also] to what extend to the students begin to say, 'you know, I could imagine that [this] experience leads me to rethink about where I want to go with my future... So altering their perspective outward.

Henry continued that he also considers the experience to be a success if students re-think about their relationship with a broader more global society, as well as the difference they can make for people not only in their home communities, but communities across the globe, which based on the conceptualization of STISL success includes long-term global agency. So while students may experience short-term impacts from STISL, global agency is a long-term effect which may not fully develop until years after the actual STISL experience. 
Henry, and other research participants assertions related to the belief that the long-term effects of service-learning extends well beyond the service experience itself is well supported in the literature (Astin et al., 2006; Warchal \& Ruiz, 2004). As Warchal and Ruiz discovered, long-term impacts of servicelearning have been identified in relationship to graduates' long-term employment choices as well as civic leadership (p. 104), including having a direct effect on choosing a career in the service field (Astin et al., 2006, p. 8). Notably, Astin et al. (2006) discovered that "performing service as part of a course (service-learning) [as opposed to service or volunteerism without a curricular connection] adds significantly to the [long-term] benefits associated with community service" (p. 45).

The host-country segment of the STISL experience seeks to positively impact a community based on a community identified need. Realistically, the research participants in this study recognized that their class in itself, during the one to four weeks that they are in country, is not going to solve the community's need completely. However, the goal of STISL does not end in the host-country; the process of developing global agency can begin on a STISL experience, however it is not expected to be fully achieved at its culmination. The rational that transformational experiences, such as developing global agency, take time (as opposed to being instantaneous) mirrors many of the principles of transformational education (Mezirow, 1991), which contends that reflection and time are essential for making meaning out of a disorienting experience and culminating in action based on a newly formed perspective (Cranton, 1994). 
As opposed to measuring success immediately, in terms of houses built or service-hours performed STISL faculty desire that students undergo a much more long-term transformational change both in relation to themselves and also to service and international development as a concept. As Briggs and Sharp (2004) assert, formal top-down development (or service) initiatives have become increasingly scrutinized because of their lack of success. When an agent who does not have a stake in the community, or is unable to understand and identify with local or indigenous approaches to development, initiatives are less likely to be accepted by a community and therefore less likely to succeed. Briggs and Sharp highlight that in years past, traditional or indigenous ways of knowing were seen as obstacles to development efforts. However, Agrawal (as cited in Briggs \& Sharp, 2004) suggests a concept that was consistently reiterated by the participants of this research study; approaching development or service initiatives must incorporate indigenous voices and perspectives are "pivotal to discussions on sustainable resource use and balanced development" (p. 1).

The host-country portion of STISL is not meant to "solve" what a community has identified as a pressing need. Instead, STISL is designed to expose students to need, learn the context and contributing factors to that need, positively contribute in addressing the need with the community while in the host-country, and learn about indigenous or community approaches to solving a problem. Considering the astonishing failure rate of international development initiatives scholars suggest, and STISL faculty from this study support, approaching need and solutions from more than a Western perspective (Briggs \& Sharp, 2004). STISL pedagogy should seek to 
expose students to the value of indigenous perspectives, and the recognition that "the indigenous knowledges of the people resident in particular places - can be of equal, or more, value" (Briggs \& Sharp, 2004, p. 3) compared to a solely Postcolonial, Western perspective.

\section{Re-entry Segment of the STISL Course}

The last segment of the STISL program is re-entry. Overall, strategies employed for a successful re-entry experience aim to ease students back into their home contexts but also address ways to integrate the entire STISL experience into the students' lives. Many of the research participants first discuss re-entry with students in the pre-departure preparation segment of the course, thereby including dimensions of both pre-re-entry and re-entry.

Pre-re-entry strategies. Many research participants reported that they employed strategies to ensure that students' were prepared to have successful reentry experiences before the students ever left their home campuses, but most pre-re-entry training took place during the last days of the host-country experience.

From the very first day I tell them, this class is going to be very fast. It is going to be 9 days... but the class is going to feel much longer than 9 days and you are going to feel like you have been together for a long time. When you come back it is going to be a different experience [for you]. (Ethan)

For other research participants, it feels more appropriate to wait until later in the session, when the reality of re-entry is close at hand. For Jacqueline, it is a struggle to balance preparing students to leave and keeping them emotionally present in their current environment. 
[I know] it's all about preparing to go and then I really want them to be in the moment. I don't want them to start thinking of coming back....[because] they all get really bummed... They are sad, they are super-sad to leave the village.

Pre-re-entry reflection is typically a group reflection session and sometimes occurs in the host-country over a celebratory dinner or meal and can last for multiple hours. The content of the pre-re-entry reflection sessions varies between research participants but generally comprises a combination of specific topics and open-ended group discussions.

Facilitating group discussions, both directed and open-ended, was an important pedagogical strategy during the pre-re-entry process. In terms of specific topics, a common theme became apparent: "you are going to have tons of pictures and we talk about the fact that people really won't want to look at your pictures" (Christina). Research participants also mentioned the fact that "people have a lot of questions about your trip but their attention span might be limited" (Isabelle). Therefore, three research participants mentioned practicing a 4-5 minute description with their students "around three things that you would like to communicate to people" about the experience itself. One RP has students role play interactions with friends or family back home, in which they practice an 'elevator speech' with 4-5 pictures that accurately convey what the students hope their friends and family will learn about their STISL course. Christina, Henry, and Isabelle mention that photographs are great ways to frame the experience for students' friends and family members: “[u]sing photography [not only creates a 
visual] memoir [for the students themselves but also provides] points of departure for explanation and reflection that they share with others" (Henry).

Isabelle, who has an extensive experiential education background through organizations like Outward Bound and the Center for Global Education, has designed and refined an elaborate pre-re-entry reflection session throughout her years of experience:

We will do number of different activities...We do role plays around three things you would like to communicate to people. We might do an activity around reflecting on [our program's] goals, to choose a goal and talk about your experience. We might talk about something you are taking away from the experience and a gift you would like to leave behind... We do appreciations of each other.

In terms of the overall experience, Isabelle initiates a discussion with her students regarding what the students want to commit to doing differently now that they have experienced this STISL course. "We do talk at the end of the course as part of our final reflection about what they will do with the experience once they arrive home in the U.S. For some the experience is a call to action. Felicia reports that her pre-re-entry sessions, to which she allocates a half day, serve as a final place to discuss as a learning community the issues that "they have grappled with, stuff around our own sort of consumerism and materialism and seeing other values from another culture."

Many research participants reported that the pre-re-entry reflection sessions can be an emotional experience for some students. On one STISL course, Jacqueline jokingly called it the "boo-hoo" night. Ethan recalls that during the 
session he "had a lot of students crying." This is not to say that re-entry is an emotionally difficult process for all students, but Isabelle posits that perhaps the level of intensity impacts whether or not a student struggles with the thought or process of re-entry.

After returning from the STISL experience that she discussed for this research project, Isabelle noted that she didn't expect much emotion, such as crying, from her students because the course itself is "more low level intensity, low to medium. I have seen more of that with higher intensity programs." When questioned further regarding what she thought caused low, medium, or highintensity on a STISL experience, this RP felt that it mainly had to do with socioeconomics.

[Socio-economics] is the prime drive, I think, as to whether it is lowintensity or high-intensity. There are lots of other factors of course. You can go to Vancouver, BC and spend time in the Old Town district with First nations people who are dealing with drugs and alcohol abuse and that would be a high-intensity experience.

When posed the question regarding what he thought students struggled with as they re-entered their home context, Henry summarized that students often battle resolving the dissonance that the STISL course caused:

I think some struggle with the discomfort of stereotypes [that] seemed so easy and so handy. [The stereotypes] helped to provide comfortable explanations of why the other is the way the other is and why we are the way we are... There is a little cognitive dissonance between what I've always believed and what has always sort of made sense to me, and now that I've been in such settings, it is difficult to believe [anymore]. People struggle with what they have learned about themselves. 
Barbara, who is very interested in the literature on study abroad and international service-learning, noted that she has combed through the literature but struggles to know how to help students through the process. "I've seen it and I've heard [students] talk about it, but I'm not sure [pedagogically] what do to about it." Jacqueline even admitted that she struggles with re-entry, "because certain things seem trite. Your reality, your whole perspective shifts." Elaborating on what she has witnessed through her students, Barbara said, "I think a lot of [the students] have a sense of guilt, that they are very fortunate, and then they go back and they are leaving people behind who don't have a lot of resources... I think they feel guilt. I have heard them say that before."

Re-entry assignments. Many research participants reported that an assignment due after students re-enter their home contexts is a primary mechanism where students are encouraged to make meaning out of their experience. In addition to re-entry serving as a place where students can make commitments for future action, in re-entry students are assigned to apply the academic discipline and service experience to a community organization, either locally or internationally. Typically, this capstone assignment was due two to four weeks after the students arrived back in their home country. This timeline was logistically challenging for some research participants, whose semesters or quarters finished before the assignments were due, resulting in students with incomplete grades. For some students, this created difficulties with financial aid disbursements in the subsequent semester or term. 
Re-entry reflection assignments. There were different examples of reentry reflection-based assignments such as videos and presentations; however, the most common was a written paper. Research participants articulated two general themes that were present in most re-entry reflection assignments, including intrapersonal and academic specific components as they relate to the host-country experience. In both of these components, students were often asked to not only reflect on what happened, but also to apply principles learned to their home context and in some instances to articulate commitments to future action. An example of this is provided by Ethan, who asks students to write a reflection paper addressing how the they thought the STISL course would impact their profession as a teacher in the years to come.

Overall, the purpose of the reflective component in the capstone assignment varied to some extent between courses; however, some strategies emerged through the data, such as:

- Articulate learning from the STISL experience particularly in relation to previously established university or department goals

- Describe lessons learned about U.S.'s role in the world

- Revisit pre-departure reflections and STISL reflection journal entries

- How did this experience match original expectations for the course? What was surprising? What was disturbing? What new questions did this experience raise? What stereotypes of [the hostcountry] culture did this experience reinforce or negate?

- Critically reflecting on the service experience, including: contributions made to site, challenges or success working with classmates, and the differences between serving internationally and locally

- Describe what service means after the STISL experience; how is that different from before the course?

- How has this experience impacted future goals? 
- What are ways that this experience can impact how you act as a local, national, and global citizen?

Repeatedly, research participants asserted that the reflective culminating assignment is intended to "pull it all together for them" (Jacqueline).

Non-reflective academic re-entry assignments. In terms of nonreflective academic re-entry assignments, some STISL courses required that students produce a piece of work that directly related to a specific academic topic. Three research participants noted that students were required to either write a paper, produce a report, or create a presentation that could be used by either their host-community partner to improve practice or a local community-partner to apply the lessons the students learned to their home context.

For David and Henry's courses, students are required to produce a report after their STISL course that is informed both by the cultural component of the service abroad and the academic content of the course. The research participants' use this project to impart the deliverable information from the students' service experience to community organization. David's courses produce a deliverable for the community partner in the host-country, while Henry's courses produce a deliverable for a community organization in the institution's home community.

During the host-country segment of the STISL course, David's course collects data at the request of the community partner. As he described it,

The primary need that they have for us at this time is for us to kind of fan out to some of the local mercado's where [local people] typically buy their food, to do surveys in the mercados, to do interviews with vendors, to 
make observations about the presence, particularly of indigenously grown foods and the relative costs to the important foods.

As a final re-entry assignment when students return to their home campus, they analyze the data that they have collected and produce a presentation and report for the community organization outlining findings. "[Students] develop some kind of a report [and present it to the community partner] ... that helps inform [the community partner's] mission and what they need to do and where they need to go." The faculty members who team-teach this STISL course actively work with students to ensure that their final product appropriately addresses the community organization's need, rather than delivering a product developed by the students that may be misinformed or inappropriate in terms of cultural context.

Henry, however, takes a different approach, but also requires that students produce a deliverable product to a community organization (in this instance a local community partner) based on the STISL academic content. Henry assigns students to produce a web-ready, multi-media type presentation to share with local environmental non-profit groups and community organizations; this presentation specifically addresses academic issues explored in the course. While the content was strongly informed by the host-country experience, it is still applicable in the home-country context, considering this local community organization interacts with immigrants from the host-country on a regular basis.

As a direct step to begin to begin to achieve this longer-term goal of awareness-building among environmental groups and non-profit 
organizations in [our state], students will utilize these community based activities to distill insights regarding current community patterns in [the host-country]...encouraging [local organizations] to think of ways to draw on cultural practices... that foster community engagement within the [host-country]-origin population, which is an expanding percentage of the state's population.

As is evident in Henry's culminating assignment and in data from other RPs, applying 'lessons learned' to students' home context is a common goal. In the course that explores emigration and immigration, students are required to make a 15-20 minute presentation of their experiences, and articulate the significance of the issue for fellow citizens of the state.

Reunions and post-STISL gatherings. For many, but not all research participants, a crucial component of the re-entry segment is when the students and the instructor gather for what many research participants called a "reunion," which is typically one to four weeks after returning to their home institutions. While they are sometimes mandatory, reunions are often student-led and student-organized. These reunions often covered a wide range of subjects, and typically only addressed academic topics if there were culminating assignments still pending, such as reports for community organizations (David, Henry)or presentations for the campus at large (Ethan). Otherwise, the reunions were mainly reflective and social:

After about a week or two, [we] have a meeting that we can all get together and usually wear... clothing or whatever 'looks' from that area. We come back and have a meal and we talk... That seems to help them with the re-entry and the realization of what all has happened and really be able to think through it. 
It is at this point where Henry poses the question, "what difference did all this make?"

Long-term, the re-entry component of the STISL experience serves two functions. One is to contribute to the long-term mission of the host-country community partner. Second, the re-entry component seeks to equip students with a concrete example of taking an experience and adapting the skills and knowledge gained during it to serve long-term commitments. While global agency manifests through many re-entry assignments, the larger goal of the re-entry segment is for students to witness how their own skills and knowledge can be applied long-term through global agency that positively impacts communities around the world.

Re-entry summary. It is unrealistic to expect that global agency will be fully developed through and by the end of a STISL course. Instead, STISL pedagogy begins, or continues the development of global agency, which develops overtime. Similar to the theory of transformational education (Mezirow, 1991, 2000), global agency is thought to take time to develop, and as Kiely (2004) noted the process of transformation "is a tremendous ongoing challenge" (p. 14) for students after they return from a STISL course, which can last for many years. The transformational learning literature (Cranton, 1994; Mezirow, 1991) as well as STISL literature (Kiely, 2004, 2005) suggests that reflection is essential in the meaning making process in order to arrive at long-lasting, transformational changes that result in new actions based on newly formed perspectives. Due to 
the short nature of these trips, however, much of this meaning making and reflection must take place after students return to their home campuses.

The longevity of the meaning making processes instigated by STISL does not end when students arrive home. Based on the data collected, STISL faculty have designed strategies in order to assist students in making meaning and continuing on the transformational journey toward global agency, however are hindered by institutional schedules. For many faculty, the re-entry segment of the course is not as well developed as they would like, however students are no longer enrolled in the course, grades are due, and the faculty and students time and attention are drawn away to the next term or semester's coursework. In order to avoid the pit-fall of STISL learning becoming isolated to the duration of the host-country experience, Kiely (2004) suggests that "a post program course might allow for greater reflection on the various dimensions of students' emerging global consciousness" (p. 17). While some STISL courses could be considered "service-light," performing unskilled labor, the research participants from this study highlighted that despite the service that was conducted, through ongoing reflection, students have the potential for tremendous growth and transformation as it pertains to global agency. Adding a post program course may provide more time for students to participate in reflective activities leading to deeper levels of meaning making, regardless of the service performed.

The limited time allowed for re-entry may be impacting the extent to which faculty are able to encourage students to reflect on issues of power and 
privilege after they return to their home campuses, which Baker-Boosmara, et al. (2006) and Heldman (2011) assert are essential in service-learning contexts. As Bringle and Hatcher (1997) contend, the service experience may in fact reinforce stereotypes and support presuppositions that may be contrary to the program's goals if not adequately reflected upon. In terms of the re-entry process there were no explicit examples of addressing issues of power and privilege, and the reasons for this are unknown. However, by creating a post program course, as Kiely (2004) suggested, there may be more of an opportunity for this reflection to take place.

\section{Specialized issues and pedagogical responses}

Both individual students' identities and their exposure to difference is noted by the research participants as something that significantly impacts their development and learning on a STISL course across the tripartite structure of pre-departure, host-country, and re-entry. Research participants note that specialized issues, which often result in dissonance, can inhibit students' learning experience, making the overarching goal of developing global agency less likely to be realized.

Despite the best designed plans for success, students often experience difference as dissonance-a disequilibrium from routine ways of knowing and experiencing the world around them. Faculty did, however, articulate some pedagogical strategies that equip students to move from disequilibrium to experiencing significant learning. The subsequent findings will report 
perceptions of the role of dissonance in the learning process as well as examples of dissonance and pedagogical strategies for equipping students to make meaning out of it. Finally, this section will outline, somewhat separate from dissonance, the role that the STISL experience has on students' spiritual ways of knowing.

\section{Disequilibrium, dissonance, and difference as a catalyst for}

development. The experience of disequilibrium, dissonance, and difference are thought by STISL faculty to be a catalyst for student learning and development. Isabelle asserted, "I am a firm believer of disequilibrium as a driver for growth and learning." In her practice, Isabelle utilizes a model called "the circles of comfort" and encourages students to move outside of a comfort zone into a stretch zone:

This is something I borrowed from Outward Bound. If you have three concentric circles, the circle in the middle is where you feel most comfortable in life. The next circle out is where you are feeling stretched in some way or challenged. And the broader circle is what I would call your panic zone. My job as an educator is as much as possible to push you into that middle circle...

Isabelle noted that just being in an international setting pushes students into the stretch zone and that she has to custom tailor her pedagogical strategies for each student, depending on where their comfort, stretch, and panic zones are.

I look at each individual student and think, okay, for Anne, who has already studied abroad or lived in Brazil, I may have to push her a little farther for her to stretch her comfort zone than for a student who is living abroad for the very first time in their life and grew up in a community where they had very little exposure to diversity. 
Many research participants noted that actually experiencing difference could be a significant learning opportunity for a student that does not happen often in a traditional classroom. David noted that in traditional classrooms:

we can talk about cultural differences abstract or theoretically, [but with STISL experiences] students really begin to see how I can be sitting here having a conversation with a person and the two of us can make completely different meanings out of the situation based on the cultural context, that a conversation is laden with all kinds of cultural significance that we are not really aware of.

Similarly, Jacqueline reflected that "we talk about difference before we leave, but nobody knows difference until you get there. Until you feel it." That feeling is, according to other research participants, a catalyst for meaning making: "I think for some students [experiencing difference] is a catalyst for a different level of insight" (Gail); "[experiencing difference] pushes them out of their comfort zones and they are forced to grow" (Jacqueline). All of these assertions are consistent with the adult learning theories that suggest that disequilibrium, dissonance, or difference are necessary catalysts for cognitive, emotional, and intercultural development (Bennett, 2008; Bennett, 1993; Cranton, 1994; Doerr, 2011; Mezirow, 1991; Otten, 2003; Robertson, 1988).

Intercultural conflicts with interpersonal identity causing dissonance.

There are many areas in which faculty have seen growth in students as a result of cultural dissonance. Clashes between intercultural norms and intrapersonal identities were the most common cause of dissonance. This occurred when the host-country's cultural norms or standards were different from and sometime in 
opposition to students' ways of knowing or when cultural values clashed with student's intrapersonal identities, such as gender and race/ethnicity. As was already mentioned by David, experiencing difference opens students' eyes to what could be considered ethnorelativism, which is understood by Bennett (1993) as "the assumption that cultures can only be understood as relative to one another and that particular behavior can only be understood within cultural context (p. 46).

First you have to recognize the difference and then you have to recognize the difference as not being a bad thing. You could put judgment on the difference, like, oh, here's difference and that is bad - you are different from me and my way is better. Then you have to figure out that it is just different, not one is better or one is worse. (Angela)

Angela's conceptualization of difference as being value neutral is well aligned with Bennett's (1993) assertion that "[t]here is no absolute standard of rightness or 'goodness' that can be applied to cultural behavior. Cultural difference is neither good nor bad, it is just different..." (p. 46). Three research participants were careful to note that while in general difference is a catalyst for development, the development varies for each student, depending on previous life experiences. The subsequent sections will elaborate specific examples of various forms of student identity clashing with the host-country's norms and the pedagogical strategies that faculty use to equip students to make meaning out of the experience. It is important to note that all of these identities were mentioned by the research participants as catalysts for both low-intensity dissonance and highintensity dissonance. While low-intensity dissonance is more easily prevented 
and overcome with background knowledge, high-intensity dissonance can be much longer-lasting and have a greater impact on student learning.

Gender. One of the most commonly noted forms of dissonance between intercultural norms and intrapersonal identities for students was in relation to gender norms and roles. Resoundingly, research participants thought that female students experienced significantly higher levels of intercultural dissonance based on gender, as compared to male classmates.

Gender-related issues, specifically culturally appropriate dress, were noted by nearly every RP as a point of low-intensity dissonance for students in the host-country. For example, Henry reports:

A good example [of low-intensity dissonance] is dress. [The host-country] can be warm in the summer and women will say, 'oh, I'm going to wear shorts. I'm going to wear a tank top, etc.' Guys will say, 'I'm going to wear shorts. What you need to do is think about how dress is understood here... It is seen as insensitive to local behavior, or sexual promotion.

Despite having prepared students for what is considered culturally appropriate dress during the pre-departure segment of the course, Henry recalls examples of his students ignoring his guidelines for dress and saying, "' $[\mathrm{t}]$ his is what I do [at home]... people just have to learn to deal with it."

Henry chooses between reflective or direct approaches for addressing these issues depending upon the situation and the risk that the student's behavior poses to students' safety and relationships with the community. Henry recalls directly asking a student, "[w]hat is it that you think gives you the right to come 
into someone else's culture and engage in behaviors that people here regard as, at the very best, as boorish and insensitive and at the worst deliberate affronts?"

Both Felicia and Angela have experienced similar situations in terms of dress and student opposition to dressing in a manner that is appropriate to the cultural context. In order to maintain a healthy relationship with her community partners, Angela has dictated non-negotiable mandates that students immediately change their clothes if they are dressed inappropriately. If challenged, Angela has reminded students that this STISL experience "is not about you. It is about them, [the host-country community]."

Overall, even though students often need reminders about culturally sensitive dress and how it impacts community relationships and student safety, research participants contend that preparation during the pre-departure segment is essential and effective. By addressing culturally sensitive dress in the predeparture segment, research participants typically are able to prepare students for what to expect, even if they need the occasional reminder during the course.

Culturally dissonant expectations for specific gender roles were also reported as a significant catalyst for high-intensity dissonance. Many research participants noted that students often struggled with understanding different expectations of appropriate behaviors based on gender identity, which was understood as more significant than a low-intensity experience, and were often difficult for students to overcome. In an extensive description, Henry tells of a 
specific incident when a male student became highly agitated by being asked to abide by local norms of gender appropriateness:

I took a group of students to a rural community that specializes in traditional medicine. They were a standard [Large Urban University] mixed group. We stay in a facility that used to be a boarding school, a dorm, but it was a large group and the room - there were two big rooms, one for males and one for females. There were so many females that they couldn't fit in the room for females. So some had to move into the other room... [We] had one male who was furious that he would be expected to sleep on a mattress on the floor, when there might have been a bed in the hostel that he could occupy, but it would have been sleeping in a room with women ... He [contested that he] had paid the same amount of money that the women had paid and saw no reason why he should be denied a bed. [Had he been allowed to sleep in the same room as the women] the community simply would not have understood this. It would have confirmed in the eyes of some people their suspicions that Americans are libertines who probably represent a threat to the good moral behavior of people in the community.

Henry, who had a long-standing relationship with this particular community, had to consider the long-term impact in regard to this particular student's complaint. Had he allowed the male student to sleep in the female dormitory, both his and his institution's reputation could have been irreparably damaged in the eyes of the host community.

Henry asserted that within the countries that his courses visit, male gender roles are generally similar to those in the United States and female gender roles are very different;, therefore, the male students have the opportunity to maintain the social status quo, while women are exposed to what may be a dissonant experience:

The idea of a woman going out to someplace and saying, oh, we are going to have a drink, let's dance or whatever, is infused with local notions of 
sexual availability, of patterns of behavior that... are figments of overactive imaginations on the part of [local] males. So the notion of what constitutes $\mathrm{X}$ 's acceptable social behavior is likely to be seen very differently through the eyes of females.

Felicia reported that in her STISL course many of her female students experience what would in the students' normal lives would be considered sexual harassment, but in the host country is relatively normal. Felicia sees the female students wrestling with what the women have always been taught was wrong in a culture that doesn't perceive the harassment as wrong. "Cultural relativism is playing a role and working out that kind of balance, sometimes that can be stressful for [the female students]."

Research participants assert that there are two overarching strategies that can be considered for handling a situation where students are experiencing highintensity dissonance based on gender. In order to decide which strategy to employ, the STISL faculty member must weigh the consequences of the students' actions with the potential impact those actions may have on the students' health and safety and the relationship with the host-country community.

When student safety or relationships with the host-country were not at risk, research participants relied upon reflective strategies in order to equip students to make meaning out of the dissonance that they were experiencing. Often, research participants would encourage students to analyze the situation from an anthropological view, noting historical and cultural influences that impact the difference that the students were experiencing. Rather than having 
students cast judgment on the host-country for the difference, faculty facilitate conversations that aim to remove value-laden perspectives and to see the differences as value neutral. If that was not possible, such as in instances sexual harassment or violence against a particular gender, students were introduced to organizations that were seeking to address the issue within the host-country so that students could witness that actions were being taken to solve the problem.

If student safety or the relationship with the host-country community members were at risk, STISL faculty take a more direct approach to fix the situation. This usually involved the STISL faculty member making a nonnegotiable decision that immediately reduced the potential risk and ensured student safety and maintained a healthy relationship with the host-country community. Research participants mentioned that whenever possible after they issued a directive, they would try to revisit the concern during reflection sessions to ensure that the students knew the perspective of the faculty member and why he or she as the group leader decided to take that action. Research participants rarely ever issued a non-negotiable directive without attempting to use the experience as a learning opportunity for students.

Race and ethnicity. The next significant identity cited by research participants as influential in impacting student experience and learning is race and/or ethnicity. Although student participants were primarily Caucasian, which is consistent with national education abroad statistics (Institute of Educational Sciences, 2010), non-Caucasian students often experienced dissonance based on 
their race/ethnicity, unlike Caucasian classmates. Both Ethan and Isabelle reflected that in their courses to Latin America, Latino or other students of color have experienced the course differently than Caucasian students. According to Ethan, "yeah, the Latino students react differently than white students when they go down there, of course!" Isabelle asserted that any student of color, especially students that speak the host country's language, would be treated differentlyworse-than white classmates

While Isabelle associated this difference with all students of color, in his perspective, Latino students with direct connections to the host country or to the social issues being explored experienced the course differently than classmates. For example, Ethan recalled learning that a Latina student's aunt was killed when trying to cross the border between the host country and the U.S. "She would cry in class and feel very upset. They feel very, very connected to the immigrant community." He even suggested that it may not be the students' ethnicity that is the most significant identity that influences their learning experience, but rather the students' identity as a brother, son, sister, daughter, friend, or spouse of someone they love who is Latino and has been impacted by issues explored through the course. He reports that students become very emotional during the class "if they have some connection to [the issues that the course explores, such as immigration]," especially if the student is Latino because they are either immigrants or just one generation away from the immigrant experience and it is still in their household. They are the ones 
who shed the tears. They are the ones who get very upset when their classmates may not get it, or they get very upset with the border patrol.

In addition to their own race/ethnicity, students also experienced dissonance when the course addressed issues that impacted students' loved ones who may be from that particular race/ethnicity. Faculty perceive student identity as a factor for how the students experience and learn on a STISL course. In an example from Ethan of someone who experienced high-intensity dissonance, a student was white but had a father who was ex-border patrol and was in a relationship with a Mexican immigrant:

She was very conflicted, not so much because she defended the border patrol, but she felt that her father, when he was in the border patrol was very sympathetic... She knew what it was like when her dad was on the border patrol. She felt that the other students were talking bad about the border patrol agents, and [therefore] they were talking about her dad... At the same time she felt understanding because her boyfriend is Mexican and her potential in-laws are Mexican immigrants, so she felt very sympathetic. She understood.

Other examples include immigrant students on a STISL course that explores border and immigration issues or students that were adopted from a country other than the United States and are serving at a site working with orphaned children. In both instances, research participants felt it was likely that these students would experience higher levels of dissonance and therefore experience the course differently than non-immigrant or non-adopted students.

Intrapersonal spiritual identities. In addition to other intrapersonal identities, such as gender, race, and ethnicity, research participants note that the STISL experiences are thought to impact students individually on a spiritual level. 
While this is not the case for every student who participates in a STISL course, Henry and Barbara noted that they have witnessed students say that STISL experiences were transformative for them as individuals, which could be a spiritual experience for some students. Barbara reported that students "talk about greater meaning" while on a STISL course and that the STISL experiences "give [the students] a sense of purpose." While a sense of purpose does not necessarily have to be categorized as spiritual, the concept is deeply personal and unique to each student. Sense of purpose is thought by research participants to be a driving force in students' lives that shapes and directs future action.

Gail and Isabelle asserted that through reflection sessions, they initiate discussions with students around questions related to what connects human beings to each other (Gail), to nature, and to history (Isabelle) and what this means in terms of future global agency. As Gail noted, she addressed with her class that "we are not just hardwired for competition. We are actually hardwired for some degree of cooperation and collaboration, being a social species."

Christina alluded to the belief that students' spiritual identities help in reinforcing career choice and engendering deeper appreciation for what the students have in their lives: "[STISL pedagogy] makes them reflect on, 'why did I come into [this profession]."' Also,

[the STISL experience] gives them a better perspective of all the blessings that we have here and that you really don't have to have as much stuff that we have to be happy, because there are people over there who have less and they are very happy. It gives them a nice balance. It helps to have a 
reality check of what I really have to have and what are just extras that I really don't have to have.

In a cumulative sense, it appears that there is a wide range of perspectives regarding what constitutes spirituality; however, many research participants noted that STISL experiences do impact students on a spiritual level or that students use a spiritual lens to interpret a STISL experience.

While some research participants did initiate reflection discussions around the concept of spirituality, only one, from a faith-based institution, actually referred to it as spiritual, while all others left the concept unnamed or vague. It may be significant to note that most research participants did not initiate discussions with students that they would consider spiritual, but rather philosophical ways of knowing.

\section{Summary: Pedagogical Strategies.}

There are a significant number of pedagogical strategies that STISL faculty employ throughout the STISL course. It is important to note that these strategies have been tested by the STISL faculty members multiple times (considering one of the criteria for participating in this study was having taught the same STISL course at least twice within the past five years), giving them the opportunity to refine and revise the strategies that are most appropriate for the context of the course. While most of these courses were taught in different cultural and geographic locations, there are pedagogical strategies that cut across the courses, enabling the field for the first time to identify potential principles of best practice. 
For the pre-departure segment of the STISL experience, there are seven primary categories to address in order to ensure the maximum potential for success during the STISL experience itself. The seven categories of pre-departure preparation are not impermeable categories and often rely upon each other in order to be fully implemented. Overall, the pre-departure preparation contains didactic delivery of information through lectures and readings focusing on practical logistics, non-negotiable behavioral expectations, basic anthropologic information, and cultural norms. Additionally, pre-departure preparation sessions are a highly reflective experience where students are equipped to begin forming meaningful relationships with classmates and the faculty member. Intrapersonally and interculturally, students are encouraged to explore their own cultural identities and how that will impact them while they are in the host country. Through both didactic and reflective pre-departure techniques, students are exposed to academic specific ideas and encouraged to abstractly conceptualize how culture and context may impact the implementation of the academic specific ideas through a service activity.

The vast majority of pedagogical strategies utilized during a STISL course are implemented while the students are in the host-country. Overall, there are five overarching strategies: service experience, reflection, assignments, teamteaching, and cultural insiders.

The service experience is understood as an integral pedagogical component of the STISL course and is essential to the experiential education 
process. As noted above, the level of skill that students bring to the service experience significantly impacts the service activity itself. This being said, there are strategies that cut across all three categories that provide insight into overarching pedagogical strategies for service integration. The service activity itself must serve multiple functions but be connected to the academic content that is being explored. The academic content cannot, however, trump culturally contextual factors regarding appropriate and meaningful service activities. Whenever possible, the service activity should put students in contact with hostcommunity members in order to collaboratively meet a community's needs, as opposed to students serving without community context.

Reflection is also an essential pedagogical strategy for STISL courses and is intimately intertwined with many other pedagogical strategies. Metaphorically, reflection is the conduit that connects the service experience, academic content, cultural context, and interpersonal identity. Through both written and oral means, reflection seeks to equip student to cognitively shift from "what did you see" and “how does this compare with what we've learned, or you've experienced in the past" to "what does this new knowledge mean for you long term?" The data importantly demonstrates that not all reflection pedagogical strategies need to look the same, and STISL faculty have the freedom to utilize various modes of reflection as they fit the learning styles of individual students.

Assignments serve a number of functions during the STISL course and aid students in developing a more holistic toolset for understanding the complex 
relationship between academic content and cultural context. Strategies including interviews with community members, pursuing answers to three self-identified questions, and language lessons are all structured to deeply embed students in the cultural context of the host-community, with the idea that this deeper context will lead toward making more culturally contextual meaning out of global action long-term.

Team teaching is a teaching strategy identified through this research project that has not yet been articulated in the ISL or STISL literature. Team teaching is utilized across STISL types and serves a number of functions, including increased supervision for the delivery of service activities (typically related to healthcare) and providing uninterrupted support for students as they individually experience difficulties interpreting and making meaning out of complex and sometimes dissonant components of the STISL course.

Finally in terms of host-country teaching strategies, utilizing cultural insiders in order to support pedagogical design and sometimes deliver content is a practice that appeared to be of significant importance across STISL type, duration, and academic discipline. Cultural insiders provided a number of services, including giving formal lectures, serving as guides to cultural sites, and collaborating with students in implementing service activities. The cultural insiders served as a bridge between the students' world and the hostcommunity's cultural context. Cultural insiders provide resources and 
perspectives that the faculty member is unable to provide, considering that the faculty member is not as familiar with the cultural intricacies as the insider.

The final segment of STISL courses is re-entry, which commonly begins as pre-re-entry near the end of the host-country portion of the course. Pre-re-entry strategies are highly reflective and encourage students to cognitively and emotionally prepare for the re-entry process. Through oral discussions, written reflections, and even role playing, students re-imagine what it means to live dayto-day in their home contexts, even when a large portion of their perspective may have changed.

After students have returned to their campus community, there are two different examples of re-entry assignments, one highly reflective and one more academic. The highly reflective assignment focuses on having students explore the nexus of intercultural and interpersonal dimensions of knowing in light of the service experience. The academic assignment focuses solely on applying academic principles to either a local or global community partner, honoring cultural context, through a deliverable report or presentation aiming to equip the community partner to improve their practice.

Finally, oral reflection, through reunions, was noted by some faculty as a pedagogical strategy utilized in the re-entry segment in order to facilitate student meaning making. However, due to time constraints both on the part of the faculty member and the student, reunions were often not mandatory and were 
commonly student driven, rather than being a formal part of the pedagogical process.

The Van Cleave Conceptual Framework for STISL Design. Thus far through data analysis, a holistic conceptualization of STISL success has been identified through the Van Cleave Framework for STISL Success. By taking this framework and the data collected in regard to pedagogical strategies as outlined above, a new conceptual framework emerges that erects a pedagogical scaffold from which STISL faculty can design pedagogical strategies in order to develop students' global agency. The Van Cleave Conceptual Framework for STISL Design (Table 10) provides an overarching framework from which STISL faculty can begin to structure the STISL experience through a tripartite organization (predeparture, host-country, and re-entry) in relation to the three factors of global agency (culturally contextualized solidarity, global civic engagement, and global competence) through the five interrelated dimensions of success (academic, professional, interpersonal, intrapersonal, and intercultural) in order to achieve desired learning outcomes. 
Table 10 The Van Cleave Conceptual Framework for STISL Design

\begin{tabular}{|c|c|c|c|}
\hline & $\begin{array}{l}\text { Factor I: Culturally Contextualized } \\
\text { Solidarity }\end{array}$ & Factor II: Global civic engagement & Factor III: Global Competence \\
\hline $\begin{array}{l}\text { Academic } \\
\text { Dimension }\end{array}$ & $\begin{array}{l}\text { (PD, HC, RE) Explore how academic } \\
\text { content can meet a host-country } \\
\text { identified need utilizing scholarly } \\
\text { literature, while recognizing and } \\
\text { honoring local ways of knowing. }\end{array}$ & $\begin{array}{l}\text { (PD, HC, RE) Apply academic content to } \\
\text { social or environmental needs on local } \\
\text { and global levels, in the short-term and } \\
\text { long-term. }\end{array}$ & $\begin{array}{l}\text { (PD, HC, RE) Explore academic } \\
\text { concepts in relation to host- } \\
\text { country's historical and cultural } \\
\text { contexts in order to perform service } \\
\text { in a culturally responsive manner. }\end{array}$ \\
\hline $\begin{array}{l}\text { Professional } \\
\text { Dimension }\end{array}$ & $\begin{array}{l}\text { (PD, HC, RE) Explore ways that } \\
\text { professional skills can be applied to } \\
\text { host-country identified need. }\end{array}$ & $\begin{array}{l}\text { (HC, RE) Apply professional skills in a } \\
\text { culturally responsive manner for the } \\
\text { wellbeing of a people and the } \\
\text { environment on both local and global } \\
\text { levels. }\end{array}$ & $\begin{array}{l}\text { (PD, HC, RE) Explore ways in which } \\
\text { professional skills can meet a } \\
\text { community-identified need in a } \\
\text { culturally responsive manner. }\end{array}$ \\
\hline $\begin{array}{l}\text { Interpersonal } \\
\text { Dimension }\end{array}$ & $\begin{array}{l}\text { (PD, HC) Develop meaningful } \\
\text { relationships with classmates, faculty } \\
\text { members, and community partners in } \\
\text { order to collaborate in meeting host- } \\
\text { country identified need. }\end{array}$ & $\begin{array}{l}\text { (HC, RE) Through relationships with } \\
\text { community partners, students } \\
\text { collaboratively perform meaningful } \\
\text { service that addresses a community- } \\
\text { identified need. }\end{array}$ & $\begin{array}{l}\text { (HC, RE) Collaboratively apply } \\
\text { culturally contextual knowledge to } \\
\text { a community-identified need in a } \\
\text { group setting. }\end{array}$ \\
\hline $\begin{array}{l}\text { Intrapersonal } \\
\text { Dimension }\end{array}$ & $\begin{array}{l}\text { (PD, HC, RE) Explore consciousness of } \\
\text { self where students are encouraged to } \\
\text { understand themselves as cultural } \\
\text { beings and feel that their fates are } \\
\text { bound with local and non-local } \\
\text { individuals. }\end{array}$ & $\begin{array}{l}\text { (PE, HC, RE) Explore the ways in which } \\
\text { students' own culture and identity } \\
\text { impact perceptions of culturally } \\
\text { contextualized engagement for } \\
\text { addressing a community-identified need. }\end{array}$ & $\begin{array}{l}\text { (RE) Students articulate sense of } \\
\text { responsibility in light of cultural } \\
\text { context regarding social and } \\
\text { environmental concerns on a local } \\
\text { and global level. }\end{array}$ \\
\hline $\begin{array}{l}\text { Intercultural } \\
\text { Dimension }\end{array}$ & $\begin{array}{l}\text { (PD, HC) Explore how culture, context } \\
\text { and local ways of knowing impact } \\
\text { approaches to addressing a } \\
\text { community-identified need. }\end{array}$ & $\begin{array}{l}\text { (HC, RE) Participate in service activities } \\
\text { with intercultural stakeholders that } \\
\text { honor cultural context when addressing } \\
\text { a community-identified need. }\end{array}$ & $\begin{array}{l}\text { (PD) Explore anthropological } \\
\text { foundations of the host-country and } \\
\text { (HC, RE) Demonstrate behaviors } \\
\text { and attitudes that equip students to } \\
\text { engage addressing local and global } \\
\text { issues with a interculturally diverse } \\
\text { stakeholders }\end{array}$ \\
\hline
\end{tabular}

(PD) Pre-Departure, (HC) Host-Country, (RE) Re-Entry 
The Van Cleave Conceptual Framework for STISL Design provides a holistic vision of design in order to achieve global agency and is broad enough that nearly any academic discipline can apply its principles to specific courses. Furthermore, this conceptual framework describes specific segments of the STISL experience into which experienced STISL faculty have incorporated the factors and dimensions of STISL learning throughout the course. While this particular conceptual framework lacks pedagogical specificity, its findings have the potential to be widely applicable. In order to understand more specific pedagogical strategies, it is essential to explicate this conceptual framework into specific design strategies to achieve the overarching intention of educating for global agency.

The Van Cleave Pedagogical Design Framework for Global Agency. Based on faculty conceptualizations of dimensions of success (academic, professional, interpersonal, intrapersonal, and intercultural) pedagogical strategies dynamically interact with epistemological factors of success (culturally contextualized solidarity, global civic engagement, and global competence) and can be organized in a way that has not yet been articulated in the literature. The Van Cleave Pedagogical Framework for STISL Success (Table 10) was designed pursuant to the data in response to both research questions that shaped this research study: 1) how do faculty conceptualize success in a STISL course and 2) what are the specific pedagogical strategies that faculty use in order to achieve this success? These pedagogical strategies are illustrated in the framework, with examples from across the tripartite course sequence segments (pre-departure, host-country and re-entry). 
Examples of this include the pre-departure preparation component, where students are exposed to academic concepts through either lectures or scholarly readings that directly relate to the host-country community-partner's identified need. For instance, in regard to the Environmental Activism and Community Engagement course, professors may explore academic literature pertaining to overarching global concepts of environmental activism , popular environmental movements, and significant barriers to environmental activism; they may also student contextualized academic literature specific to the region in Mexico where the students will be studying. By contextualizing the academic content to the specific region, faculty can better prepare students to make decisions regarding environmental service activities as they relate to that particular context.

Examples from the host-country component in relation to the intercultural dimension and the factor of global civic engagement may include participating in a meaningful service activity with intercultural stakeholders that honors cultural context while addressing a community-identified need. This pedagogical design can be witnessed from the example provided by Angela, who partners with and serves with Nicaraguan healthcare providers in addressing the healthcare needs of Nicaraguan senior citizens. As this RP reported, even though healthcare is relatively similar across cultures, due to limited resources students must follow the community-partner's lead in deciding how to deliver "quality" health care services without the aid of what many students would consider essential equipment. In 
addition to performing the service, the students reflect on how they think that culture and context has impacted the way that service was performed.

A third example, which comes from the re-entry component in relation to professional culturally contextualized solidarity, is illustrated by Jacqueline who, as a culminating reflection assignment (due two weeks after the course has returned to the U.S.), poses to students various reflection questions that have the students consider the relationships that were developed during the service experience. Students are encouraged to articulate how professional skills from their chosen field, whatever that may be, can be applied not just in a work setting but also in a broader context in order to meet community needs.

It is essential to note that while the Van Cleave Pedagogical Design Framework for Global Agency articulates separate dimensions of design as they relate to specific design factors, none of the pedagogical strategies are isolated. In fact, the design strategies often overlap across multiple dimensions and factors, accomplishing more than one purpose with just one pedagogical strategy. 
Table 11

The Van Cleave Pedagogical Design Framework for Global Agency

\begin{tabular}{|c|c|c|c|}
\hline & $\begin{array}{c}\text { Factor I: Culturally } \\
\text { Contextualized Solidarity }\end{array}$ & $\begin{array}{l}\text { Factor II: Global Civic } \\
\text { Engagement }\end{array}$ & $\begin{array}{l}\text { Factor III: Global } \\
\text { Competence }\end{array}$ \\
\hline 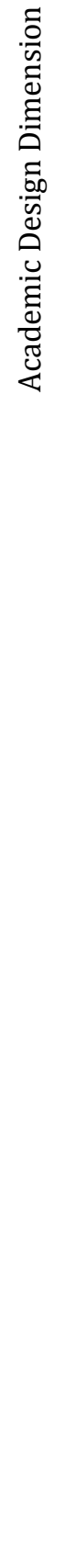 & $\begin{array}{l}\text { (PD) Explore academic course } \\
\text { content through scholarly } \\
\text { literature in relation to a } \\
\text { community-identified need in } \\
\text { the host-country. If necessary, } \\
\text { develop skills utilizing } \\
\text { academic literature in order } \\
\text { to perform service activities. } \\
\text { (HC) While in the host- } \\
\text { country, perform service } \\
\text { activities informed by } \\
\text { culturally contextualized } \\
\text { academic literature and } \\
\text { reflect either in writing or as } \\
\text { groups in terms of balancing } \\
\text { academic knowledge with } \\
\text { local ways of knowing. } \\
\text { (RE) Through written } \\
\text { reflection articulate how } \\
\text { academic knowledge can be } \\
\text { applied to a community- } \\
\text { identified need, honoring } \\
\text { local ways of knowing, in } \\
\text { order to improve quality of } \\
\text { life or the environment. }\end{array}$ & $\begin{array}{l}\text { (PD) Investigate how the } \\
\text { community partner currently } \\
\text { meets the needs of the host- } \\
\text { community and } \\
\text { compare/contrast with the } \\
\text { scholarly literature. Propose } \\
\text { hypothesizes regarding the } \\
\text { impact of culture and context } \\
\text { (from the global competence } \\
\text { portion) on meeting a } \\
\text { community-identified need for } \\
\text { the host-country. } \\
\text { (HC) Through service } \\
\text { experiences, apply academic } \\
\text { specific principles through } \\
\text { meaningful action in order to } \\
\text { meet community-identified } \\
\text { needs and reflect either in } \\
\text { writing or as groups in terms } \\
\text { of balancing academic } \\
\text { knowledge with local ways of } \\
\text { knowing. } \\
\text { (RE) As a culminating } \\
\text { assignment academic } \\
\text { principles to a local or global } \\
\text { community need, honoring } \\
\text { local ways of knowing though } \\
\text { developing a final product a } \\
\text { community partner can use to } \\
\text { improve upon their work. }\end{array}$ & $\begin{array}{l}\text { (PD) Through readings, } \\
\text { presentations or videos, } \\
\text { explore anthropological } \\
\text { foundations and current } \\
\text { events relevant to the host- } \\
\text { community and reflect on } \\
\text { how this impacts the } \\
\text { application of academic } \\
\text { principles to community- } \\
\text { identified need. Identify } \\
\text { and attempt to answer self- } \\
\text { developed questions that } \\
\text { students have in about how } \\
\text { context and culture impacts } \\
\text { the academic discipline } \\
\text { being explored through the } \\
\text { course. } \\
\text { (HC) Participate in } \\
\text { meaningful service } \\
\text { activities that apply } \\
\text { academic knowledge in a } \\
\text { way that honors knowledge } \\
\text { of host-country's culture } \\
\text { and context. Use the } \\
\text { experience to revisit } \\
\text { original questions through } \\
\text { written journal reflections. } \\
\text { (RE) As a culminating } \\
\text { assignment, apply academic } \\
\text { knowledge through } \\
\text { principles of global } \\
\text { competency in order to } \\
\text { develop an intervention in } \\
\text { order to meet a global or } \\
\text { local community-identified } \\
\text { need. Synthesize findings to } \\
\text { original questions about } \\
\text { the impact of context and } \\
\text { culture in relation to the } \\
\text { academic discipline. } \\
\text { Articulate how these } \\
\text { findings were different or } \\
\text { similar to previous } \\
\text { conceptions. }\end{array}$ \\
\hline
\end{tabular}




\begin{tabular}{|c|c|c|c|}
\hline 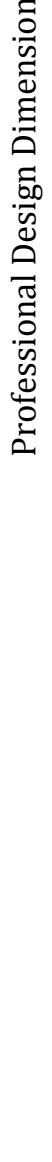 & $\begin{array}{l}\text { (PD) Investigate how } \\
\text { professional skills can be } \\
\text { applied to meet a community- } \\
\text { identified need. } \\
\text { (HC) Through a meaningful } \\
\text { service experience apply } \\
\text { professional skills to a } \\
\text { community-identified need, } \\
\text { honoring cultural context and } \\
\text { local ways of knowing; } \\
\text { Performing service in close } \\
\text { proximity to host-country } \\
\text { citizens impacted by issue to } \\
\text { be addressed through the } \\
\text { service experience. } \\
\text { (RE) In light of relationships } \\
\text { developed and service } \\
\text { performed reflect on and } \\
\text { articulate how professional } \\
\text { skills can be applied to } \\
\text { community-identified needs } \\
\text { in the future, or develop a } \\
\text { plan to acquire professional } \\
\text { skills in order to meet } \\
\text { community-identified needs } \\
\text { in the future. }\end{array}$ & $\begin{array}{l}\text { (HC) Apply professional skills } \\
\text { in a meaningful and culturally } \\
\text { responsive manner for the } \\
\text { wellbeing of people and or the } \\
\text { environment in the host- } \\
\text { country. } \\
\text { (RE) Through written } \\
\text { reflection, articulate how } \\
\text { professional skills can be used } \\
\text { in the future, either in local or } \\
\text { global settings, in order to } \\
\text { meet community-identified } \\
\text { needs, or develop a plan to } \\
\text { acquire professional skills in } \\
\text { order to meet a community- } \\
\text { identified needs in the future. }\end{array}$ & $\begin{array}{l}\text { (PD) Discuss how the } \\
\text { application of professional } \\
\text { skills can be impacted by } \\
\text { local cultural context. } \\
\text { (HC) Participate in } \\
\text { meaningful service that } \\
\text { applies professional skills } \\
\text { honoring cultural context } \\
\text { and local ways of knowing. } \\
\text { (RE) Explore future ways in } \\
\text { which professional skills } \\
\text { can meet a community- } \\
\text { identified need in a } \\
\text { culturally responsive } \\
\text { manner, or discuss how } \\
\text { students can incorporate } \\
\text { honoring cultural context } \\
\text { and local ways of knowing } \\
\text { into their professional } \\
\text { practices. }\end{array}$ \\
\hline
\end{tabular}




\begin{tabular}{|c|c|c|c|}
\hline 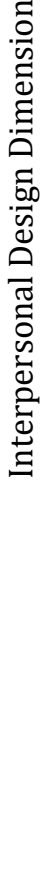 & $\begin{array}{l}\text { (PD) Through written or } \\
\text { group reflection, articulate } \\
\text { the pro's and con's of } \\
\text { international service. Reflect } \\
\text { on the concept of solidarity } \\
\text { and responsibility in relation } \\
\text { to a global context } \\
\text { (HC) Participate in direct } \\
\text { service experiences where } \\
\text { students are able to develop } \\
\text { meaningful relationships with } \\
\text { host-country citizens. Listen } \\
\text { to the stories of host-country } \\
\text { citizens who have been } \\
\text { personally impacted by the } \\
\text { community-identified need. } \\
\text { Reflect on the concept of } \\
\text { solidarity and how it relates } \\
\text { to meeting a community- } \\
\text { identified need. }\end{array}$ & $\begin{array}{l}\text { (HC) Participate in meaningful } \\
\text { service experiences where } \\
\text { students have the opportunity } \\
\text { to work as a cohesive team } \\
\text { with a host-country } \\
\text { community partner in order to } \\
\text { meet a community-identified } \\
\text { need. } \\
\text { (RE) As a class or in small } \\
\text { groups develop a final product } \\
\text { that a local or global } \\
\text { community partner can use to } \\
\text { improve upon their work in } \\
\text { meeting a community- } \\
\text { identified need. }\end{array}$ & $\begin{array}{l}\text { (HC) Utilize knowledge of } \\
\text { host-country's culture and } \\
\text { context in order effectively } \\
\text { and efficiently partner with } \\
\text { the community-partner in } \\
\text { order to deliver culturally } \\
\text { contextualized service. } \\
\text { (RE) As a class or in small } \\
\text { groups develop a final } \\
\text { product that a local or } \\
\text { global community partner } \\
\text { can use to improve upon } \\
\text { their work in meeting a } \\
\text { community-identified need, } \\
\text { honoring local ways of } \\
\text { knowing. }\end{array}$ \\
\hline
\end{tabular}




\begin{tabular}{|c|c|c|c|}
\hline 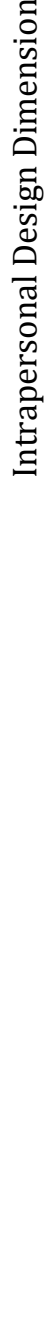 & $\begin{array}{l}\text { (PD) Through written 'pre- } \\
\text { flection,' articulate } \\
\text { expectations about the } \\
\text { experience, either positive or } \\
\text { negative. Through activities } \\
\text { and reflection to explore the } \\
\text { self as a cultural being. Reflect } \\
\text { on the concept of solidarity } \\
\text { and connection to the global } \\
\text { community. As a writing } \\
\text { assignment, begin to explore } \\
\text { self-efficacy and the concept } \\
\text { of 'the power of one' } \\
\text { (HC) Through group and } \\
\text { written reflection, begin by } \\
\text { articulating how what the } \\
\text { students have done or seen is } \\
\text { impacting them on an } \\
\text { affective, emotional level. } \\
\text { Continue to explore the } \\
\text { concept of solidarity and the } \\
\text { personal connection to a } \\
\text { global community. } \\
\text { (RE) As a culminating } \\
\text { assignment, using reflection } \\
\text { journals as data, articulate } \\
\text { personal growth and a plan of } \\
\text { action in light perceptions of } \\
\text { an interconnected global } \\
\text { community }\end{array}$ & $\begin{array}{l}\text { (PE) Through activities and } \\
\text { reflection, articulate how } \\
\text { students think their own } \\
\text { cultural perspectives will } \\
\text { impact the service experience } \\
\text { in the host-country. } \\
\text { (HC) Through written or oral } \\
\text { reflection explore how } \\
\text { students' own cultures and } \\
\text { identities impact perceptions } \\
\text { of culturally contextualized } \\
\text { solidarity as it is related to } \\
\text { meeting a community- } \\
\text { identified need in a different } \\
\text { culture that students' own. } \\
\text { (RE) As a culminating } \\
\text { reflective assignment, } \\
\text { synthesize learning as it } \\
\text { relates to students' own } \\
\text { cultures and identities and } \\
\text { how that learning will inform } \\
\text { future service endeavors. }\end{array}$ & $\begin{array}{l}\text { (RE) As a component of a } \\
\text { culminating assignment, or } \\
\text { in final reflection sessions, } \\
\text { students address the } \\
\text { connection between } \\
\text { conceptualization of self } \\
\text { and how that compares } \\
\text { with and differs from other } \\
\text { cultural contexts. Students } \\
\text { are encouraged to discuss } \\
\text { how to approach a } \\
\text { community-identified need } \\
\text { in light of differing } \\
\text { culturally influenced } \\
\text { values. }\end{array}$ \\
\hline
\end{tabular}




\begin{tabular}{|c|c|c|c|}
\hline 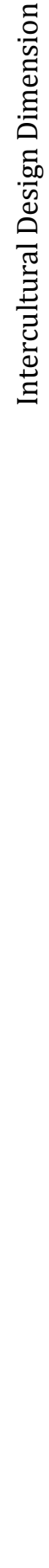 & $\begin{array}{l}\text { (PD,) Through reading, } \\
\text { lecture or multimedia, } \\
\text { explore pros and cons of the } \\
\text { term global citizenship and } \\
\text { international service in } \\
\text { general. Reflect on initial } \\
\text { perceptions regarding how to } \\
\text { meet a global community- } \\
\text { identified need while } \\
\text { honoring the culture and } \\
\text { identity of its people. } \\
\text { (HC) Through service } \\
\text { activities, work with host- } \\
\text { country community members } \\
\text { in order to meet a } \\
\text { community-identified need. } \\
\text { Through written or oral } \\
\text { means, reflect the concept of } \\
\text { solidarity between } \\
\text { individuals from differing } \\
\text { cultural backgrounds who are } \\
\text { working together to meet a } \\
\text { community-identified need. }\end{array}$ & $\begin{array}{l}\text { (HC) Participate in meaningful } \\
\text { service activities with } \\
\text { intercultural stakeholders that } \\
\text { honor cultural context when } \\
\text { addressing a community- } \\
\text { identified need. Reflect on how } \\
\text { students have observed } \\
\text { culture impacting the } \\
\text { implementation of service. } \\
\text { (RE) As a class or in small } \\
\text { groups develop a final product } \\
\text { that a local or global } \\
\text { community partner can use to } \\
\text { improve upon their work in } \\
\text { meeting a community- } \\
\text { identified need and honors } \\
\text { local identity and ways of } \\
\text { knowing. }\end{array}$ & $\begin{array}{l}\text { (PD) Through readings, } \\
\text { lectures, and multimedia } \\
\text { explore anthropological } \\
\text { foundations, cultural norms } \\
\text { and current event that } \\
\text { shape the context of the } \\
\text { host-country. Also, explore } \\
\text { general principles of } \\
\text { culture and culture shock. } \\
\text { (HC) Reflect as a group our } \\
\text { individually regarding how } \\
\text { students have witnessed } \\
\text { cultural practices, } \\
\text { mannerisms or other } \\
\text { norms that have differed } \\
\text { from students' culture. } \\
\text { Students analyze } \\
\text { observations and identify if } \\
\text { they are value neutral or } \\
\text { value laden, highlighting } \\
\text { the difference between } \\
\text { neutral observations and } \\
\text { culturally laden } \\
\text { interpretations; Participate } \\
\text { in meaningful service } \\
\text { experiences applying } \\
\text { knowledge about cultural } \\
\text { norms and local ways of } \\
\text { knowing as appropriate to } \\
\text { the context; Students have } \\
\text { the opportunity to } \\
\text { participate in language } \\
\text { training. } \\
\text { (RE) As a class or in small } \\
\text { groups develop a final } \\
\text { product that a local or } \\
\text { global community partner } \\
\text { can use to improve upon } \\
\text { their work in meeting a } \\
\text { community-identified need } \\
\text { and honors local identity } \\
\text { and ways of knowing. }\end{array}$ \\
\hline
\end{tabular}

The Van Cleave Framework of STISL Design Strategies is an in depth articulation of various course design strategies, teaching strategies, and implementations of service 
as reported by experienced STISL faculty members. The framework was designed based on the Van Cleave Framework of STISL Success, the Van Cleave Conceptual Framework for STISL design, and the data provided by experienced STISL faculty members. The framework offers a conceptualization of STISL design that has not yet been articulated in the literature; it is an operational design framework of principles of best practice. Ultimately, this design framework equips faculty to design a holistic STISL program with the ultimate goal of developing students' agency.

\section{Iterative Teaching}

In addition to course design, teaching strategies, and implementation of service, the fourth element of service-learning pedagogy is assessment in order to learn what worked and what did not and to identify what changes to implement in the next iteration of the course. This concept is known as iterative teaching (Stokamer, 2011). It is important to note that assessment and iterative teaching are not synonymous. Iterative teaching occurs only when changes are implemented in future iterations of a course based on assessment data. Overall, there are four modes of assessment that research participants utilize in order to understand program effectiveness. Two of the assessment techniques clearly impacted the iterative teaching process, while two assessment techniques did not and cannot be considered iterative teaching strategies. Before considering these, however, it is first essential to understand motivations behind why faculty continue teaching STISL courses and improving their practice in each iteration. 


\section{Why Would Faculty Teach and Keep Teaching Using STISL?}

Research participants were asked to articulate why they initially chose to teach STISL courses and their motivations for why they continue teaching using the pedagogy, refining the course in subsequent iterations for student learning and development. Some faculty answered citing logistical reasons, while others noted educational reasons for leading and re-leading these courses.

Regardless of duration, research participants reported that international service experiences serve a unique purpose in student learning and development in terms of developing agency for global action. In light of this, data show that even though the experience is short, it is, according to research participants, "better than nothing, especially if we make it very intense." Angela feels that even though her class is only ten days, "those students learn more in those ten days than I could ever teach them in a semester class...it is a lot, a lot of work but it is a big bang for your buck."

Similar to Angela, other research participants feel that STISL teaches students lessons that are difficult to incorporate into a traditional on-campus classroom and can instill in students a desire to pursue additional international experiences. Ethan believes that his course supplements traditional teacher preparation programs with real life experiences that will translate into having more empathetic and understanding teachers when it comes to working with students from immigrant backgrounds. Both empathy and understanding are concepts that Ethan asserted are difficult to teach in a traditional classroom, and "teachers who 
work with very diverse communities [including immigrant populations] need to have this experience."

In terms of long-term commitment to international work, Jacqueline noticed that there was a connection between the extent to which students are embedded in the culture and the commitments they make long-term related to international engagement. Because of this, Jacqueline decided to immerse students' into one community organization for the duration of the course, as opposed to switching service placement nearly every day. Jacqueline believes that "[a]s long as you can build [a STISL course] that is authentic, that is a real cultural exchange, that students are fully in the culture... it gives them the decision that maybe they think about their studies and maybe they do want to go abroad... live abroad after the experience." For Isabelle, her own international study experiences motivated her to create international experiences for students that equips them to live "big lives" where they "are exposed to big ideas, [and] understand their existence beyond their local area. I think study abroad is often very transformative. I think the classroom isn't always transformative." One possible lesson that STISL courses may teach that similar domestic courses may not offer is noted by Gail:

Just coming face-to-face with what that means to be in a foreign place, what that means to be traveling in a place where you are really pretty much the other...It is that kind of personal growth experience of what it is like to immerse yourself into ... a different culture with different food and just all of that stuff that traveling can sometimes do for us in terms of pushing our boundaries and pushing our own personal growth and revelations about ourselves. 
The idea of pushing boundaries and being in what Isabelle called the "stretch zone" was a recurring theme for many research participants. Through assessing student learning and experience, research participants are constantly looking for ways to push students into the stretch zone, while still ensuring that students are not pushed too far into the "panic zone," where cognitive and emotional learning is severely hindered.

Overall, STISL faculty believe that STISL courses provide opportunities that traditional courses are unable to, including exposure to difference and intercultural development; participants are therefore better able to make lifelong decisions regarding international engagement. And despite the fact that there were few resources that were used to originally design the STISL courses, previous iterations provide valuable data that faculty use to ensure the pedagogy is further developed and refined.

STISL faculty self-study and intuition. The first method of program assessment is conducted by the STISL faculty members themselves and is consistent with the concept of self-study (LaBoskey, 2004; Loughran, 2004; Murphy, 2011). Unanimously, research participants reported that qualitative content analysis of assignments, including reflection journals, final reflection papers, and other student produced documents, is influential for STISL faculty members and helps them understand and assess program effectiveness. Ethan's course has no formal evaluation process and only uses student assignments: "We take from the journals and other assignments to use as our base for being successful." In the content 
analysis, Ethan is looking for signs of growth and articulated commitments to be social justice advocates. Isabelle intentionally incorporates evaluation questions into the final assignments, such as questions concerning what students feel went well and what students say they would change for future iterations of the course. Isabelle then highlights key comments, identifies themes, and considers the students' suggestions the next time she teaches the course.

In line with self-study, faculty members use their own reactions to the effectiveness of specific components or the program as a whole to evaluate their success. Research participants in general noted that they usually have an accurate perspective on how well certain components of the experience worked, based on the fact that they experienced many of the same things as the students. As was previously mentioned by Angela, "I am right there with them and I know what their experience is." Henry, who has been teaching STISL courses for over twenty years, noted that:

Mostly, and this is supposed to be the way academics thinks about this, is a matter of visceral insight. You can tell when students after an experience or encounter or reading or whatever are pumped. They want to have conversations about it. They are looking for additional insights for ways of making sense, for ways to extend the quality of the experience. When I get that, I go, ok, for his group, doing A and B and C and D worked.

Similarly, Christina conducts her own evaluation of the course and considers what was good, what didn't work, and what would be better "to do differently next time." Felicia noted that she relies on her instincts to understand what worked and what did not, but she also noted that after reviewing students' written surveys, she 
sometimes discovers issues or concerns that she would not have noticed had she not had another assessment tool other than her own intuition.

Departmental issued summated rating scales. The second method of assessment is through a standard departmental summated rating scale survey (see Johnson \& Christensen, 2012, pp. 178-179), which in many instances was a Likert scale with options ranging from strongly agree to strongly disagree in response to a variety of questions. Typically these departmental surveys are the same surveys utilized for courses that take place at the research participants home institution. Repeatedly, research participants asserted that these departmental surveys were inadequate and did not provide the insights that the faculty members felt they needed to know in order to understand student learning; this is consistent with Nasser and Fresco's (2002) findings that faculty find qualitative feedback more informative than quantitative. Additionally, and also consistent with the literature, there was little evidence to support the idea that the quantitative summated rating scale assessment was in anyway helpful for research participants to improve their teaching in future iterations of the course (Hampton \& Reiser, 2004; Kember, Leung, \& Kwan, 2002; Nasser \& Fresko, 2002).

In Isabelle's opinion, the standard departmental evaluation “doesn't really ask deeper questions or questions that are relevant to international study abroad." Henry concurs with Isabelle and considers the departmental evaluation to be only marginally helpful in understanding the students' learning experience. Isabelle also noted that administering the departmental surveys is "tricky" because faculty are 
not allowed to touch the evaluation, but logistically she feels she has to in order to ensure it is delivered to her department chair.

\section{STISL faculty initiated qualitative assessment and scholarly}

quantitative inventories. The third method of assessment research participants

mentioned using in order to evaluate the STISL course is their own survey or assessment form and a scholarly inventory. Typically, the faculty's own survey collects open ended, qualitative data. In a survey for Felicia's STISL course, she specifically references the goals that are have already been articulated and requires that students reflect on the extent to which they believe those goals have been met. For example:

so the goals of this course are [that] you will learn about another culture, that you will develop a deeper sense of what service means, that you will take risks and get out of your comfort zone and have a broader understanding of strengths and be able to identify strengths of other cultures. So what has been effective and what has not been effective kinds of things? Some years I have done those kinds of things, asking about specific assignments... the journal, the final reflection, the pre-departure stuff.

While most faculty use a survey or assessment form, Isabelle conducts a reflection session with the students that she calls "Plus-Delta," where students get the opportunity to talk about what they felt went well and what they would suggest changing. Christina asks students to write a reflective paper similar to Isabelle's Plus-Delta evaluation but also asks that they describe their most memorable "thing" about the course.

Another faculty initiated assessment technique was mentioned only by Barbara and consistent of a formal, scholarly, and quantitative cultural competency 
inventory. In this instance, Barbara incorporated her scholarly agenda into the evaluation of her STISL course. In her research project, Barbara measured students pre- and post- STISL cultural development inventory, called the Inventory for Assessing the Process of Cultural Competence among Health Care ProfessionalsStudent Version@.

The IAPCC-SV $\odot$ is a pencil/paper self-assessment tool that measures the level of cultural competence among undergraduate students. It consists of 20 items that measure the five cultural constructs of desire, awareness, knowledge, skill and encounters. The IAPCC-SV $\odot$ uses a 4-point Likert scale reflecting the response categories of strongly agree, agree, disagree, strongly disagree. Completion time is approximately $10-15$ minutes. Scores range from 20-80 and indicate whether a student is operating at a level of cultural proficiency, cultural competence, cultural awareness or cultural incompetence. Higher scores depict a higher level of cultural competence. (Transcultural C.A.R.E. Associates, 2013, para. 2)

While both Barbara and Ethan incorporated data from their STISL course for scholarly presentations, only Barbara has published scholarly articles investigating student learning and gains in cultural competency.

Education abroad assessment. The fourth evaluation method is through a standard education abroad survey, typically emailed to students after they return to their home institution. For most research participants, they either did not know that this survey was ever given to students or knew that it was given to students but had never seen the results. The researcher for this project confirmed that every student who participated in a faculty-led international course at Public Urban University should have been issued an evaluation survey, but very few reported ever seeing the results; some did not even know that they were being issued: "No, I haven't seen those," (Gail) and "I have never had any feedback... from [Education Abroad]." Only 
Isabelle from Public Urban University said she had seen results from an education abroad office's evaluation. At Small Private College, Angela reported having seen the results of the education abroad office's evaluation, but did not feel the results were especially meaningful, similar to the department issued evaluations mentioned above. "[The evaluation asks] were the accommodations ok, was the food ok, were you comfortable and all this stuff- the difference [between our program and other international courses is that faculty] didn't go on the trip with students." Angela believes she already knows what the students' responses will be to these questions, because "I am in the same hotel with them, I am sharing a room with two other people, I am right there with them and I know what their experience is." Overall, the vast majority of the research participants did not know that education abroad offices were issuing evaluations, knew and had not seen results, or had seen the results but did not believe they were important in their evaluation process.

\section{Iterative Teaching Summary}

As many research participants reported, there is not a guidebook outlining how to structure and implement STISL courses. Instead, faculty use data from previous STISL experiences in order to improve the STISL experience, thus providing students with a deeper and more enriching long-term transformational experience. As noted earlier, without implementing changes in subsequent STISL courses, all of the above mentioned evaluative strategies would merely be assessment and not iterative teaching. There was not evidence to support that some of the assessment techniques inform them in future iterations of the STISL courses, 
namely departmental and education abroad generated summated evaluations.

Therefore, these two assessment techniques are not considered informative in the iterative teaching process and can only be considered programmatic assessments. However, other forms of assessment, including self-study through faculty intuition and faculty generated assessments (both qualitative and quantitative), significantly impacted the iterative teaching process when faculty considered revising components of the STISL experience for future iterations of the course.

Overall, assignments such as reflection papers, reflection journals, hostcountry assignments, re-entry assignments, and reflection discussions (both on-onone with faculty and as a whole class) are rich with data that reveal the extent to which students experience significant learning on a STISL course. In fact, these are the most influential data points for the iterative teaching process. Many research participants noted that if they do not see evidence student learning in these assignments as they had hoped, it is not necessarily a reflection on the students' effort or ability and may actually be a flaw in the assignment itself. Therefore, faculty must identify how various factors may have contributed to the short-coming and strategize regarding how equip students to succeed in the future.

An example of the iterative process comes from Gail, whose course was originally six weeks long. This particular course originally involved travelling long distances to work with community partners; after reflecting on students' attitudes and level of engagement after traveling a long distance and six weeks of service work, Gail decided that the course itself was simply too long and too involved. In 
light of her observations and student reflections during the second component of the course, Gail and her co-instructor decided that the structure of the course would better support intended learning outcomes if it were shorter and did not move to another service site. Additionally, through oral and written reflection, Gail noticed that because of the fast-paced nature of the course she originally implemented, students were exhausted to the point that they could not cognitively engage in the experience as it was designed. Therefore, Gail altered the program's schedule to allow for students to get more rest, which in future iterations of the course enabled students to be more engaged throughout the experience.

Also pertaining to self-study, Felicia realized that her course's assignment to interview a community member was not working out as she had intended, seeing that students were simply asking random questions to a host-country citizen who was most likely sunbathing on the beach. In light of this, Felicia decided to set up parameters for interview questions and discussions about who would be the most appropriate people to interview to glean intercultural perspectives that better related to the learning objectives for the course.

Through self-study and faculty's intuition Isabelle, who did not have rules about technology in the past, discovered that "in the last two years it has become an issue." Because of their experience, David, Henry, and Isabelle all express concerns that technology on a STISL course may inhibit the quality and depth of a students' STISL experience on multiple levels. "I've noticed things, like - something is missing in the experience if when we are walking from place to place, students have their 
iPods and they are listening [to music]. More specifically Henry has noticed that students "may be investing more time staying in touch than delving into the [STISL] experience." Henry feels that technological intrusion on a STISL course may negatively impact students' language acquisition in that students can "go out and struggle for half an hour having a simple conversation with someone [in the host country], or you can spend a half an hour ... on the Internet in your own language. It is easy to gravitate toward the latter." According to these research participants, technology has the potential to diminish the depth of a student's STISL experience in that the student may avoid challenging yet surmountable challenges, isolate themselves from the group and the host culture, and potentially stifle group cohesion and limit the depth of emotional support the class as a whole (both students and faculty) could otherwise provide. As a result, many research participants have instituted non-negotiable expectations regarding technology that may distract from the STISL experience, such as no iPods except in students' rooms. Other research participants explain expected group engagement, which includes self-regulating the amount that students rely on and utilize technology that may detract from the learning process.

Finally, data show that the impact of assessment on program design, iterative teaching, was most commonly witnessed as research participants planned future pre-departure preparation sessions for subsequent years. Often after a STISL experience, faculty ask students through a qualitative open-ended survey what they had wished they had known before being in the host-country that would have better 
prepared them for the experience. Many times, faculty took those suggestions, such as knowing basic phrases in the host-country's language, and incorporated them into the pre-departure preparation sessions for students in the STISL course the next time it was taught.

\section{Summary of Key Findings}

In summary, chapter four has outlined findings through the data pursuant to the two overarching research questions around which this study was developed: (a) How do STISL faculty define a successful STISL experience, and (b) how do STISL faculty intentionally design teaching, learning and service experiences to achieve their desired outcomes?

Through this research, findings show what is now known as the Van Cleave Conceptual Framework of STISL Success, which answers this research project's first question regarding how STISL faculty define success. Overall, five dimensions of success-academic, professional, interpersonal, intrapersonal, and interculturaleach manifest through three separate success factors: culturally contextualized solidarity, global civic engagement, and global competence. When conceptualized holistically the overarching hallmark of success, according to STISL faculty members, is global agency.

Next, in order to answer the second research question for this project, data were organized chronologically from pre-departure through re-entry and were aligned with the various dimensions and factors of success. 
First, during the pre-departure segment of the STISL course, the application process is used not only to find which students would benefit most from the experience, but also to assist the faculty member in preparing students for what is often a disorienting and dissonant experience. Both lodging and fundraising efforts need to be preemptively addressed to prepare students to succeed during the experience and to possibly procure additional service supplies as well and lower overall costs for the students. Next, data show seven interrelated categories of strategy: practical, academic, professional, interpersonal, intrapersonal, intercultural, and global civic engagement preparation. In terms of pedagogical strategies, in each of these interrelated categories both didactic and reflective practices are implemented in order to ensure that students are cognitively, emotionally, and relationally prepared to succeed and experience significant learning experiences by testing abstract conceptualizations of global agency in the concrete experiences during the host-country segment of the STISL course.

Second, examining the host-country segment of the STISL course proved to be pedagogically complex and detailed, but it provides examples of overarching pedagogical strategies that can be applied to most any STISL course, regardless of academic topic or geographic location. The host-country segment serves as the place where students apply abstract conceptualizations made during the predeparture segment to concrete service experiences; students subsequently reflect on those experiences in order to refine and further develop concepts related to global agency. 
The amount of previously acquired skills that student had before the service experience impacted service pedagogical strategies more than any other factor. However, regardless of skill level, all service experiences were strategically implemented in ways that were integrally intertwined with local ways of knowledge, as opposed to imposing perceptions of service on a community without acknowledging cultural context. No service experiences were implemented outside of local ways of knowing, affirming that global competence is very much related to global civic engagement.

Furthermore, reflection was articulated as possibly the most important pedagogical strategy used during the host-country segment. Reflection strategies included both written and oral reflection (group and solo), and reflection served as the place where students made connections between what they had learned or read about the culture or academic concept and what they were actually experiencing. The DEAL model (Ash \& Clayton, 2009), with its describe, evaluate, and articulate learning dimensions, directly aligns with the pedagogical design that the participants for this research project articulated as significant components of their reflection strategies. Also, the fact that reflection strategies are varied, in that they include oral and written reflection, aligns well with Gardner's (1993) theory that there are multiple ways to pedagogically approach elements of design that correspond with individual learner's multiple intelligences.

In assignments due during the host-country segment of the STISL course, many faculty creatively integrated pedagogical strategies such as the "Three 
Questions" assignment, interviews with host-country citizens, and language courses that are thought to substantively aid and inform students as they explore both academic and cultural components of the host-country and the needs that it faces.

One teaching strategy that became apparent through the data has not yet been mentioned in other ISL or STISL literature-the concept of team-teaching. Of the faculty who participated in this course, only one did not teach the course in tandem with a co-instructor or co-facilitator. Research participants consistently mentioned the importance of being available to students twenty-four hours a day, seven days a week and indicated that it was nearly impossible for them to provide this type of individual support on their own. Because of this, faculty consistently taught their STISL course with other faculty members, graduate assistants, alumni, institutional administrators, and in one instance a private education abroad company. By having two facilitators present, students were given more individualized and uninterrupted attention, which research participants feel is essential for the STISL experience.

Finally, during the host-country segment of the STISL course faculty consistently reported that cultural insiders, or individuals who were from the hostcountry's culture, were an invaluable resource utilized to supplement what the STISL faculty member themselves may be lacking in terms of cultural expertise related to the host-country. Strategies involving cultural insiders included the insiders providing cultural specific lectures, performing service with students, 
accompanying students on cultural heritage visits, and in some instances participating in reflection sessions, all to provide in depth cultural insights that otherwise would not be included in the design of the course.

Overall, all of the strategies that were articulated can be categorized according to the five dimensions and three factors of success outlined in the Van Cleave Framework of STISL Success, as was Van Cleave Pedagogical Design Framework for Global Agency. The Van Cleave Pedagogical Design Framework for Global Agency succinctly answers this research project's second question regarding how faculty design STISL courses in order to achieve success as they have defined it. The Van Cleave Pedagogical Design Framework for Global Agency displays and organizes pedagogical design strategies that the research participants reported utilizing in order to achieve success as they have conceptualized it, culminating with the development of students' global agency. This Framework serves as a starting point from where potential STISL faculty can begin to plan design strategies for what used to be an ambiguous and difficult to operationalize pedagogical strategy.

While all STISL faculty interviewed through this study sought to create learning experiences that were both challenging and supportive, even the best pedagogical design strategies can be catalysts for dissonance within students.

First, faculty reported that intercultural dissonance was one of the most obvious and pervasive forms of dissonance that they witnessed during their years of experience. While there were different components of cultural difference that 
caused the dissonance, research participants articulated two overall strategies for addressing the dissonance. First, when the students' reaction had the potential to irreparably damage the institution's relationship with the community-partner, STISL faculty often directly confronted students and made non-negotiable decisions in order to rectify the situation. Second, when the dissonance would not damage relationships, faculty used reflection, both written and oral, in order to facilitate student learning and making connections between the dissonant experience and potential cultural roots of what was making students feel uncomfortable. As opposed to perceiving the difference in binary "good versus bad" categories, faculty sought to equip students to approach the situation from a nonvalue laden perspective, thus avoiding casting judgment on the host-country's culture.

Second, and in some ways related to intercultural dissonance, intrapersonal dissonance occurred when students' identities and ways of knowing were different from and in some instances conflicting with local cultural norms. The identities most significantly impacted by dissonance included gender, race/ethnicity, and personal connection to the service activity. Similar to the second approach noted above with intercultural dissonance, interpersonal dissonance was most often addressed through oral or written reflection (either in a group or solo); this was intended to help the students draw larger connections between what they were feeling and factors that were influencing them. Again, the ultimate goal was to 
move students from a place of value-based judgments to ethnorelative understandings of the situation.

Additionally, while the data does not show that it caused dissonance within students, students' spiritual identities did, according to many research participants, impact how students intrapersonally understood and interpreted the STISL experience. Both in terms of overall purpose in life and connection to professional ambitions, humanity, and possibly a divine entity, a spiritual element did become apparent to various research participants through students' reflections and comments.

Finally, the iterative teaching process, using assessment data in order to improve teaching, was a significant influence on how STISL faculty re-structured their courses in subsequent years. While departmental and education abroad offices issued summated assessment tools that were not informative in the iterative process, self-study, faculty intuition, faculty generated qualitative assessment, and scholarly quantitative assessment techniques were reported by research participants as being important and influential data points that informed what they decided to change in subsequent iterations of the course. Commonly, data from the above assessment techniques impacted the content and quality of the predeparture process and served as a catalyst for other research participants to provide more opportunities for in depth service, rather than multiple one-time service experiences. 
In terms of why faculty initially chose to utilize a STISL pedagogy and improve pedagogical practices in future iterations, STISL faculty reported that the short-term nature of the experience made the course more accessible to a larger number of students, especially those with major life responsibilities outside of the classroom. As many research participants mentioned, any international service experience, regardless of duration, is better than none. Additionally, research participants consistently reported that the STISL experience provided students with educational opportunities that are not traditionally possible on students' home campuses.

Overall, this research project has clearly and specifically identified what STISL faculty hope to achieve through these experiences and explicit pedagogical strategies that have been thoroughly vetted by experienced STISL faculty members. These findings have the potential to significantly improve STISL practice and design and garner increased support for STISL from institutional administrators looking for innovative techniques that equip graduates to succeed in a complex and interconnected global society. In order to fully understand these implications and recommended future steps, it is essential to look at the relationship between STISL pedagogy and institutions of higher education from a variety of viewpoints. In order to do this, the implications and significance of these findings and recommended future steps will be considered by revisiting Bolman and Deal's (2008) four frames of organizational behavior and theory (structural, human resources, political, and symbolic). By doing this, it will be possible to more 
thoroughly understand the depth and breadth of how these findings will impact institutional commitments, resources, and future global initiatives. 


\section{CHAPTER 5}

\section{IMPLICATIONS, SIGNIFICANCE, AND NEXT STEPS}

\section{Introduction}

Up until this point, STISL has been lauded as a pedagogical technique that has the potential to significantly impact the way students learn to relate to an interconnected global society that is facing a precarious future (Bringle \& Hatcher, 2011; Monard-Weissman, 2003; Plater et al., 2009). While this is a laudable goal, the literature had yet to articulate operational and implementable pedagogical design strategies, and the standards of success were ambiguous. This research project sought to fill this gap in the literature by answering two questions: (a) how do STISL faculty define a successful STISL experience and (b) how do STISL faculty intentionally design teaching, learning and service experiences to achieve their desired outcomes?

The findings of this research have the first of these research questions by providing the field with a holistic conceptualization of STISL success that culminates in global agency (the Van Cleave Framework for STISL Success, see Figure 8). The Van Cleave Framework for STISL Success moves the field from what were confusing and enigmatic ideals of success to specific and operational hallmarks that can be addressed through clearer pedagogical strategies.

Additionally, the data gathered from this research project led to the articulation of a new conceptual framework that outlines overarching design strategies (the Van Cleave Conceptual Framework for STISL Design) and serves as a model that demonstrates how STISL pedagogy can culminate in developing global 
agency, as faculty have defined it; this answers the second research question. Finally, specific principles of best practice have been identified that serve as an operational design framework (the Van Cleave Pedagogical Design Framework for Global Agency) that equips faculty from nearly any academic discipline to apply design strategies that have been identified as effective by experienced STISL faculty members.

These findings have the potential to significantly improve STISL course design and garner deeper institutional commitments to utilizing this pedagogy; STISL courses advance the missions of institutions by developing students who are both able and willing to act in order to address some of the most significant issues facing the world today. In order to understand how these findings have the potential to achieve this, it is important to first analyze the implications of, the significance of, and future steps for STISL pedagogy using different perspectives on institutions of higher education. In order to do this, the findings will be organized by revisiting Bolman and Deal's (2008) four frames of organizational behavior and theory, which were discussed in Chapter two primarily as they related to the integration of servicelearning pedagogy in general, not specifically STISL Chapter five will conclude with suggestions for future research and an examination of the limitations of the study.

\section{Implications, Significance, and Next Steps}

Whether one reads news reports or scholarly research, the evidence shows that in the $21^{\text {st }}$ century, the world is plagued with significant human and environmental problems that threaten our future as a society and as a planet (Burns, 2009; Hughes et al., 2009; Kaplinsky, 2005; Plater, 2011; Thompson-Jones, 2013). 
However, as scholars note, while the challenges set before us are large, they are not insurmountable. Individuals, governments, non-profit organizations, and educational institutions all have the potential to meet these challenges head on. Educational institutions in particular can produce students that are able and willing to institute interventions that can redirect the detrimental course on which the planet is heading (Brainard, Grahm, Purvis, Radelet, \& Smith, 2003; Burns, 2009; Hughes et al., 2009; Juarez, 2013).

In response to the challenges that face the next generation of health care providers, business people, NGO leaders, and policy makers, society is looking to institutions of higher education to develop a new generation of graduates who are able to meet complex global needs (Jacoby \& Brown, 2009; Stearns, 2009; ThompsonJones, 2013). Colleges and universities have responded by broadening their mission and vision statements to reflect their new dedication to graduate students who are able to function and succeed in an increasingly internationalized and globalized society (Braskamp, 2008; Jacoby \& Brown, 2009; Mestenhauser, 2011). This, is as Stearns (2009) noted, the new norm for the field.

Thus far, the international service-learning literature has made lofty yet anecdotal suppositions that ISL pedagogy seeks to equip students to be able to address significant human and environmental needs throughout the world. Specifically, as Bringle and Hatcher (2011) posit, ISL "may be a pedagogy that is best suited to prepare college graduates to be active global citizens in the $21^{\text {st }}$ century" (p. 3). This assertion aligns with many institutions' newly internationalized 
organizational commitments and President Obama's (2009) challenge to improve the quality of life for people not only in the United States, but also across the globe.

According to the literature, there has been limited evidence to support the idea that ISL programs-specifically ISL faculty members-consider long-term student transformation for global agency as a hallmark of success. As has been articulated through the findings of this study, the data show that this is true; ISL programs, specifically STISL, ultimately strive for students to develop global agency, with which they are able to contribute to addressing the world's most pressing concerns. It is important to note that addressing issues of global concern is not limited to the duration of the class itself, but instead the class serves as a catalyst for a life-long commitment to global society.

Additionally, a significant finding from this study includes that long-term success does not just mean the desire to meet global needs, but addresses the ways in which students (and future graduates) approach meeting global needs. STISL pedagogy in itself is a postcolonial pedagogy, which rejects the notion that "Western science and rationally are more advanced or refined than other positions, or, more simply, that they are the norm" (Briggs \& Sharp, 2004, p. 2). STISL faculty consistently reiterated the point that service and international development actions should not be approached from a U.S. or Western standpoint and should incorporate and honor indigenous community perspectives. Whether addressing a global issue related to the human condition or ecology, in order to fulfill President Obama's (2009) call to action, service and future development activities need to be approached from a culturally 
contextualized postcolonial perspective that honors indigenous ways of knowing in order to be well positioned to institute sustainable and long-term change.

It is essential to acknowledge that in terms of developing global agency, STISL pedagogy is not to be perceived as a culminating experience, but rather as a component of a larger personal journey. The research participants in this study never explicitly or implicitly conveyed that they expected a STISL course to instantaneously or automatically develop students as global agents. Instead, similar to transformational education (Mezirow, 1991, 2000), global agency takes time and intentional reflection in order to develop. Much depends on the extent of experience that students bring into the STISL course, as well as the effort that they spend reflecting on personal development and transformation.

In a very tangible sense, STISL pedagogy uses abstract institutional (Stearns, 2009) and national commitments (Obama, 2009) as a basis for concrete action to improve the quality of life for people around the world and operationalizes a process for designing curricula that foster individuals' life-long willingness and ability to be a part of initiatives that benefit the entire global community. The STISL experiences themselves are not intended to change the world in and of themselves. Nor do these courses intend to be, as Butin (2010) describes it, a "'white knight' riding in to save anyone" (p. 5). STISL pedagogy is meant to be a catalyst for developing the desire to make a change, as well as developing the desire to acquire the skills in order to do so.

The findings of this study have the potential to significantly impact on how institutions view and execute international service-learning courses. Because of the 
breadth and depth of this study, institutional organizations have the opportunity to deepen the extent to which their rhetoric about global engagement is manifested through pedagogy and educational opportunities.

In order further the implementation and support of STISL, it is essential that the findings be understood and analyzed according to the organizational structure of institutions. This will provide a holistic vision of how STISL pedagogy can impact students, institutions, and communities, and how institutions can best approach operationalizing these findings. To do this, both its significance and its implications will be addressed using Bolman and Deal's (2008) four frame model of conceptualizing organizational behavior and theory. For as Hampden-Turner (as cited in Bolman \& Deal, 2008) note, “The world simply can't be made sense of, facts can't be organized, unless you have a mental model to begin with" (p. 10).

\section{Insights From the Four Frames of Organizational Behavior and Theory for}

\section{Supporting and Promoting STISL}

Bolman and Deal's (2008) four frame approach to conceptualizing organizational behavior and theory seeks to illuminate varying approaches to understanding organizations. Initially, due to the limited literature regarding ISL and STISL, the literature review section of this paper inferred many potential implications from the SL literature. However, considering the scope of this study, it is possible to return to the four frames in order to better understand how to support and promote STISL pedagogy. 


\section{Structural Frame Implications}

\section{A1. Organizations exist to achieve established goals and objectives.}

According to Bolman and Deal (2008), "organizations exist to achieve established goals and objectives" (p. 47). Most often, goals and objectives that institutions of higher education intend to achieve are outlined in the college or university's mission statement (Middaugh, 2010, p. 25). For each of the research participants who participated in this study, their institutions included somewhere in its mission, vision, or value statement a commitment related to graduating students who are able to positively contribute to the global community. Additionally, overarching organizations, such as the Association of Colleges and Universities (2013a), a "leading national association concerned with the quality, vitality, and public standing of undergraduate liberal education," (para. 1), have articulated that their initiatives shares ideals similar to institutions' commitments to the global community:

[The] Shared Futures: Global Learning and Social Responsibility is a multiproject, national initiative of AAC\&U. The initiative was built on the assumption that we live in an interdependent but unequal world and that higher education can prepare students to not only thrive in such a world, but to creatively and responsibly remedy its inequities and problems. (2011, para.1)

While this commitment is lofty, some institutions and educational organizations have made more specific organizational goals while still in a similar vein, including initiatives to further develop educational opportunities for sustainability (Morris, 2008; Sammalisto \& Lindhqvist, 2008) as well as cross-cultural or intercultural competence (Clark, Bouls, Subbaraman, \& Balón, 2004; Otten, 2003). 
In terms of sustainability, the United Nations Educational, Scientific and Cultural Organization (UNESCO) declared that 2005-2014 be the decade of "Education for Sustainable development" (Morris, 2008, p. 180) calling for strategies that will “encourage [changes for both educational institutions' and students] in [relation to their] behavior that will create a more sustainable future in terms of environmental integrity, economic viability, and a just society for present and future generations" (UNESCO, as cited in Morris, 2008, p. 180). Sustainability education has manifested itself in many ways including "mere formulations of policy statements to integration into courses, [and] curricula... [to] a more practical approach to promote sustainable development... with tangible environmental impacts" (Sammalisto \& Lindhqvist, 2008, p. 222). Institutions of higher education are being increasingly seen as an integral resource in terms of research and scholarship related to sustainability, as well as an incubator for developing students who are capable and willing to address sustainability and ecology related issues facing the planet in the $21^{\text {st }}$ century.

Cross-cultural and intercultural competencies have been identified by scholars as necessary for $21^{\text {st }}$ century graduates in terms of employment (Livermore, 2011) as well as for international development efforts (Williams, 2002). Williams (2002) alluded to the fact that good or bad may actually be culturally contextual, which may impact the extent to which efforts to which meeting the needs of a community is received, and ultimately succeeds or fails. Williams warned that international or global efforts that impose a value system on another culture or country risks "cultural imperialism, or the imposition of particular, Western values" (p. 50). Therefore, while 
higher education has articulated lofty goals for meeting the needs of an $21^{\text {st }}$ century world, culture and context must be considered, and incorporated as a core value in the educational process.

Central to not only the United States' democratic principles, but also to global organizational bodies, the AAC\&U asserts that "it is more urgent than ever that higher education... offer vehicles through which students expand their knowledge of each other's cultures and develop skills to work across differences toward shared goals (para. 2). Higher education has responded to this call. Institutions are currently undertaking new initiatives in order to prepare students for intercultural competence (encompassing the terms multi-cultural and diversity) "in the face of ever increasing diversity, intensified globalization, and hardening political polarization" (AAC\&U, 2013b, para. 2).

The overarching goal of STISL, developing students' global agency, directly aligns with both individual institutions and national educational organizations' goals and ambitions. In a tangible sense, STISL pedagogy is the embodiment of organizational and industry commitments related to how they hope graduates will interact with global society long-term. As was mentioned by various research participants through this study, faculty are often left with few strategies for operationalizing their institution's mission statement; this is a criticism of non-profit organizational mission statements in general (Sawhill \& Williamson, 2001).

The Van Cleave Pedagogical Design Framework for Global Agency, however, provides a concise yet thorough design strategy transforming an institutional 
commitment for global agency from an abstract and vague conceptualization to an implementable and operational pedagogical design strategy, while the Van Cleave Framework for STISL Success in many instances clearly aligns pedagogy-specific goals with institutional missions and visions. This alignment has the potential to solidify STISL's role in a $21^{\text {st }}$ century educational institution.

\section{A2. Organizations increase efficiency and enhance performance through} specialization and appropriate division of labor. The second assumption related to the structural frame of understanding organizations is that "organizations increase efficiency and enhance performance through specialization and appropriate division of labor" (Bolman \& Deal, 2008, p. 47). Division of labor is readily apparent in higher education, and while in some instances division of labor may increase efficiency, it can also lead to redundancies and inefficiency (Chan, 2002).

Faculty are experts in their academic fields and bring that expertise to the STISL experience. In general, faculty are not initially experts in international education or service-learning and are often left implementing STISL experiences for the first time without significant or strategic pedagogical support. In the vast majority of institutions that were represented through this study, education abroad and service-learning offices did not interact with each other and collaboration between offices rarely if ever impacted STISL pedagogical design. While there is evidence that new STISL faculty seek out more experienced STISL faculty on their own for help when first designing a STISL course, there are no data that showed institutional support or collaboration between institutional silos. Both education abroad and 
service-learning are specific and complex teaching strategies and theoretically have the potential to significantly impact STISL design. However, outside of logistics, budgets, and program assessments (which STISL faculty find unhelpful), the division of labor seemingly inhibits meaningful collaboration between offices of education abroad and service-learning with STISL faculty themselves. Organizationally, STISL faculty have no formal way to learn from experts that are already at their institutions or to share what they have learned through the iterative process of teaching STISL, something from which other STISL faculty could benefit. In fact, research participants from this study repeatedly asked for a copy of the findings so that they could learn what other STISL faculty members have found beneficial pedagogical strategies that they could incorporate in their own STISL courses.

\section{A3. Suitable forms of coordination and control ensure that diverse efforts}

of individuals and units mesh. The third assumption for understanding organizations' structures is that "suitable forms of coordination and control ensure that diverse efforts of individuals and units mesh" (p. 47). Related to what was discussed while considering assumption A2, the division of labor within institutions may be hindering the process of preparing new STISL faculty and keeping education abroad departments, service-learning departments, and experienced STISL faculty from sharing their expertise. Overall, there is little evidence to support the idea that institutions have instituted forms of coordination across the organization that have been strategically designed in order to build off the knowledge base and experience of other groups across campus. 
This research project has gathered the perspectives and expertise of seasoned STISL faculty members. The data show that in addition to specific academic discipline content impacting pedagogical design, principles well known by education abroad (i.e. culture shock, intercultural communication) and service-learning (i.e. reciprocity, reflection, and service integration) departments are also integral to program success. However, because of organizational structure and division of labor, STISL courses are potentially not being initially implemented using principles of best practice and are instead relying on the "trial and error" method of STISL faculty discovering by themselves what worked, what did not, and what to change for future courses. This "trial and error" method of program design does not have to be the norm for the field anymore.

The Van Cleave Pedagogical Design Framework for Global Agency has filled what was an expansive gap in the literature and practice across campuses, which are principles of best practice for STISL pedagogy. This framework provides an opportunity for STISL faculty to build upon and learn from the successes of experienced STISL instructors. Intentionally designed to be approachable by faculty of any academic discipline from any type of postsecondary institution, the pedagogy is customizable by faculty in ways that suit each course's specific context. However, rather than give faculty the Van Cleave Pedagogical Design Framework for Global Agency and subsequently expect them to design a holistic STISL experience, institutions could best approach the framework through a faculty development experience, such as a seminar, where faculty are coached and equipped to understand 
the importance of the various dimensions of design and taught specific design strategies that other STISL faculty have found beneficial. It would be most beneficial for these faculty development experiences to be a coordinated effort between education abroad, service-learning, and STISL faculty members. This suggestion aligns with Driscoll and Sandmann's (2004) recommendation that institutions interested in integrating civic engagement throughout a university capitalize on the strengths that are already present within an organization. Additionally, the professional development experience may put into place safeguards that ensure student safety, mitigate potential risks, and reinforce the importance of reciprocity and culturally contextualized service experiences. Practically, a professional development seminar could reduce the anxiety of faculty who are considering a STISL course, do not know where to start, or without support would never teach a STISL course.

A4. Problems arise and performance suffers from structural deficiencies, which can be remedied through analysis and restructuring. The last of Bolman and Deal's (2008) assumptions that relate to the significance and implications of this research study's findings is that "problems arise and performance suffers from structural deficiencies, which can be remedied through analysis and restructuring" ( $p$. 47). As was discussed in assumption A3, STISL courses are often first designed using a "trial and error" mentality that may in fact risk the quality of the STISL experience for many of its stakeholders. Trial and error may put students in danger of being traumatized by the experience, risk institutional resources due to lack of planning in terms of risk management, or unintentionally damage community partners' 
reputation within the community that they are serving. In many ways, the trial and error design strategy originally utilized by many STISL faculty makes sense considering few individuals have the expansive literature and experience base that is required to design a holistic STISL course.

Again, findings from this research, as articulated in the Van Cleave Pedagogical Design Framework for Global Agency, rectify this problem in practice. While the structure of colleges and universities may in fact be detrimental to crossdepartmental pedagogical collaboration, this framework bridges the pervasive structural gap by incorporating principles of best practice through the lenses of education abroad and service-learning, which can be applied to most any academic discipline.

Organizational structures prove a useful way of understanding the implications of any research findings, especially findings that are as broad and inclusive as the findings from this project. This being said, structures themselves comprise not only organizational sectors, but also the people that make up the structures of an organization. Therefore, it is necessary to discuss the people who make up organizations; they will be analyzed through the human resources frame of organizations.

\section{Human Resource Frame Implications}

B1. People and organizations need each other. The first assumption related to the human resource frame is that "people and organizations need each other. Organizations need ideas, energy, and talent; people need careers, salaries, and 
opportunities" (p. 122). Institutions need STISL faculty in order to implement the STISL pedagogy, which in turn fulfills institutional commitments to developing graduates with global agency. Faculty, on the other hand, need to be compensated for their time. This, however, is not always happening with STISL courses. Often, STISL faculty teach the pre-departure component unpaid the term before the course begins and are not compensated for planning the intricate logistics of the course, which takes extensive time and effort. Therefore, while the institution is achieving its goal of developing graduates with global agency, STISL faculty are often left donating their time and effort to the institution.

\section{B2. When the fit between individual and system is poor, one or both suffer.}

The second assumption related to the human resource frame is that "When the fit between individual and system is poor, one or both suffer. Individuals are exploited..." (p. 122). As described in assumption B1, there is a mismatch between what STISL faculty provide for the institution and what the institution provides for STISL faculty.

While faculty are compensated for teaching the STISL course, often, more planning, effort, and time are expended on STISL courses than on courses that are taught on campus. While faculty are affectively rewarded simply by the enjoyment of facilitating these courses, there is no evidence to suggest that STISL faculty are compensated for the extra time that is required in order to plan and implement STISL courses. And while the findings of this research study have the potential to improve STISL practices, the initial implementation of the Van Cleave Pedagogical Design Framework for Global Agency may be time intensive; this may in turn dissuade STISL 
faculty from participating in a faculty development experience using the framework. Regardless, there are some strategies that may help institutions improve STISL practice while honoring the investment that STISL faculty are already making. Institutions should creatively design mechanisms by which faculty can be compensated the term or semester before a STISL course for the time and effort that they put into the course preparation and the pre-departure segment of the experience. One strategy may include having students register for a one-credit pre-departure preparation course, for which students receive a grade and faculty are paid. While this strategy may marginally increase the overall cost of the STISL experience for students, students would be rewarded with an academic grade that could be counted as an elective towards a degree, which may in turn increase student motivation to invest their time and energy in the pre-departure process.

Another strategy for compensating faculty for the STISL experience would be to provide financial incentives for the faculty development experience that was described in the structural frame discussion (Furco \& Holland, 2004). Whether through a faculty development or internationalization mini-grant opportunity, providing a financial incentive to participate in the faculty development experience may increase the likelihood that faculty would wish to participate, because they would be compensated for their time. This would be beneficial not only for the STISL faculty member, but also for other stakeholders (such as community partners and the students) because, as Beere, Votruba, and Wells (2011) note, internal institutional grants can increase faculty engagement with the course planning process. 
A final strategy suggested for institutions in terms of recognizing STISL faculty's extensive effort in STISL course implementation would be through an annual awards program or STISL celebration. Both award programs and celebrations call attention to institutional efforts related to international service-learning and provide an opportunity for uninvolved faculty to learn about the work of their colleagues (Beere, Votruba, \& Wells, 2011). The data-collection process for this project demonstrated that STISL faculty enjoy discussing what they are doing with STISL, and an annual showcase may prove to be a well supported outlet for the dissemination of this information and possibly encourage faculty who have not yet taught a STISL course to do so.

In addition to compensation, there is little evidence to support the idea that faculty's STISL experience is considered in regard to promotion and tenure. In fact, one tenure-line RP reported that he felt that his STISL involvement hurt his chances of being promoted. Overall, the integration of service-learning or civic engagement as a factor for promotion and tenure is a contentious issue (Beere et al., 2011; Bringle \& Hatcher, 2004). However, as Beere and colleagues (2011) assert, "the implementation of [promotion and tenure] policies should be a blend of consistency and variability... The system should be open to rewarding differences as long as quality and rigor are not sacrificed" (p. 138). The Van Cleave Pedagogical Design Framework for Global Agency can be used to measure the quality and rigor of a program; this can be expressed to promotion and tenure reviewers or utilized by reviewers as a baseline set of best practices for the pedagogy. Beere and colleagues go on to state that in 
order to do this, promotion and tenure reviewers should engage in professional development opportunities that explain how quality and rigor can manifest in many ways, including through STISL pedagogy. This may in fact serve as a catalyst for experienced STISL faculty to be recognized for their expertise or improve their current practice, or for junior faculty to engage in STISL without the fear that it will harm their chances of earning tenure.

While organizations are organized by structure and comprise people, other factors of human and organizational behavior are influential in the implementation of findings, such as those from this research project. Therefore, it is important to look at the different influences that impact both structural and human resources frames, such as political and symbolic influences.

\section{Political Frame Implications}

\section{C1. Organizations are coalitions of assorted individuals and interest}

groups. According to the first assumption related to the political frame, Bolman and Deal (2008) assert that "organizations are coalitions of assorted individuals and interest groups... with enduring differences in values, beliefs, information, interests, and perceptions of reality" (p. 194). This is especially true when specifically addressing STISL, which involves faculty members, service-learning administrators, education abroad administrators, departmental administrators, accrediting bodies, students, and community partners. While many of these stakeholders may have varying priorities when it comes to the STISL experience, the Van Cleave Pedagogical Design Framework for Global Agency serves as a framework that addresses the most 
significant priorities for every party involved, ensuring that one stakeholder's "perception of reality" does not irreparably impede other stakeholder's goals or identities. This idea mirrors Butin's (2010) assertion that "not only should the service be meaningful and relevant service to those he is serving, but often members of the community being served should be the ones responsible for articulating what service should be done in the first place" (p. 5). Indigenous voice is especially evident in the framework's incorporation of a meaningful service activity that is implemented according to cultural context in response to a community-identified need (which relates to Briggs and Sharp's (2004) assertions about indigenous voices and development issues). In the same vein, honoring cultural context is at the heart of what the intercultural literature alludes to when it describes approaching cultural differences and perspectives as value neutral, not right or wrong (Bennett, 1993); it is because of this that reciprocity and respecting the priorities and cultural identities of non-institutional stakeholders are essential to the framework.

C2. Allocation of scarce resources - who gets what. The second assertion relevant to this study from the political frame is that within organizations, the "most important decisions involve allocating scarce resources - who gets what" (Bolman \& Deal, 2008, p. 195). It is common knowledge that institutions of higher education are facing significant budgetary shortfalls across the country. With tuition costs consistently rising and students graduating with significantly more student loan debt than ten years ago (Project on Student Debt, 2010), institutions have been charged to identify ways to reduce costs while delivering the same or even higher quality 
education (Obama, 2013b). Most recently, as Barr and McClellan (2011) note, the 2008-2009 recession has impacted both private and public institutions of higher education, resulting in increased competition for funds within both the public and private economic sectors; increased regulation, including a rise in unfunded mandates at the state and federal levels; a rise in the cost of technology; increased competition for faculty and staff; increased competition for students; concerns about the rising cost of higher education to students and their families; and rising costs for the purchase of goods and services (p. 2). With such dire financial concerns, it may seem unrealistic to propose that increased financial resources be allocated for STISL courses, specifically preparation and professional development experiences. However, institutions will be better poised to justify the cost, because STISL success (as described in the Van Cleave Framework of STISL Success) is so well aligned with institutional values, the fulfillment of which is essential in terms of long-term and sustainable financial support (see Furco \& Holland, 2004; Plater 2004).

Plater (2004) asserted while mini-grants and professional development support are important to program success (specifically service institutionalization), senior academic officers must ensure that all portions of the institution are set up to support rhetoric that is expressed in value and mission statements. Institutional leaders and policy makers "need to ensure that the promotion, tenure, and salary procedures, policies, and rewards for service are commensurate with institutional rhetoric about the value of [what the institution has articulated as important]" (p. 19). 
While the political frame serves as an important way of understanding organizational behavior, it alone does not fully encompass the various factors that impact organizations. Therefore, it is important to look at organizations, such as colleges and universities, through the symbolic frame, a way of understanding the role that organizations play in larger and possibly more influential dimensions of organizational behavior.

\section{Symbolic Frame Implications}

D1. Facing uncertainty and ambiguity, people create symbols to resolve confusion, find direction, and anchor hope and faith. The first assertion made by Bolman and Deal regarding the symbolic frame that is relevant to the implications of this research project is that when "facing uncertainty and ambiguity, people create symbols to resolve confusion, find direction, and anchor hope and faith" (p. 253). Historically, colleges and universities have been seen as cornerstones of society (Boyer, 1987). In addition to being institutions of teaching and research, colleges and universities have recently been reclaiming their identity as a body that meets the environmental and social needs within local communities (Beere et al., 2011). As world is becoming more interconnected, universities and colleges have responded through their mission and vision statements; their rhetoric expresses a commitment to produce graduates that are able to meet the complex needs of a global community.

The overarching hallmark of STISL success, global agency, seeks to develop individuals who are able to tackle some of the world's most pressing problems. This 
moves colleges away from being simply a mechanism of financial security and individual prosperity toward functioning as a symbol of hope for the world as a whole.

It is essential to note that the findings from this study are not a declaration that knowledge from Western, academic, or scientific method based frames are in any way superior to or more useful than indigenous ways of knowing. The findings from this study provide evidence that central to the hope that universities provide is through intentionally educating the future generation of global agents the value that indigenous knowledge has in meeting significant human and ecological needs. Briggs and Sharp's (2004) insights regarding indigenous knowledge aligns well with the concept of cultural context, which is essential to STISL pedagogy; "The recognition of indigenous knowledges [presents] an alternative experiences with which to challenge conventional development praxis and, indeed with a way of potentially empowering...neglected populations (see, for example, Leach \& Mearns, 1996; Holland \& Blackburn 1998)" (p. 663). STISL pedagogy provides hope that the next generation of graduates will care enough to address pressing global needs, the desire to acquire the skills to do so, but also the hope that they will do so in ways that honor and respect cultural context and indigenous knowledge.

In a very practical and operational way, the Van Cleave Pedagogical Design Framework for Global Agency makes it so faculty and institutions, regardless of specializing or classification, can design programs that deliver quality educational experiences, meet an immediate community need, and develop students as change 
agents capable of and willing to make a difference without devaluing cultural context and knowledge or cultural identities.

While the overarching hallmark of global agency seeks to fulfill the needs of a complex and interconnected $21^{\text {st }}$ century world, a notable pedagogical component was not readily evident through the data, even though the literature suggests its necessity, which is an in depth understanding of the role that power and privilege plays in service activities. As was described in the literature review section of this paper, understanding how power and privilege impacts global disparities is essential when approaching service activities and in developing solidarity with community members (Baker-Boosamra et al., 2006). This is not to say that in order to fulfill the symbolic role of higher education in addressing global human and ecological needs,

STISL faculty are not incorporating pedagogical strategies directly related to addressing power and privilege, only that none were readily identifiable through the data.

\section{D2. Culture forms the superglue that bonds an organization, unites}

people, and helps an enterprise accomplish desired ends. The second assertion from Bolman and Deal (2008) related to the symbolic frame that is relevant to this research project is the assertion that "culture forms the superglue that bonds an organization, unites people, and helps an enterprise accomplish desired ends" (p. 253). Culture is not something that can solely be created through institutional rhetoric or mission and value statements. In fact, institutional rhetoric in itself is empty without action (Plater, 2004). Therefore, in order to be a symbol of hope, 
institutions cannot simply stop at articulating commitments to develop students with global agency, but must rather take tangible steps toward that goal.

In order to do this, institutional administrators must recognize the value that STISL contributes to the identity of the institution and the benefit that a holistic STISL design, as represented in the Van Cleave Pedagogical Design Framework for Global Agency, can bring to an institution, i.e. confidence that the next generation of graduates can positively contribute to the global community. In addition to recognizing these two concepts, administrators must develop strategies for supporting high quality STISL courses through actions, such as providing financial resources for preparation and professional development and creatively increasing accessibility to all students, regardless of financial constraints. Lastly, by utilizing the Van Cleave Pedagogical Design Framework for Global Agency, institutions will be better equipped to address global problems through cultural context, honoring local ways of knowing and not imposing interventions that may be detrimental to a community's unique identity.

\section{Future Research}

As has been articulated in the literature, STISL is a young, emerging pedagogy (Bringle \& Hatcher, 2011; Plater et al., 2009; Plater, 2011), much of which has yet to be explored through empirical research (Eyler, 2011; Kiely \& Hartman, 2011; Tonkin, 2011). The findings from this research project are a substantial first step in articulating what are currently understood as pedagogical principles of best practice for the field. 
This being said, these principles were developed second-hand, using data from faculty who were observing student learning and not data that directly showed student learning. Therefore, future research projects should investigate the extent to which the articulated principles of best practice for STISL facilitate the depth and quality of student learning. Also, while global agency has been highlighted as the overarching hallmark of success for STISL courses that faculty hope students develop as a result of the experience, there remains a significant gap, in that there is not yet evidence to support that global agency has actually been achieved through a STISL course. Or, if global agency has been achieved and we do articulate a way to measure the concept, how long does it last?

Also, as is evident throughout the service-learning literature, reciprocity is a major concern for both community partners and for institutions of higher education (Dear, 2012; Jacoby, 2003). The data show that there were wide variations regarding what constituted a reciprocal relationship, and most research participants noted that reciprocity was often different with an international community-partner (as opposed to a domestic community-partner). Regardless, while there are standards of best practice for ensuring domestic reciprocity (Jacoby, 2003), there have yet to be articulated standards of best practice for international reciprocity that serve as guidelines for developing, maintaining, and honoring reciprocal relationships with international community partners. Future research should seek to fill this void by soliciting data directly from international community partners and articulate principles by which institutions and international community partners should be held 
accountable, so as to ensure long lasting and meaningful partnerships that educate students and accomplish a community-identified goal.

Finally, as was previously noted, there were no pedagogical strategies identified that explicitly addressed issues of power and privilege within a service context, and few identified alluded to the concept. While some research participants cited assigning readings such as Zemach-Bersin's (2008) American Students Abroad Can't Be Global Citizens, and Ivan Illich's (1990) To Hell With Good Intentions, it remains unclear how faculty approach equipping students to make meaning out of these articles, or other pedagogical strategies. Considering the centrality that issues of power and privilege play in relation international service and development efforts, future investigations specifically into strategies of best practice related to power and privilege would significantly benefit the field.

\section{Study Limitations}

The researcher for this study identified potential study limitations in Chapter three and subsequently strategically planned actions that would mitigate such limitations, such as member checking transcribed data with research participants, reviewing all transcripts in relation to audio recordings, and ensuring that the results were not influenced by the researcher's own STISL experience. Even though these efforts were taken, there are other limitations that may have impacted the findings of this project.

First, even though research participants were told during the initial stages of the interview that the purpose of this project was not to judge the research 
participants' teaching style and only sought to learn about perceptions of and strategies for success, the possibility remains that the research participants provided data that they thought the researcher wanted to hear, as opposed to truthful perspectives. Validating strategies through reviewing artifacts such as syllabi and program descriptions helped to mitigate this issue; however, not every RP provided artifacts to the researcher, and therefore validation was not always possible.

Second, there was only one researcher responsible for interpreting the data associated with this process, and therefore gathering alternative perspectives by member checking the interpreted data, as opposed to the raw data gathered directly from the research participants, was not possible.

Third, faculty were always e-mailed and asked to read Ogden's (2010) Three Dimensions of Global Citizenship before the interview was to take place. Not every RP read the document and thus they did not all have time to process the complex conceptualizations and had to give the researcher their initial reaction to what were very complex and detailed descriptions.

Finally, as was previously mentioned, no pedagogical strategies were identified that specifically addressed students' understanding of power and privilege. While many students appreciated or felt guilt from the privilege that they discovered they had compared to the host community, faculty were not asked to specifically identify what they did or how they structured their class in order to intentionally address the issue. Further investigation into proven pedagogical strategies that address power 
and privilege, such as Heldmen's (2011) work in domestic service-learning, would be a significant contribution to the STISL field.

\section{Next Steps}

As the findings from this research study have noted, STISL pedagogy offers a unique educational experience for preparing students to develop not only the motivation to address significant issues facing the $21^{\text {st }}$ century global community, but also the skills to do so in ethical and efficient ways. Due to STISL pedagogy's direct alignment with individual institutional missions as well as higher education overall, colleges and universities should further investigate how to develop strategic initiatives for increasing faculty support for implementing and studying this pedagogy, as well as increasing student access to STISL courses. Finally, institutional opportunities for strengthening the pre-departure and re-entry segments of the STISL experience will be discussed.

\section{Increasing STISL Faculty Support}

If institutions want to further incorporate STISL pedagogy, institutions are advised to investigate ways and resources that support faculty in the planning and execution of these courses, and the reward structure for engaged STISL scholarship. As the research participants in this study noted, most faculty felt that they had few, if any resources from which to draw in order to design the pedagogical dimensions of the STISL courses. Also based on the literature as well as this study's findings, there are significant amounts of knowledge within institutions for designing and implementing STISL. In order to better support faculty in this process, institutions 
should give serious consideration to solving institutional siloing that prevents knowledge being utilized from various parts of the organization. To start, institutions should consider hosting a conversation between experienced STISL faculty, servicelearning and education abroad offices to discuss perceived institutional strengths and weaknesses related to faculty support initiatives and resources. Second, it is advisable to widen the conversation, perhaps through an online survey, to discover broader perceptions of what related to STISL courses is working well and what are growth areas. Based on the findings of this institutional survey, a taskforce of experienced STISL faculty, service-learning and education abroad offices should design faculty development opportunities for those who are already facilitating STISL, as well as those who are considering it in the future.

A key component of these faculty development opportunities could include the various frameworks put forth in this research study. The taskforce would be able to use the Van Cleave Conceptual Framework for STISL Design as well as the Van Cleave Pedagogical Design Framework for Global Agency as a blueprint for equipping STISL faulty in designing a holistic pedagogical strategy that would maximize the potential for students to develop the overarching hallmark of STISL success, global agency. These faculty development opportunities would help to reduce, or possibly even eliminate the trial and error design strategy that most STISL faculty report using as well as ensure that institutional goals are being met through these courses.

The possibility remains that individual institutions might not have the interest or resources to devote many additional resources to supporting faculty who teach or 
want to teach STISL, despite STISL's direct connection to many institutional mission statements. Regardless of institutional initiatives, STISL faculty can still work on their own or together in unofficial working groups in order further develop STISL pedagogical strategies utilizing the findings from this study. Both the conceptual framework and the pedagogical design framework were structured in ways that intend to be approachable and usable either as a group or as an individual. While it would be best to capitalize on the knowledge of service-learning, education abroad and experienced STISL faculty, the participation of these stakeholders is not necessarily essential for using these frameworks which were designed to be usable across either as an individual faculty member or as a whole institution.

Another advisable next step for increasing support for faculty who facilitate STISL would be to survey the extent to which faculty feel that scholarship related to STISL pedagogy is recognized in the promotion and tenure process. If faculty do not feel that STISL scholarship would be beneficial to promotion and tenure, or possibly even harmful, academic administrators would be advised to investigate whether this is a misperception or reality. If it is a misperception, senior academic administrators should consider more public rhetoric regarding institutional support of engaged scholarship, such as STISL, as well as reiterating this point with individual academic departments and promotion and tenure committees. If in fact scholarship of STISL pedagogy would not be beneficial for the tenure and promotion process, senior academic officials as well as departmental leaders should consider convening and developing an institutional strategy for integrating engage scholarship, such as STISL, 
into the reward structure. It is advisable to refer to the literature related to the institutionalization of service-learning and engaged scholarship as a guide for this process (see Beere et al, 2011; Bringle \& Hatcher, 2004; Furco \& Holland, 2004; Plater, 2004).

\section{Increasing Student Access to STISL}

While STISL courses are a large financial investment for students, colleges and universities committed to fulfilling their mission statements through STISL pedagogy should consider alternative funding sources in order to increase the accessibility of STISL to all students regardless of financial constraints. Many institutions across the country, including one at which a research participant from this study are employed, are working to lessen the financial burden of STISL on students by securing external sources of funding such as grants, institutional endowments and private foundations. For example, in 2007 Duke University founded the DukeEngage program, a fully funded 8-week international or domestic service experience for up to 425 undergraduate students per year; Funding sources include the Duke Endowment and the Bill and Melinda Gates Foundation (DukeEngage, 2013). According to their 2017 strategic plan, published in 2012, DukeEngage has decided to increase the number of students that it can support in these service experiences by raising a minimum of $\$ 20$ million that will be applied to its endowment and would fully nearly 600 students in the DukeEngage experience (DukeEngage, 2012). While not all institutions will be able to secure foundation support, such as that provided to DukeEngage by the Bill 
and Melinda Gates Foundation, it does provide an example of deliberate efforts which succeeded in increasing access to international service experiences for students.

\section{Increasing Institutional Support of Pre-Departure and Re-Entry Credit}

\section{Opportunities}

Throughout this research project STISL faculty consistently reiterated the importance of both the pre-departure and the re-entry segments of the course. Faculty also reported feeling that they were not able to engage students at the level they would like considering the timing of both of these segments. Pre-departure preparation sessions were often the term before the STISL course, and both students and faculty were preoccupied with other course; re-entry components were significantly impacted by the limited amount of time between the end of the STISL course and the beginning of the next term or semester. The logistics of the academic schedule are impacting two components of the STISL experience which conflicts with the literature that has been reviewed and asserts that both the pre-departure and reentry segments are essential. Therefore institutions interested in increasing the depth and quality of the STISL experience should consider credit bearing pre-departure and re-entry courses, which could be recognized as elective credits and applied toward graduation requirements. While this may increase the cost of the overall STISL experience, students will ideally be receiving needed academic credit. Notably, academic credit for the pre-departure and re-entry components of a STISL course is not the only option for increasing the time and effort expended on these segments. Each institution interested in furthering their engagement with STISL pedagogy 
should creatively design an intervention to this issue that fits with the needs of their students and faculty, as well as the resources of the college or university.

\section{Increasing Strategies to Understand Power and Privilege in STISL Pedagogy}

As was previously described in Chapter two of this research project, issues of power and privilege need to be addressed in service-learning pedagogy (Heldman, 2011). Arguably, serving and learning in an international and intercultural context compounds issues of power and privilege, leading to an increasingly strong call that STISL faculty intentionally design strategies that equip students to understand how power and privilege impacts international service and development initiatives. Therefore, as a next step, STISL faculty are encouraged to explore pedagogical strategies which move the discussion of power and privilege from the periphery of STISL pedagogy, to a more central place. Briefly, some research participants reported using Zemach-Bersin (2008) and Illich (1990) as reading resources. While these readings provide provocative points on which students can reflect, neither provide exceptionally usable points on which students can base future action and engagement related to service and development work. This is not to say that these two pieces are not appropriate for the STISL, in fact, Jacqueline noted that they are great resources for a critique of service initiatives.

On the other hand, there are a plethora of resources available that in addition to critiquing service through lenses of power and privilege also provide usable and implementable strategies. Resources could include resources on critical theory (such as McLaren \& Farahmandpur, 2005), Freire's (1970) emancipatory pedagogy, 
indigenous knowledge in development initiatives (such as Briggs \& Sharp, 2004), as well as literature from service-learning that directly addresses power and privilege (such as Monard-Weissman, 2003; Heldman, 2011; Rosenberger, 2000). Also, as was previously suggested, the gathering of experienced STISL faculty as well as campus service-learning and education abroad offices could prove to be significant resources related to pedagogical ideas and strategies for incorporating issues of power and privilege in an international service context.

\section{Conclusion}

Arguably, the world is changing faster today than ever before. Many of these changes are not improving the quality of human life or the environment and are in fact degrading it. While over time institutions of higher education have recognized and articulated a role for themselves in solving some of the world's most pressing problems, there have been a limited number of articulated and operational strategies that can aid in achieving this goal. As the data show, STISL seeks to do this: to develop students who are able and willing to face some of the most significant social and environmental needs that the world has ever seen. And, by connecting the hallmarks of STISL directly to institutional rhetoric, senior administrators with both policy and budgetary responsibilities should be able to more easily identify how STISL embodies the mission and vision of the institution.

Significantly, the findings from this research project provide approachable design strategies that operationalize abstract institutional commitments. This makes it possible to expand both the breadth and depth of institutional global engagement 
and the number of graduates that develop a strong sense of global agency. In addition, the Van Cleave Pedagogical Design Framework for Global Agency ensures that in addition to the dissemination of academic concepts, student identity, group dynamics, culture, and community context are central fixtures of the pedagogical design process. While these findings provide practical and approachable pedagogical design strategies which are an substantial addition to the field of STISL, they may possibly reignite a sense of hope that while the world may be facing mammoth and daunting challenges, the final chapter has not yet been written; through STISL pedagogy, institutions can develop the next generation of individuals that will use their skills and talents to leave the world better than when they found it.

When asked why she continued to teach STISL courses, one RP replied using a quote that one of her students included in a final reflection, on that has stayed close to this faculty member's heart and eloquently summarizes this research project: "one class might not save the world, but a student in that class might." 


\section{REFERENCES}

Abes, E. S., Jackson, G., \& Jones, S. R. (2002) Factors that motivate and deter faculty use of service-learning. Michigan Journal of Community Service Learning, 9(1), 5-17.

Althen, G., \& Bennett, J. (2011). America ways: A cultural guide to the United States (3rd ed.). San Antonio, TX: Intercultural Press.

American Institute For Foreign Study. (2012). Study abroad in Gaborone: Service learning - Spring 2012. Retrieved April 9, 2012, from http://www.aifsabroad.com/botswana/gaborone/year1112/servicelearning .asp

Anderson, K., \& Miller, E. D. (1997). Gender and student evaluations of teaching. PS: Political science \& politics, 30(2), 216-219.

Andrews, M., Squire, C., \& Tamboukou, M. (2008). Introduction: What is narrative research? In M. Andrews, C. Squire, \& M. Tamboukou (Eds.), Doing narrative research (pp. 1-21). Los Angeles, CA: Sage.

Annette, J. (2002). Service learning in an international context. Frontiers: The Interdisciplinary Journal of Study Abroad, 8(1), 83-93.

Appiah, K. A. (2006). Cosmopolitanism: Ethics in a world of strangers. New York, NY: W. W. Norton \& Co.

Armstrong, T. (2000). Multiple intelligences in the classroom (2nd ed.). Alexandria, VA: Association for Supervision and Curriculum Development.

Ash, S. L., \& Clayton, P. H. (2004). The articulated learning: An approach to guided reflection and assessment. Innovative Higher Education, 29(2), 137-154.

Ash, S. L., \& Clayton, P. H. (2009). Sample resources - curricular engagement. PHC Ventures. Retrieved May 15, 2013, from http://curricularengagement.com/resources/DEAL_model_graphic.pdf

Association of American Colleges and Universities. (2011). Shared futures: General education for a global century. Programs. Retrieved November 20, 2011, from http://www.aacu.org/SharedFutures/global_century/cfp.cfm

Association of American Colleges and Universities. (2013a). About AAC\&U. About $A A C \& U$. Retrieved May 19, 2013, from http://www.aacu.org/about/index.cfm 
Association of American Colleges and Universities. (2013b). Programs | Shared Futures. Retrieved May 19, 2013, from http://www.aacu.org/SharedFutures/index.cfm

Association of American Colleges and Universities. (2013b). Bridging cultures to form a nation: Difference, community and democratic thinking. Retrieved July 20, 2013, from http://www.aacu.org/bridgingcultures/

Association of International Educators. (2011). Press Room: U.S. House of Representatives passes Simon Study Abroad Bill. NAFSA: Association of International Educators. Retrieved from http://www.nafsa.org/press_releases.sec/press_releases.pg/house_passes_si mon/

Astin, A. W. (2004). Why spirituality deserves a place in liberal education. Liberal Education, 90(2), 34-41.

Astin, A. W., Astin, H. S., \& Lindholm, J. A. (2011). Cultivating the spirit: How college can enhance students' inner lives. San Francisco, CA: Jossey Bass.

Astin, A. W., Astin, H. S., Lindholm, J. A., \& Bryant, A. N. (2005). The spiritual life of college students: A national study of students' search for meaning and purpose. Los Angeles, CA: UCLA Higher Education Research Institute.

Astin, A. W., Vogelgesang, L. J., Misa, K., Anderson, J. Denson, N., Jayakumar, U., ... Yamamura, E. (2006). Understanding the effects of service-learning. A study of students and faculty. Los, Angeles, CA: UCLA Higher Education Research Institute.

Baker-Boosamra, M., Guevara, J. A., \& Balfour, D. L. (2005). From service to solidarity: Evaluation and recommendations for international service learning. Journal of Public Affairs Education, 12(4), 479-500.

Barr, M. J., \& McClellan, G. S. (2011). Budgets and financial management in higher education. San Francisco, CA: Jossey Bass.

Beere, C. A., Votruba, J. C., \& Wells, G. W. (2011). Becoming an engaged campus: A practical guide for institutionalizing public engagement. San Francisco, CA: Jossey Bass.

Bennett, J. M. (2008). On becoming a global soul: A path to engagement during study abroad. In V. Savicki (Ed.), Developing intercultural competence and transformation: Theory, research and application in international education. Sterling, VA: Stylus. 
Bennett, M. J. (1993). Towards ethnorelativism: A developmental model of intercultural sensitivity. In R. M. Paige (Ed.), Education for the intercultural experience (pp. 21-71). Yarmouth, ME: Intercultural Press.

Bentley, R., \& Ellison, K. J. (2007). Increasing cultural competence in nursing through international service-learning experiences. Nurse Educator, 32(5), 207-211. doi:10.1097/01.NNE.00002893581.14007.b4

Bento, R. F. (2000). The little inn at the crossroads" A spiritual approach to the design of a leadership course. Journal of Management Education, 24(5), 650661.

Berg, W. (2006). Making a difference, making connections: Perspectives of college faculty and practitioners learning in a service experience abroad (Ph.D. dissertation). The University of North Dakota, North Dakota. Retrieved from Dissertation \& Theses: full Text. (Publication No. AAT3241658).

Bogdan, R. C., \& Knopp Bilken, S. (2007). Qualitative research for education: An introduction to theories and methods (5th ed.). Boston, MA: Pearson.

Bok, D. (2006). Our underachieving colleges: A candid look at how much students learn and why they should be learning more. Princeton, NJ: Princeton University Press.

Bolman, L. G., \& Deal, T. E. (2008). Reframing Organizations: Artistry, choice and leadership (4th ed.). San Francisco, CA: Jossey Bass.

Bosustow, N. J. (2006). The reentry experience: An examination of Peace Corps volunteers' experience of returning home after service (Psy.D. dissertation). The Wright Institute, Berkley, CA. Retrieved from Dissertations \& Theses: Full Text. (Publication No. AAT 3206361).

Boyer, E. L. (1987). College: The undergraduate experience in America. New York, NY: Harper and Row.

Brabant, S. C., Palmer, E., \& Gramling, R. (1990). Returning home: An empirical investigation of cross-cultural reentry. International Journal of Intercultural Relations, 14(4), 387-404. doi:10.1016/0147-1767(90)90027-T

Brainard, L., Grahm, C., Purvis, N., Radelet, S., \& Smith, G. E. (2003). The other war: global poverty and the Millennium Challenge Account. Washington D.C.: The Brookings Institute.

Braskamp, L. A. (2008). Developing global citizens. Journal of College \& Character, $X(1), 1-5$. 
Brewer, E., \& Cunningham, K. (2009). Capturing study abroad's transformative potential. In E. Brewer \& K. Cunningham (Eds.), Integrating study abroad into the curriculum (pp. 1-20). Sterling, VA: Stylus.

Briggs, J. \& Sharp, J. (2004). Indigenous knowledges and development: A postcolonial caution. Third World Quarterly, 25(4), 661-676

Bringle, R. G., \& Hatcher, J. A. (1997). Bridging the gap between service and learning. College Teaching, 45(4), 153-158.

Bringle, R. G., \& Hatcher, J. A. (1999). Reflection in service learning: Making meaning of experience. Educational Horizons, Summer, 179-185.

Bringle, R. G., \& Hatcher, J. A. (2004). Indiana University-Purdue University Indianapolis: Advancing civic engagement through service-learning. In M. Langseth \& W. M. Plater (Eds.), Public work and the academy (pp. 125-146). Bolton, MA: Anker.

Bringle, R. G., \& Hatcher, J. A. (2011). International service learning. In R. G. Bringle, J. A. Hatcher, \& S. G. Jones (Eds.), International service learning: Conceptual frameworks and research (pp. 3-28). Sterling, VA: Stylus.

Brock, S. E. (2010). Measuring the importance of precursor steps to transformative learning. Adult Education Quarterly, 60(2), 122-142.

Brookfield, S. (1990). The skillful teacher. San Francisco, CA: Jossey Bass.

Brown, N. (2007). Embedding engagement in higher education: Preparing global citizens through international service-learning. Campus Compact. Retrieved November 20, 2011, from http://www.compact.org/resources/future-ofcampus-engagement/embedding-engagement-in-higher-educationpreparing-global-citizens-through-international-service-learning/4235/

Brustein, W. (2007). The global campus: Challenges and opportunities for higher education in North America. Journal of Studies in International Education, 11(3/4), 382-391. doi:10.1177/1028315307303918

Burns, H. (2009). Education as sustainability: An action research study of the Burns model of sustainability pedagogy (Ed.D. dissertation). Portland State University, Portland, OR. Retrieved from Dissertations \& Theses @ Portland State University. (Publication No. AAT 3391670).

Butin, D. W. (2010). Service-learning in theory and practice. New York, NY: Palgrave MacMillan. 
Campus Compact. (2000). Benchmarks for campus/community partnerships. Providence, RI.

Carnegie Foundation. (2013). Community Engagement Elective Classification. Carnegie FoundatinoFoundation for the Advancement of Teaching. Retrieved from http://classifications.carnegiefoundation.org/descriptions/community_enga gement.php

Carsello, C., \& Creaser, J. (1976). How college students change during study abroad. College Student Journal, 10(3), 276-278.

Chan, Y. E. (2002). Why haven't we mastered alignment? The importance of the informal organizational structure. MIS Quarterly Executive, 1(2), 97-112.

Chickering, A. W. (2006). Authenticity and spirituality in higher education: My orientation. Journal of College \& Character, 7(1), 1-5.

Chickering, A. W. (2009). Our orientation. In A. W. Chickering, J. C. Dalton, \& L. Stamm (Eds.), Encouraging authenticity and spirituality in higher education (pp. 5-36). San Francisco, CA: Jossey Bass.

Chisholm, L. A. (2003). Partnerships for international service-learning. In B. Jacoby (Ed.), Building partnerships for service-learning (pp. 259-288). San Francisco, CA: Jossey Bass.

Chisholm, L. A., \& Berry, H. A. (2002). Understanding the education - And through it the culture - In education abroad. New York, NY: The International Partnership for Service-Learning.

Clark, C., Bouis, G. J., SubbermanSubbaraman, S., \& Balóon, D. (2004). Diversity initiatives in higher education: Social justice from classroom to community. Multicultural Education, 12[2], 55-59.

Colby, A., Ehrlich, T., Beaumont, E., Rosner, J., \& Stephens, J. (2000). Introduction: Higher education and the development of civic responsibility. In T. Ehrlich (Ed.), Civic responsibility and higher education (pp. xxi-xliii). Phoenix, NM: Oryx Press.

Colby, A., Ehrlich, T., Beaumont, E., \& Stephens, J. (2003). Educating citizens: Preparing America's undergraduates for lives of moral and civic responsibility. San Francisco, CA: Jossey Bass. 
Coghlan, D. (2000). Reframing organizations: Artistry, choice and leadership by Lee G. Bolman and Terrence E. Deal. International Journal of Organizational Analysis, 8(4), 427-429.

Collier, P. J., \& Williams, D. R. (2005). Reflection in action: The learning-doing relationship. In C. M. Cress (Ed.), Learning through serving (pp. 83-97). Sterling, VA: Stylus.

Comp, D. (2008). U.S. heritage-seeking students discover minority communities in Western Europe. Journal of Studies in International Education, 12(1), 29-37. doi:10.1177/1028315307299417

Cortland University. (n.d.). Multiple Intelligence (MI) - Howard Gardner. Retrieved April 17, 2012, from http://web.cortland.edu/andersmd/learning/MI\%20Theory.htm

Crabtree, R. D. (2008). Theoretical foundations for international service-learning. Michigan Journal of Community Service Learning, 15(1), 18-36.

Cranton, P. (1994). Understanding and promoting transformative learning: A guide for educators of adults. San Francisco, CA: Jossey Bass.

Cress, C. M. (2005). What is service-learning. In C. M. Cress (Ed.), Learning through serving (pp. 7-16). Sterling, VA: Stylus.

Cress, C. M. (2011). Pedagogical and epistemological approaches to service-learning: Connecting academic content to community service. In C. M. Cress \& D. M. Donahue (Eds.), (pp. 43-54). Sterling, VA: Stylus.

Cress, C. M., Burack, C., Giles, D. E., Elkins, J., \& Stevens, M. C. (2010). A promising connection: Increasing college access and success through civic engagement. Boston: Campus Compact. Retrieved from http://www.compact.org/wpcontent/uploads/2009/01/APromising- Connection.pdf.

Cress, C. M., \& Patton, J. (2005). Expanding horizons. In C. M. Cress, P. J. Collier, \& V. L. Reitenauer (Eds.), Learning through serving (1st ed., pp. 113-122). Sterling, VA: Stylus.

Cress, C. M., Stokamer, S. T., Van Cleave, T. J., Edwin, C. (2013). Global and immersive service-learning: What you need to know as you go. In C. M. Cress, P. J., Collier \& V. L. Reitenauer (Eds.), Learning through serving (2nd ed. pp. 177-198). Sterling, VA: Stylus. 
Cressy, K. (2005). A long-term vision for diversity in education abroad. IIENetworker Magazine: Diversity in International Education. Retrieved April 24, 2012, from http://www.iienetwork.org/page/71207/

Creswell, J. W. (2003). Research design: Qualitative, quantitative and mixed methods approaches (2nd ed.). Thousand Oaks, CA: Sage.

Creswell, J. W. (2007). Qualitative inquiry research and design: Choosing among five traditions (2nd ed.). Thousand Oaks, CA: Sage.

Davies, L. (2006). Global citizenship: Abstraction or framework for action? Educational Review. 58[1], 5-22. doi: 10.1080/00131910500352523.

Day-Vines, N., Barker, J. M., \& Exum, H. A. (1998). Impact of diasporic travel on ethnic identity development of African American college students. College Student, 32(3), 463-471.

Dean, G. J. (1994). Designing instruction for adult learners. Malabar, FL: Kreiger.

Deans, T. (1999). Service-learning in two keys: Paulo Freire's critical pedagogy in relation to John Dewey's pragmatism. Michigan Journal of Community Service Learning, 6(4), 15-29.

Dear, S. (2012). Exploring reciprocity in international service-learning programs (Master's Thesis). Brock University, St. Catherines, Ontario, Canada.

Dewey, J. (1916). Democracy and education: An introduction to the philosophy of education. New York, NY: Macmillan.

Dockter, M. K. (2004). An international service-learning experience for physical therapy students: its meaning and effect on civic engagement and leadership skills. University of North Dakota, North Dakota.

Doerr, E. (2011). Cognitive dissonance in international service-learning: Possibilities and challenges for service-learning pedagogy. In B. J. Porfilio \& H. Hickman (Eds.), Critical service-learning as revolutionary pedagogy: A project of student agency in action (pp. 71-94). Charlotte, NC: Information Age Publishing.

Donahue, T. (2009). The making of global citizenship through education abroad programs: Aligning missions and visions with education abroad programs (Doctoral dissertation). University of Southern California, Los Angeles, CA. Retrieved from Dissertation \& Theses: Full Text (Publication No. AAT 3355245).

Dossey, B. M. (1989). Spirituality and healing. Frederick, MD: Aspen. 
Dostilio, L. D., Brackmann, S. M., Edwards, K. E., Harrison, B., Kliewer, B., \& Clayton, P. H. (2012). Reciprocity: Saying what we mean and meaning what we say. Michigan Journal of Community Service Learning, 19(1), 17-32.

Dower, N. (2008). Are we all global citizens or are only some of us global citizens? The relevance of this question to education. In A. A. Abdi \& L. Shultz (Eds.), Educating for human rights and global citizenship. Albany, NY: State University of New York Press.

Dower, N., \& Williams, J. (Eds.). (2002). Global citizenship: a critical introduction. New York, NY: Routledge.

Driscoll, A. (1998). Comprehensive design of community service: New undertakings, options, and vitality in student learning at Portland State University. In E. Zlotkowski (Ed.), Successful service-learning programs: New models of excellence in higher education. (150-168). Boston, MA: Anker.

Driscoll, A., \& Sandmann, L. R. (2004). Roles and responsibilities of academic administrators: Supporting the scholarship of civic engagement. In M. Langseth \& W. M. Plater (Eds.), Public work and the academy (pp. 51-68). Bolton, MA: Anker.

DukeEngage (2012). DukeEngage 2017: A blueprint for deeper and broader engagement. DukeEngage. Retrieved July 20, 2013, from http://dukeengage.duke.edu/uploads/media_items/dukeengage-strategicplan-2017.original.pdf

DukeEngage (2013). About DukeEngage. Duke Engage. Retrieved July 20, 2013, from dukeengage.duke.edu/about-dukeengage

Dwyer, M. M., \& Peters, C. K. (2004). The benefits of study abroad. Transitions Abroad, 37, 56-59.

Eckerman, A. K., Dowd, T., Chong, E., Nixon, L., Gray, R., \& Johnson, S. (2010). Binan Goonj: Bridging cultures in Aboriginal health (3rd ed.). Chatswood, Australia: Churchill Livingston.

Einfeld, A., \& Collins, D., (2008). The relationship between service-learning, social justice, multicultural competence, and civic engagement. Journal of College Student Development, 49(2), 95-109.

Elliott, R., \& Timulak, L. (2005). Descriptive and interpretive approaches to qualitative research. In J. Miles \& P. Gilbert (Eds.), A handbook of research methods for clinical and health psychology (pp. 145-159). Oxford: Oxford University Press. 
Ellis, M. (2008). Clemson University prepares for possibility of more budget cuts. IndependentMail.com.. Retrieved July 1, 2013, from http://www.independentmail.com/news/2008/nov/12/clemsonuniversity-prepares-possibility-more-budge/

Enos, S. L., \& Troppe, M. L. (1996). Service-learning in the curriculum. In B. Jacoby (Ed.), Service-learning in higher education. San Francisco, CA: Jossey Bass.

Eyler, J. (2002). Reflection: Linking service and learning - linking students and communities. Journal of Social Issues, 58(3), 517-537.

Eyler, J. (2011). What international service learning research can learn from research on service learning. In R. G. Bringle, J. A. Hatcher, \& S. G. Jones (Eds.), International Service Learning: Conceptual Frameworks and Research (pp. 225-241). Sterling, VA: Stylus.

Eyler, J., \& Giles, D. E. (1999). Where's the learning in service-learning. San Francisco, CA: Jossey Bass.

Falk, R. (1993). The making of global citizenship. In J. Brecher, J. Brown Childs, \& J. Cutler (Eds.), Global visions: Beyond the new world order (pp. 39-50). New York, NY: Black Rose Books.

Ferdig, M. A. (2007). Sustainability leadership: Co-creating a sustainable future. Journal of Change Management 7,(1), 25-35.

Forum on Education Abroad. (2009). Standards of good practice for short-term education abroad programs (pp. 1-15). Carlile, PA: Dickinson College. Retrieved from www.forumea.org/documents/ForumEAStandardsShortTermProg.pdf

Freire, P. (1970). Pedagogy of the oppressed. New York, NY: Continuum.

Fullerton, J. (2010). Transformative learning in college students: A mixed methods study (Doctoral dissertation). University of Nebraska, Lincoln, NE. Retrieved from Dissertation \& Theses: Full Text (Publication No. AAT 3398454).

Furco, A., \& Holland, B. A. (2004). Institutionalizing service-learning in higher education: Issues and strategies for chief academic officers. In M. Langseth \& W. M. Plater (Eds.), Public work and the academy (pp. 23-40). Bolton, MA: Anker.

Galston, W. A. (2001). Political knowledge, political engagement, and civic education. Annual Review of Political Science, 4, 217-234. doi:10.1080/01900690701215888 
Gardner, H. (1993). Frames of mind: The theory of Multiple intelligences (10th anniversary ed.). New York, NY: BasicBooks.

Gergen, K. (2009). An invitation to social construction (2nd ed.). Los Angeles, CA: Sage.

Glesne, C., \& Peshkin, A. (1992). Becoming qualitative researchers: An introduction. White Plains, NY: Longman.

Gray, M. J., Ondaatje, E. H., Fricker, R. D., Geschwind, S. A., Goldman, C. A., Kaganoff, T., et al. (1998). Coupling service and learning in higher education: the final report of the evaluation of the Learn and Serve America, Higher Education. Santa Monica, CA: RAND.

Gray, M. J., Ondaatje, E. H. \& Zakaras, L. (1999). Combining service and learning in higher education: Summary Report. Santa Monica, CA: RAND.

Goodwin, C. D. W., \& Nacht, M. (1988). Abroad and beyond: Patterns in American overseas education. New York, NY: Cambridge.

Goulding, C. (2002). Grounded theory: A practical guide for management, business and market researchers. Thousand Oaks, CA: Sage.

Greenstreet, W. M. (1999). Teaching spirituality in nursing: A literature review. Nurse Education Today, 19(8), 649-658.

Grusky, S. (2000). International service learning: A critical guide from an impassioned advocate. American Behavioral Scientist, 43(5), 858-867. doi:10.1177/000276400021955513

Gutierrez, R., Auerbach, J., \& Bhandari, R. (2009). Expanding U.S. study abroad capacity: FingingsFindings from an IIE-Forum survey (IIE White Papers on Expanding Capacity and DiveristyDiversity in Study Abroad Issue 6) (pp. 617). New York, NY: Institute of International Education.

Hampton, S. E., \& Reiser, R. A. (2004). Effects of a theory-based feedback and consultation process on instruction and learning in college classrooms. Research in Higher Education, 45(5), 497-527.

Hanna, G. S., Hoyt, D. P., \& Aubrecht, J. D. (1983). Identifying and adjusting for biases in student evaluations of instruction: Implications for validity. Educational and Psychological Measurement, 43, 1175-1185.

Harper, F. D., \& Guibault, M. (2008). Maslow's Hierarchy of Basic Needs. In N. J. Salkind (Ed.), Encyclopedia of Educational Psychology (Vols. 1-2, Vol. 2). 
Thousand Oaks, CA: Sage. Retrieved from http://www.sageereference.com/educationalpsychology/n166.xml

Higher Education Research Institute - UCLA. (1996). A Social Change Model of Leadership Development (3rd ed.). Los Angeles, CA: UCLA.

Heldman, C. (2011). Solidarity, not charity: Issues of privilege in service-learning. In C. M. Cress \& D. M. Donahue (Eds.), Democratic dilemmas of teaching servicelearning: Curricular strategies for success (pp. 33-39). Sterling, VA: Stylus.

Holmes, T. L. (2008). Student involvement, experiences, and perceptions in study abroad programs (Dissertation). Northern Illinois University, DeKalb, IL.

Hover-Kramer, D. (1989). Creating a context for self healing: The transpersonal perspective. Holistic Nursing Practice, 3(3), 27-34.

Hughes, B. B., Ifran, M. T., Khan, H., Kumar, K. B., Rothman, D. S., \& Solorzano, J. R. (2009). Reducing Global Poverty (Vol. 1). Denver, CO: Pardee Center for International Futures, University of Denver.

Hunter, A. (2008). Transformative learning in international education. In V. Savicki (Ed.), Developing intercultural competence and transformation: Theory, research and application in international education (pp. 267-285). Sterling, VA: Stylus.

Hutchings, P., \& Wutzdorff, A. (1988). ExperentialExperiential learning across the curriculum: Assumptions and principles. In P. Hutchings \& A. Wutzdorff (Eds.), Knowing and doing: Learning through experience (Vol. 35). San Francisco, CA: Jossey Bass.

Illich, I. (1990). To hell with good intentions. In J. C. Kendall, J. Duley, T. Little, J. Permaul, \& S. Rubin (Eds.), Combining service and learning: A resource book for community and public service (Vol. 1, pp. 314-320). Raleigh, NC: National Society for Internships and Experiential Education.

Institute of International Education. (2011). Fall survey 2011: U.S. study abroad. Who We Are. Press Release. Retrieved November 30, 2011, from http://www.iie.org/Who-We-Are/News-and-Events/Press-Center/PressReleases/2011/2011-11-14-Open-Doors-Fall-Survey-Study-Abroad

Institute of International Education. (2012). 2000-2010 | Student Profile | U.S. Study Abroad | Open Doors Data. Institute of International Education: Open Doors Data U.S. Study Abroad Student Profile. Retrieved April 24, 2012, from http://www.iie.org/Research-and-Publications/Open-Doors/Data/USStudy-Abroad/Student-Profile/2000-10 
International Partnership for Service-Learning and Leadership. (2012). IPSL | The International Partnership for Service-Learning and Leadership. Retrieved April 9, 2012, from http://www.ipsl.org/

Jackson, J. (2006). Ethnographic pedagogy and evaluation in short0term study abroad. In M. Byram \& A. Feng (Eds.), Living and Studying Abroad: Research and Practice (pp. 134-156). Tonawonda, NY: Multilingual Matters.

Jacoby, B. (1996). Service-learning in today's higher education. In B. Jacoby (Ed.), Service-learning in higher education (pp. 3-25). San Francisco, CA: Jossey Bass.

Jacoby, B. (2003). Fundamentals of Service-Learning Partnerships. In Building partnerships for service-learning (pp. 1-19). San Francisco, CA: Jossey Bass.

Jacoby, B. (2009). Facing the unsettled questions about service-learning. In J. R. Strait \& Lima (Eds.), The future of service-learning: New solutions for sustaining and improving practice (pp. 90-105). Sterling, VA: Stylus.

Jacoby, B., \& Brown, N. C. (2009). Preparing students or global civic engagement. In B. Jacoby (Ed.), Civic engagement in higher education: Concepts and practices (pp. 213-226). San Francisco, CA: Jossey Bass.

Jaschik, S. (2012). Teaching, stress, adjuncts. Inside Higher Ed. Retrieved July 3, 2013. http://www.insidehighered.com/news/2012/10/24/new-survey-facultyactivities-and-attitudes

Johnson, B., \& Christensen, L. (2012). Qualitative research. In Educational research: Quantitative, qualitative, and mixed approaches (4th Edition, pp. 375-408). Los Angeles, CA: Sage.

Juarez, C. E. (2013). Global learning in American higher education: Strategies for developing global citizens in an era of complex interdependence. In A. Altmann \& B. Ebersberger (Eds.), Universities in change (pp. 75-86). New York, NY: Springer.

Jones, R. J., (2004). Johnson C. Smith University: A new era of excellence. In M. Langseth \& W. M. Plater (Eds.), Public work and the academy (pp. 147-164). Bolton, MA: Anker.

Juffer, K. A. (1993). the first step in cross-cultural orientation: Defining the problem. In R. M. Paige (Ed.), Education for the intercultural experience (pp. 201-218). Yarmouth, ME: Intercultural Press.

Kaplinsky, R. (2005). Globalization, poverty and inequality. Malden, MA: Polity. 
Keene, A. S., \& Colligan, S. (2004). Service-learning and anthropology. Michigan Journal of Community Service Learning, 10(3), 5-15.

Kember, D., Leung, D. Y. P., \& Kwan, K. P. (2002). Does the use of student feedback questionnaires improve the overall quality of teaching? Assessment and Evaluation in Higher education, 27(5), 411-425.

Kiely, R. (2004). A chameleon with a complex: Searching for transformation in international service-learning. Michigan Journal of Community Service Learning, 10(2), 5-20.

Kiely, R. (2005). A transformative learning model for service-learning: a longitudinal case study. Michigan Journal of Community Service Learning, 12(1), 5-22.

Kiely, R. (2011). What international service learning can learn from research on international learning. In R. G. Bringle, J. A. Hatcher, \& S. G. Jones (Eds.), International service learning: Conceptual frameworks and research. Sterling, VA: Stylus.

Kiely, R., \& Hartman, E. (2011). Qualitative research methodology and international service learning: Concepts, characteristics, methods, approaches, and best practices. In R. G. Bringle, J. A. Hatcher, \& S. G. Jones (Eds.), International service learning: Conceptual frameworks and research (pp. 291-218). Sterling, VA: Stylus.

King, J. T. (2004). Service-learning as a site for critical pedagogy: A case of collaboration, caring, and defamiliarization. Journal of Experiential Education, 26(3), 121-137.

Kleingeld, P. (2012). Kant and cosmopolitanism: The philosophical ideal of world citizenship. Cambridge: Cambridge University Press.

Knutson Miller, K., \& Gonzalez, A. M. (2010). Domestic and international service learning experiences: A comparative study of pre-service teacher outcomes. Issues in Educational Research, 20(1), 29-38.

Kohls, L. R. (2001). Survival kit for overseas living: For Americans planning to live and work abroad (4th ed.). London, England: Nicholas Brealey Publishing.

Kolb, D. (1984). Experiential learning: Experiences as the source of learning and development. Englewood Cliffs, NJ: Prentice Hall.

Kostigen, T. M. (2008). You are here: Exposing the vital link between what we do and what that does to our planet. New York, NY: HarperOne. 
Kvale, S., \& Brinkmann, S. (2009). InterViews: Learning the craft of qualitative research interviewing (2nd ed.). Los Angeles, CA: Sage.

La Brack, B. (1993). The missing linkage: The process of integrating orientation and reentry. In R. M. Paige (Ed.), Education for the intercultural experience. Yarmouth, ME: Intercultural Press.

La Brack, B. (2010, June). Why re-entry matters: Critical lessons and practical advice. Presented at the Summer Institute for Intercultural Communication, Portland, OR.

LaBoskey, V. K. (2004). The methodology of self-study and its theoretical underpinnings. In J. Loughran, M. L. Hamilton, V. K. LaBoskey, \& T. Russell (Eds.), International handbook of self-study of teaching and teacher education practices. Dordrecht: The Netherlands: Kluwer.

Langseth, M., \& Plater, W. M. (Eds.).(2004) Public work and the academy: An academic administrator's guide to civic engagement and service-learning. Bolton, MA: Anker.

Lewis, T. L., \& Niesenbaum, R. A. (2005). Extending the stay: Using communitybased research and service learning to enhance short-term study abroad. Journal of Studies in International Education, 9, 251-264.

Lincoln Commission. (2005). Global competence and national needs: One million Americans studying abroad. Final Report from the Commission on the Abraham Lincoln Fellowship Program, Washington DC.

Livermore, D. A. (2011). The cultural intelligence difference: Mastering the one skill you can't do without in today's global economy. New York, NY: AMACOM American Management Association.

Loughran, J. (2005). Researching teaching about teaching: Self-study of teacher education practices. Studying Teacher Education, 1(1), 5-116.

Loughran, J. J. (2004). A history and context of self-study of teaching and teacher education practices. In J. J. Loughran, M. L. Hamilton, V. K. LaBoskey, \& T. Russell (Eds.), International handbook of self-study of teaching and teacher education practices (Vols. 1-2, Vol. 1, pp. 7-40). Boston, MA: Kluwer.

Lutterman-Aguilar, A., \& Gingerich, 0. (2002). Experiential pedagogy for study abroad: Educating for global citizenship. Frontiers: The Interdisciplinary Journal of Study Abroad, 8, 41-82. 
Lyons, N., \& Kubler LaBoskey, V. (2002). Introduction. In N. Lyons \& V. Kubler LaBoskey (Eds.), Narrative inquiry in practice: Advancing the knowledge of teaching (pp. 1-10). New York, NY: Teachers College, Columbia University.

Madsen Camacho, M. (2004). Power and privilege: Community service learning in Tijuana. Michigan Journal of Community Service Learning, (10)1, 31-42.

Marshall, C., \& Rossman, G. B. (2011). Designing qualitative research (5th Edition.). Thousand Oaks, CA: Sage.

Maslow, A. H. (1970). Motivation and personality. New York, NY: Harper \& Row.

Martin, J. N. (1993). The intercultural reentry of student sojourners: recent contributions to theory, research and training. In Education for the intercultural experience. Yarmouth, ME: Intercultural Press.

Martin, J. N., \& Harrell, T. (2004). Intercultural reentry of students and professionals: Theory and practice. In D. Landis, J. M. Bennett, \& M. J. Bennett (Eds.), Handbook of intercultural training (3rd ed.). Thousand Oaks, CA: Sage.

Mather, P. C., Karbley, M., \& Yamamoto, M. (2012). Identity matters in a short-term, international service-learning program. Journal of College \& Character, 13(1), 1-14. doi:10.1515/jcc-2012-1835

McGregor, I., Newby-Clark, I. R., \& Zanna, M. P. (1999). “Remembering” dissonance: Simultaneous accessibility of inconsistent cognitive elements moderates epistemic discomfort. In E. Harmon-Jones \& J. Mills (Eds.), Cognitive dissonance: Progress on a pivotal theory in social psychology. Washington D.C.: American Psychological Association.

McLaren, P., \& Farahmandpur, R. (2005). Teaching against global capitalism and the new imperialism: A critical pedagogy. Lanham, MD: Rowman \& Littlefield.

McIntosh, P. (2005). Gender perspectives on educating for global citizenship. In N. Noddings (Ed.), Educating citizens for global citizenship (pp. 22-39). New York, NY: Teachers College Press.

McMahon, S. D., Rose, D. S., \& Parks, M. (2004). Multiple intelligences and reading achievement: An examination of the Teele Inventory of Multiple Intelligences. Journal of Experiential Education, 73(1), 41-52.

Mellom, P., \& Jakubiak, C. (2011). We know what you need“: Problematizing English language teaching in the "global south. In B. Harrison, B. O'Steen, P. Clayton, K. Edwards, \& Editorial Fellows (Eds.), Proceedings of the International 
Association for Research on Service-Learning and Community Engagement 11th Annual Conference (pp. 56-57). New Orleans, LA: IARSLCE.

Merriam, S. B. (1998). Qualitative research and case study applications in education. San Francisco, CA: Jossey Bass.

Merriam, S. B., Caffarella, R. S., \& Baumgartner, L. M. (2007). Learning in adulthood: A comprehensive guide (3rd Edition.). San Francisco, CA: Jossey Bass.

Merriam-Webster. (2012). Affect - Definition and More from the Free MerriamWebster Dictionary. Retrieved May 10, 2012, from http://www.merriamwebster.com/dictionary/affect

Merriam-Webster. (2013). Solidarity - Definition and More from the Free MerriamWebster Dictionary. Retrieved June 30, 2013, from http://www.merriamwebster.com/dictionary/solidarity

Merrill, M. C. (2005). The cultural and intercultural contexts of service-learning. In L. A. Chisholm (Ed.), Knowing and doing: The theory and practice of servicelearning (pp. 177-201). New York, NY: International Partnership for ServiceLearning and Leadership.

Mestenhauser, J. A. (2011). Reflections on the past, present, and future of internationalizing higher education: Discovering opportunities to meet the challenges. Minneapolis, MN: University of Minnesota.

Mezirow, J. (1978). Perspective transformation. Adult Education, 28, 100-110.

Mezirow, J. (1991). Transformative dimensions of adult learning. San Francisco, CA: Jossey Bass.

Mezirow, J. (2000). Learning as transformation: Critical perspectives on a theory in progress. San Francisco, CA: Jossey Bass.

Mezirow, J. (2009). Transformative learning theory. In J. Mezirow \& E. W. Taylor (Eds.), Transformative learning in practice: Insights rom community, workplace, and higher education (pp. 18-32). San Francisco, CA: Jossey Bass.

Middaugh, M. M. (2010). Starting at the beginning: Mission-driven planning and assessment. San Francisco, CA: Jossey Bass.

Milkin Institue. (2012). 2012 Global Conference. Milkin Institute. Retrieved July 1, 2013 http://www.milkeninstitute.org/gc2012/ 
Morris. L. V. (2008). Higher education and sustainability. Innovative Higher Education, 32(4), 179-180.

Monard-Weissman, K. (2003). Fostering a sense of justice through international service-learning. Academic Exchange, (Summer), 164-169.

Montrose, L. (2002). International study and experiential learning: The academic context. Frontier: The Interdisciplinary Journal of Study Abroad, 8, 1-15.

Morais, D. B., \& Ogden, A. C. (2010). Initial development and validation of the global citizenship scale. Journal of Studies in International Education, 20(10), 1-22. doi:10.1177/1028315310375308

Morton, K., \& Campbell, J. (2007). Reflection. In J. Campbell \& J. Hamerlink (Eds.), Civic engagement in higher education: Reflections on power, evaluation and risk management (pp. 7-39). Upper Midwest Campus Compact Consortium.

Murphy, D. (2011). The impact of faculty reflection on international service learning experiences. Journal for Civic Engagement, 17, 1-16.

Murray Brux, J., \& Fry, B. (2010). Multicultural students in study abroad: Their interests, their issues, and their constraints. Journal of Studies in International Education, 14(5), 508-527.

Narayanasamy, A. (1991). Spiritual care: A resource guide. Lancaster: Quay/BKT.

Narrative Inquiry. (n.d.). Narrative Inquiry: The Forum for Theoretical, Empirical, and Methodological Work on Narrative. Retrieved April 14, 2012, from http://www.clarku.edu/faculty/mbamberg/narrativeINQ/

Nasser, F., \& Fresko, B. (2002). Faculty views of student evaluation of college teaching. Assessment and Evaluation in Higher education, 27(2), 187-198. doi:10.1080/0260293022012875 1

Neff, A. R. (2001). Discovering heritage and more by studying abroad. Black Issues in Higher Education, 18(2), 38.

Neher, A. (1991). Maslow's Theory of Motivation: A critique. Journal of Humanistic Psychology. 31(3). 89-112. doi:10.1177/0022167891313010

O’Brien, M. E. (1983). the need for spiritual integrity. In H. Yura \& M. B. Walsh (Eds.), Human needs and the nursing process. Norwalk, CT: Appleton-Century-Crofts.

O'Sullivan, E. (1999). Transformative learning: Educational vision for the 21st century. Toronto, Ontario: University of Toronto Press. 
Obama, B. H. (2009). The inaugural address. New York, NY: Penguin.

Obama, B. H. (2013a). Remarks by the President at The Ohio State University Commencement | The White House. The White House: Speeches and Remarks. Retrieved May 8, 2013, from http://www.whitehouse.gov/the-pressoffice/2013/05/05/remarks-president-ohio-state-universitycommencement

Obama, B. H. (2013b). Remarks by the President in the State of the Union Address | The White House. The White House: Speeches and Remarks. Retrieved May 20, 2013, from http://www.whitehouse.gov/the-pressoffice/2013/02/12/remarks-president-state-union-address

Ogden, A. C. (2010). Education abroad and the making of global citizens: Assessing learning outcomes of course-embedded, faculty-led international programming (Ph.D. dissertation). The Pennsylvania State University, Philadelphia.

Otten, M. (2003). Intercultural learning and diversity in higher education. Studies in International Education, 7, 12-26.

Pace, J. L., \& Bixby, J. S. (2008). Introduction: Studying citizenship education in trouble times. In J. Bixby S. \& J. Pace L. (Eds.), Educating Democratic citizens in troubled times: Qualitative studies of current efforts (pp. 3-21). Albany: State University of New York Press.

Paige, R. M., Cohen, A. D., Kappler, B., Chi, J. C., \& Lassegard, J. P. (2009). Maximizing study abroad (2nd ed.). Minneapolis, MN: University of Minnesota.

Paige, R. M. (1993). On the nature of intercultural experiences and intercultural education. In R. M. Paige (Ed.), Education for the intercultural experience. Yarmouth, ME: Intercultural Press.

Palmer, P. (1999). The grace of great things: reclaiming the sacred in knowing, teaching, and learning. In E. Glaser (Ed.), The heart of learning: Spirituality in education (pp. 15-32). New York, NY: Jeremy P. Tarcher/Putnam.

Palmer, P. (2003). Teaching with heart and soul: Reflections on spirituality in teacher education. Journal of Teacher Education, 54(5), 376-385.

Parker, B., \& Dautoff, D. A. (2007). Service-learning and study abroad: Synergistic learning opportunities. Michigan Journal of Community Service Learning, 13(2), 40-53. 
Parker-Gwin, R., \& Mabry, J. B. (1998). Service learning as pedagogy and civic education: Comparing outcomes for three models. Teaching Sociology, 26(4), 276-291.

Parmley, K. A. (2009). Raising the institutional research profile: Assessing the context and expanding the use of organizational frames. New Directions for Institutional Research, 143, 73-84.

Pascarella, E. T., \& Terenzini, P. T. (2005). How college affects students: A third decade of research (2nd ed.). San Francisco, CA: Jossey Bass.

Peacock, J. O. (2008). Transforming perspectives through service-learning participation: A case study of the college counts program (Ed.D. dissertation). Utah State University, Logan, UT.

Petkus, E. (2000). A theoretical and practical framework for service-learning in marketing: Kolb's experiential learning cycle. Journal of Marketing Education, 22(1), 64-70.

Phelps, A. L., \& Dostilio, L. (2008). Studying student benefits of assigning a servicelearning project compared to a traditional final project in a business statistics course. Journal of Statistics Education, 16(3), 1-11.

Plater, W. M. (2004). Civic engagement, service-learning, and intentional leadership. In M. Langseth \& W. M. Plater (Eds.), Public work and the academy (pp. 1-22). Bolton, MA: Anker.

Plater, W. M. (2011). The context for international service learning: An invisible revolution is underway. In R. G. Bringle, J. Hatcher A., \& S. G. Jones (Eds.), International service learning: Conceptual frameworks and research (pp. 2956). Sterling, VA: Stylus.

Plater, W. M., Jones, S. G., Bringle, R. G., \& Clayton, P. H. (2009). Educating globally competent citizens through international service learning. In R. Lewin (Ed.), The handbook of practice and research in study abroad (pp. 485-505). New York, NY: Routledge.

Pless, N. M., Maak, T., \& Stahl, G. K. (2012). Promoting corporate social responsibility and sustainable development through management development: What can be learned from international service learning programs? Human resource management, 51(6), 873-904. doi:10.1002/hrm.21506

Poland, B. D. (2002). Transcription quality. In J. F. Gubrium \& J. A. Holstein (Eds.), Handbook of interview research: Context and method. Thousand Oaks, CA: Sage. 
Polkinghorne, D. E. (2005). Language and meaning: Data collection in qualitative research. Journal of Counseling Psychology, 52(2), 137-145.

Porter, M., \& Monard, K. (2001). Anyi in the global village: Building relationships of reciprocity through international service-learning. Michigan Journal of Community Service Learning, 8(1), 5-17.

Project on Student Debt. (2010). Quick facts about student debt. Oakland, CA: Institute for College Access and Success. Retrieved from http://projectonstudentdebt.org/files/File/Debt_Facts_and_Sources.pdf

Rapley, T. (2005). Interviews. In C. Seale, G. Gobo, J. F. Gubrium, \& D. Silverman (Eds.), Qualitative research practice. Thousand Oaks, CA: Sage.

Robertson, D. L. (1988). Self-directed growth. Muncie, IN: Accelerated Development.

Roman, L. G. (2003). Education and the contested meanings of "global citizenship." Journal of Educational Change, 4, 269-293.

Rosenberger, C. (2000). Beyond Empathy: Developing critical consciousness through service learning. In C. O'Grady (Ed.), Integrating service learning and multicultural education in colleges and universities. (pp. 23-43). Mahwah, NJ: Lawrence Erlbaum.

Russ, T. L., Simonds, C. J., \& Hunt, S. K. (2002). Coming out in the classroom...an occupational hazard?: The influence of sexual orientation on teacher credibility and perceived student learning. Communication Education, 51(3), 311-324.

Sahin, N. H. (1990). Re-entry and the academic and psychological problems of the second generation. Psychology and Developing Societies, 2, 165-182.

Sammalisto, K., \& Lindhqvist, T. (2008). Integration of sustainability in higher education: A study with international perspectives. Innovative Higher Education, 32(4), 221-233.

Sawhill, J., \& Williamson, D. (2001). Measuring what maters in nonprofits. The McKinsey Quarterly, 2, 98-107.

Sawyer, K. L., \& Lopopolo, R. (2004). Perceived impact on physical therapy students of an international pro bono clinical education experience in a developing country. Journal of Physical Therapy Education, 18(2), 40.

Schattle, H. (2009). Global citizenship in theory and practice. In The handbook of practice and research in study abroad (pp. 3-20). New York, NY: Routledge. 
Schmidt-Rinehart, B. C. (2004). The homestay component of study abroad: Three perspectives. Foreign Language Annals, 67(2), 254-262.

Schrader, D. E. (2004). Intellectual safety, moral atmosphere, and epistemology in college classrooms. Journal of Adult Development, 11(2), 87-101.

Shaheen, S. (2004). The effect of pre-departure preparation on student intercultural development during study abroad programs (Ph.D. dissertation). The Ohio State University, Ohio. Retrieved from http://etd.ohiolink.edu/view.cgi?acc_num=osu1091481152

Shahjahan, R. A. (2004). Centering spirituality in the academy. Journal of Transformative Education, 2(4), 294-314. doi:10.177/1541344604268330

Sigmon, R. L., \& Pelletier, S. G. (Eds.). (1996). Journey to service-learning: Experiences from independent liberal arts colleges and universities. Washington D.C.: Council of Independent Colleges.

Skiula, J., \& Sikula, A. (2005). Spirituality and service learning. New Directions for Teaching and Learning, 104, 75-81.

Smith, B. H., Gahagan, J., McQuillin, S., Haywood, B., Pender Cole, C., Bolton, C., \& Wampler, M. K. (2011). The development of a service-learning program for first-year students based on the hallmarks of high quality service-learning and rigorous program evaluation. Innovative Higher Education, 36, 317-329.

Speck, B. W. (2005). What is spirituality. New Directions for Teaching and Learning, 104(3), 3-13.

Stanton, T. K. (1990). Liberal arts, experiential learning and public service: Necessary ingredients for socially responsible undergraduate education. In J. Kendall \& Associates (Eds.), Combining service and learning I (pp. 175-189). Raleigh: National Society for Internships and Experiential Education.

Stearns, P. N. (2009). Educating global citizens in colleges and universities. New York, NY: Routledge.

Stokamer, S. T. (2011). Pedagogical catalysts of civic competence: The development of a critical epistemological model for community-based learning (Ed.D. dissertation). Portland State University, Portland, OR.

Tabor, R. G., Carter, D. M., Kovar, M., \& Ramsing, R. (2008). International Service Learning. Journal of Dental Hygiene, 82(5), 49-49. 
Tacey, K. D. (2011). Perspective transformation: Analyzing the outcomes of international education (Doctoral dissertation). Texas A\&M University. Retrieved from Dissertation \& Theses: Full Text. (Publication No. AAT 3486138).

Talburt, S., \& Stewart, M. A. (1999). What's the subject of study abroad?: Race, gender and "living culture." The Modern Language Journal, 83(2), 163-175.

Tarrant, M. A. (2010). A conceptual framework for exploring the role of studies abroad in nurturing global citizenship. Journal of Studies in International Education, 14(5), 433-451.

Thomas, K., \& Harrell, T. (1994). Counseling student sojourners: Revisiting the Ucurve of adjustment. In G. Althen (Ed.), Learning across cultures (pp. 89-108). Washington D.C.: National Association for Foreign Student Affairs.

Thompson-Jones, M. (2013). World Bank needs global grads. Boston.com. Retrieved May 18, 2013, from http://www.boston.com/business/blogs/globalbusiness-hub/2013/04/world_bank_need.html\#

Tierny, W. G. (1988). Organizational culture in higher education: Defining the essentials. Journal of Higher Education, 59(1), 2-21.

Tonkin, H. (2011). A research agenda for international service learning. I In R. G. Bringle, J. Hatcher A., \& S. G. Jones (Eds.), International service learning: Conceptual frameworks and research (pp. 191-224). Sterling, VA: Stylus.

Tonkin, H., \& Quiroga, D. (2004). A qualitative approach to the assessment of international service-learning. Frontier: The Interdisciplinary Journal of Study Abroad, 10(Fall), 131-150.

Transcultural C.A.R.E. Associates. (2013). Inventory for Assessing the Process of Cultural Competence Among Healthcare Professionals-Student Version. Transcultural C.A.R.E. Retrieved April 7, 2013, from http://www.transculturalcare.net/

Van Cleave, T. (2011). Democratic lessons of faith, sexuality and service. In C. M. Cress \& D. M. Donahue (Eds.), Democratic dilemmas of teaching servicelearning: Curricular strategies for success (pp. 124-128). Sterling, VA: Stylus.

Vande Berg, M. (2007). Intervening in the learning of U.S. students abroad. Journal of Studies in International Education, 11(3-4), 392-399.

Vande Berg, M., Connor-Linton, J., \& Paige, R. M. (2009). The Georgetown consortium project: Interventions for student learning abroad. Frontiers, 18(1), 1-75. 
Vande Berg, M., \& Paige, R. M. (2012). Student learning abroad: Paradigms and assumptions. In M. Vande Berg, R. M. Paige, \& K. Hemmin (Eds.), Student learning abroad: What are students are learning, what they're not, and what we can do about it (pp. 29-60). Sterling, VA: Stylus.

Wandersman, A., Imm, P., Chinman, M., \& Kaftarian, S. (2000). Getting to outcomes: a results-based approach to accountability. Evaluation and Program Planning, 23, 389-395.

Warren, C. A. B. (2002). Qualitative interviewing. In J. F. Gubrium \& J. A. Holstein (Eds.), Handbook of interview research: Context and method (pp. 83-101). Thousand Oaks, CA: Sage.

Weatherly, L. A. (2003). Human capital - the elusive asset. Society for Human Resource Management Quarterly, 48, 1-9.

Wells, K. (2011). Narrative inquiry. Oxford: Oxford University Press.

Western Michigan University. (n.d.). A Simple Multiple Intelligence Inventory. A Simple Multiple Intelligence Inventory. Retrieved April 26, 2012, from http://homepages.wmich.edu/ buckleye/miinventory.htm

Wielkiewicz, R. M., \& Turkowski, L. W. (2010). Reentry issues upon returning from study abroad programs. Journal of College Student Development, 51(6), 649664.

Williams, D. R. \& Stewart, S. I. (1998). Sense of place: An elusive concept that is finding a home in ecosystem management. Journal of Forestry, (96), 18-23.

Williams, D. R., \& Van Cleave, T. J. (2011). At the crossroads of dissonance: Border pedagogy and meaning-making of service-learning in India. Presented at the International Association for Research on Service-Learning and Community Engagement, Chicago, IL.

Williams, J. (2002). Good international citizenship. in N. Dower \& J. Williams (Eds.), Global citizenship: a critical introduction (pp 41-52). New York, NY: Routledge.

Wolfer, T. A., \& McNown Johnson, M. (2003). Re-evaluating student evaluation of teaching: The teaching evaluation form. Journal of Social Work Education, $39(1), 111-121$.

Wong, W., Green, P. M., \& Wan, B. (2012). In search of experiential learning in the Jesuit traditions: Loyola Experience. In S. K. S. Cheung, J. Fong, L. F. Kwok, K. Li, \& R. Kwan (Eds.), Hybrid Learning (pp. 274-282). Guangzhou, China: Springer. 
Woolley, R. (2008). Spirituality and education for global citizenship: Developing student teachers' perceptions and practices. International Journal of Children's Spirituality, 13(2), 145-156. doi:10.1080/13644360801965966

Zemach-Bersin, T. (2008). American students abroad can't be "global Citizens." Chronicle of Higher Education. Retrieved April 29, 2013, from http://chronicle.com/article/American-Students-Abroad-Cant/25527/

Zlotkowski, E. (1996). Opportunity for all: Linking service-learning and business education. Journal of Business Ethics, 15(1), 5-19. 


\section{APPENDIX A}

\section{INTERVIEW PROTOCOL}

Time:

Date:

Location:

Interviewee:

Interviewer:

Before the interview begins, interviewees will be asked to read and sign the informed consent form.

I: Background information:

- Research participant's (RP) areas expertise, academic rank, years of experience in higher education?

- STISL experience - courses, countries, number of times

II: Successful STISL Experiences:

- What is "program success," both in terms of long-term and short-term learning outcomes?

- What is the research participant's "gut reaction" to the term "global citizenship"?

- Using Ogden's three dimensions of global citizenship, does the RP believe that social responsibility, global competence, and global civic engagement are outcomes the RP strives for? If yes how does the RP develop pedagogy for these three dimensions? If no, why are these not applicable learning outcomes for the course?

- What are specific strategies that the RP utilizes overall to achieve intended learning outcomes?

- Structure of class and examples of pedagogical strategies used by the RP

- Use of education or learning theories to structure the course? Mezirow, Kolb, Gardner, Maslow or another? Does the RP use an inventory to identify students' learning styles or multiple intelligences?

III: Program Design:

- Describe application and selection process.

- Have the RP ever had to turn students away from the course? If yes, can the RP explain why they chose to exclude the student from the course?

- Pre-departure - What content does the RP include in the pre-departure orientation sessions? Are there assigned readings or papers before students 
depart? Does the RP use bonding/trust building/group learning intention agreements?

\section{- Community Partners -}

- Name of partner, type of work. Why this community partner?

- Does the RP have a long-term commitment to working with this/these particular partner(s)?

- What service activities do they do? Hours? Does the RP perform service with the students, or do students perform service without the RP present?

- What is a reciprocal relationship with overseas community partners and does the RP have a reciprocal relationship with these community partners?

\section{- Host Country Experience -}

0 Assignments and Reflection-What assignments are required of students while in the host-country? Is there a reflective component to the assignments? What role does reflection have in the research participant's pedagogical practice? How does the RP facilitate reflection? Does the RP use any models for reflection?

- The Role of Difference - What role does difference play in students' experience?

- Has the RP witnessed students experiencing low/high intensity dissonance? How did the RP identify this, and did the RP respond? How did the RP encourage and facilitate meaning making?

- Can the RP share a memorable experience about a student struggling to make meaning out of a dissonant experience?

- How does the RP identify a student that may be struggling with emotionally or cognitively resolving a dissonant experience?

- Miscellaneous - Other components, and the research participant's role in the experience

- Are there program any rules about students and technology?

- What type of housing do they provide students?

- What is the role of host country faculty

- Assessment During Experience - How does the RP gauge "where students are at" while in the host-country? Can the RP give an example of having to readjust the program, or pedagogical strategies based on observations of student learning?

\section{- Re-Entry}

- At what point does the RP begin to prepare students for the reentry experience

- Reunions - Does the RP meet with students after the STISL experience, if yes, how many times and what do those gatherings look like? Formal, informal? Reflective, social? 
- How many times, and how soon after the experience

- Re-entry Struggles - What does the RP think students struggle with most as they reenter their home context? And how does the RP think this affect students?

- What does the RP do to support students in this?

- What is the research participant's biggest struggle when reentering?

- Is there a culminating or final assignment? What does it entail and how is it assessed?

IV: Learning

- Does the RP notice that students, based on gender, race, ethnicity, sexual orientation, etc. experience the STISL course differently than classmates?

- Does the RP think STISL is a spiritual experience for students, as students would define spirituality? Why or why not? What do students say?

V: Evaluation

- How do you evaluate your own teaching in a STISL course?

○ Iterative teaching, student evaluations, student learning, selfstudy?

IV: Faculty Experience:

- Why does the RP teach using a STISL pedagogy?

- As the RP defines spiritual, would they consider this a spiritual experience for themselves?

- What supports or hinders the faculty from teaching using a STISL pedagogy?

- What has the faculty learned as you have implemented STISL numerous times? How did you come to learn this?

- Is there anything else you would like to tell me? 


\section{APPENDIX B}

\section{INVITATION TO PARTICIPATE}

\section{Good Morning Professor XXXXXX,}

My name is Thomas Van Cleave, and I am a doctoral candidate from Portland State University in the Postsecondary Educational Leadership program. I received your name from [specific person] [specific department] at [your institution] and was wondering if you would be interested in participating in my research, sharing your experience and expertise. My area of scholarship is focused on understanding pedagogical strategies employed by faculty members on short-term international service-learning courses (STISL) in order to achieve learning goals.

For this dissertation I am looking to speak with faculty who have facilitated STISL courses in order to better understand what faculty hope students take away from an STISL course, as well as 'what faculty do' to help ensure that these goals are met. Specifically for the purpose of this dissertation, I am interested in speaking with faculty who have taught at least two STISL courses to the same location within the past five years. Additionally, I am only researching 'short-term' courses, which I am defining as anything less than a full academic term or semester. If you have a January-term, this would qualify as short term. For your reference, I am using Bringle and Hatcher's (2011) definition of international service-learning, which is:

- A structured academic experience in another country in which students (a) participate in an organized service activity that addresses identified community needs; (b) learn from direct interaction and cross-cultural dialogue with others; and; (c) reflect on the experience in such a way as to gain further understanding of course content, a deeper understanding of global and intercultural issues, a broader appreciation of the host country and the discipline, and an enhanced sense of their own responsibilities as citizens, locally and globally. (p. 19)

I will gather data using interviews, which would take about 60-90 minutes, depending on your availability. Ideally, I would like to review course syllabi from each year in preparation for the interview, although this is not a requirement for participating.

If you decide to participate in this study you will have the option of a pseudonym being used in lieu of your name, and your institution's name will automatically be confidential, and only referred to by institutional classification and possibly general geographic area. 
Overall I have three questions for you, which would help me move forward:

- Would you say that the short term international experience you coordinate has a service-learning component, as defined by Bringle and Hatcher (2011) listed above?

- If yes, have you facilitated at least two short-term international servicelearning experiences to the same location, teaching the same course within the past five years?

- If yes again, would you be interested in participating in this study?

I have had great success conducting these interviews over Skype, or am happy to drive to your institution for an in person conversation.

Thank you so much for your time. Please let me know if you have any questions. I would be happy to clarify any points.

Best Regards,

Thomas J. Van Cleave, M.S. 